\title{
Regulation der Neurogenese durch bHLH-O-Proteine in Xenopus laevis
}

\author{
Dissertation \\ zur Erlangung des Doktorgrades \\ der Mathematisch-Naturwissenschaftlichen Fakultäten \\ der Georg-August-Universität zu Göttingen
}

vorgelegt von

Marion Sölter

aus Northeim

Göttingen 2005 
Die vorliegende Arbeit wurde

am Zentrum für Biochemie und Molekulare Zellbiologie

in der Abteilung Entwicklungsbiochemie

der Georg-August-Universität zu Göttingen angefertigt.

D7

Referent: Prof. Dr. T. Pieler

Korreferent: Prof. Dr. E.A. Wimmer

Tag der mündlichen Prüfung: 18. Januar 2006 
1. Einleitung 1

1.1 Die Neurogenese in Xenopus laevis 1

1.2 bHLH-Proteine: Eine große und komplexe Oberfamilie von Transkriptionsfaktoren 4

1.3 bHLH-O-Proteine 6

1.3.1 bHLH-O-Proteine: Familien und Nomenklatur 6

1.3.2 bHLH-O-Proteine: Basische Domäne, DNA-Bindungsstellenspezifität, Zielgene 8

1.3.3 bHLH-O-Proteine: Repressionsdomänen, Corepressoren, aktive Repression 10

1.3.4 bHLH-O-Proteine: Notch-Effektoren 12

1.3.5 bHLH-O-Proteine: Funktionen während der Entwicklung des Vertebraten-Nervensystems 14

$\begin{array}{ll}\text { 1.3.5.1 Die Hairy- und E(spl)-Unterfamilien } & 14\end{array}$

$\begin{array}{ll}\text { 1.3.5.2 Die Hey-Unterfamilie } & 17\end{array}$

$\begin{array}{ll}\text { 1.3.5.3 Helt/Heslike } & 18\end{array}$

$\begin{array}{ll}\text { 1.3.5.4 Die Dec-Unterfamilie } & 18\end{array}$

1.4 Zielsetzung der Arbeit $\quad 19$

$\begin{array}{lr}2 . & 20\end{array}$

$2.1 \quad$ Identifizierung neuer bHLH-O-Proteine in Xenopus laevis 20

2.2 Charakterisierung des bHLH-O-Proteins XHes2 aus Xenopus laevis 22

2.2.1 Isolierung eines XHes2-cDNA-Klons aus Xenopus laevis 22

$\begin{array}{ll}\text { 2.2.2 Strukturanalyse von XHes2 aus Xenopus laevis } & 24\end{array}$

2.2.3 Untersuchungen zur Expression von XHes2 in Xenopus laevis 26

2.2.3.1 Zeitliche Expressionsanalyse von XHes2 während der Embryonalentwicklung 26

2.2.3.2 Räumlich-zeitliche Expressionsanalyse von XHes2 während der Embryogenese 27

2.2.3.3 Räumliche Expressionsanalyse von XHes2 im adulten Frosch 31

2.2.3.4 Vergleichende Expressionsanalyse von XHes2, XHairy1, XHairy2b und ESR1 während der embryonalen Neurogenese von Xenopus laevis 33

2.2.4 Analysen zur Regulation der XHes2-Expression Regulation der XHes2-Expression während der Neurogenese 36

2.2.4.1 Regulation der XHes2-Expression durch den Notch-Signalweg 36

2.2.4.2 Regulation der XHes2-Expression durch X-Ngnr-1 37

2.2.5 Funktionsanalyse von XHes2 Untersuchungen zur Funktion von XHes2 während der Neurogenese 40

2.2.5.1 Überexpression von XHes2-Varianten in Xenopus-Embryonen 40

2.2.5.1.1 Effekte der XHes2-Varianten in frühen Neurulastadien 44

2.2.5.1.2 Effekte von XHes2- $\Delta$ C-VP16 in ektodermalen Xenopus-Explantaten 46

2.2.5.1.3 Effekte von XHes2 und XHes2- $\Delta$ W-VP16 in späten Neurulastadien 48

2.2.5.2 Überexpression von induzierbaren XHes2-Varianten in Xenopus-Embryonen 53

2.2.5.2.1 Effekte der induzierbaren XHes2-Varianten in frühen Schwanzknospenstadien 54

2.2.5.2.2 Effekte von induzierbarem XHes2- $\Delta$ C-VP16-GR in ektodermalen Explantaten 58

2.2.5.3 Überexpression von XHes2 und X-Ngnr-1 bzw. NeuroD in Xenopus-Embryonen 60

2.2.5.4 Gezielte Hemmung der XHes2-Proteinsynthese in Xenopus-Embryonen 63

2.2.5.4.1 Effekte von XHes2-MO in frühen Neurulastadien $\quad 64$

2.2.5.4.2 Effekte von XHes2-MO in späten Neurulastadien 66 
2.3 Charakterisierung der Xenopus-bHLH-O-Proteine ESR8, ESR9 und ESR10

2.3.1 Strukturanalysen Säuger-Hes5-ähnlicher Proteine aus Xenopus 68

2.3.1.1 Sequenzvergleich von Säuger-Hes5-ähnlichen Proteinen aus Xenopus 68

2.3.1.2 Sequenzvergleich alleler Varianten von ESR8, ESR9 und ESR10 aus Xenopus 71

2.3.2 Untersuchungen zur Expression von ESR8, ESR9 und ESR10 in Xenopus laevis 74

2.3.2.1 Expressionsanalyse von ESR8, ESR9 und ESR10 während der Embryogenese 74

2.3.2.2 Räumliche Expressionsanalyse von ESR8, ESR9 und ESR10 im adulten Frosch 77

2.3.2.3 Regulation der Expression von ESR8, ESR9 und ESR10 durch den Notch-Signalweg 78

2.3.3 Funktionsanalysen von ESR8, ESR9 und ESR10 während der Neurogenese 79

2.3.3.1 Überexpression induzierbarer Varianten von ESR8, ESR9 und ESR10 in XenopusEmbryonen

2.3.3.1.1 Effekte induzierbarer Varianten von ESR8, ESR9 und ESR10 auf die Neurogenese 80

2.3.3.1.2 Überexpression von induzierbarem ESR8 und X-Ngnr-1 in Xenopus-Embryonen 85

2.3.3.2 Gezielte Hemmung der Proteinsynthese von ESR8, ESR9 und ESR10 in XenopusEmbryonen

2.3.3.2.1 Effekte von ESR8-MO, ESR9-MO und ESR10-MO auf die neuronale Differenzierung 89

3. Diskussion 93

3.1 bHLH-O-Gene und Proteine in Xenopus und anderen Vertebraten 93

3.2 Das Drosophila Hairy und E(spl) verwandte Protein XHes2 aus Xenopus laevis 96

3.2.1 XHes2 und der Notch-Signalweg 96

3.2.2 XHes2 hemmt die neuronale Differenzierung 97

3.2.3 XHes2 reprimiert proneurale bHLH-Gen- und Proteinaktivität 98

3.2.4 XHes2 und die primäre Neurogenese 99

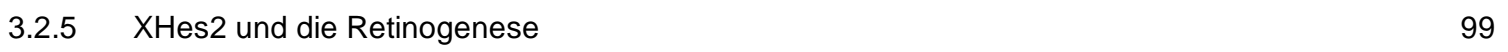

3.2.6 XHes2 und die frühe Innenohrentwicklung 104

3.2.7 XHes2 und seine orthologen Proteine in Vertebraten 106

3.3 Die Drosophila E(spl)-verwandten Proteine ESR8, ESR9 und ESR10 aus Xenopus laevis 107

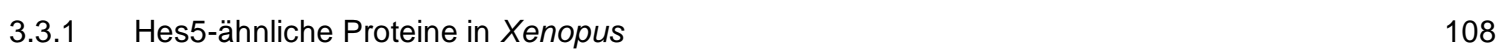

$\begin{array}{ll}3.4 & \text { Ausblick } \\ \end{array}$

4. Material und Methoden $\quad 115$

4.1 Sequenz- und Datenbankanalyse 115

$\begin{array}{ll}4.2 & 115\end{array}$

$\begin{array}{lll}4.3 & \text { Expressionskonstrukte } & 116\end{array}$

4.4 Embryonen, Mikroinjektionen, animale Kappen und Hormon-Induktion 117

$\begin{array}{lll}4.5 & \text { In situ-Hybridisierungen } & 118\end{array}$

$\begin{array}{llr}4.6 & \text { RT-PCR-Analysen } & 118\end{array}$

5. Zusammenfassung $r$

6. Literaturverzeichnis $r$

$\begin{array}{lr}7 . & 136\end{array}$

8. Danksagung $r 147$

$\begin{array}{lr}\text { 9. } & 148\end{array}$

$\begin{array}{lr}\text { 10. Lebenslauf } & 149\end{array}$ 


\section{Einleitung}

Die Bildung des Vertebraten-Nervensystems erfordert eine zeitliche und räumliche Koordination zahlreicher Prozesse, einschließlich Neuralinduktion, Zellproliferation, Zellzyklusaustritt und Differenzierung mit begleitender Neuron-spezifischer Genexpression.

Die Induktion von neuralem Gewebe aus naivem Ektoderm grenzt anfänglich die zukünftige Neuralplatte vom nicht-neuralen Ektoderm durch die Aktivierung von Markern, wie Sox2 und Sox3, in proliferierenden neuralen Vorläufern ab (Bylund et al., 2003; Graham et al., 2003; Hardcastle und Papalopulu, 2000; Miyagi et al., 2004).

Wenn diese neuralen Vorläufer prolifererieren, um die Zellzahl zu erzeugen, die für die Bildung des Nervensystems benötigt wird, beginnen Untergruppen dieser Zellen proneurale Gene, wie die Vertebraten-Homologe von Drosophila Achaete-scute und Atonal, zu exprimieren (Bertrand et al., 2002; Kintner, 2002).

Diese proneuralen Faktoren induzieren anschließend neuronale Differenzierungsgene, wie NeuroD, die den Zellzyklusaustritt und die terminale neuronale Differenzierung regulieren (Bertrand et al., 2002). Die proneuralen und neuronalen Differenzierungsgene kodieren Transkriptionsfaktoren, die zur großen Oberfamilie von bHLH-Proteinen gehören, und als Heterodimere mit ubiquitär exprimierten E2A-Proteinen (einschließlich seiner alternativen Produkte E12 und E47) agieren. Diese Proteine teilen die Fähigkeit in Enhancer- und Promoterregionen von Zielgenen an Stellen mit dem Consensus CANNTG, die als E-Boxen bezeichnet werden, zu binden.

\subsection{Die Neurogenese in Xenopus laevis}

Niedere Vertebraten, wie Xenopus laevis und Danio rerio, erzeugen ein einfaches Muster von primären Neuronen, die das frühe larvale Verhalten regulieren und in drei Längsdomänen auf jeder der beiden Seiten der dorsalen Mittellinie lokalisiert sind. Zellen, die in diesen Domänen differenzieren, entsprechen drei Klassen von primären Neuronen, Motorneuronen, Interneuronen und sensorischen Neuronen, in medial-nach-lateraler Anordnung (Abb.1-1A). In Xenopus stellt die primäre Neurogenese ein attraktives experimentelles System für die Analyse molekularer Aspekte der Neurogenese dar (Abb.1-1,2).

Die primäre Neurogenese innerhalb der proneuronalen Domänen wird durch bHLHAktivatoren positiv reguliert (Abb.1-1B, 1-2B). Die früheste proneurale Genexpression in Xenopus ist die von X-Ngnr-1 (Neurogenin), die später-agierende bHLH-Gene, einschließlich NeuroD, induziert. X-Ngnr-1 aktiviert auch die Transkription des Notch- 
Liganden $X$-Delta-1 und des Zinkfinger-Transkriptionsfaktors X-MyT1 in neuronalen Vorläuferzellen (Abb.1-2B). Die Expression von X-Delta-1 stimuliert die laterale Hemmung, eine durch den Notch-Signalweg-vermittelte negative Rückkopplungsschleife, in benachbarten Zellen (Abb.1-1C,D, 1-2C, 1-3), während X-MyT1 die neuronalen Vorläufer resistent gegen aktives Notch macht. Folglich fördern die sequentiellen Aktivitäten von X-Ngnr-1, X-MyT1 und NeuroD die neuronale Differenzierung von einigen kompetenten neuralen Vorläufern, während die Aktivierung des Notch-Signalwegs und die dadurch induzierten bHLH-Repressoren, wie ESR1, in benachbarten Zellen einen undifferenzierten Zustand aufrechterhalten (Bellefroid et al., 1996; Chitnis et al., 1995; Lee et al., 1995; Ma et al., 1996; Wettstein et al., 1997).

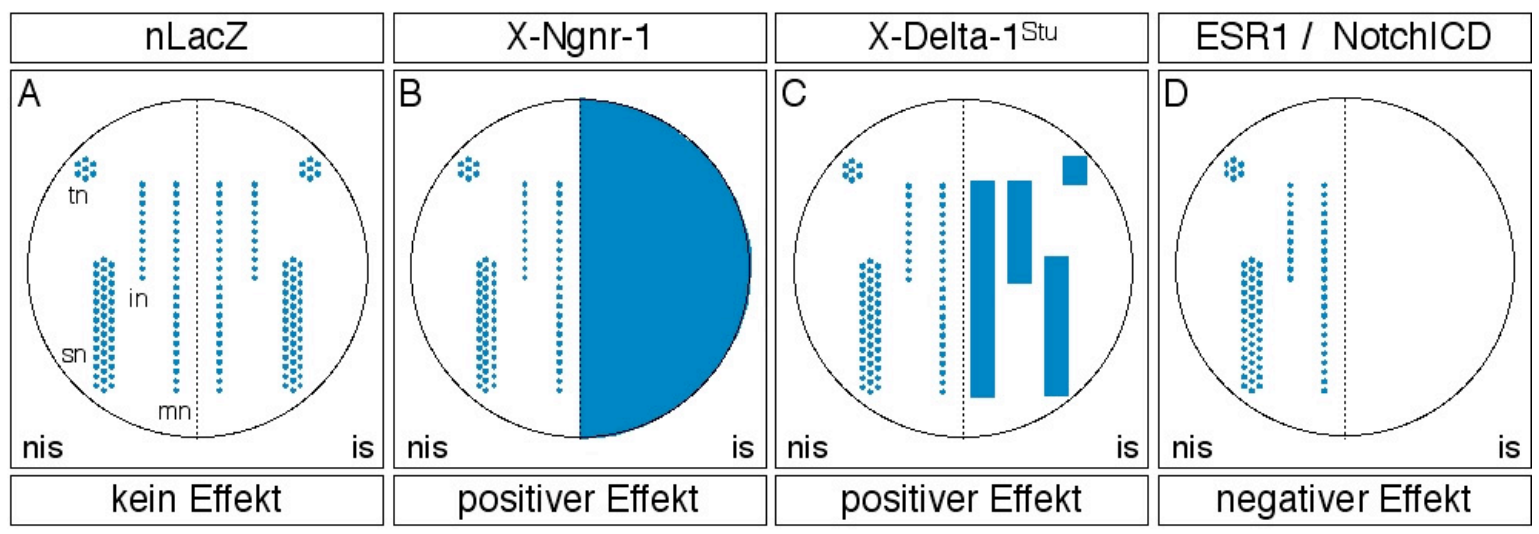

Abb.1-1: Die primäre Neurogenese in Xenopus als experimentelles System für die Analyse molekularer Aspekte der Neurogenese in Vertebraten.

Schematische Darstellung der Auswirkungen überexprimierter Neurogenese-Regulatoren auf die Differenzierung primärer Neuronen in Xenopus-Embryonen. (A) In Xenopus laevis-Embryonen werden bereits im offenen Neuralplattenstadium erste Neuronen-spezifische Differenzierungsgene, wie z.B. N-tubulin (blau), in einem charakteristischen Muster exprimiert, die die Entstehung von primären Neuronen (anteriore, profundal-trigeminale Neuronen, sowie posteriore sensorische Neuronen, Interneuronen und Motorneuronen) anzeigen. Durch die Mikroinjektion von synthetischer RNA in eine Blastomere im Zweizellstadium können verschiedenste Proteine gezielt in einer Embryohälfte überexprimiert werden, die nicht-injizierte Embryohälfte dient dabei als interne Kontrolle. Die Mikroinjektion von $n L a c Z-R N A$ für die Überexpression von nucleärer $\beta$ Galactosidase, deren Aktivitätsnachweis die injizierten Zellen markiert, hat keinen Einfluß auf die Differenzierung der primären Neuronen. (B) Durch die Überexpression von Faktoren, die die neuronale Differenzierung fördern, wie der bHLH-Aktivator X-Ngnr-1 (Ma et al., 1996), entstehen zusätzliche Neuronen im Neuroektoderm und häufig auch im Ektoderm. (C) Die Blockierung des Notch-Signalwegs, z.B. durch die Überexpression von X-Delta- ${ }^{\text {Stu }}$ (Chitnis et al., 1995), verhindert die laterale Hemmung und alle Zellen in den proneuronalen Domänen differenzieren zu Neuronen. (D) Die ektopische Aktivierung des Notch-Signalwegs, z.B. durch Mikroinjektion von Notch-ICD-RNA (Chitnis et al., 1995), oder die Überexpression von bHLHRepressoren, wie z.B. ESR1 (Schneider et al., 2001), bewirken hingegen eine Hemmung der neuronalen Differenzierung. Der infolge der Überexpression erzielte positive oder negative Effekt auf die primäre Neurogenese ermöglicht somit Rückschlüsse auf die Funktion eines potentiellen neuronalen Regulators. Abkürzungen: in, Interneuronen; is, injizierte Seite; mn, Motorneuronen; nis, nicht-injizierte Seite; sn, sensorische Neuronen; tn, profundal-trigeminale Neuronen.

Die an der Regulation der primären Neurogenese beteiligten fördernden und hemmenden Faktoren sind auch an der Regulation der sekundären Neurogenese im Neuralrohr (Abb.1-2D) beteiligt. 

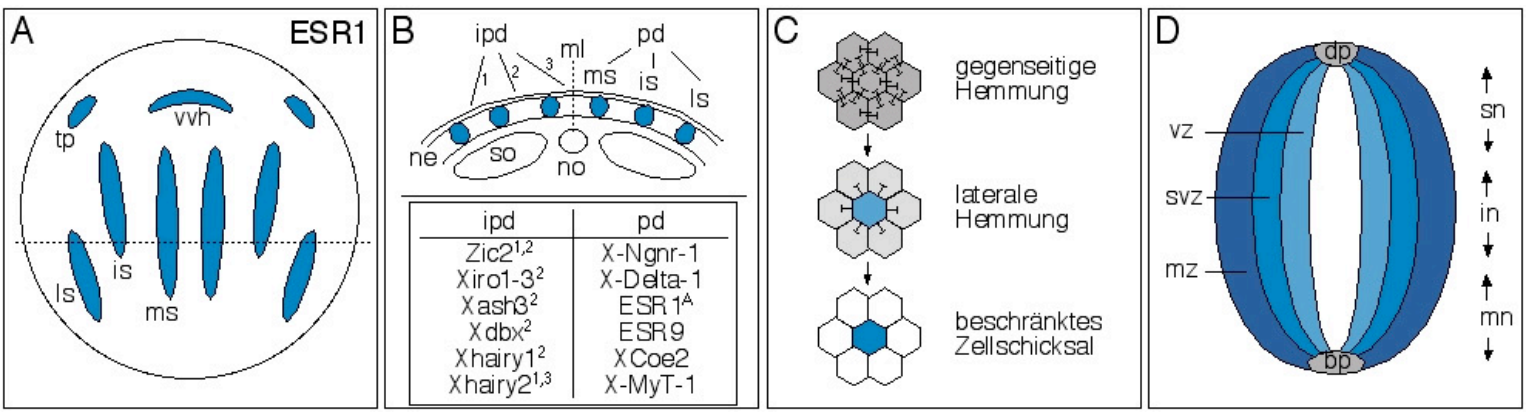

Abb.1-2: Positive und negative Regulatoren der neuronalen Differenzierung in Xenopus.

(A) Der bHLH-Repressor ESR1 wird in proneuronalen Domänen (blau) früher Neurulastadien exprimiert (dorsale Aufsicht, anterior oben). (B) Auch andere Regulatoren der Neurogenese werden ähnlich in den proneuronalen Domänen (blau) der posterioren Neuralplatte exprimiert (Querschnitt, dorsal oben; Schnittebene siehe gestrichelte Linie in A). Zu den fördernden Faktoren der neuronalen Differenzierung zählen die Aktivatoren X-Ngnr-1, XCoe2 und X-MyT-1. Der durch XDelta-1 aktivierte Notch-Signalweg und die dadurch induzierten bHLH-Repressoren ESR1 und ESR9 hemmen hingegen die Differenzierung von Neuronen in benachbarten Zellen (Notch-abhängige laterale Hemmung, siehe auch $C$ ) In den interproneuronalen Domänen verhindern Faktoren, wie Zic2, Xiro1-3, Xash3, Xdbx und Xhairy1,2, die neuronale Differenzierung (Übersichtsartikel: Bally-Cuif und Hammerschmidt, 2003; Bellefroid und Souopgui, 2003). (C) Zellschicksalsbeschränkung durch die laterale inhibitorische Notch-Aktivierung: Zunächst senden und empfangen alle Zellen innerhalb einer Gruppe, die ein spezielles Zellschicksalspotential gemeinsam haben (grau), Notch-Signale (gegenseitige Hemmung). Nach der Festlegung einer Zelle auf ein spezialisiertes Zellschicksal (erst hellblau, dann blau) hemmt diese ihre umgebenden Zellen (erst hellgrau, dann weiß), ebenfalls dieses Zellschicksal anzunehmen (laterale Hemmung) (Übersichtsartikel: Lai, 2004). (D) Nach abgeschlossener Neurulation findet im Neuralrohr, außer in Boden- und Dachplatte, die spätere, sekundäre neuronale Differenzierung statt. Das Neuralrohr besitzt drei unterschiedliche Zonen: die innere, ventrikuläre Zone (hellblau), die proliferiende Zellen enthält, die mittlere subventrikuläre Zone (blau) mit postmitotischen Zellen und die Marginalzone (dunkelblau), in der bereits differenzierte Zellen zu finden sind. Im ventralen Neuralrohr differenzieren Motorneuronen, sensorische Neuronen entstehen in dorsalen Regionen, Interneuronen hingegen zwischen dorsalen und ventralen Regionen. Abkürzungen: bp, Bodenplatte; dp, Dachplatte; in, Interneuronen; ipd, interproneuronale Domänen; is, intermediärer Streifen; Is, lateraler Streifen; ml, Mittellinie; mn, Motorneuronen; ms, medialer Streifen; mz, Marginalzone; ne, Neuroektoderm; no, Notochord; pd, proneuronale Domänen; sn, sensorische Neuronen; so, Somiten; svz, subventrikuläre Zone; tp, profundal-trigeminale Plakode; vvh, ventrales Vorder- und Mittelhirn; vz, ventrikuläre

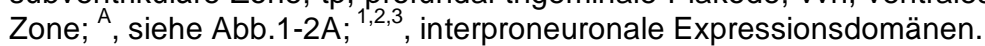

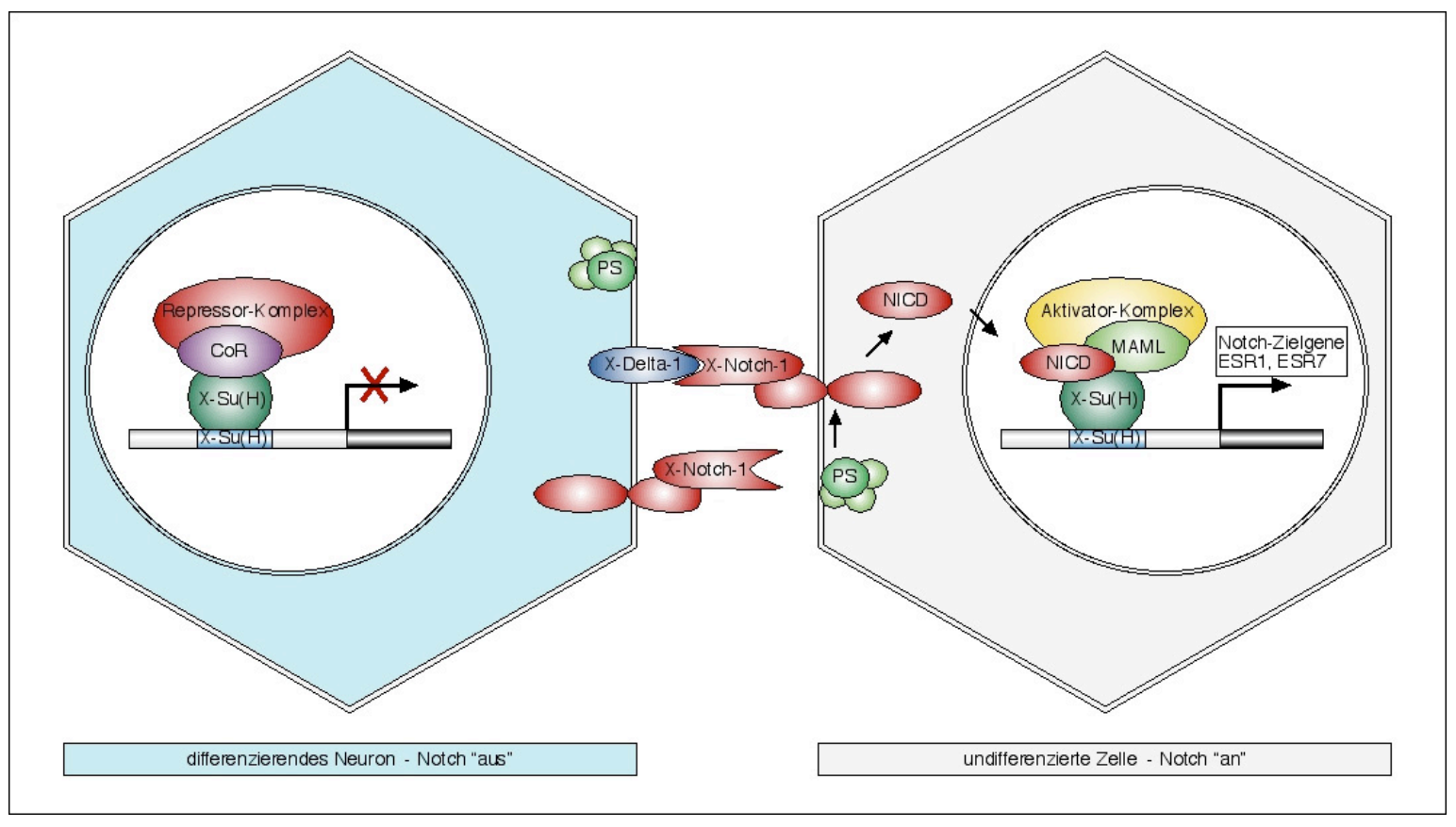

Abb.1-3: Der Notch-Signalweg in Xenopus.

Die vereinfachte schematische Darstellung zeigt die Hauptkomponenten des Notch-Signalwegs in Xenopus laevis, die u.a. bei der lateralen Hemmung während der primären Neurogenese von Bedeutung sind. In der differenzierenden Nervenzelle (hellblau) wird zunächst infolge proneuraler bHLH-Proteinaktivität verstärkt das 
Transmembranprotein X-Delta-1 (blau) exprimiert. X-Delta-1 bindet an den Notch-Rezeptor X-Notch-1 (rot), ebenfalls ein Transmembranprotein, einer benachbarten Zelle (grau). Durch diese Bindung wird letztlich eine proteolytische Abspaltung der intrazellulären Domäne des Notch-Rezeptors (NICD) durch einen $\gamma$-SekretaseKomplex (grün/hellgrün) ermöglicht, der aus verschiedenen Proteinen, u.a. Presenilin (PS), besteht. Die zunächst ins Cytoplasma freigesetzte intrazelluläre Domäne des Notch-Rezeptors gelangt schließlich in den Zellkern, bindet zusammen mit dem Coaktivator Mastermind (MAML) (hellgrün) an den Transkriptionsfaktor Suppressor of Hairless (X-Su(H)) (dunkelgrün) und rekrutiert einen Aktivatorkomplex (gelb), der Corepressor (violett) und sein Repressor-Komplex (rot) (siehe differenzierendes Neuron) werden dadurch verdrängt. Die Umwandlung des Transkriptionsrepressors in einen Transkriptionsaktivator fördert schließlich die Transkription von Genen mit X-Su(H)-Bindungstellen, wie ESR1 und ESR7. Die Expression dieser bHLH-OGene verhindert in der durch X-Delta-1-aktivierten Zelle (Notch „an“) die neuronale Differenzierung durch Hemmung proneuraler Aktivität. Die Transkriptionsrepression dieser Notch-Zielgene in der nicht durch XDelta-1-aktivierten Zelle (Notch „aus“) gestattet hingegen eine neuronale Differenzierung.

\section{2 bHLH-Proteine: Eine große und komplexe Oberfamilie von Transkriptionsfaktoren}

bHLH-Proteine besitzen als Transkriptionsregulatoren Schlüsselfunktionen bei einer Vielzahl von Entwicklungsprozessen. Die Proteine dieser Superfamilie haben eine bHLHDomäne, die ungefähr 60 Aminosäuren umfaßt und aus einer DNA-bindenden basischen Region gefolgt von zwei $\alpha$-Helices besteht, die durch einen variablen Loop-Bereich voneinander getrennt sind (Ferré-D’Amaré et al., 1993). Die HLH-Domäne unterstützt die Dimerisierung und ermöglicht die Bildung von homo- oder heterodimeren Komplexen zwischen verschiedenen Familienmitgliedern. Die basischen Domänen dieser Dimere binden spezifische Hexanukleotidsequenzen (Abb.1-4).

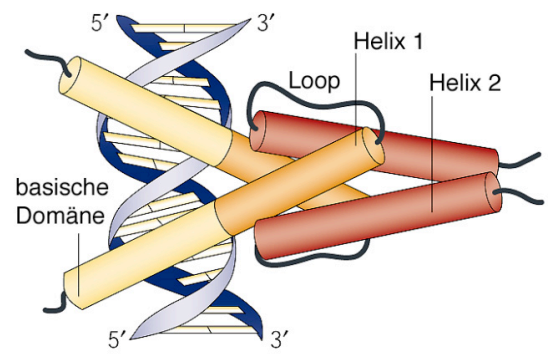

Abb.1-4: Modell eines bHLH-Transkriptionsfaktors.

Schematische Darstellung der Struktur eines bHLH-Dimers im Komplex mit DNA (übernommen von Bertrand et al., 2002). Die zwei $\alpha$-Helices beider Partner bilden zusammen ein paralleles VierHelix Bündel, was ermöglicht, dass die basische Region in die große DNA-Furche paßt. Aber auch einzelne Aminosäurereste in den Helices und der Loop-Region stehen in Kontakt zur DNA.

Durch phylogenetische Analysen konnten 44 verschiedene Familien von tierischen bHLHProteinen, sowie 6 übergeordnete Gruppen definiert werden, die neben ihrer evolutionären Verwandtschaft der bHLH-Domäne außerdem strukturelle und biochemische Eigenschaften gemeinsam haben (Atchley und Fitch, 1997; Ledent et al., 2002) (Tab.1-1).

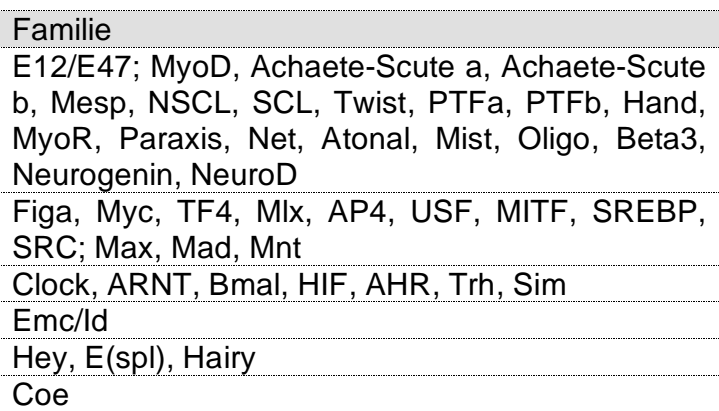

\begin{tabular}{|c|c|c|c|}
\hline Gruppe & Klasse & Struktur & DNA-Consensus \\
\hline A & I; II & bHLH & A/E \\
& & & \\
\hline B & III; IV & bHLH-LZ & B/E \\
\hline C & VII & bHLH-PAS & C \\
\hline D & V & HLH & (D) \\
\hline E & VI & bHLH-O & B/C/N \\
\hline F & & bHLH/Coe & $?$ \\
\hline
\end{tabular}


Tab.1-1: Zusammenfassung der 44 bHLH-Familien zu übergeordneten phylogenetischen Gruppen.

Eine ältere Klassifizierung, die auf Gewebeverteilung, Dimerisierungsfähigkeiten und DNABindungsspezifitäten basiert und bei der 7 Klassen unterschieden werden (Massari und Murre, 2000), ist zusätzlich zu der von Ledent et al. (2002) beschriebenen Gruppierung (A-F) aufgeführt. Die DNABindungsspezifitäten der Gruppen/Klassen sind ebenfalls angegeben. Consensus-Bindungsstellen der Klassen A (CANCTG: CACCTG/CAGCTG) und B (CANGTG: CACGTG/ CATGTG) sind Unterarten der E-Box (CANNTG). Klasse C (CACGNG: CACGCG/CACGAG) und N-Box (CACNAG: CACGAG/CACAAG) überlappen sich gegenseitig (Iso et al., 2003). Gruppe D-Proteine, die keine basische Domäne besitzen, binden nicht an DNA (D). Die DNA-Bindungsstellen für Gruppe F-Proteine sind nicht bekannt (?).

HLH-Proteine können als aktive oder passive Transkriptionsregulatoren fungieren (Massari und Murre, 2000; Ross et al., 2003). Bei der aktiven Form der Transkriptionsregulation rekrutieren an E- oder N-Box gebundene bHLH-Homo- oder Heterodimere über die direkte Bindung von Coaktivatoren (p300, SAGA) oder Corepressoren (Groucho, Sin3) Aktivator- oder Repressorkomplexe, die zum einen mit der basalen Transkriptionsmaschinerie interagieren und zum anderen Histonacetyltransferasen (HAT) bzw. Histondeacetylasen (HDAC) enthalten, die das Chromatin modifizieren (Abb.1-5A-C,E-I). Bei der passiven Form der Transkriptionsregulation fangen $\mathrm{HLH}-$ Proteine andere $(\mathrm{HLH}-)$ Transkriptionsregulatoren oder Cofaktoren durch direkte Bindung ab, so dass diese für die Regulation aufgrund blockierter DNA-Bindung bzw. Aktivität nicht mehr zur Verfügung stehen (Abb.1-5D,J-L).

A

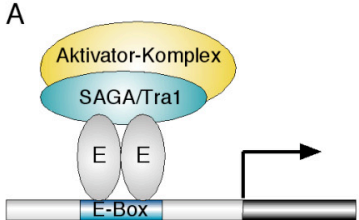

$\mathrm{E}$

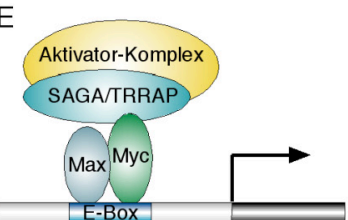

I

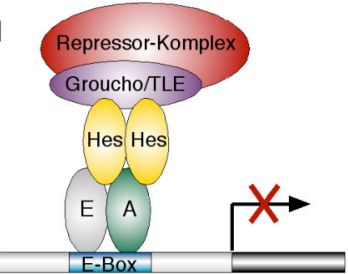

B

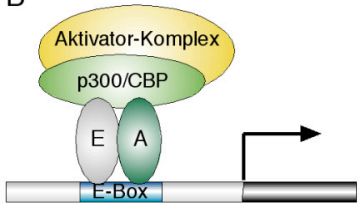

$\mathrm{F}$
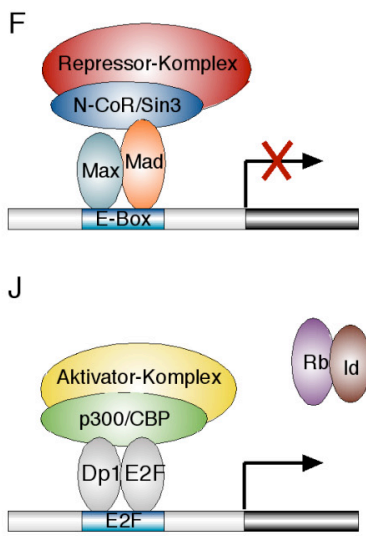

C

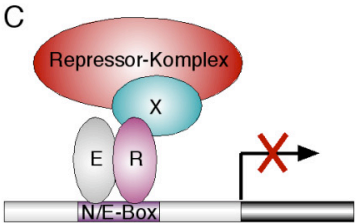

G

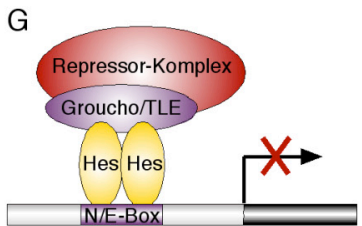

K

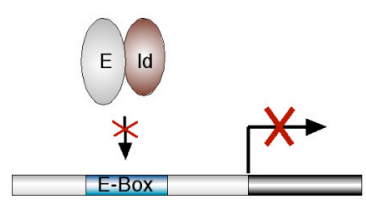

D

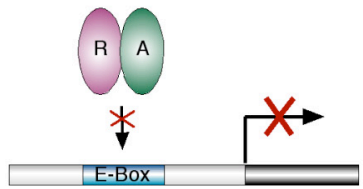

$\mathrm{H}$

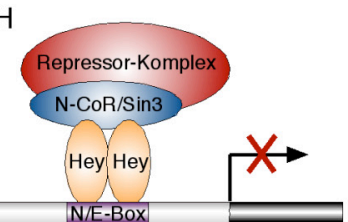

L

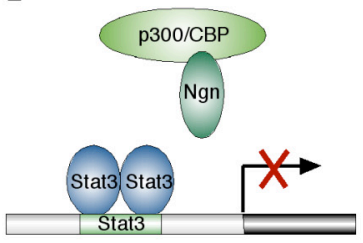

Abb.1-5: Mechanismen der aktiven und passiven Transkriptionsregulation durch HLH-Proteine. (abgewandelt dargestellte Beispiele aus: Massari und Murre, 2000; Ross et al., 2003). (A) E-Box-gebundene Homodimere aus E-Proteinen (E) rekrutieren den Tra1-SAGA-HAT-Aktivator-Komplex direkt über eine Nterminale Transaktivierungsdomäne und/oder den p300/CBP-HAT-Aktivator-Komplex über ihre bHLHund/oder Aktivierungsdomänen. (B) Zelltyp-spezifische Aktivatoren (A), wie Neurogenin, die als Heterodimere mit E-Proteinen, wie E12, an E-Boxen der Klasse A binden, können direkt mit dem p300/CBP-HAT-AktivatorKomplex interagieren. (C) HLH-Repressoren (R) rekrutieren als an N- oder E-Box-gebundene Homodimere bzw. Heterodimere mit E-Proteinen Corepressoren $(X)$ und hemmen über assoziierte Repressor-Komplexe aktiv die Transkription (Mist1, ABF-1), oder sie binden nur an die entsprechenden DNA-Sequenzen und blockieren dadurch die Bindung von Aktivatoren (Tal1) (nicht dargestellt). (D) Durch Heterodimerisierung mit einem bHLH-Aktivator (A) wie MyoD kann ein Repressor (R) wie Twist oder Mist dessen Bindung an DNA (siehe B) verhindern und die Transkription indirekt reprimieren. Der Repressor Twist kann Coaktivatorabhängige Genexpression aber auch durch direkte Hemmung der HAT-Aktivität negativ regulieren (nicht dargestellt). (E) Myc kann im Heterodimer mit Max gebunden an E-Boxen der Klasse B über die Interaktion 
mit TRRAP SAGA-HAT-Aktivator-Komplexe rekrutieren und die Transkription aktivieren. (F) Mitglieder der Mad-Familie können im Heterodimer mit Max gebunden an E-Boxen der Klasse B über die Interaktion mit Sin3 mittels ihrer N-terminalen Repressionsdomäne N-CoR-HDAC-Repressor-Komplexe rekrutieren und die Transkription aktiv reprimieren. (G) Hes-Proteine binden als Homo- oder Heterodimere an N- oder E-Boxen und rekrutieren über die Bindung des Corepressors Groucho/TLE HDAC-Repressor-Komplexe. (H) An Noder E-Box gebundene Hey-Homodimere reprimieren aktiv die Transkription ihrer Zielgene über die Interaktion mit Sin3-N-CoR-HDAC-Repressor-Komplexen. Alternativ können Hey-Hes-Heterodimere als aktive Transkriptionsrepressoren fungieren (nicht dargestellt). (I) Hes-Proteine können die Transkription aktiv reprimieren, indem sie durch Bindung an bHLH-Aktivatoren deren Interaktion mit Coaktivatoren verhindern, und selbst Corepressoren rekrutieren. $(\mathrm{J})$ Id-Proteine, die keine basische DNA-Bindungsdomäne besitzen, fördern Proliferation, indem sie durch Bindung an das Retinoblastoma-Protein (Rb) dessen Fähigkeit hemmen, die E2F-vermittelte Transaktivierung von Genen zu stören, die für das Fortschreiten des Zellzyklus entscheidend sind (indirekte Aktivierung). (K) Die Bildung nicht-DNA-bindender Id-E-Protein-Heterodimere kann die Funktion von bHLH-Aktivatoren (siehe B) hemmen, indem die verfügbare Menge an E-Proteinen weggefangen wird (passive Repression). (L) Neurogenin1 (Ngn) blockiert die Differenzierung von Astrocyten, indem es den Coaktivator p300/CBP von Stat3 wegfängt und dadurch die Transaktivierung von Stat3Zielgenen verhindert.

\section{3 bHLH-O-Proteine}

\subsection{1 bHLH-O-Proteine: Familien und Nomenklatur}

bHLH-Proteine, die mit Drosophila Hairy- und Enhancer-of-split-Proteinen verwandt sind, gehören aufgrund ihrer Struktur $\mathrm{zu}$ den bHLH-O-Proteinen und regulieren als Transkriptionsrepressoren zahlreiche biologische Prozesse in Vertebraten und Invertebraten. Zusätzlich zu der bHLH-Domäne (Helix I/II) besitzen sie eine einzigartige, konservierte Domäne, die aus zwei $\alpha$-Helices (Helix III/IV) besteht und als OrangeDomäne bezeichnet wird. bHLH-O-Proteine werden basierend auf ihrer Primärstruktur in vier Familien, Hairy, E(spl), Hey und Stra13/Dec, untergliedert, die nach dem jeweils zuerst beschriebenen Protein benannt sind. Mit Ausnahme der Stra13/Dec-Proteine weisen die Mitglieder einer jeden Familie ein konserviertes Tetrapeptid-Motiv am Carboxylende auf, entweder WRPW bei Hairy- und E(spl)-Proteinen oder YXXW bei HeyProteinen. Die Hairy-Familie unterscheidet sich von der E(spl)-Familie durch ihre Größe und eine konservierte Domäne innerhalb der Region zwischen Orange-Domäne und WRPW-Motiv, die als HC-Domäne bezeichnet wird (Abb.1-6) (Davis und Turner, 2001).

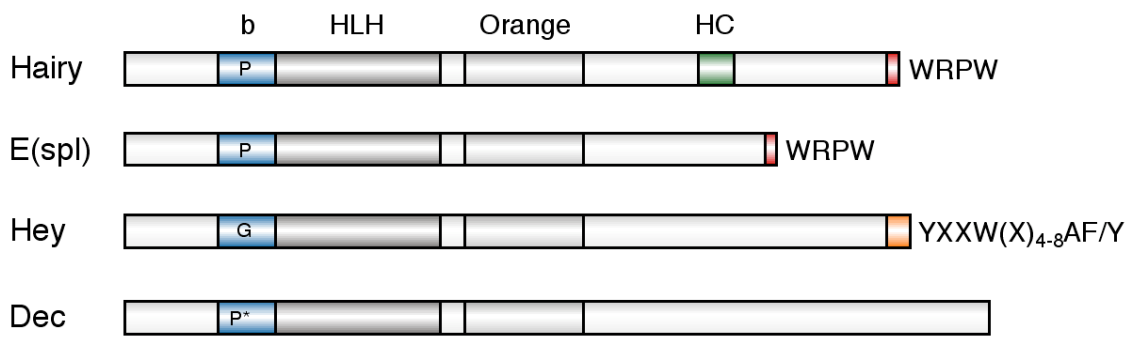

Abb.1-6: Domänenstruktur der bHLH-O-Proteinfamilien.

(nach: Davis und Turner, 2001; Iso et al., 2003). bHLH- und Orange-Domänen sind in allen Familienmitgliedern vorhanden. Unterschiede bestehen in den für die Familien (Hairy, $E(s p l)$, Hey, Dec/Stra13) charakteristischen Aminosäuren Prolin $(P){ }^{*}$ : andere Position) und Glycin $(G)$ innerhalb der basischen Domänen (blau), sowie in den carboxyterminalen Motiven (WRPW: rot, $\mathrm{YXXW}(\mathrm{X})_{4-8} \mathrm{AF} / \mathrm{Y}$ : orange). Proteine der Hairy-Familie besitzen im Vergleich zur E(spl)-Familie einen längeren carboxyterminalen Anteil mit einer konservierten Domäne (HC: „hairy conserved“) (grün). 
Die Nomenklatur der bHLH-O-Proteine ist aufgrund der unabhängigen Isolierung in zahlreichen Laboratorien, sowie das Vorkommen von mehreren Familien kompliziert. Die Namen der meisten bHLH-O-Proteine leiten sich von den aus der Fruchtfliege Drosophila melanogaster isolierten hairy und $E(s p l)$-Genen $a b$, die historisch gesehen die ersten Mitglieder der bHLH-O-Gruppe waren und deren Bezeichnungen, wie bei den meisten Genen in Drosophila, auf den Phänotyp einer Mutation in dem entsprechenden Gen zurückzuführen sind. Drosophila melanogaster besitzt 13 bHLH-O Proteine, drei HairyProteine (hairy, deadpan und side), acht E(spl)-Proteine (sieben m-Typ und her), und zwei Hey-Proteine (Hesr-1 und sticky/ch1), Stra13/Dec-Proteine sind nicht bekannt und wurden bisher nur in Vertebraten gefunden. Während in Xenopus und Huhn bei der Benennung der Hairy- und $\mathrm{E}(\mathrm{spl})$-verwandten Proteine die Familienstruktur meistens berücksichtigt wurde, sind in Säugern und Zebrafisch Hairy- und E(spl)-verwandte Proteine jeweils unter dem Begriff Hes (ㅂairy/E(spl)) und Her („,Hairy/E(spl)-related“) zusammengefaßt und nach der Reihenfolge ihrer Isolierung nummeriert. Die Mitglieder der Hey-Familie („Hairy/E(spl)-

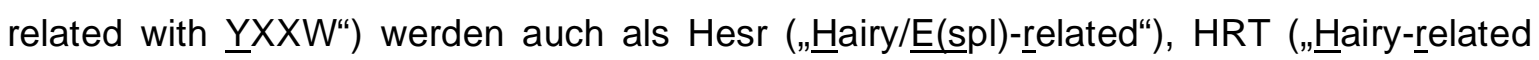
transcription factor") oder Herp („Hes-related repressor proteins“) Proteine bezeichnet. Stra13/Dec-Proteine besitzen ebenfalls weitere Namen wie Sharp, Clast und bHLHB2.

\begin{tabular}{|c|c|c|c|c|c|}
\hline $\begin{array}{l}\text { Mensch } \\
\text { Homo sapiens }\end{array}$ & $\begin{array}{l}\text { Maus/Ratte } \\
\text { Mus musculus/ } \\
\text { Rattus } \\
\text { norvegicus }\end{array}$ & $\begin{array}{l}\text { Huhn } \\
\text { Gallus } \\
\text { gallus }\end{array}$ & $\begin{array}{l}\text { Frosch } \\
\text { Xenopus laevis }\end{array}$ & $\begin{array}{l}\text { Zebrafisch } \\
\text { Brachydanio } \\
\text { rerio }\end{array}$ & $\begin{array}{l}\text { Familie/ } \\
\text { Unterfamilie }\end{array}$ \\
\hline HES1=HRY & $\begin{array}{l}\text { Hes } 1 / \\
\text { Hes1=Rhl }\end{array}$ & Hairy2 & Hairy1 & Her6 & Hairy \\
\hline HES2 & Hes2/Hes2 & & & & $E(\mathrm{spl})$ \\
\hline HES3 & Hes3/Hes3 & & & Her3 & $E(\mathrm{spl})$ \\
\hline HES4 & & Hairy1 & Hairy2a/b & Hairy $1=$ Her9? & Hairy \\
\hline HES5 & Hes $5 /$ Hes 5 & & Esr1/2/3=7/6e/9/10 & Her4 (/2?) & $\mathrm{E}(\mathrm{spl})$ \\
\hline HES6 & Hes6 & & Hes6 & Her8 & $\mathrm{E}(\mathrm{spl})$ \\
\hline HES7 & Hes7 & & Esr5 (/4?) & Her1/5(/7?) & $E(\mathrm{spl})$ \\
\hline $\begin{array}{l}\mathrm{HEY} 1=\mathrm{HESR} 1= \\
\mathrm{HRT} 1=\mathrm{CHF} 2= \\
\mathrm{HERP} 2\end{array}$ & $\begin{array}{l}\text { Hey1=Hesr1= } \\
\text { Hrt1=Herp2/ } \\
\text { Herp2 }\end{array}$ & Hey1 & Hesr1=Hey $1=$ Hrt1 & & Hey \\
\hline $\begin{array}{l}\text { HEY2=HESR2= } \\
\text { HRT2=CHF1= } \\
\text { HERP1= } \\
\text { Gridlock }\end{array}$ & $\begin{array}{l}\text { Hey2=Hesr2= } \\
\text { Hrt2=Herp1/ } \\
\text { Herp1 }\end{array}$ & Hey2 & & Gridlock & Hey \\
\hline $\begin{array}{l}\mathrm{HEYL}=\mathrm{HESR3}= \\
\text { HRT3= } \\
\text { HERP3 }\end{array}$ & $\begin{array}{l}\text { HeyL=Hesr3= } \\
\text { Hrt3= } \\
\text { Herp3/Herp3 }\end{array}$ & & & & Hey \\
\hline HELT $=$ Heslike & Helt=Heslike & & & Helt=Heslike & Helt \\
\hline STRA13/DEC1 & $\begin{array}{l}\text { Stra13(=Dec1= } \\
\text { Clast5)/Sharp2 }\end{array}$ & & & & $\mathrm{E}(\mathrm{spl}) / \mathrm{Dec}$ \\
\hline DEC2 & Dec2/Sharp1 & & & & $\mathrm{E}(\mathrm{spl}) / \mathrm{Dec}$ \\
\hline
\end{tabular}

Tab.1-2: Nomenklatur und Homologien von bHLH-O-Proteinen in Vertebraten.

Mitglieder der bHLH-O-Proteine einer Art sind in der jeweiligen Spalte, homologe Proteine in der jeweiligen Reihe mit Familienzuordnung aufgeführt. Bei unsicherer Homologie befindet sich ein Fragezeichen (?) hinter dem Proteinnamen. 
13 bHLH-O-Proteine sind bisher im Menschen identifiziert worden, zwei Hairy-Proteine (HES1 und HES4), fünf E(spl)-Proteine (HES2,3,5,6,7), drei Hey-Proteine (HEY1,2,L), ein Helt-Protein (Helt) und zwei Stra13/Dec-Proteine (Stra13/DEC1 und DEC2). Beim Menschen hat sich somit die Anzahl von bHLH-O-Proteinen im Vergleich zur Fruchtfliege nicht signifikant verändert, bei vielen anderen Transkriptionsfaktorfamilien, wie z.B. Homeobox- und bHLH-Aktivator-Proteinen, hat dagegen die Komplexität eindeutig zugenommen. Aufgrund der uneinheitlichen Namensgebung, die zudem in den meisten Fällen nicht auf Homologien beruht, ist die Zuordnung homologer bHLH-O-Proteine nicht offensichtlich. In Tabelle 1-2 sind daher die publizierten bHLH-O-Proteine aus Mensch, Maus, Ratte, Huhn, Frosch und Zebrafisch mit sämtlichen Namen unter Berücksichtigung ihrer Homologien aufgeführt (Davis und Turner, 2001; Gajewski und Voolstra, 2002; Iso et al., 2003; Ledent et al., 2002; Li et al., 2003; Miyoshi et al., 2004; Nakatani et al., 2004).

\subsection{2 bHLH-O-Proteine: Basische Domäne, DNA-Bindungsstellenspezifität, Zielgene}

Die DNA-Bindung von bHLH-O-Proteinen wird, wie bei anderen bHLH-Proteinen, von einer Region basischer Aminosäuren direkt N-terminal zur HLH-Dimerisierungsdomäne vermittelt. Im Gegensatz zu anderen bHLH-Proteinen weisen Hairy- und E(spl)-Proteine ein konserviertes Prolin, Hey-Proteine dagegen ein konserviertes Glycin an der gleichen Position innerhalb der basischen Domäne auf. Stra13/Dec-Proteine besitzen hingegen an anderer Position ein konserviertes Prolin in der basischen Domäne (Abb.1-6). Die funktionelle Bedeutung dieser konservierten Aminosäuren ist bisher nicht aufgeklärt. Während ein Threoninrest in MyoD, der sich an der gleichen Position wie das Prolin der Hairy- und $\mathrm{E}(\mathrm{spl})$-Proteine befindet, essentiell für die myogene Spezifität ist (Davis et al., 1990), haben Mutationen des konservierten Prolins zu Threonin in Drosophila Hairy- oder E(spl)-Proteinen keine Erfordernis für diesen Rest gezeigt (Tietze et al., 1992; Dawson et al., 1995). Widersprüchlich dazu bewirkte die Mutation des Prolins in ein Asparagin in einer anderen Studie eine deutliche Verringerung der DNA-Bindungsaktivität des untersuchten E(spl)-Proteins (Oellers et al., 1994). Die Mutation des konservierten Glycins in ein Prolin in Hey1 zeigte keinen eindeutigen Effekt auf die Repression der MyogeninPromotoraktivität in Zellkulturen oder der myogenen Umwandlung von 10T1/2 Zellen durch MyoD (Sun et al., 2001).

Zahlreiche bHLH-Proteinfamilien binden als Hetero- oder Homodimere an die sogenannte E-Box, eine Hexanukleotidsequenz mit dem Consensus CANNTG. Bindungsspezifität wird durch Interaktionen der basischen Regionen mit den mittleren zwei Basen, sowie den E-Box flankierenden Basen erreicht (Blackwell und Weintraub, 1990). 
Für E(spl)-Proteine der Fliege wurde zunächst beschrieben, dass diese als Homodimere an eine abweichende Sequenz mit dem Consensus CACNAG, die als N-Box bezeichnet wird, binden (Oellers et al., 1994; Tietze et al., 1992). "In vitro random oligonucleotide binding site selection"-Experimente haben jedoch gezeigt, dass Drosophila E(spl)Proteine bevorzugt an ESE-Boxen (E$(\underline{s} \mathrm{pl})$-EE-Boxen) binden, eine palindromische 12Basenpaar-Sequenz (TGGCACGTG(C/T)(C/T)A) mit einem Klasse B-Kern (CACGTG). Im Vergleich mit diesen Klasse B-Boxen ist die Bindungsaktivität der $\mathrm{E}(\mathrm{spl})$-Proteine für $\mathrm{N}$ Boxen (CACGAG) und Klasse C-Stellen (CACGCG) viel geringer. Die Beobachtung von dramatischen Auswirkungen auf die LacZ-Reporter-Genexpression in transgenen Fliegen infolge von minimalen Sequenzveränderungen innerhalb des Klasse B-Kerns hat die Bedeutung der Klasse B-Box auch in vivo bestätigt (Jennings et al., 1999).

Drosophila Hairy-Homodimere binden in vitro sowohl an Klasse B als auch an Klasse CSequenzen. Die Mutation der Klasse C-Sequenz im Promotor des achaete-Gens verursacht, wie bei Hairy-Mutanten, ektopische sensorische Haarorgane in der Fliege, was die Vermutung nahe legt, dass Hairy seine Funktion in vivo über die Bindung an die Klasse C-Sequenz ausübt (Ohsako et al., 1994; Van Doren et al., 1994).

Hes1, Hes2, Hes3 und Hes5 der Säuger können als Homodimere an die N-Box binden (Akazawa et al., 1992; Hirata et al., 2000; Ishibashi et al., 1993; Sasai et al., 1992;). Hes2 bevorzugt allerdings die Bindung an eine E-Box (Ishibashi et al., 1993). Hingegen bindet Hes1 zwar auch an die E-Box (Hirata et al., 2000), zieht aber die N-Box vor (Sasai et al., 1992). In vivo Zielgene sind bisher nur für Hes1 bekannt. Hes1 kann in ReportergenVersuchen in Säugerzellkulturen seine eigene Genexpression über die N-Box in einer negativer Rückkopplungsschleife regulieren (Takebayashi et al., 1994), sowie Mash1 durch Bindung an eine Klasse C-ähnliche Sequenz (CACGCA) aktiv reprimieren (Chen et al., 1997). Ein weiteres mögliches Zielgen von Hes1 ist CD4. Die Überexpression von Hes1 führt zu einer N-Box-abhängigen Repression des CD4-Promotors und der Verringerung endogener CD4-Expression in CD4+CD8-T-Helferzellen (Kim und Siu, 1998). Auch der saure $\alpha$-Glucosidase-Promotor wird in Hepatom-abstammenden HepG2Zellen durch Hes1 abhängig von einer Klasse C-Sequenz (CACGCG) reprimiert (Yan et al., 2001). Für das vermeintliche Hes1-Zielgen, p21WAF, einem Cyclin-abhängigen Kinase-Inhibitor, steht der Nachweis einer Hes1-Bindungsstelle in der Promotorregion noch aus (Castella et al., 2000).

Zusammenfassend läßt sich sagen, dass Hairy-Proteine in Drosophila und Säugern in vivo vermutlich Klasse $\mathrm{C}$-Sequenzen und $\mathrm{N}$-Boxen bevorzugen, während Klasse B-Stellen die in vivo-Zielsequenzen für $\mathrm{E}(\mathrm{spl})$-Proteine in Drosophila darstellen. Ausgehend von der

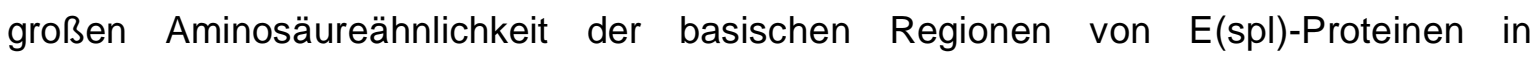


Drosophila und Vertebraten scheinen Klasse B-Stellen auch in Vertebraten gute Kandidaten für in vivo-Zielsequenzen zu sein.

Hey1 und Hey2 bevorzugen Klasse B- und C-Bindungsstellen, können aber auch auch an $\mathrm{N}$-Boxen und sogar Klasse A-Sequenzen (CAGGTG) binden (Iso et al., 2001; Nakagawa et al., 2000). An welche Sequenzen Hey3 bindet ist nicht bekannt (Nakagawa et al., 2000). Zielgene für Hey-Proteine sind bisher nicht eindeutig identifiziert worden. Hey2 kann zwar seine eigene Genexpression negativ regulieren (Nakagawa et al., 2000), jedoch enthält das kürzeste Reportergenkonstrukt des Hey2-Promotors weder Klasse Anoch Klasse B- und C- Sequenzen, was vermuten läßt, dass die Autoregulation entweder über die Bindung von Hey2 an bisher unbekannte Sequenzen oder über einen passiven Mechanismus stattfindet.

Für Stra13/Dec-Proteine ist bisher keine DNA-Bindungsstelle identifiziert worden, sie binden jedoch weder an E- noch an N-Boxen (Boudjelal et al., 1997; Garriga-Canut et al., 2001).

Die Fähigkeit der bHLH-O-Proteine an E-Boxen zu binden, könnte ihnen ermöglichen, mit bHLH-Aktivatoren um die Bindung an E-Box-Zielsequenzen zu konkurrieren (Abb.1$2 \mathrm{G}, \mathrm{H})$, wie es bisher nur für Drosophila $\mathrm{E}(\mathrm{spl})$-Proteine und Heterodimere aus Daughterless (E12/47-Familie) und Lethal-of-scute (Achaete-scute a-Familie) in in vitroDNA-Bindungsstudien gezeigt wurde (Jennings et al., 1999).

\subsection{3 bHLH-O-Proteine: Repressionsdomänen, Corepressoren, aktive Repression}

Alle Mitglieder der Hairy- und E(spl)-Familien besitzen als charakteristisches Merkmal das C-terminale WRPW-Motiv, über das sie den Drosophila Corepressor Groucho oder eines seiner homologen Proteine in Vertebraten, die in Säugern auch als TLE-Proteine bezeichnet werden, rekrutieren können (Grbavec et al., 1998; Grbavec und Stifani, 1996; Paroush et al., 1994). Das WRPW-Motiv allein ist ausreichend, um als Fusionsprotein mit der Gal4-DNA-Bindungsdomäne aus Hefe durch die Interaktion mit Groucho die Transkription eines Promotors mit Gal4-Bindungsstellen zu reprimieren (Fisher et al., 1996). Groucho/TLE-Proteine, die auch von vielen anderen DNA-gebundenen Repressoren, wie Engrailed und Runt, rekrutiert werden (Fisher und Caudy, 1998), interagieren mit Histondeacetylasen (HDAC) (Chen et al., 1999), die vermutlich durch Veränderung der lokalen Chromatinstruktur die Transkription reprimieren (Chen und Courey, 2000). Außerdem vermitteln Groucho/TLE-Proteine auch cooperative Interaktionen zwischen bHLH-O-Proteinen und andersartigen Repressoren. So kann die Hes1-Repression durch die TLE-vermittelte Interaktion zwischen Hes1 und BF-1, einem "Winged-Helix"-Repressor, potenziert werden (Yao et al., 2001). Die aktive Transkriptionsrepression von Zielgenen unterliegt somit einer komplexen Kontrolle. 
Während alle Drosophila Hairy- und E(spl)-Proteine mit dem WRPW-Motiv enden, haben einige der Vertebraten-Familienmitglieder zusätzliche Aminosäuren, so endet z. B. das Säuger-Hes1-Protein mit WRPWRN. Trotz dieser zusätzlichen Aminosäuren ist eine Interaktion von Hes1 mit TLE1 möglich (Grbavec und Stifani, 1996). Die Bedeutung der Variationen im WRPW-Motiv ist bisher nicht geklärt, doch könnten sie für die Spezifität der Bindung eines bestimmten Groucho/TLE-Proteins entscheidend sein, da Vertebraten im Gegensatz zu Drosophila mehrere dieser Corepressoren besitzen.

Hairy- und $\mathrm{E}(\mathrm{spl})$-Proteine interagieren vermutlich auch mit anderen Corepressoren. CtBP, ein "short-range"-Corepressor in Fliegen (Nibu et al., 1998), interagiert mit dem PLSLV-Motiv in der C-terminalen Region des Drosophila Hairy-Proteins und mit einem ähnlichen Motiv in $\mathrm{E}(\mathrm{spl})$ mdelta (=mC) (Poortinga et al., 1998). Die Groucho-vermittelte Repression von Hairy wird jedoch durch CtBP, das gleichzeitig mit Groucho an Hairy binden kann, negativ reguliert (Zhang and Levine, 1999; Phippen et al., 2000). Es bleibt somit zu klären, ob CtBP auch mit Hairy kooperieren kann, um die Transkription in einem anderen Kontext zu reprimieren. bHLH-O-Proteine der Vertebraten besitzen kein PLSLVMotiv, trotzdem ist nicht auszuschließen, dass sie über ein anderes Motiv mit CtBP interagieren.

Mitglieder der Hey-Familie besitzen zwar das WRPW-ähnliche Motiv YXXW, aber die Repressionsaktivität von Hey2 liegt primär in der bHLH-Domäne, die notwendig und ausreichend für die Rekrutierung eines Corepressor-Komplexes ist, der N-CoR, mSin3A und HDAC1 enthält (Iso et al., 2001). Da weder der gereinigte Säuger-Sin3-Komplex NCoR (Zhang et al., 1997), noch der N-CoR-verwandte SMRT-Komplex Sin3 (Guenther et al., 2000; Li et al., 2000) enthält, bleibt zu klären, ob Hey-Proteine diese CorepressorKomplexe gleichzeitig rekrutieren können. Für die Autoregulation von Hey2 ist die basische Domäne ebenfalls erforderlich, jedoch werden weder Deacetylierung durch HDAC noch die C-terminale Region mit dem YXXW-Motiv benötigt (Nakagawa et al., 2000). Ob diese konservierte Region der Hey-Proteine in einem anderen spezifischen Zusammenhang für die Bindung von Groucho/TLE-Proteinen oder anderen HDACassoziierten Corepressoren von Bedeutung ist, muß noch geklärt werden.

Stra13/Dec-Proteine enthalten weder das WRPW- noch das YXXW-Motiv. Für die Transkriptionsrepression über einen HDAC-abhängigen Mechanismus sind jedoch ebenfalls Sequenzen nahe des Carboxylendes erforderlich (Garriga-Canut et al., 2001; Sun und Taneja, 2000). Stra13/Dec-Proteine können die Transkription aber auch HDACunabhängig negativ regulieren (Boudjelal et al., 1997; Sun und Taneja, 2000).

bHLH-O-Proteine sind somit durch die Rekrutierung verschiedenster Corepressoren in der Lage, die Transkription ihrer Zielgene über einen aktiven Regulationsmechanismus zu reprimieren. 


\subsection{4 bHLH-O-Proteine: Notch-Effektoren}

Der Notch-Signalweg, der Neurogenese und Zellschicksalsentscheidungen, sowie zahlreiche andere Entwicklungsprozesse in Vertebraten und Invertebraten kontrolliert, ist von großer Bedeutung für die Transkriptionsregulation zahlreicher bHLH-O-Gene in Vertebraten (Übersichtsartikel: Davis und Turner, 2001; Iso et al., 2003; Lai, 2004; Yoon und Gaiano, 2005). Die Aktivierung des Notch-Signalwegs erfolgt durch die Bindung eines auf einer benachbarten Zelle lokalisierten Notch-Transmembran-Liganden, zu denen in Vertebraten mehrere Delta- und Jagged/Serrate-Proteine zählen. Als Folge der Ligandenbindung wird die intrazelluläre Domäne des Notch-Transmembranrezeptors durch Proteolyse freigesetzt, wandert in den Kern und bindet an den Transkriptionsfaktor $\mathrm{CSL} / \mathrm{Su}(\mathrm{H})$, der von einem Transkriptionsrepressor in einen Transkriptionsaktivator umgewandelt wird und dann die entsprechenden Notch-Zielgene induziert (Abb.1-3).

Eines der direkt induzierten Notch-Zielgene und somit ein Notch-Effektor in Säugern ist Hes1, das ein Hairy-ähnliches Protein kodiert. Die Aktivierung der Expression eines transient transfizierten Reporters mit dem Hes1-Promotor durch eine konstitutiv aktive Form von Notch erfordert CSL-Bindungsstellen im Promotor (Jarriault et al., 1995). Zudem ist die Hes1-Expression im segmentierten Mesoderm von der Notch-Funktion abhängig (Jouve et al., 2000). Auch in retinalen Vorläufern stimuliert ein konstitutiv aktives NotchProtein die Hes1-Transkription (Ohtsuka et al., 1999). Im sich entwickelnden zentralen Nervensystem von Notch- und RBP-JK/CSL-Knockout-Mäusen konnte hingegen keine Veränderung der Hes1-Expression festgestellt werden (de la Pompa et al., 1997), was für eine nicht Notch-abhängige Hes1-Expression spricht. Somit bestimmt der Entwicklungskontext, ob Hes1 als Notch-Effektor oder Notch-unabhängig fungiert.

Im Gegensatz zur Hes1-Expression ist die Expression von Hes5, das ein E(spl)-ähnliches Protein kodiert, in Notch- und RBP-JK/CSL-Knockout-Mäusen reduziert oder nicht vorhanden (de la Pompa et al., 1997). Die Abhängikeit der Hes5-Expression von einem intakten Notch-Signalweg legt nahe, dass Hes5 im sich entwickelnden ZNS der Maus und vermutlich auch anderswo als Notch-Effektor fungiert.

In Xenopus können mehrere E(spl)-verwandte Gene durch den Notch-Signalweg aktiviert werden, einschließlich der Hes5-ähnlichen Gene ESR1 und ESR7, sowie ESR4, ESR5 und ESR6e (Deblandre et al., 1999; Jen et al., 1999; Koyano-Nakagawa et al., 2000; Wettstein et al., 1997). In einigen Fällen konnte außerdem gezeigt werden, dass die Expression einiger dieser Gene durch einen dominant-negativen Liganden für Notch, Delta $^{\text {Stu }}$, oder ein dominant-negatives CSL-Protein, X-Su(H)-DBM, blockiert werden konnte (Chitnis et al., 1995; Jen et al., 1997; Jen et al., 1999; Wettstein et al., 1997). Auch 
die E(spl)-ähnlichen Gene her1 und her4 im Zebrafisch werden durch Notch-Signale aktiviert (Takke et al., 1999; Takke und Campos-Ortega, 1999).

Die Gene, die zur Hey-Unterfamilie in Vertebraten gehören, werden ebenfalls durch Notch reguliert. Die Expression der Hey-Gene in der Maus hängt von der Funktion des NotchLiganden DII-1 ab (Kokubo et al., 1999). Zudem enthalten alle drei Säuger-Hey-Gene in ihren Promotorregionen CSL-Bindungsstellen, und die Expression transient transfizierter Reporter mit diesen Promotoren kann durch eine konstitutiv aktive Form von Notch aktiviert werden (Maier und Gessler, 2000; Nakagawa et al., 2000).

Einige andere bHLH-O-Gene scheinen jedoch keine Notch-Effektoren zu sein. Die Maus und Xenopus Hes6-Gene oder das Maus Hes3-Gen und das Xenopus HR1-Gen können nicht durch aktiviertes Notch induziert werden (Bae et al., 2000; Hirata et al., 2000; Koyano-Nakagawa et al., 2000; Takada et al., 2005). Hes6 wird vermutlich durch neurale bHLH-Aktivatoren in Maus und Xenopus reguliert (Koyano-Nakagawa et al., 2000). Inwieweit die Dec-Gene durch Notch reguliert werden, ist bisher nicht bekannt, eine Vielzahl Notch-unabhängiger Signale, die die Dec-Gene induzieren können, sind aber aus Zellkulturen bekannt (Boudjelal et al., 1997; Ivanova et al., 2001; Rossner et al., 1997; Sun und Taneja, 2000).

In Drosophila erfordert die Induktion der meisten E(spl)-Gene ein Notch-Signal, die der Hairy und Hairy-ähnlichen Gene hingegen nicht (Bailey und Posakony, 1995; Bier et al., 1992; Jennings et al., 1994; Langeland und Carroll, 1993;). Diese offensichtliche Abgrenzung dieser zwei bHLH-O-Unterfamilien wurde evolutionär jedoch nicht konserviert, da in Vertebraten Gene beider Unterfamilien, wie z.B. Hes1 und Hes5, durch Notch reguliert werden.

Für die Erzeugung der normalen Expressionsmuster von E(spl)-Genen während der Drosophila-Entwicklung sind zusätzliche transkriptionelle Inputs erforderlich (Nellesen et al., 1999), und dies gilt auch für die durch Notch-regulierten Vertebraten bHLH-O-Gene. In Xenopus-Embryonen induziert aktiviertes Notch das ESR6e-Gen in der sich entwickelnden Epidermis, aber nicht im sich entwickelnden Nervensystem, während ESR1 und ESR7 durch Notch sowohl in neuralen als auch in epidermalen Zellen aktiviert werden können (Deblandre et al., 1999). Im Gegensatz dazu induziert Notch ESR4 und ESR5 nur im segmentierten Mesoderm (Jen et al., 1999). 


\subsection{5 bHLH-O-Proteine: Funktionen während der Entwicklung des Vertebraten- Nervensystems}

\subsubsection{Die Hairy- und E(spl)-Unterfamilien}

Bei verschiedensten Entwicklungsprozessen in Vertebraten werden Hairy- und $E(s p l)$ Gene durch die Aktivierung des Notch-Signalwegs induziert und dienen als NotchEffektoren. Ihre Expression und Funktion kann jedoch auch Notch-unabhängig sein (Übersichtsartikel: Davis und Turner, 2001; Iso et al., 2003).

Die Hairy- und E(spl)-Proteine und der Notch-Signalweg besitzen essentielle Funktionen bei der Begrenzung der neuronalen Differenzierung aus neuralen Vorläuferzellen.

Im sich entwickelnden Nervensystem von Säugern ist die Expression von Hes 1 und Hes5 auf Regionen beschränkt, die undifferenzierte neurale Vorläufer aufweisen (Akazawa et al., 1992; Ishibashi et al., 1995; Sasai et al., 1992). Die konstitutive Expression von Hes1 in neuralen Vorläufern mittels eines retroviralen Vektors verhindert die neuronale Differenzierung sowohl im Hirn (Ishibashi et al., 1994) als auch der Retina (Tomita et al., 1996). Auch die Transfektion von primären hippocampalen neuralen Vorläufern der Ratte hemmt deren Differenzierung (Castella et al., 1999). Im Gegensatz dazu führt die gezielte Zerstörung des Hes1-Gens in Mäusen zu einer vorzeitigen Differenzierung der Neuronen im Telencephalon (Ishibashi et al., 1995), in der Riechplakode (Cau et al., 2000), im Innenohr (Zheng et al., 2000) und in der Retina (Tomita et al., 1996).

Infolge der ektopischen Expression von E(spl)-verwandten Proteinen wird auch die Differenzierung primärer Neuronen in Zebrafisch (Takke et al., 1999) und Xenopus (Koyano-Nakagawa et al., 2000; Schneider et al., 2001) gehemmt.

In Drosophila grenzen die Hairy- und E(spl)-Proteine die Neurogenese ein, indem sie zum einen die Expression proneuraler bHLH-Gene reprimieren und zum anderen der Fähigkeit proneuraler bHLH-Proteine, ihre Zielgene zu aktivieren, entgegenwirken (Ohsako et al., 1994; Van Doren et al., 1994). Diese regulatorische Beziehung zwischen bHLH-ORepressoren und proneuralen bHLH-Aktivatoren wurde in Vertebraten konserviert.

So ist im Telencephalon und der Riechplakode von Hes1-Knockout-Mäusen eine gesteigerte Transkription des proneuralen bHLH-Gens Mash1 zu beobachten (Cau et al., 2000; Ishibashi et al., 1995). Dies dürfte, basierend auf Studien in Zellkulturen (Chen et al., 1997), das Fehlen der direkten Repression von Mash1 durch Hes1 reflektieren. Weiterhin hemmt Hes1 in vitro die Bindung von Mash1 an DNA und wirkt der Mash1Aktivierung von Reportern und Zielgenen in kultivierten Mauszellen entgegen (Castella et al., 1999; Castella et al., 2000; Hirata et al., 2000; Sasai et al., 1992).

In der Riechplakode von Hes5-Knockout-Mäusen wurde hingegen keine gesteigerte Mash1-mRNA-Expression gefunden, aber in Hes1/Hes5-Knockout-Mäusen konnte 
zusätzlich zur hochregulierten Transkription von Mash1 eine gesteigerte Expression des bHLH-Gens Neurogenin1 (Ngn1) festgestellt werden (Cau et al., 2000). Ngn1 wird in der Riechplakode (Riechknolle) in einer Population von Vorläufern mit eingeschränktem Potential exprimiert, und diese Expression ist abhängig von Mash1 (Cau et al., 1997). Diese Beobachtungen legen nahe, dass Hes1 die Mash1-Expression in frühen olfaktorischen Vorläufern begrenzt, während Hes 1 und Hes5 redundant agieren, um die Expression von Ngn1 in späteren Vorläufern einzuschränken. Somit können Hes1 und Hes5 nicht nur die terminale Differenzierung von Neuronen begrenzen, sondern können auch die Übergänge der Genexpression innerhalb einer mitotisch aktiven neuralen Vorläuferpopulation regulieren. Es scheint wahrscheinlich, dass die Aktivität von Hes1 und Hes5 in Vorläufern zumindest zum Teil daraus besteht, die Aktivierung des Ngn1-Gens durch Mash1 zu hemmen.

Auch infolge der ektopischen Expression von zher4 konnte eine Repression der Neurogenín-Expression in Zebrafisch-Embryonen beobachtet werden (Takke et al., 1999).

Der Funktionsverlust von Komponenten des Notch-Signalwegs innerhalb des sich entwickeInden Nervensystems führt ebenfalls zu einer ekzessiven und vorzeitigen Differenzierung von Neuronen (Chitnis et al., 1995; de la Pompa et al., 1997; Handler et al., 2000), was im Einverständnis zur Regulation der Hes1 und Hes5-Expression durch den Notch-Signalweg steht. Hes1 und Hes5 sind redundant für die effektive Notchvermittelte Differenzierungshemmung erforderlich, da die konstitutive Aktivierung von Notch mittels eines retroviralen Vektors in neuralen Vorläufern isoliert aus WildtypMäusen bzw. Hes1 oder Hes5-Knockout-Mäusen die neuronale Differenzierung nahezu vollständig hemmte, während aktiviertes Notch die neuronale Differenzierung neuraler Vorläufer isoliert aus Hes1/Hes5-Knockout-Mäusen nicht effizient inhibieren konnte (Ohstuka et al., 1999).

Einige Mitglieder der Hairy und $\mathrm{E}(\mathrm{spl})$-Unterfamilien werden in differenzierenden und differenzierten Neuronen exprimiert. Hes3 wird in den Purkinje-Zellen des Kleinhirns exprimiert (Hirata et al., 2000). Hes6-Transkripte sind in differenzierenden und reifen Neuronen in vielen Regionen des Nervensystems vorhanden (Bae et al., 2000; KoyanoNakagawa et al., 2000; Pissarra et al., 2000; Vasiliauskas and Stern, 2000).

Im Gegensatz zu anderen Hairy und E(spl)-Proteinen fördert die ektopische Expression von Hes6 in Xenopus-Embryonen die neuronale Differenzierung in proneuronalen Domänen und bedingt eine hochregulierte Expression von neuralen bHLH-Genen einschließlich NeuroD und X-Ngnr-1 (Koyano-Nakagawa et al., 2000). Auch die Überexpression von Hes6 in retinalen Vorläufern fördert die neuronale Differenzierung (Bae et al., 2000). Protein-Protein-Interaktionsstudien und andere Experimente legen 
nahe, dass Hes6 die Neurogenese durch die Hemmung anderer bHLH-O-Proteine, wie Hes1 bzw. Xhairy1 und Xhairy2, fördert (Bae et al., 2000; Koyano-Nakagawa et al., 2000).

Zusätzlich zur Hemmung der neuronalen Differenzierung und Aufrechterhaltung eines undifferenzierten Zustandes nehmen Hairy- und E(spl)-Proteine, wie Hes1 und Hes5, sowie der Notch-Signalweg auch Einfluß auf die Entscheidung zwischen einem neuronalen Zellschicksal oder einem Glia-Zellschicksal (Furukawa et al., 2000; Gaiano et al., 2000; Hojo et al., 2000; Morrison et al., 2000).

In der Retina von Hes5-Knockout-Mäusen ist die Anzahl der Müller-Gliazellen reduziert, während die konstitutive Expression von Hes5 mittels eines retroviralen Vektors in retinalen Zellen dazu führt, dass die meisten der infizierten Zellen zu Müller-Gliazellen werden (Hojo et al., 2000). Entsprechend wird Hes5 in der postnatalen Retina in der Schicht exprimiert, die differenzierende Müller-Gliazellen enthält. Auch für Hes1 und aktiviertes Notch konnte gezeigt werden, dass sie das Zellschicksal retinaler Vorläufer wie Hes5 zugunsten von Müller-Gliazellen beeinflußten, während die konstitutive Expression eines vermutlich dominant-negativen Hes1-Proteins mit einer mutierten DNABindungsdomäne die Müller-Gliazelldifferenzierung verhinderte (Furukawa et al., 2000).

Obwohl es möglich wäre, dass Hairy und E(spl)-Proteine die Gliogenese aktiv fördern, scheint es eher wahrscheinlich, dass sie den Vorläuferzellen durch die Repression der neuronalen Differenzierung gestatten, ein Glia- anstelle eines neuronalen Zellschicksals anzunehmen.

Wie bereits zuvor erwähnt, können Hes1 und Hes5 die Funktion neuraler bHLH-Proteine, wie Mash1, hemmen. In Mash1/Math3- und Mash1/Ngn2-Knockout-Mäusen wurde, ähnlich wie nach der konstitutiven Expression von Hes1 und Hes5 in retinalen Zellen, eine ekzessive Gliadifferenzierung gefunden (Tomita et al., 2000; Nieto et al., 2001). Die Analyse neuraler Vorläufer aus Mash1/Ngn2-Knockout-Mäusen zeigte, dass bei Fehlen neuraler bHLH-Funktion retinale Vorläufer zu Gliazellen und nicht zu Neuronen differenzieren. Zudem fördert die Überexpression des neuralen bHLH-Proteins Ngn1 nicht nur die neuronale Differenzierung neuraler Vorläufer, sondern hemmt auch ihre Differenzierung zu Gliazellen (Sun et al., 2001). Somit dürften die bHLH-O-Proteine durch die Hemmung der Expression und/oder Funktion von neuralen bHLH-Proteinen die Gliogenese fördern (Übersichtsartikel: Frisen and Lendahl, 2001; Wang and Barres, 2000). 


\subsubsection{Die Hey-Unterfamilie}

Die Mitglieder der Hey-Unterfamilie in Vertebraten spielen nicht nur bei der Angiogenese, der Somitogenese und der Myogenese, sondern auch bei der Ausbildung des Nervensystems eine wesentliche Rolle. Ihre Genexpression wird wie die zahlreicher Hairy- und E(spl)-Gene durch die Aktivierung des Notch-Signalwegs positiv reguliert, was nahelegt, dass sie als Notch-Effektoren fungieren (Übersichtsartikel: Davis und Turner, 2001; Iso et al., 2003).

Das einzige bisher in Xenopus beschriebene Hey-Gen, XHRT1 bzw. Xhey1, wird im sich entwickelnden Nervensystems von Schwanzknospenstadien im dorsalen Hinterhirn, im Telencephalon, sowie in den Augenvesikeln und Riechplakoden exprimiert (Pichon et al., 2002; Rones et al., 2002). XHRT1-Transkripte sind aber auch in medialen Neuralplattenzellen und später in der Bodenplatte vorhanden (Pichon et al., 2002; Taelman et al., 2004). Die infolge der XHRT1-Überexpression beobachtete Hemmung der Differenzierung neuraler Vorläuferzellen in der Neuralplatte legt nahe, dass XHRT1 dazu beiträgen dürfte, dass die Zellen der Bodenplatte kein neuronales Schicksal annehmen (Taelman et al., 2004). Die Coexpression von Xhairy2 in Bodenplattenzellen und dessen Interaktion mit XHRT1 in Coimmunopräzipitationsexperimenten lassen vermuten, dass Xhairy2 ein biologisch relevanter Heterodimerisierungspartner von XHRT1 ist (Taelman et al., 2004). Zudem konnte mittels Überexpressionsstudien in Embryonen und animalen Kappen von Xenopus laevis gezeigt werden, dass die XHRT1-Expression in medialen Neuralplattenzellen durch Notch induziert werden kann und dass sich die Regulation von $X H R T 1$ von der anderer Notch induzierbarer E(spl)-Gene, wie ESR1, hinsichtlich anderer regulatorischer Faktoren, wie z.B. X-Ngnr-1, unterscheidet (Pichon et al., 2002).

Im ZNS der Maus werden die Hey-Gene spezifisch und komplementär exprimiert, was auf verschiedene Funktionen bei der Entwicklung des ZNS hindeutet (Kokubo et al., 1999; Leimeister et al., 1999; Nakagawa et al., 1999). Alle drei Maus-Hey-Gene Hey1, Hey2 und HeyL werden auch in der sich entwickelnden Retina exprimiert, wobei Hey2-Transkripte vorwiegend in der mittleren Region der inneren nucleären Schicht der Retina, die u.a. Müller-Gliazellen enthält, lokalisiert sind. Überexpressionsstudien in Retina-Explantaten von embryonalen oder neugeborenen Mäusen zeigten, dass nur Hey2, nicht aber Hey1 oder HeyL, eine Gliogenese fördernde und Neurogenese/Photorezeptoren inhibierende Aktivität besitzt ohne die Zellproliferation oder den Zelltod zu verändern, was darauf hindeutet, dass Hey2 an der Auswahl des Glia-Zellschicksals aufkosten des neuralen Zellschicksals beteiligt sein dürfte. Für eine positive Rolle von Hey2 bei der retinalen Gliogenese spricht ebenfalls, dass in Maus-Doppelmutanten für die neuronalen Determinationsgene Mash1 und Math3 der Anstieg der Anzahl von Müller-Gliazellen 
aufkosten der bipolaren Zellen mit einer hochregulierten Hey2-Expression einhergeht. Die antagonistische Regulation zwischen Hey2 und Mash1-Math3 dürfte daher die Verhältnisse von Neuronen und Glia bestimmen. Die Ähnlichkeit der gliogenen Aktivität infolge der Notch-Aktivierung und der gliogenen Aktivität von Hey2 in der Retina legen nahe, dass Hey2 neben Hes1 und Hes5 als Notch-Effektor bei der Förderung der retinalen Gliogenese fungiert (Satow et al., 2001). Ob die Gliogenese durch NotchAktivierung in der Retina ein rein instruktiver Mechanismus oder ein Grundzustand infolge der Neurogenese-Hemmung ist, konnte bisher nicht vollständig geklärt werden.

\subsubsection{Helt/Heslike}

Helt bzw. Heslike, ein erst kürzlich identifiziertes bHLH-O-Protein, dessen bHLH-Domäne zwar der von Hairy und Hey-Proteinen ähnelt, aber keiner der bekannten bHLH-OUnterfamilien angehört, wird in undifferenzierten neuralen Vorläufern im sich entwickelnden Mesencephalon und caudalen Diencephalon der Maus exprimiert (Miyoshi et al., 2004; Nakatani et al., 2004). Die Expression von Helt überlappt in einige dieser Hirnegionen, in denen GABAerge Neuronen entstehen, mit der Expression von Mash1 was auf eine Funktion von Helt und Mash1 bei der Spezifizierung von GABAergen Neuronen hindeutet und durch verschiedene experimentelle Daten belegt werden konnte (Miyoshi et al., 2004). In Maus-Embryonen überexprimiertes Helt erzeugte in Mash1positiven Regionen ektopische GABAerge Neuronen. GABAerge Neuronen fehlten hingegen zugunsten anderer neuronaler Subtypen fast vollständig im Helt-positiven Mesencephalon und caudalen Diencephalon von Mash1-Knockout-Mäusen. Zudem konnte in Zellkulturen von neuralen Vorläufern gezeigt werden, dass nur die Coexpression von Helt und Mash1, nicht aber Helt oder Mash1 allein, die GABAerge Neurogenese deutlich fördert. Somit dürfte Helt zu den bHLH-Transkriptionsfaktoren zählen, die in Kombination mit anderen Transkriptionsfaktoren für die Spezifizierung verschiedener neuronaler Subtypen verantwortlich sind und dadurch die neuronale Diversität erhöhen. Studien zur Regulation von Helt wurden bisher nicht veröffentlicht.

\subsubsection{Die Dec-Unterfamilie}

Dec1/Sharp2/Stra13 und Dec2/Sharp1 sind Regulatoren der molekularen Uhr in Säugern, deren Expression durch Licht und das Clock-Protein im suprachiasmatischen Nucleus hochreguliert wird (Butler et al., 2004; Grechez et al., 2004; Honma et al., 2002). Die Expression von Dec1 und Dec2 in verschiedenen Zelltypen neuroektodermaler, mesodermaler und endodermaler Herkunft während der Maus-Entwicklung läßt vermuten, dass die Dec-Proteine auch bei der embryonalen Zelldifferenzierung eine regulatorische 
Funktion besitzen (Azmi und Taneja, 2002; Boudjelal et al., 1997). Diese Hypothese wird u.a. durch die Fähigkeit von Dec1 gestützt, die mesodermale und endodermale Differenzierung von P19-Zellen zu hemmen, und stattdessen die neuronale Differenzierung dieser embryonalen Carcinomzellen zu fördern, ein Effekt der auch durch Retinsäure in P19-Zellen induziert werden kann (Boudjelal et al., 1997). Die bisherigen Studien sind ausschließlich in Säugersystemen durchgeführt worden, und die Funktion dieser Proteine während der Embryogenese ist nur wenig untersucht. Mitglieder der DecUnterfamilie aus Xenopus und Zebrafisch sind ebenfalls noch nicht beschrieben.

Dec1 und Dec2 können durch eine Vielzahl von Notch-unabhängigen Signalen in verschiedenen Zellkulturen induziert werden, wie z.B. durch Retinsäure (Boudjelal et al., 1997), NGF und Kainsäure, ein natürliches Glutaminsäure-Strukturanalogon, das eine Neurodegeneration induziert (Rossner et al., 1997), durch Insulin über den Phosphoinositol-3-Kinase-Weg (Yamada et al., 2003), durch TGF- $\beta$ (Zawel et al., 2002), cAMP (Shen et al., 1997; Shen et al., 2001) und Hypoxie (Ivanova et al., 2001; Yoon et al., 2001). Hinweise auf die Regulation durch den Notch-Signalweg gibt es bisher nicht.

\subsection{Zielsetzung der Arbeit}

bHLH-O-Proteine spielen eine wichtige Rolle bei der Ausbildung des Nervensystems in Vertebraten und Invertebraten (Übersichtsartikel: Davis und Turner, 2001; Fisher und Caudy, 1998; Iso et al., 2003). Auch in Xenopus laevis waren zu Beginn dieser Arbeit bereits mehrere bHLH-O-Proteine bekannt, wie Xhairy1 (Dawson et al., 1995), Xhairy2 (Schmidt et al., 1995), ESR1 (Wettstein et al., 1997), ESR3/7 (Perron et al., 1998), ESR9, ESR10 (Gawantka et al, 1998), ESR4, ESR5 (Jen et al., 1999), ESR6 (Deblandre et al., 1999). ESR8 wurde im Rahmen meiner Diplomarbeit identifiziert und näher charakterisiert (Sölter, 1999). Im Verlauf der Arbeit wurden weitere bHLH-O-Proteine in Xenopus laevis beschrieben, wie XHes6 (Koyano-Nakagawa et al., 2000), XHR1 (Shinga et al., 2001) und XHRT1 (Pichon et al., 2002; Rones et al., 2002).

Da einerseits nicht alle Säuger-bHLH-O-Proteine als Homologe unter den isolierten Xenopus-bHLH-O-Proteinen vertreten waren, und andererseits mehrere Xenopus-bHLHO-Proteine einem einzigen Säuger-bHLH-O-Protein zugeordnet werden konnten, lag die Annahme nahe, dass in Xenopus laevis weitere, noch nicht beschriebene bHLH-OProteine existieren. Solche unbekannten bHLH-O-Proteine sollten identifiziert und näher charakterisiert werden, vor allem hinsichtlich ihrer Funktion während der Neurogenese. 


\section{Ergebnisse}

\subsection{Identifizierung neuer bHLH-O-Proteine in Xenopus laevis}

Um herauszufinden, ob neben den bereits identifizierten bHLH-O-Proteinen weitere bHLH-O-Proteine in Xenopus laevis existieren, wurden verschiedene SequenzDatenbanken (GenBank, NIBB-DB, TIGR) mit bekannten bHLH-O-Proteinsequenzen aus Xenopus, Maus oder Mensch nach neuen Xenopus-bHLH-O-Proteinen durchsucht. Während die bHLH-Domänen verschiedener bHLH-O-Proteine einer Familie häufig stark konserviert sind, lassen sich neue Proteine leicht an den Unterschieden in den übrigen Regionen erkennen. Durch eine Datenbanksuche mit den entsprechenden cDNASequenzen konnten partielle Proteinsequenzen häufig ergänzt und Allel-Varianten des pseudotetraploiden Xenopus laevis identifiziert werden. Die in Xenopus laevis gefundenen bHLH-O-Proteine wurden für die Identifizierung von bHLH-O-Proteinen in Xenopus tropicalis eingesetzt, der einen diploiden Chromosomensatz besitzt. Sämtliche bHLH-OProteine aus Xenopus laevis und Xenopus tropicalis, die im Verlauf dieser Arbeit in den Datenbanken gefundenen werden konnten, wurden schließlich mit anderen bHLH-OProteinen aus Mensch, Maus und Zebrafisch verglichen (Clustal V, MegAlign, DNASTAR). Die Ergebnisse dieses Proteinsequenzvergleichs sind in Form zweier phylogenetischer Stammbäume für bHLH-O-Proteine mit bzw. ohne WRPW-Motif im Anhang (Abb.7-1,7-2) dargestellt. Ein vereinfachter phylogenetischer Baum der bHLH-OProteine aus Xenopus laevis und dem Mensch dient an dieser Stelle zur Erläuterung der erhaltenen Daten (Abb.2-1). Um die Komplexizität zu reduzieren, wurden allele Varianten der einzelnen bHLH-O-Proteine aus Xenopus laevis nicht dargestellt.

Der Sequenzvergleich mit humanen bHLH-O-Proteinen zeigt, dass in Xenopus laevis die Zahl der Mitglieder von bHLH-O-Proteinen mit WRPW-Motiv, besonders die der Enhancer of split $(E(s p l))$-Familie, deutlich höher ist. Allein 8 verschiedene Proteine, ESR1-2, sowie ESR6-11, besitzen eine größere Ähnlichkeit zu HES5 als zu allen anderen HES-Proteinen und werden daher in der Hes5-Gruppe zusammengefaßt (Li et al., 2003). Neben den zu Beginn der Arbeit bekannten Hes5-ähnlichen Proteinen, ESR1, sowie ESR 6-10, konnten zwei weitere Mitglieder dieser Gruppe identifiziert werden, ESR2 und ESR11. Die Sequenz von ESR2 wurde erst im Verlauf der Arbeit veröffentlicht (GenBank), und bis auf die Expression im sich entwickelnden ZNS und den Somiten sind keine weiteren Daten bekannt. Das in der Literatur bisher noch nicht erwähnte bHLH-O-Protein der Hes5Gruppe, das hier als ESR11 bezeichnet wird, konnte erst zum Ende dieser Arbeit identifiziert werden und wurde daher, wie ESR2, nur im Sequenzvergleich der Hes5Gruppe im dritten Teil dieser Arbeit berücksichtigt. 
Unter den bekannten Mitgliedern der anderen Hes-Gruppen konnte ein neues bHLH-OProtein in Xenopus laevis identifiziert werden, das aufgrund seiner Ähnlichkeit zu SäugerHes2-Proteinen den Namen XHes2 bekommen hat. XHes2 schien für eine ausführlichere Charakterisierung besonders geeignet zu sein. Abgesehen vom frühen Zeitpunkt der Identifizierung konnte zum einen aus mehreren überlappenden EST-Sequenzen ein vollständiges bHLH-O-Protein abgeleitet werden, zum anderen war und ist nur wenig über Hes2 aus Säugern bekannt, vor allem hinsichtlich seiner Funktion bei der Embryonalentwicklung (Ishibashi et al., 1993; Nishimura et al., 1998).

Während die Hey-Familie in Säugern und Zebrafisch jeweils drei Mitglieder hat, konnte in Xenopus neben XHRT1 kein weiteres Mitglied gefunden werden. Auch ein Helt-ähnliches Protein wurde bei der Datenbanksuche nicht identifiziert. Allerdings konnten vor kurzem mehrere Xenopus-Sequenzen bHLH-O-Proteinen der Dec-Familie zugeordnet werden.

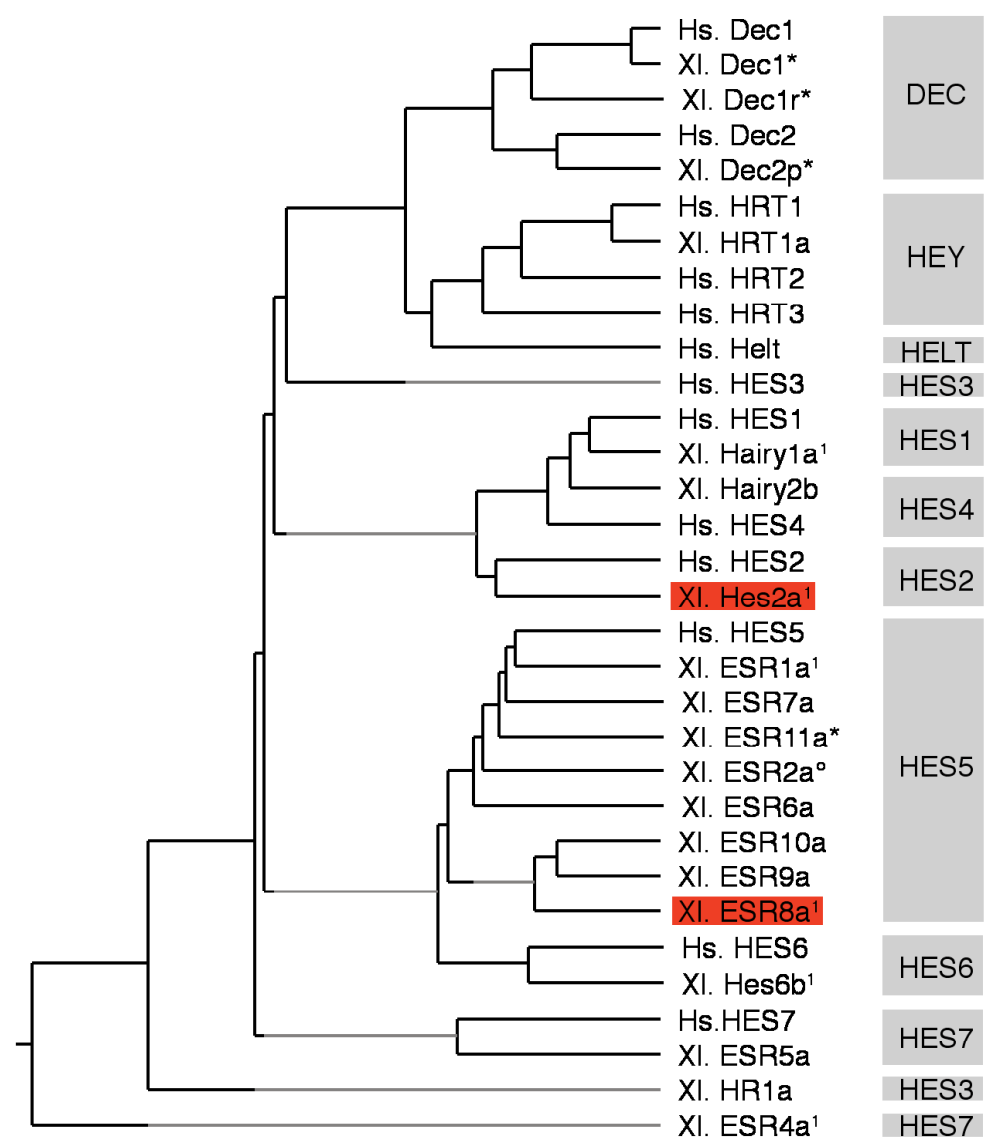

Abb.2-1: In Xenopus laevis existieren mehrere, bisher noch nicht beschriebene bHLH-O-Proteine. Die bHLH-O-Proteine aus Xenopus wurden entsprechend ihrer Verwandtschaft mit Säuger-Proteinen verschiedenen Familien (DEC, HELT und HEY) und Gruppen (HES1-7) zugeordnet, die rechts als graue Felder dargestellt sind. Der phylogenetische Stammbaum basiert auf einem Sequenzvergleich der Gesamtproteine. Die in der Arbeit näher charakterisierten Proteine sind rot unterlegt. Weitere, bisher noch nicht publizierte bHLH-O-Proteine sind mit einem Stern $\left(^{*}\right)$ gekennzeichnet, oder mit einem Kreis $\left(^{\circ}\right)$ bei ausschließlicher Veröffentlichung der Sequenz. Die Datenbank-Zugriffsnummern befinden sich im Anhang (Abb.7-1). Abkürzungen: Hs., Homo sapiens; Xl., Xenopus laevis; a,b, vermutlich pseudoallele Varianten des tetraploiden Xenopus laevis; $a^{1}$, Existenz einer sehr ähnlichen, hier nicht aufgeführten Variante $a^{2}(T a b .7-1)$; p, partielles Protein; r, „related“, ähnliches Protein, das aufgrund der Sequenzunterschiede vermutlich keine pseudoallele Variante darstellt. 


\subsection{Charakterisierung des bHLH-O-Proteins XHes2 aus Xenopus laevis}

\subsubsection{Isolierung eines XHes2-cDNA-KIons aus Xenopus laevis}

Die Sequenzinformation mehrerer überlappender EST-Klone (Abb.7-3), die zum Zeitpunkt der Identifizierung von XHes2 zur Verfügung stand und den gesamten offenen Leserahmen, sowie kurze Bereiche der 5'- und 3'-UTR umfasste, wurde für das Design von Primern benutzt, die den gesamten offenen Leserahmen amplifizieren. Mit diesen XHes2-spezifischen Primern (XHes2-P1F, XHes2-P1R) wurden mittels PCR die Fraktionen einer embryonalen Kopf-cDNA-Bank und einer Gesamt-Oocyten-Bank aus Xenopus laevis ermittelt, die XHes2-cDNA-Klone mit vollständiger Protein-kodierender Sequenz enthielten. Da das Ziel war, möglichst lange cDNA-Klone zu isolieren, die neben dem offenen Leserahmen vor allem auch weitere 5'UTR-Sequenzinformationen für das spätere Morpholino-Oligonukleotid-Design zur endogenen Translationshemmung enthielten, wurden die positiven Fraktionen mit einem Primerpaar untersucht, das aus einem Vektor-spezifischen (CMV-F) und einem XHes2-spezifischen Primer (XHes2$\mathrm{RT} 1 \mathrm{R})$ bestand. Aus beiden cDNA-Banken wurde jeweils die Fraktion mit den größten XHes2-spezifischen PCR-Produkten für die Filter-Hybridisierung zur Isolierung von XHes2-cDNA-Klonen ausgewählt. Ein aus der entsprechenden Kopfbank-Fraktion amplifiziertes PCR-Produkt, das den offenen Leserahmen von XHes2 enthielt, wurde als Sonde verwendet.

Nach zwei Hybridisierungsrunden, bei denen positive Plaques immer durch PCR mit den oben erwähnten XHes2-spezifischen Primerpaaren bestätigt wurden, konnte ein Phage mit einem XHes2-cDNA-Insert aus der Xenopus laevis Gesamt-Oocyten-Bank vereinzelt und durch in vivo Excision in ein Phagemid überführt werden (Abb.2-2). Die XHes2-cDNA des isolierten Klons besteht aus 1075 Nukleotiden, von denen die letzten 20 dem Poly(A)Schwanz (1056-1075) angehören. Die 5'-UTR besitzt 32 Nukleotide (1-32), die 3'-UTR ohne Poly(A)-Schwanz 447 Nukleotide (609-1055). Ein vermeintliches Polyadenylierungssignal (AATAAA) befindet sich an Position 1037-1042. Der offene Leserahmen einschließlich Stop-Codon umfaßt 576 Nukleotide (33-608) und kodiert für ein Protein mit 191 Aminosäuren und einem berechneten Molekulargewicht von 21,8 kD. Der isolierte XHes2-cDNA-KIon enthält eine 13 Nukleotide längere 5'UTR im Vergleich zur XHes2-Consensus-Sequenz der identifizierten EST-Klone, sowie eine 66 Nukleotide längere 3‘-UTR inklusive Polyadenylierungssignal und Poly(A)-Schwanz (Abb.7-3). In der 3'-UTR konnten 4 Nukleotid-Unterschiede zur EST-Sequenz ausgemacht werden. Auch in der Protein-kodierenden Region unterscheidet sich der isolierte XHes2-cDNA-Klon von der EST-Consensus-Sequenz, allerdings nur geringfügig. Zwei dieser 
Nukleotidaustausche haben keine Auswirkungen auf die Kodierung der jeweiligen Aminosäure. CGA (EST) und AGA (XHes2-Klon) kodieren beide Arginin (R), GCA (EST) und GCG (XHes2-Klon) jeweils Alanin (A). Der einzige Unterschied in den Proteinsequenzen betrifft die Aminosäure 93, die nach der EST-Consensus-Sequenz ein Glutamin (Q: CAA; ungeladen, polar), im XHes2-Klon jedoch ein Prolin (P: CCC; neutral) ist. Da dieser Aminosäurenaustausch zwischen bHLH- und Orange-Domäne liegt, sind vermutlich keine für die Funktion wichtigen Domänen betroffen. Neuere SequenzDatenbankeinträge konnten die anfänglich verwendete EST-Consensus-Sequenz in 5'und 3'-UTR ergänzen und zeigten, dass sich der isolierte XHes2-cDNA-Klon in der 5'UTR nicht von innen unterschied, wohl aber in der Protein-kodierenden Region und der 3-UTR wie zuvor beschrieben (Abb.7-3). Da diese Unterschiede über die gesamte cDNASequenz kleiner als $1 \%$ sind, handelt es sich bei der isolierten XHes2-cDNA entweder um ein äußerst stark konserviertes zweites Allel im pseudotetraploiden Xenopus laevis oder um Sequenzvariationen eines Allels bei unterschiedlichen Zuchtlinien.

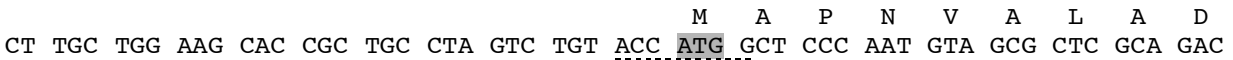

Abb.2-2: Nukleotid- und Aminosäuresequenz des isolierten XHes2-cDNA-Klons aus Xenopus laevis. Die Nukleotidsequenz (1075 bp) und die abgeleitete Aminosäuresequenz (191 AS) des aus einer Xenopus laevis Oocyten-cDNA-Bank isolierten XHes2-Klons sind im Einbuchstabencode dargestellt. Die Zahlen am rechten Rand geben die Position der Nukleotide (normal) bzw. der abgeleiteten Aminosäuren (fett) innerhalb der jeweiligen Sequenz an. Der offene Leserahmen beginnt mit dem ersten Start-Codon (grau hinterlegt), das zusammen mit den flankierenden Nukleotiden (gepunktet unterstrichen) mit der Kozak-Consensus-Sequenz für einen optimalen Translationstart (Kozak, 1991) übereinstimmt, und endet mit dem ersten Stop-Codon (umrahmt), das in der Aminosäuresequenz durch einen Stern (*) gekennzeichnet ist. Das Polyadenylierungssignal ist einfach unterstrichen. 


\subsubsection{Strukturanalyse von XHes2 aus Xenopus laevis}

Für die weitere Strukturanalyse wurde das vom isolierten XHes2-cDNA-Klon kodierte Protein zunächst mit anderen Mitgliedern der Vertebraten-Hes2-Gruppe verglichen, zu der die bekannten Hes2-Proteine aus Maus und Mensch, aber auch bisher nicht beschriebene Hes2-Proteine aus Xenopus tropicalis und Zebrafisch gehören (Abb.2-3, 71, 7-4, 7-5). XHes2 besitzt, wie die Hes2-Proteine der anderen Vertebraten, die typischen Merkmale der Hairy- und E(spl)-Familien von bHLH-O-Proteinen, wie das konservierte Prolin an Position 8 der basischen Domäne und das WRPW-Motiv. Die für die HairyFamilie charakteristische HC-Domäne zwischen Orange-Domäne und WRPW-Motiv (Davis und Turner, 2001) ist in keinem der Hes2-Proteine vorhanden. Zudem spricht eine Gesamtlänge von weniger als 200 Aminosäuren, die vor allem auf die Länge der Cterminalen Region ab der Orange-Domäne zurückzuführen ist, für die Zugehörigkeit der Hes2-Gruppe zur E(spl)-Familie.

Die Ähnlichkeit der identifizierten Sequenzen für Hes2-Proteine aus Xenopus laevis und Xenopus tropicalis mit 92,7\% bei gleicher Gesamtlänge von 191 Aminosäuren und noch höherer Konservierung in den bHLH-Domänen (98,4\%) legt nahe, dass es sich hier um orthologe Proteine handelt. Dass diese eng mit den Hes2-Proteinen aus Säugern und Zebrafisch verwandt sind und auch deren Orthologe darstellen könnten, zeigt sich sowohl durch die Ähnlichkeit der bHLH- und Orange-Domänen als auch durch die Ähnlichkeit der an diese Domänen angrenzenden Aminosäuren. Weiterhin sind zwei Proline in der Nähe des WRPW-Motivs in den Prolin-reichen C-terminalen Regionen der Hes2-Proteine konserviert. Auch das Prolin an Aminosäureposition 93 zwischen bHLH- und OrangeDomäne des isolierten XHes2-Klons ist in Xenopus tropicalis und Säugern konserviert, was bedeutet, dass die isolierte XHes2-Variante (AS93:P) den anderen Hes2-Proteinen stärker ähnelt als der Datenbank-Klon (AS93:Q). Außerhalb der eben genannten Regionen unterscheiden sich die Hes2-Proteine verschiedener Wirbeltierklassen erheblich, das betrifft vor allem die N-terminalen Bereiche und die C-terminalen Regionen zwischen Orange-Domäne und WRPW-Motiv und bedingt eine Gesamtähnlichkeit von unter $50 \%$.

Der Vergleich von XHes2 mit anderen bHLH-O-Proteinen aus Xenopus laevis zeigt außerdem, dass deren Verwandtschaft weniger eng ist, als die zu den Mitgliedern der Vertebraten-Hes2-Gruppe (Abb.2-3B, 7-1, 7-4, 7-5). Die größte Ähnlichkeit besteht zu Hairy1 und Hairy2, die wie die Säuger-Hes2-Proteine mehr als 70\% Ähnlichkeit innerhalb der bHLH-Domänen besitzen, die Orange-Domänen sind allerdings bedeutend weniger gut konserviert. 
Zusammenfassend kann somit gesagt werden, dass die aus Xenopus laevis isolierte XHes2-cDNA ein Protein kodiert, das vermutlich das Ortholog der Säuger-Hes2-Proteine darstellt und somit, wie auch die neu identifizierten Hes2-Proteine aus Xenopus tropicalis und Zebrafisch, der Vertebraten-Hes2-Gruppe zuzurechnen ist. Einerseits besitzen Hes2Proteine mehrere Merkmale der E(spl)-Familie, wie Gesamtlänge und Fehlen der HCDomäne, andererseits stehen sie aufgrund der Ähnlichkeit ihrer bHLH-Domänen eher den Mitgliedern der Hairy-Familie nahe.

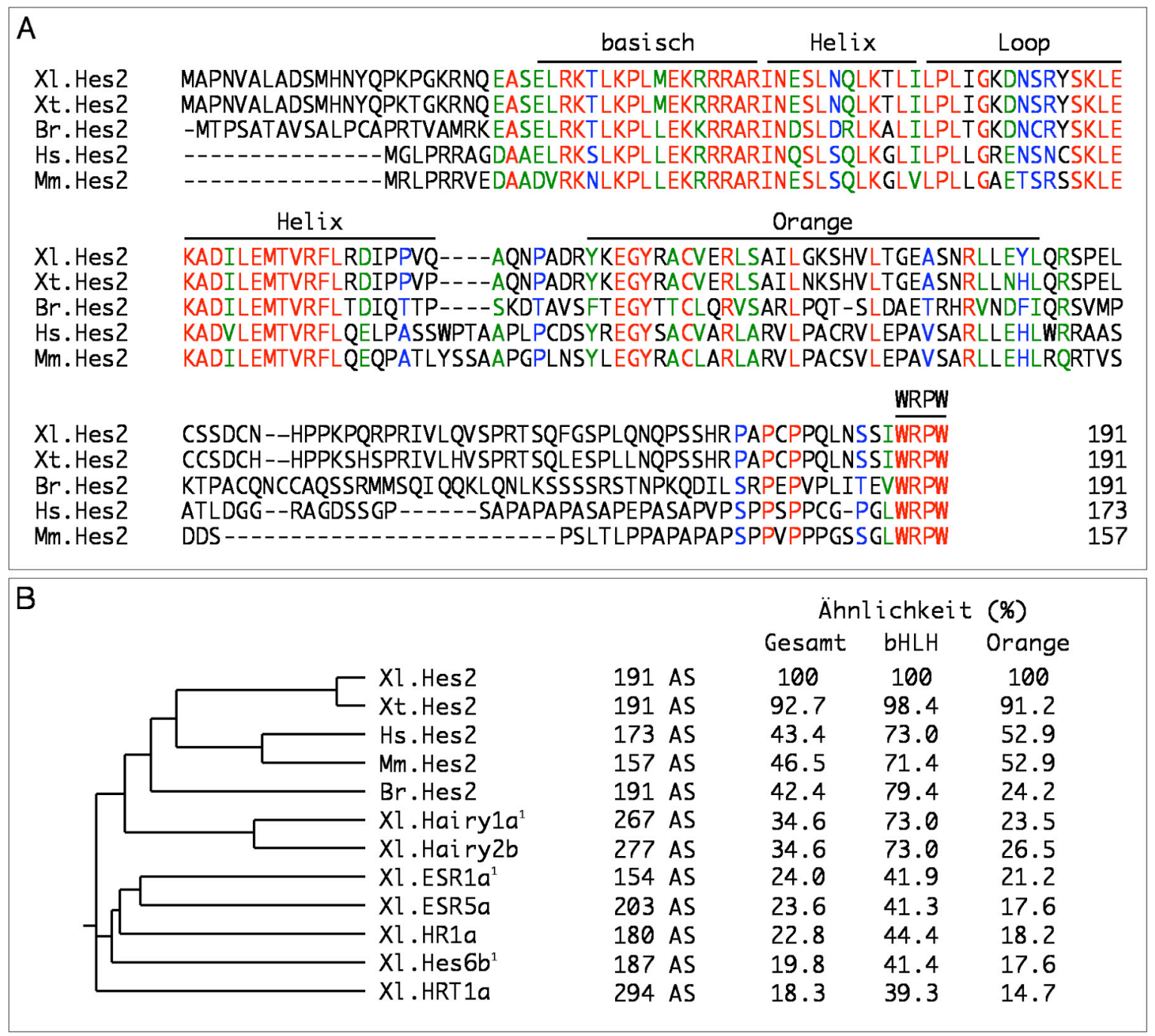

Abb.2-3: Neu identifizierte bHLH-O-Proteine aus Xenopus und Zebrafisch sind eng mit Hes2 verwandt. (A) Sequenzvergleich von Hes2-Proteinen aus Wirbeltieren. bHLH- und Orange-Domänen (Davis und Turner, 2001) sind durch Balken gekennzeichnet. Alle Proteine enthalten ein WRPW-Motif am Carboxylende, sowie das konservierte Prolin an Position 8 der basischen Domäne, beides Merkmale der Hairy- und der E(spl)Familie. Der Grad der Aminosäurekonservierung ist wie folgt dargestellt: rot, identisch; grün, starke Ähnlichlichkeit; blau, schwache Ähnlichkeit; Bindestriche (-), fehlende Aminosäuren. (B) Sequenzähnlichkeiten zwischen XHes2 und anderen Wirbeltier-bHLH-O-Proteinen. Hes2-Proteine sind enger mit Mitgliedern der Hairy-Familie als mit anderen bHLH-O-Familien verwandt. Der phylogenetische Stammbaum basiert auf einem Vergleich der Gesamtproteine. Die Datenbank-Zugriffsnummern befinden sich im Anhang (Abb.7-1). Abkürzungen: AS, Aminosäuren; Br., Brachydanio rerio; Hs., Homo sapiens; Mm., Mus musculus; XI., Xenopus laevis; Xt., Xenopus tropicalis. 


\subsubsection{Untersuchungen zur Expression von XHes2 in Xenopus laevis}

\subsubsection{Zeitliche Expressionsanalyse von XHes2 während der Embryonalentwicklung}

Zur Charakterisierung der zeitlichen Expression von XHes2 auf RNA-Ebene während der Embryogenese wurde eine semiquantitative RT-PCR-Analyse auf Gesamt-RNA verschiedener Embryonalstadien von Xenopus laevis (Nieuwkoop und Faber, 1994) durchgeführt (Abb.2-4).

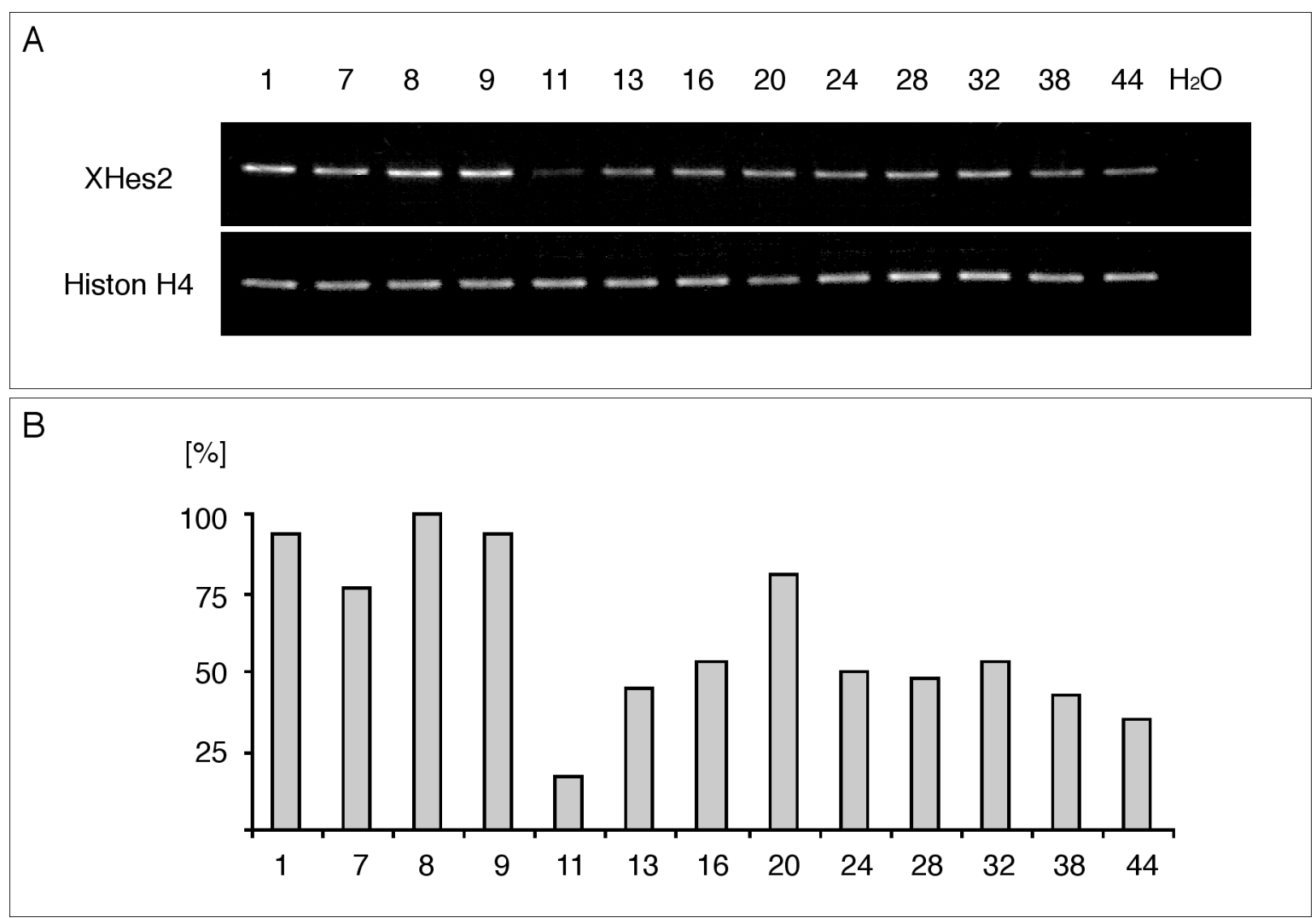

Abb.2-4: XHes2-Transkripte sind während der gesamten Embryogenese von Xenopus laevis vorhanden.

Zeitliche Expressionsanalyse von XHes2 in Embryonalstadien von Xenopus laevis mittels semiquantitativer RT-PCR. (A) RT-PCR-Analyse. Die Stadien der eingesetzten Gesamt-RNA-Präparationen sind über den jeweiligen DNA-Spuren angegeben. Um DNA-/RNA Kontaminationen der RT-PCR Reagenzien auszuschließen, wurde eine Kontrollreaktion durchgeführt bei der Wasser $\left(\mathrm{H}_{2} \mathrm{O}\right)$ anstelle von Stadien-RNA verwendet wurde. Alle RNA-Präparationen sind frei von Verunreinigungen mit genomischer DNA (nicht gezeigt). Zur Überprüfung der für die cDNA-Synthese eingesetzten RNA-Menge wurde die Expression von Histon H4 analysiert. RT-PCR Primer/Produktlängen Histon H4: H4_RTF/H4_RTR/188bp, XHes2: Hes2_RT1F/Hes2_RT1R/269bp. (B) Graphische Darstellung der XHes2-Expression nach Quantifizierung (MD Image Quant 3.3) und Histon H4 Normalisierung. Auf der x-Achse sind die untersuchten Stadien aufgetragen, die $y$-Achse zeigt den prozentualen Anteil der stadien-spezifischen relativen XHes2-Produktmenge in Relation zur maximalen XHes2-Produktmenge (St.8) nach Normalisierung auf Histon H4. Dem Abbau der maternalen XHes2-Transkripte während der Gastrulation (St.11) folgt mit Beginn der Neurulation (St.13) eine zunehmende zygotische XHes2-Transkription, die bis ins Kaulquappenstadium (St.44) erhalten bleibt.

Wie aufgrund der Isolierung des XHes2-Klons aus einer Gesamt-Oocyten-cDNA-Bank zu erwarten ist, sind im befruchteten $\mathrm{Ei}$ (Stadium 1) maternale XHes2-Transkripte 
vorhanden. Nach mehreren Zellteilungen ist in der frühen Blastula (Stadium 7) vermutlich infolge von Abbau maternaler XHes2-Transkripte ein leichtes Absinken des Expressionsniveaus zu beobachten. Im Midblastulastadium (Stadium 8), in dem die erste zygotische Transkription von "frühen" Genen in Xenopus laevis stattfindet, steigt die $X$ Hes2-Expression kurzzeitig auf ihr Maximum an, wobei wahrscheinlich nur der kleinere Anteil zygotische XHes2-Transkripte sind. Mit Einsetzen der Gastrulation erreicht das Expressionsniveau im Stadium 11 seinen geringsten Stand. Ob es sich dabei um einen unvollständigen Abbau der vorhandenen Transkripte, oder eine komplette Degradation mit wieder einsetzender Expression handelt, kann hier nicht beurteilt werden. Zu Beginn der Neurulation (Stadium 13) steigt das Expressionsniveau wieder an. Diese erneute Phase zygotischer XHes2-Transkription besitzt ihr Maximum im Stadium 20 und bleibt bis in das Kaulquappenstadium (Stadium 44) erhalten, wobei eine geringfügig schwächere Expression in den späten Stadien zu verzeichnen ist. Das Vorliegen unterschiedlicher Mengen von XHes2-Transkripten während der Embryonalentwicklung von Xenopus laevis läßt vermuten, dass das XHes2-Gen nicht nur ein zeitlich-, sondern auch ein räumlichdynamisches Expressionsverhalten besitzt.

\subsubsection{Räumlich-zeitliche Expressionsanalyse von XHes2 während der Embryogenese}

Um die räumliche Verteilung der XHes2-Transkripte während der Embryonalentwicklung zu untersuchen, wurde eine „whole-mount“ in situ Hybridisierung (wmISH) mit einer XHes2-spezifischen Sonde auf verschiedenen Embryonalstadien von Xenopus laevis durchgeführt (Abb.2-5).

In Embryonen des Vier-Zell-Stadiums, sowie in frühen und späten Blastulastadien sind maternale XHes2-Transkripte in der animalen Hälfte detektierbar (Abb.2-5A-C). Die beobachtete Zunahme der XHes2-Expressionsstärke in der animalen Hälfte später Blastulastadien verglichen mit der animalen Hälfte früher Blastulastadien könnte auf das Einsetzen der zygotischen XHes2-Transkription zurückzuführen sein (Vergleich: Abb.2-5B und C) und stimmt mit den Ergebnissen aus der RT-PCR-Analyse überein (Abb.2-4, St.79).

Zu Beginn der Gastrulation im Stadium 10 sind keine XHes2-Transkripte mehr nachweisbar (Abb.2-5D), was auf eine Degradierung der im späten Blastulastadium vorhandenen XHes2-Transkripte ohne eine erneute Expression hindeutet. Im Stadium 11 wird XHes2 in isolierten Zellen des animalen Ektoderms vorübergehend exprimiert (Abb.2-5E). Eine Beschränkung der Expression auf das ventrale animale Ektoderm, wie im Fall der Expression von X-Delta-1 und $\alpha$-tubulin (Deblandre et al., 1999), konnte 
allerdings nicht festgestellt werden. Zum Ende der Gastrulation im Stadium 12,5/13 sind keine XHes2-Transkripte mehr detektierbar (Daten nicht gezeigt). Diese begrenzte Expression von XHes2 während der Gastrulation erklärt auch die geringe Menge von XHes2-Transkripten im Stadium 11 bei der RT-PCR-Analyse (Abb.2-4, St.11). 

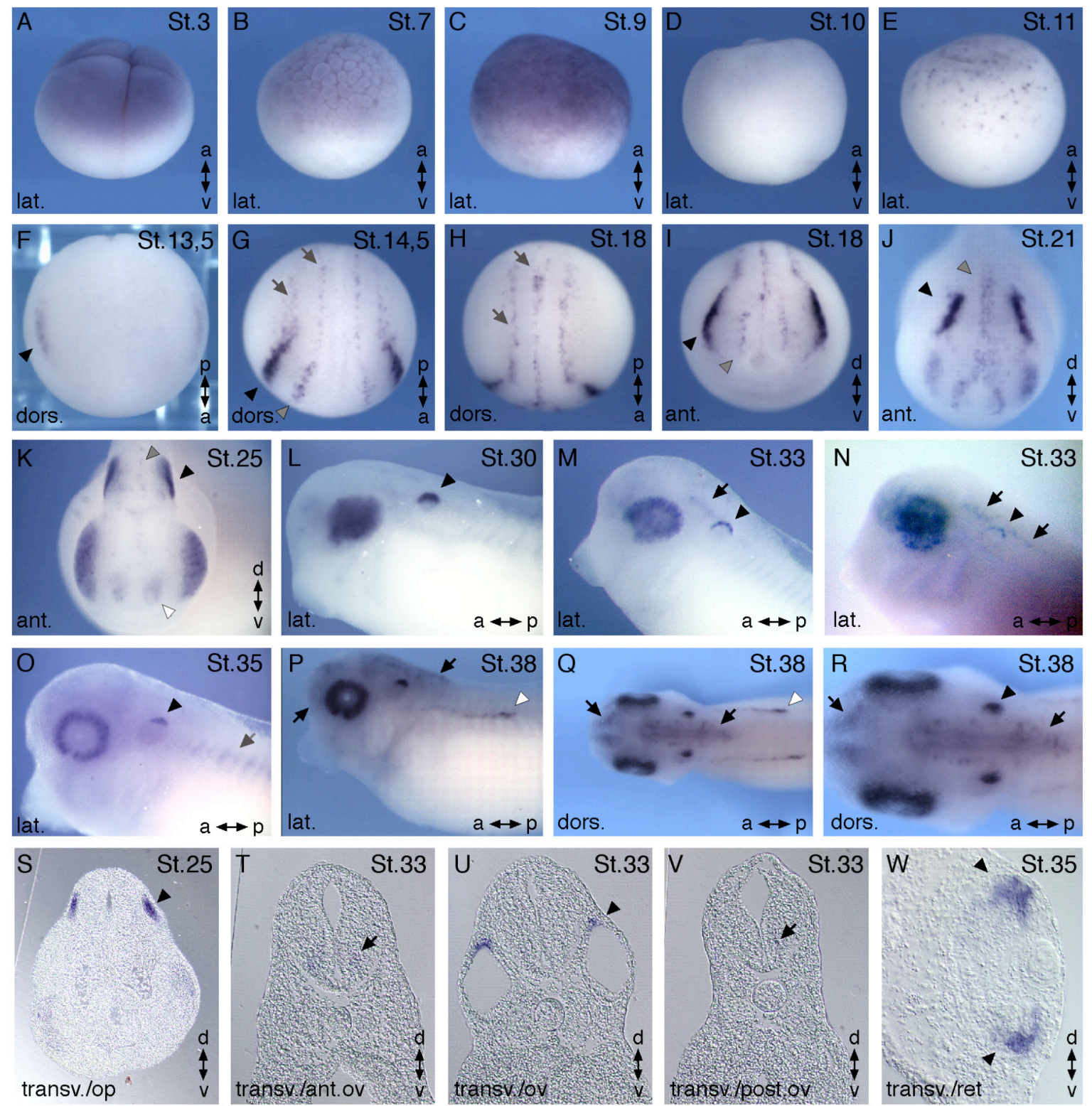

Abb.2-5: XHes2 wird in entstehenden Sinnesorganen und im späteren ZNS von Xenopus exprimiert.

Räumlich-zeitliche Expressionsanalyse von XHes2 in Embryonalstadien von Xenopus laevis mittels wmISH. (A-C) XHes2-Transkripte sind bis zum späten Blastula-Stadium in der animalen Hälfte detektierbar. (D,E) Gastrulation. Im St.10 sind XHes2-Transkripte nicht nachweisbar (D), im St.11 dagegen sind kurzfristig einzelne XHes2-positive Zellen im animalen Ektoderm vorhanden (E). (F-S,U) Frühe Innenohrentwicklung (schwarze Pfeilspitzen). Ab St.13,5 sind XHes2-Transkripte in der Ohrplakode sichtbar (F-K,S), in späteren Stadien sind sie im dorsalen Teil des Ohrvesikels zu finden (L-R,U). (G-I) XHes2-Expression in anteriorer (graue Pfeilspitzen) und posteriorer (graue Pfeile) Neuralplatte. Ab St.14,5 erscheinen XHes2-positive Zellen in zwei dünnen Streifen jeweils zwischen Mittellinie und Ohrplakode auf Höhe der Ohrplakodenexpression in der anterioren Neuralplatte (G,I). In der posterioren Verlängerung der anterioren Expressionsdomänen sind ab St.14,5 schmale Streifen XHes2-positiver Zellen am lateralen Rand der posterioren Neuralplatte und nahe der Mittellinie detektierbar, die entsprechend der Neuralplatteneinfaltung in Richtung der Mittellinie wandern $(\mathrm{G}, \mathrm{H})$. (J-R,W) Retinogenese. XHes2 wird ab St.21 in Retina-Vorläuferzellen und dann in der gesamten undifferenzierten neuralen Retina exprimiert (J-N). Ab St.35 sind XHes2-Transkripte vorwiegend in der peripheren Region der neuralen Retina detektierbar (O-R,W). (K) XHes2 wird im St.25 auch in der Riechplakode (weiße Pfeilspitze) exprimiert. (K) Weitere XHes2-positive Zellen durchziehen fadenartig das Hirn (graue Pfeilspitze). (J) Die anteriore XHes2-Expression in Form eines umgekehrten Ypsilons im St.21 ähnelt der Schlupfdrüse, liegt vermutlich aber unter dem Oberflächenektoderm (graue Pfeilspitze). (M,N,P$\mathrm{R}, \mathrm{T}, \mathrm{V})$ XHes2-Expression in Hinterhirn und Vorderhirn (schwarze Pfeile). XHes2-Transkripte sind im St.33 in einer stark abgegrenzten Region in der subventrikularen Zone des ventralen Hinterhirns anterior und posterior zum Ohrvesikel detektierbar (M,N,T,V). Im St.38 wird XHes2 sowohl im Vorderhirn, als auch in dorsalen Zellen des Hinterhirns exprimiert (P-R). (O) Auch im ventralen Rückenmark im St.35 sind XHes2-positive Zellen zu erkennen (grauer Pfeil). (P,Q) Ab St.38 wird XHes2 im entstehenden Seitenliniensystem exprimiert (weiße Pfeilspitzen). Abkürzungen: lat./ dors./ ant., laterale/ dorsale/ anteriore Ansicht; a, animal (A-E) bzw. anterior; v, vegetativ (A-E) bzw. ventral; p, posterior; d, dorsal; transv., transversal; op, Ohrplakode; ant./ post.ov, anterior/ posterior zum Ohrvesikel; St., Entwicklungsstadium. (N) Geklärter Embryo, (R) Vergrößerung von (Q), (S-W) 30um VibratomSchnitte. 
Die XHes2-Expression während der Neurulation und Organogenese ist komplex und wird daher im folgenden nicht nach Stadien, sondern nach Expressionsdomänen beschrieben. Eine Region im Embryo, in der XHes2 besonders stark exprimiert wird, liegt im Bereich der Ohrplakode und später im dorsalen Anteil des Ohrvesikels, aus denen Teile des Innenohres entstehen. Bereits im frühen Neurulastadium (Stadium 13,5) können erste XHes2-Transkripte in zwei schmalen Domänen am lateralen Rand der Neuralplatte detektiert werden, die auf beiden Seiten ungefähr in der Mitte der Neuralplatte in anteroposteriorer (rostro-caudaler) Orientierung verlaufen und vermutlich im Bereich der Ohrplakode liegen (Abb.2-5F). Die XHes2-Expression in diesen beiden Domänen, die sich infolge der Zellbewegungen mit beginnender Einfaltung der Neuralplatte im Stadium 14,5 bereits weiter anterior befinden, wird stärker (Abb.2-5G) und ist auch in späteren Stadien sehr prominent (Abb.2-5I-K). In Stadium 21 und 25 befinden sich die beiden Expressionsdomänen lateral des sich entwickelnden Hinterhirns im Bereich der Ohrplakode (Abb.2-5J,K,S). Ab Stadium 30 sind XHes2-positive Zellen ausschließlich im dorsalen Ohrvesikel zu finden (Abb.2-5L-R,U).

$X H e s 2$ wird zudem in Zellen der sich einfaltenden Neuralplatte exprimiert. Ab Stadium 14,5 erscheinen XHes2-positive Zellen in zwei dünnen Streifen jeweils zwischen Mittellinie und Ohrplakode auf Höhe der Ohrplakodenexpression in der anterioren Neuralplatte (Abb.2-5G,I). Ihre Spezifität und ihr Schicksal sind unbekannt und bisher nicht beschrieben. Aufgrund der Lage könnten sie später im Hinterhirn lokalisiert sein. In der posterioren Verlängerung der anterioren Expressionsdomänen sind ab Stadium 14,5 schmale Streifen XHes2-positiver Zellen am lateralen Rand der posterioren Neuralplatte und nahe der Mittellinie detektierbar, die entsprechend der Neuralplatteneinfaltung in Richtung der Mittellinie wandern (Abb.2-5G,H). Diese Zellen sollten später im Rückenmark zu finden sein. Auch ihre Spezifität und ihr Schicksal sind unbekannt und bisher nicht beschrieben.

Eine weitere charakteristische Expressionsdomäne von XHes2 stellt die sich entwickelnde Retina dar. Ab Stadium 21 sind XHes2-Transkripte in Vorläuferzellen der späteren Retina zu finden (Abb.2-5J). Die Expression bleibt in der gesamten undifferenzierten neuralen Retina mit sich teilenden Retinoblasten erhalten (Abb.2-5K-N). Ab Stadium 35 wird XHes2 vorwiegend in der peripheren Region der neuralen Retina, die sich teilende Vorläuferzellen enthält, exprimiert (Abb.2-5O-R,W).

Im Stadium 23 und 25 sind XHes2-Transkripte auch in den Riechplakoden nachweisbar. Außerdem durchziehen in diesen Stadien XHes2-positive Zellen unbekannter Spezifität fadenartig das sich ausbildende Hirn (Daten nicht gezeigt, Abb.2-5K). Die anteriore XHes2-Expression in Form eines umgekehrten Ypsilons im Stadium 21 dagegen ähnelt 
der Schlupfdrüse, scheint aber tiefer als diese unter dem Oberflächenektoderm im dorsalen, anterioren Neuralrohr zu liegen (Abb.2-5J).

Später wird XHes2 auch in Vorder- und Hinterhirn, sowie im Rückenmark exprimiert. $X$ Hes2-Transkripte sind im Stadium 33 in einer sehr kleinen Region in der subventrikularen Zone des ventralen Hinterhirns anterior und posterior zum Ohrvesikel detektierbar (Abb.2-5M,N,T,V). Die Spezifität dieser Zellen ist unklar. Im Stadium 35 wird XHes2 in ventralen Zellen des Rückenmarks exprimiert (Abb.2-5O). Im Stadium 38 sind XHes2-positive Zellen im Vorderhirn und in dorsalen Zellen des Hinterhirns vorhanden (Abb.2-5P-R). Zusätzlich können XHes2-Transkripte ab Stadium 38 im entstehenden Seitenliniensystem nachgewiesen werden (Abb.2-5P,Q).

Zusammenfassend läßt sich sagen, dass XHes2 in entstehenden Sinnesorganen, wie Auge, Ohr, Nase und Seitenliniensystem, von Xenopus laevis exprimiert wird, vor allem in deren frühen Entwicklungsphasen und in solchen Regionen, in denen Zellen proliferieren. Im sich ausbildenden ZNS sind XHes2-Transkripte nur in einigen, sehr spezifischen Zellen vorhanden, ob es sich bei innen um proliferierende oder um bereits differenzierende Zellen handelt, ist unklar.

Somit hat die wmISH-Expressionsanalyse zum einen die RT-PCR-Expressionsanalyse bestätigen können und gezeigt, dass XHes2-Transkripte in fast allen Embryonalstadien vorhanden sind, zum anderen konnte mittels wmISH das dynamische und komplexe Muster der XHes2-Expression nachgewiesen werden.

\subsubsection{Räumliche Expressionsanalyse von XHes2 im adulten Frosch}

Um nach der XHes2-Expressionsanalyse während der Embryonalentwicklung auch einen ersten Eindruck der räumlichen Expression im adulten Tier zu erhalten, wurde eine semiquantitative RT-PCR-Analyse auf Gesamt-RNA verschiedener adulter Organe von Xenopus laevis durchgeführt (Abb.2-6).

Die eindeutig stärkste Expression von XHes2 wurde im adulten Auge gefunden. Somit scheint XHes2 nicht nur im embryonalen, sondern auch im adulten Auge von Bedeutung zu sein. Die Haut weist ebenfalls ein hohes Expressionsniveau auf. Zwar konnten in der embryonalen Epidermis in der wmISH keine XHes2-Transkripte detektiert werden, dafür aber zeitweilig im embryonalen animalen Ektoderm (Abb.2-5E) und im embryonalen Seitenliniensystem (Abb.2-5P,Q), das auch Bereiche der adulten Haut durchzieht. Zudem sind viele der embryonalen Expressionsdomänen, wie Ohr- und Riechplakoden, ektodermale Derivate. XHes2-Transkripte sind ebenfalls in Ovar, Hoden, Muskel, Magen, Pankreas, Dünndarm und Herz vorhanden, wenn auch in geringeren Mengen im Vergleich zum Auge. Noch niedriger ist das XHes2-Expressionsniveau in Leber, Niere 
und Lunge. Während der Entwicklung konnte hingegen keine Expression von XHes2 in diesen Organen detektiert werden. In Milz und Gehirn konnten keine XHes2-Transkripte in der zu erwartenden Länge nachgewiesen werden. Im embryonalen Hirn (Abb.2-5P-R) dagegen wird XHes2 exprimiert. Zusätzlich wurden kleinere RT-PCR-Produkte in Gehirn und Niere des adulten Frosches detektiert (Abb.2-6A). Ob es sich dabei um alternativ gespleißte XHes2-Transkripte oder um eine Kreuzhybridisierung der Primer an ein anderes Gen handelt, bleibt zu klären und könnte durch Sequenzierung des RT-PCRProdukts beantwortet werden.

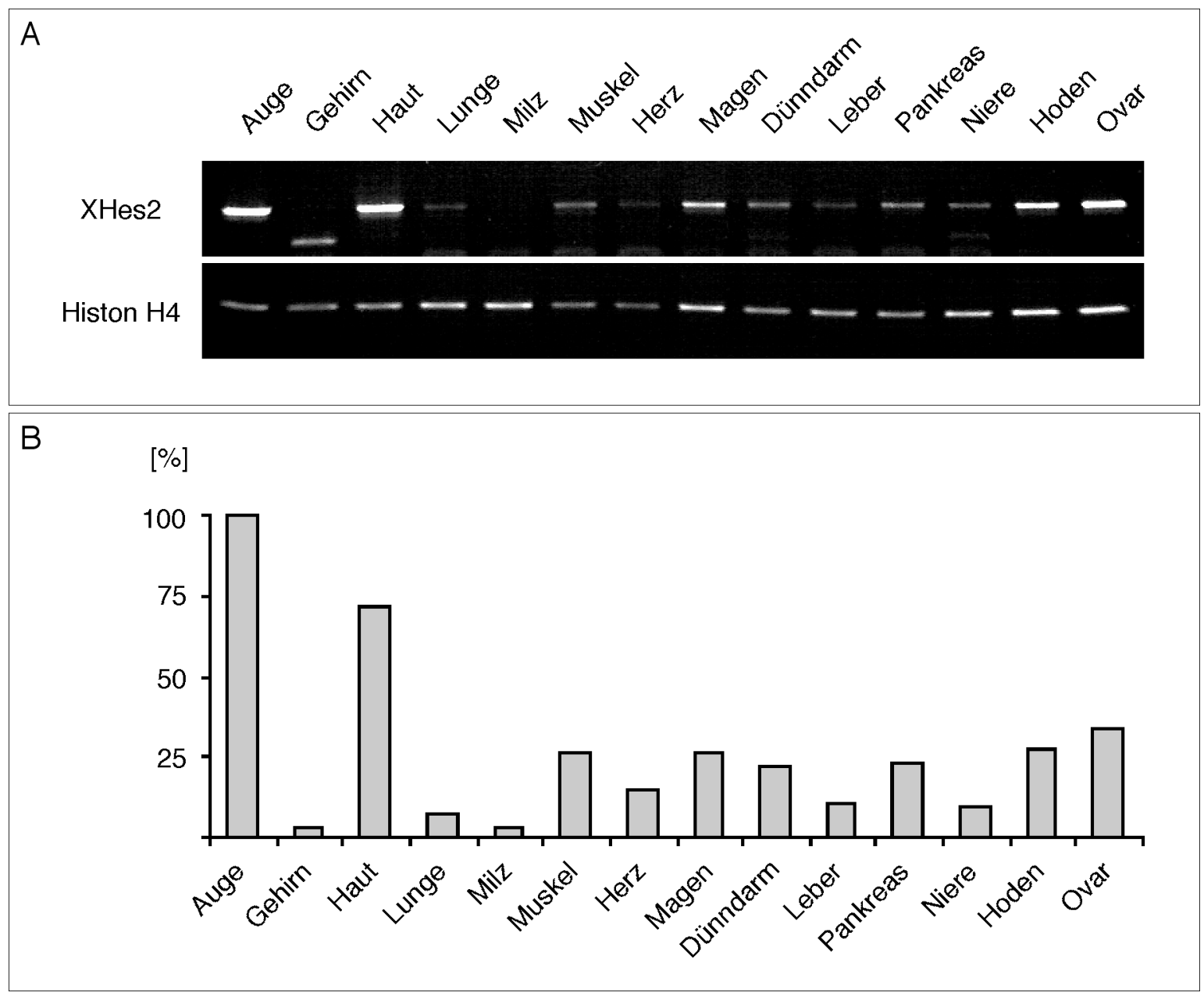

Abb.2-6: XHes2 wird in zahlreichen adulten Organen exprimiert, besonders stark in Auge und Haut. Expressionsanalyse von XHes2 in adulten Organen von Xenopus laevis mittels semiquantitativer RT-PCR. (A) RT-PCR-Analyse. Die untersuchten Organe sind über den jeweiligen DNA-Spuren angegeben. Um DNA-und RNA-Kontaminationen der RT-PCR Reagenzien auszuschließen, wurde eine Kontrollreaktion durchgeführt bei der Wasser $\left(\mathrm{H}_{2} \mathrm{O}\right)$ anstelle von RNA aus Organen verwendet wurde (s. Abb.2-4). Alle RNA-Präparationen sind frei von Verunreinigungen mit genomischer DNA (nicht gezeigt). Zur Überprüfung der für die cDNA-Synthese eingesetzten RNA-Menge wurde die Expression von Histon $\mathrm{H} 4$ analysiert. RT-PCR Primer/Produktlängen Histon H4: H4_RTF/H4_RTR/188bp, XHes2: Hes2_RT1F/Hes2_RT1R/269bp. (B) Graphische Darstellung der XHes2-Expression nach Quantifizierung (MD Image Quant 3.3) und Histon H4 Normalisierung. Auf der XAchse sind die untersuchten Organe aufgetragen, die y-Achse zeigt den prozentualen Anteil der relativen XHes2-Produktmenge im jeweiligen Organ in Relation zur maximalen XHes2-Produktmenge (Auge) nach Normalisierung auf Histon H4. Die stärkste Expression von XHes2 wurde im Auge detektiert, auch die Haut weist ein hohes Expressionsniveau auf. Außerdem wird XHes2 auch in Ovar, Hoden, Muskel, Magen, Pankreas, Dünndarm, Herz, sowie schwach auch in Leber, Niere und Lunge exprimiert. In Gehirn und Milz konnten keine XHes2-Transkripte in der zu erwartenden Länge nachgewiesen werden. 


\subsubsection{Vergleichende Expressionsanalyse von XHes2, XHairy1, XHairy2 $b$ und ESR1 während der embryonalen Neurogenese von Xenopus laevis}

Das interessante und bisher nicht beschriebene Expressionsmuster von XHes2 während der Embryonalentwicklung, besonders in Regionen der Neurogenese, machte XHes2 zu einem guten Kandidaten für weitere Analysen. Da auch andere bHLH-O-Gene während der Entwicklung des Nervensystems von Xenopus laevis exprimiert werden, wurde zur Herausstellung von Ähnlichkeiten und Unterschieden die Expression von XHes2 mit der Expression von Xhairy1, Xhairy2b (Davis et al., 2001; Tsuji et al., 2003; Taelman et al., 2004) und ESR1 (Perron et al., 1998; Schneider et al., 2001) in drei verschiedenen Embryonalstadien mittels wmISH verglichen (Abb.2-7A).

Während XHes2 zu Beginn der Neurulation im Stadium 13,5 nur schwach in zwei schmalen Domänen am lateralen Rand der Neuralplatte exprimiert wird, die sich vermutlich im Bereich der Ohrplakoden befinden (Abb.2-7A1, Abb.2-5F), sind die Expressionsmuster von Xhairy1, Xhairy2b und ESR1 in diesem Stadium bereits weitaus komplexer (Abb.2-7A5,9,13). Xhairy1-Transkripte sind ebenfalls im Bereich der Ohrplakoden am lateralen Rand der Neuralplatte zu finden, sowie an der Abgrenzung der anterioren Neuralplatte zur Haftdrüse, des Vorderhirns zum Mittelhirn und der anterioren zur posterioren Neuralplatte, in der Bodenplatte des späteren Neuralrohrs und in einem Streifen zwischen späteren Inter- und Motorneuronen (Abb.2-7A5). Xhairy2b wird in der Bodenplatte und der gesamten Grenze der anterioren und lateralen Neuralplatte exprimiert, besonders breit im Bereich der anterioren Neuralfalten (Abb.2-7A9). ESR1positive Zellen befinden sich im Stadium 13,5 im präsomitischen Mesoderm und in Regionen der primären Neurogenese in der posterioren Neuralplatte, im ventralen Vorderhirn und in den trigeminalen Plakoden (Abb.2-7A13). Somit scheint es keine Überlappung der Expression von XHes2 und ESR1, sowie von Xhairy1 und ESR1 zu geben. Inwieweit die Expressionsdomänen von XHes2, Xhairy1 und Xhairy2b im Bereich der Ohrplakoden am lateralen Rand der Neuralplatte im Stadium 13,5 überlappen, ist in diesem Expressionsvergleich in verschiedenen Embryonen nicht genau bestimmbar, könnte aber durch eine Doppel-wmISH analysiert werden.

Im Stadium 24, in dem das Neuralrohr bereits geschlossen ist, befinden sich die dominanten Expressionsdomänen von XHes2 in der späteren Retina und der dorsalen Ohrplakode, aber auch in Riechplakoden und Hirn sind XHes2-positive Zellen vorhanden (Abb.2-7A2,3, Abb.2-5K). ESR1 wird ähnlich wie XHes2 in der späteren Retina und den Riechplakoden exprimiert, allerdings sind die Domänen größer und die Expression erscheint stärker. ESR1-Transkripte sind aber auch im präsomitischen Mesoderm, in einigen Hirnnerven und vor allem im Neuralrohr, ausgenommen der Grenzen zwischen 
Vorder-, Mittel-, Hinterhirn und Rückenmark, zu finden (Abb.2-7A14,15). Xhairy1-positive Zellen sind ebenfalls in der späteren Retina detektierbar, stärker ist die Expression allerdings im anterioren Teil des Auges, dem Augenbecher, und im Augenstiel, sowie im ventralen Bereich der Ohrplakoden. Außerdem wird Xhairy1 in bestimmten Abschnitten im Neuralrohr, in Neuralleistenzellen, der Epidermis und entstehenden Somiten exprimiert (Abb.2-7A6,7). Xhairy2b-Transkripte sind vor allem in den dorsalen Bereichen der Augen, im Neuralrohr und in Neuralleistenzellen, sowie in Vorniere und entstehenden Somiten vorhanden (Abb.2-7A10,11). Um die Expressionsdomänen im Bereich der Ohrplakode und des Auges im Stadium 24 näher zu charakterisieren, wurde die XHes2-Expression mit der Expression von XHairy1, ESR1, X-Ngnr-1 und NeuroD mittels Doppel-wmISH verglichen (Abb.2-7B). Die Expression von XHes2 im dorsalen Anteil der Ohrplakode überlappt weder mit der Expression von XHairy1 in der ventralen Ohrplakode (Abb.27B1), noch mit den Expressionen von ESR1 (Abb.2-7B2), X-Ngnr-1 (Abb.2-7B3) und NeuroD (Abb.2-7B4) in den sich ausbildenden Hirnnerven (Trigeminus). In der Region der späteren Retina scheint sich dagegen die XHes2-Expression mit den Expressionen von XHairy1 (Abb.2-7B1), ESR1 (Abb.2-7B2), X-Ngnr-1 (Abb.2-7B3) und NeuroD (Abb.2-7B4) zu überschneiden, was allerdings durch Schnitte bestätigt werden müßte. Der Expressionsvergleich im Stadium 24 zeigt, dass die vier untersuchten bHLH-O-Gene spezifische Muster mit teilweise überlappenden, aber auch mit benachbarten, klar gegeneinander abgegrenzten Expressionsdomänen besitzen.

Ähnlichkeiten und Unterschiede in der Expression zeigen sich auch im Stadium 39. Während XHes2 (Abb.2-7A4, Abb.2-5O,P,W) und ESR1 (Abb.2-7A16) im Bereich der ciliären Marginalzone exprimiert werden, die sich teilende Vorläuferzellen, aber keine Stammzellen enthält, werden Xhairy1 (Abb.2-7A8) und Xhairy2b (Abb.2-7A12) vorwiegend in der peripheren Region der ciliären Marginalzone exprimiert, der sich teilende Stammzellen enthält und direkt an die sich entwickelnde Linse angrenzt. Zudem wird XHes2 (Abb.2-7A4, Abb.2-5M,P,U) im dorsalen Ohrvesikel und Xhairy1 (Abb.2-7A8) im ventralen Ohrvesikel exprimiert, Transkripte von Xhairy2b (Abb.2-7A12) und ESR1 (Abb.2-7A16) sind nicht detektierbar. Weitere Expressionsunterschiede finden sich in ZNS, Seitenliniensystem, Epidermis, Kiemenbögen und Pankreas.

Insgesamt wird durch den Expressionsvergleich deutlich, dass XHes2 während der Entwicklung des Nervensystems von Xenopus laevis, besonders durch die markante Transkription in dorsaler Ohrplakode und Retina, ein spezifisches Expressionsmuster besitzt, dass sich von den Expressionsmustern der bHLH-O-Gene Xhairy1, Xhairy2b und ESR1 unterscheidet.

Diese Unterschiede in der Expression lassen vermuten, dass die Transkription von XHes2, Xhairy1, Xhairy2b und ESR1 während der Embryonalentwicklung durch 
verschiedene Faktoren reguliert wird, und dass die vier bHLH-O-Gene unterschiedliche Aufgaben bei der Ausbildung des Nervensystems übernehmen.
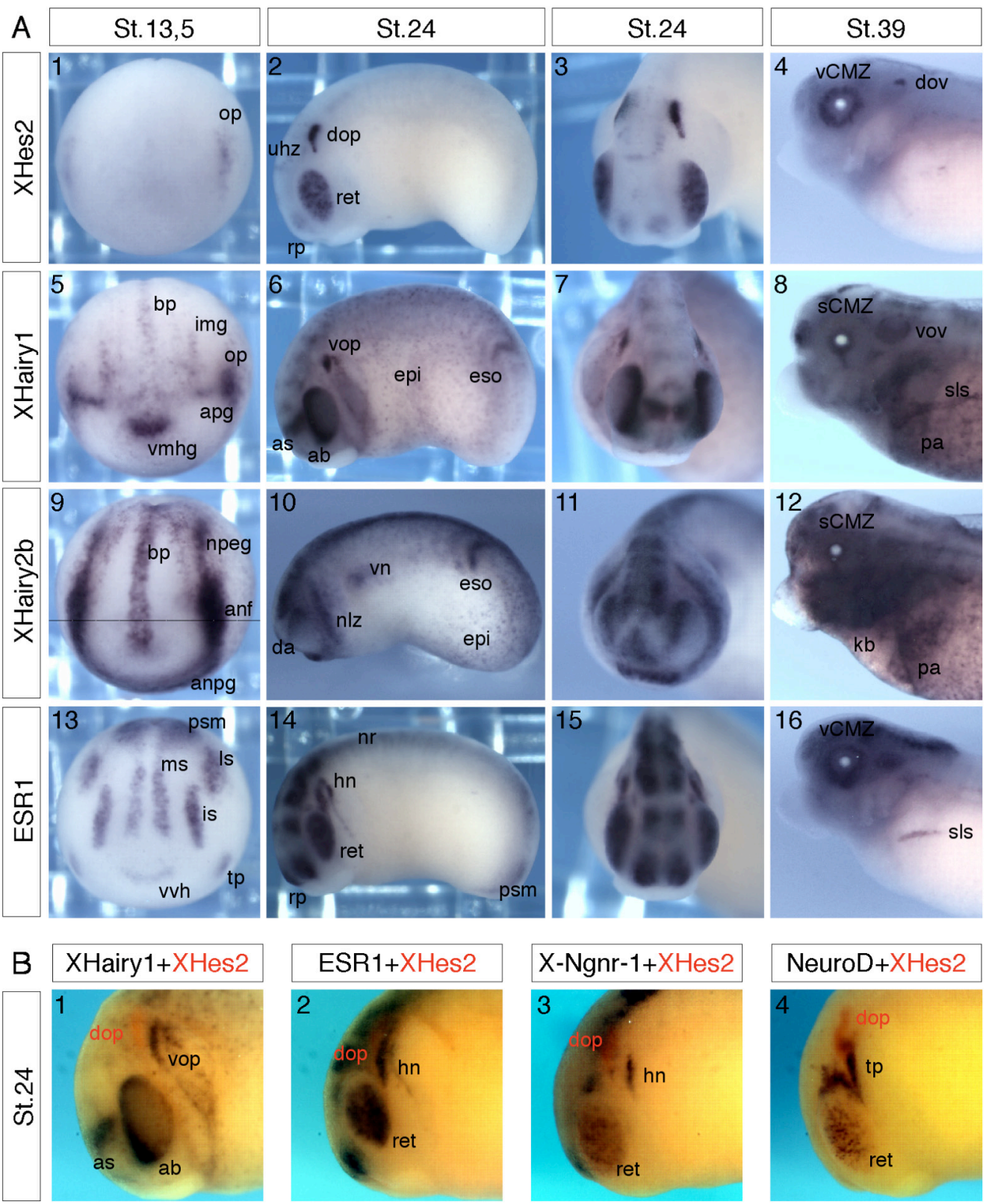

Abb.2-7: Das Expressionsmuster von $X H$ es 2 unterscheidet sich von dem verwandter bHLH-O-Gene.

(A) Vergleichende Expressionsanalyse von XHes2, Xhairy1, Xhairy2b und ESR1 während der Neurogenese von Xenopus laevis mittels wmISH. Die Embryonalstadien sind oberhalb der Fotos und die untersuchten Genexpressionen links der Fotos angegeben. Die Embryonen sind wie folgt orientiert: $(A 1,5,9,13)$ dorsale Ansicht, anterior unten; $(A 2,4,6,8,10,12,14,16)$ laterale Ansicht, anterior links; $(A 3,7,11,15)$ anteriore Ansicht, dorsal oben. (B) Vergleichende Expressionsanalyse von XHes2, XHairy1, ESR1, X-Ngnr-1 und NeuroD im St.24 von Xenopus laevisEmbryonen mittels Doppel-wmISH. Das Embryonalstadium ist links der Fotos und die untersuchten Genexpressionen sind oberhalb der Fotos angegeben (XHes2, rot; zweites Gen, braun). Die Embryonen sind wie folgt orientiert: laterale Ansicht, anterior links. Abkürzungen: ab, Augenbecher; anf, anteriore Neuralfalten; anpg, Abgrenzung der anterioren Neuralplatte zur Haftdrüse; apg. Abgrenzung der anterioren zur posterioren Neuralplatte; as, Augenstiel; bp, Bodenplatte; da, dorsales Auge; dop, dorsale Ohrplakode; dov, dorsaler Ohrvesikel; epi, Epidermis; eso, entstehende Somiten; hn, Hirnnerven; hzus, Zellen im Hirn unbekannter Spezifität; img, Streifen zwischen späteren Inter- und Motorneuronen; is, intermediärer Streifen späterer Interneuronen; kb, Kiemenbögen; Is, lateraler Streifen späterer sensorischer Neuronen; ms, medialer Streifen späterer Motorneuronen; nlz, Neuralleistenzellen; npeg, Neuralplatten-Ektoderm-Abgrenzung; nr, Neuralrohr; op, Ohrplakode; pa, Pankreas; psm, präsomitisches Mesoderm; ret, spätere Retina; rp, Riechplakode; sCMZ, ciliäre Marginalzone mit sich teilenden Stammzellen; sls, Seitenliniensystem; tp, trigeminale Plakode; vCMZ, ciliäre Marginalzone mit sich teilenden Vorläuferzellen; vmhg, Abgrenzung des Vorderhirns zum Mittelhirn; vn, Vorniere; vop, ventrale Ohrplakode; vov, ventraler Ohrvesikel; vvh, ventrales Vorderhirn. 


\subsubsection{Analysen zur Regulation der XHes2-Expression während der Neurogenese}

Mehrere Studien in Xenopus laevis und anderen Vertebraten haben gezeigt, dass die Transkription von einigen bHLH-O-Genen durch Faktoren positiv reguliert werden kann, die Schlüsselfunktionen bei der Neurogenese übernehmen, wie Neurogenin oder Notch (Koyano-Nakagawa et al., 1999; Koyano-Nakagawa et al., 2000; Davis und Turner, 2001; Iso et al., 2003). Neurogenin/X-Ngnr-1 fördert die neuronale Differenzierung (Ma et al., 1996), während die Aktivierung des Notch-Signalwegs die neuronale Differenzierung verhindert (Chitnis et al., 1995).

\subsubsection{Regulation der XHes2-Expression durch den Notch-Signalweg}

Da nicht alle bHLH-O-Gene durch die Aktivierung des Notch-Signalwegs induzierbar sind, wie z.B. das Maus-Hes2-Gen und das Hes6-Gen aus Maus und Xenopus (Nishimura et al., 1998; Koyano-Nakagawa et al., 2000), galt es zu klären, ob die XHes2-Expression durch Notch stimuliert werden kann. Um dies zu untersuchen, wurden Komponenten des Notch-Signalwegs in Xenopus-Embryonen überexprimiert und die Effekte auf die XHes2Transkription mittels RT-PCR in animalen Kappen (Abb.2-8) und mittels wmISH in Embryonen (Abb.2-9; Tab.2-1) analysiert.

Die ektopische Expression von Notch-ICD, einer konstitutiv-aktiven Form des X-Notch-1Rezeptors (Coffman et al., 1993), führt weder in neuralisierten animalen Kappen (Abb.28B, Spur 9 vs. 7) noch in naiven animalen Kappen (Abb.2-8B, Spur 5 vs. 3) zu einer gesteigerten $X$ Hes2-Transkription. Vielmehr scheint das Expressionsniveau von XHes2 in den Explantaten infolge der Überexpression von Notch-ICD leicht erniedrigt zu sein. Bekannte Notch-Zielgene, wie ESR7 (Koyano-Nakagawa et al., 2000), werden im Unterschied $\mathrm{zu}$ XHes2 im neuralisierten und nicht-neuralisierten animalen Kappenektoderm induziert (Abb.2-8B, Spur 9 vs. 7; Spur 5 vs. 3).

In Embryonen verursacht die Überexpression von Notch-ICD und X-Su(H)-Ank, einer konstitutiv-aktiven Form von X-Su(H) (Wettstein et al., 1997), eine schwache ektopische Transkriptionsaktivierung von XHes2 ausschließlich im Randbereich der Neuralplatte, nicht aber innerhalb der Neuralplatte oder im gesamten Ektoderm (Abb.2-9B1,2,4,5; Tab.2-1).

Diese Daten sprechen dafür, dass XHes2 kein direktes Notch-Zielgen, wie z.B. ESR7, ist. Allerdings scheinen einige Zellen im Randbereich der Neuralplatte die Kompetenz zu besitzen, infolge des Notch-Signals die XHes2-Transkription aktivieren zu können. 


\subsubsection{Regulation der XHes2-Expression durch X-Ngnr-1}

Neben den bekannten Notch-Zielgenen, wie z.B. ESR7, kann auch XHes6, das kein Notch-Zielgen ist, durch den frühen Determinierungsfaktor X-Ngnr-1 induziert werden (Koyano-Nakagawa et al., 2000). Um der Frage nachzugehen, ob XHes2 durch X-Ngnr-1 reguliert wird, wurde X-Ngnr-1 in Xenopus-Embryonen überexprimiert und die Effekte auf die XHes2-Transkription mittels RT-PCR in animalen Kappen (Abb.2-8) und mittels wmISH in Embryonen (Abb.2-9) analysiert.

Die Überexpression von X-Ngnr-1 bewirkt sowohl in naiven, nicht-neuralisierten animalen Kappen als auch in neuralisierten animalen Kappen (Abb.2-8B, Spur 4 vs. 3, Spur 8 vs. 7) eine signifikante Hochregulation der XHes2-Expression. Durch die gleichzeitige Überexpression von Notch-ICD läßt sich die durch X-Ngnr-1 induzierte Erhöhung des XHes2-Expressionsniveaus jedoch verhindern (Abb.2-8B, Spur 6 vs. 4, Spur 10 vs. 8). Die Transkription von ESR7 wird hingegen bei Coexpression von Notch-ICD und X-Ngnr1 in naiven und neuralisierten Kappen stark aktiviert (Abb.2-8B, Spur 6 vs. 4, Spur 10 vs. 8), allerdings induziert Notch-ICD allein bereits die Expression von ESR7 (Abb.2-8B, Spur 5 vs. 3, Spur 9 vs. 7 ).

In Embryonen resultiert die ektopische Expression von X-Ngnr-1 einerseits in der Hemmung der endogenen XHes2-Transkription, andererseits aber auch in der Induktion von $X$ Hes2 in isolierten Zellen vorwiegend im Ektoderm, vereinzelt im Neuroektoderm (Abb.2-9A1,2; Tab.2-1).

Somit kann die Transkription von XHes2 zwar durch X-Ngnr-1 in einigen kompetenten Zellen, vor allem im Ektoderm, aktiviert werden, die endogene Expression wird jedoch verhindert, was vermuten läßt, dass XHes2 durch andere Mechanismen als ESR7 oder XHes6 induziert wird.

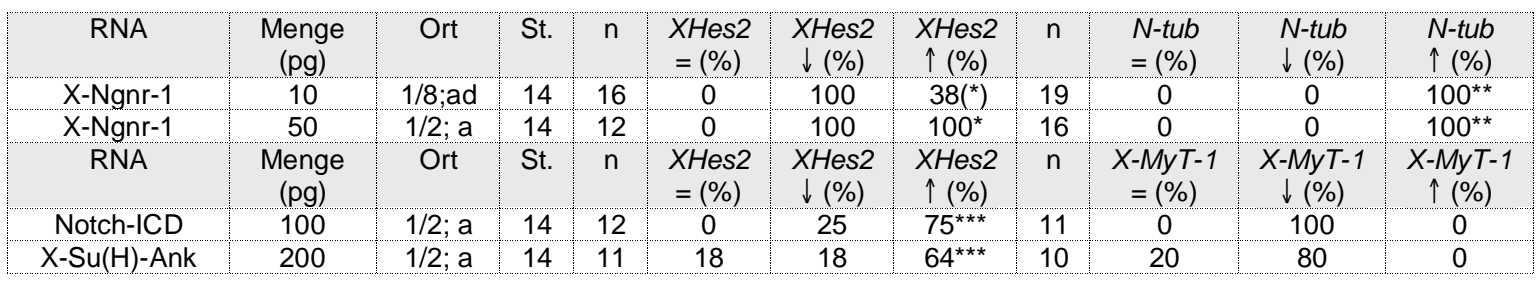

Tab.2-1: Einfluß von X-Ngnr-1 und Notch-Aktivierung auf die XHes2-Expression in Embryonen. Abkürzungen und Symbole: a, animal; d, dorsal; n, Anzahl analysierter Embryonen; N-tub, N-tubulin; St., Stadium; =, Expression unverändert; $\downarrow$, weniger bis keine positiven Zellen in Expressionsdomäne; $\uparrow$, mehr positive Zellen in Expressionsdomäne; $\left({ }^{*}\right)$, ektopisch in wenigen einzelnen Zellen im Ektoderm; *, ektopisch in einzelnen Zellen im Ektoderm und Neuroektoderm; ${ }^{* *}$, ektopisch in Neuroektoderm und Ektoderm; ${ }^{* * *}$, schwache ektopische Expression nur im Grenzbereich von Neuroektoderm und Ektoderm. Bei mehr als 100\% zeigt ein Teil der Embryonen eine Kombination von Reduktion und ektopischer Expression in einzelnen Zellen. 


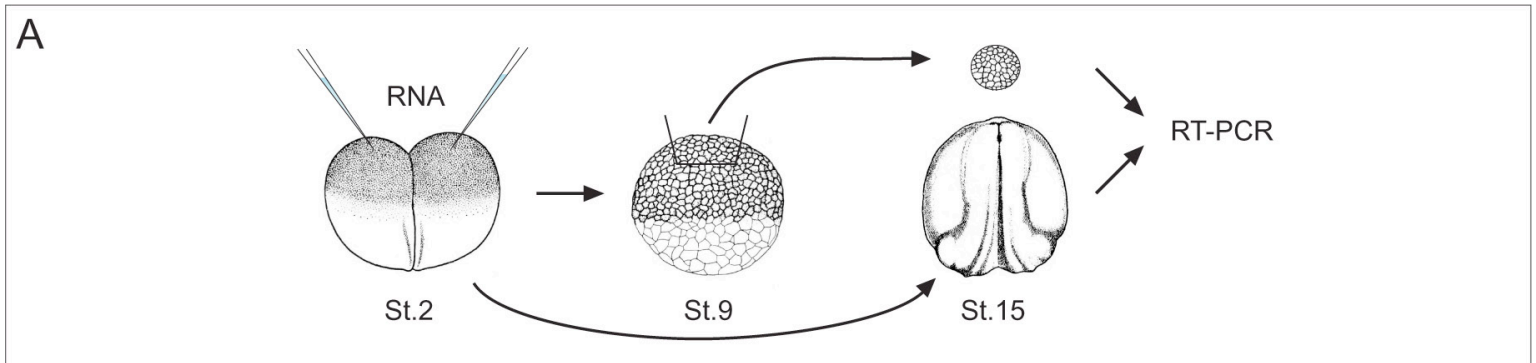

B

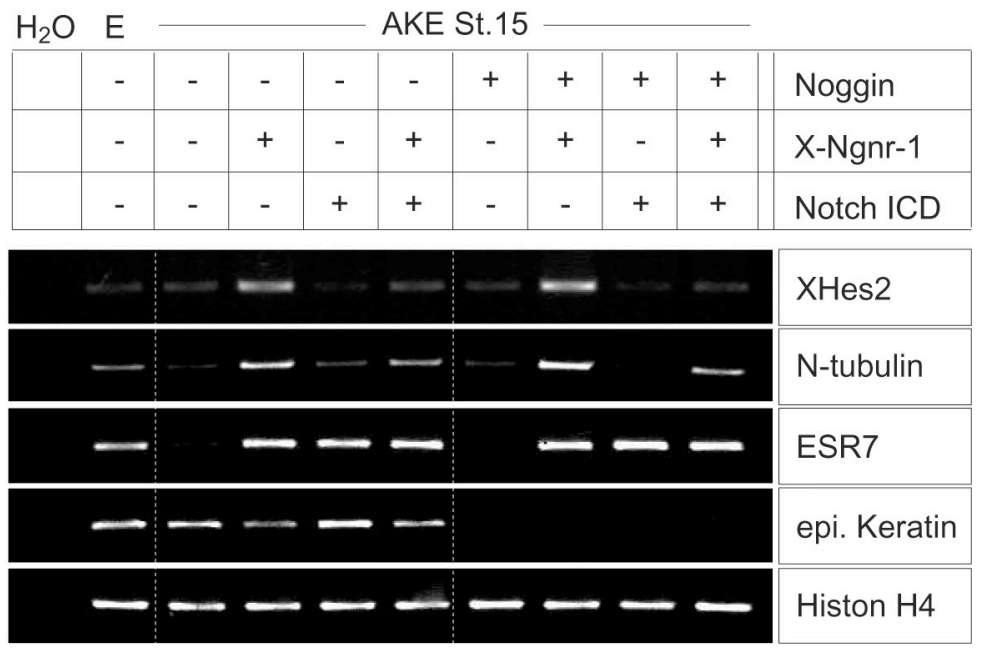

$\begin{array}{llllllllll}1 & 2 & 3 & 4 & 5 & 6 & 7 & 8 & 9 & 10\end{array}$

Abb.2-8: X-Ngnr-1 und Notch haben unterschiedliche Effekte auf die XHes2-Transkription in animalen Kappen.

Untersuchungen zur Regulation der XHes2-Expression durch X-Ngnr-1 und Notch-ICD in naivem und durch Noggin neuralisiertem animalen Kappenektoderm mittels semiquantitativer RT-PCR. (A) Schematische Darstellung der experimentellen Strategie. Verschiedene Kombinationen von RNAs (siehe 8B) wurden im animalen, polnahen Bereich in beide Blastomeren des Zwei-Zell-Stadiums (St.2) von Xenopus laevisEmbryonen injiziert, animale Kappen (AKE) wurden im Stadium 9 (St.9) isoliert und solange kultiviert bis nichtinjizierte Kontrollembryonen (E) das Stadium 15 (St.15) erreichten. Die aus animalem Kappenektoderm und Kontrollembryonen gewonnenen RNA-Präparationen wurden dann mittels semiquantitativer RT-PCR analysiert. (B) RT-PCR-Analyse. Im naiven AKE und in durch Noggin neuralisierten Explantaten wird die XHes2-Expression durch X-Ngnr-1 signifikant hochreguliert (Spur 4 vs. 3 und Spur 8 vs. 7). Notch-ICD hat hingegen einen leicht inhibitorischen Effekt auf die Transkription von XHes2 (Spur 5 vs. 3 und Spur 9 vs. 7) und verhindert die durch X-Ngnr-1 induzierte Erhöhung des XHes2-Expressionsniveaus (Spur 6 vs. 4 und Spur 10 vs. 9). Die Kombinationen der injizierten RNAs sind über den jeweiligen DNA-Spuren angegeben. Wasser $\left(\mathrm{H}_{2} \mathrm{O}\right)$ wurde anstelle von RNA als Negativkontrolle (Spur 1) und St.15-RNA als Positivkontrolle (Spur 2) eingesetzt. Alle RNA-Präparationen sind frei von Verunreinigungen mit genomischer DNA (nicht gezeigt). Zur Überprüfung der eingesetzten RNA-Menge wurde die Expression von Histon $\mathrm{H} 4$ analysiert. Injizierte animale Kappen wurden mit den entsprechenden nicht-injizierten oder neuralisierten Explantaten verglichen. Die Effektivität der RNA-Injektionen wurde mit direkten oder indirekten Zielgenen der überexprimierten Faktoren kontrolliert: X-Ngnr-1 mit N-tubulin und ESR7 (Spur 4 vs. 3, Spur 8 vs. 7: Aktivierung), Notch-ICD mit ESR7 (Spur 5 vs. 3, Spur 9 vs. 7: Aktivierung) und Noggin mit epidermalem (epi.) Keratin (Spur 7-10 vs. 3-6: Hemmung). RNA/Embryo: 100pg X-Ngnr-1, 300pg Notch-ICD, 500pg Noggin. RT-PCR-Primer/Produktlängen epidermales Keratin: epi.Keratin_RTF/epi.Keratin_RTR/217bp, ESR7: ESR7_RT1F/ESR7_RT1R/212bp, Histon H4: H4_RTF/H4_RTR/188bp, N-tubulin: N-tubulin_RTF/N-tubülin_RTR/250b̄p, XHes2: Hes2_RT1F/Hes2_RT1R/ 269bp. 

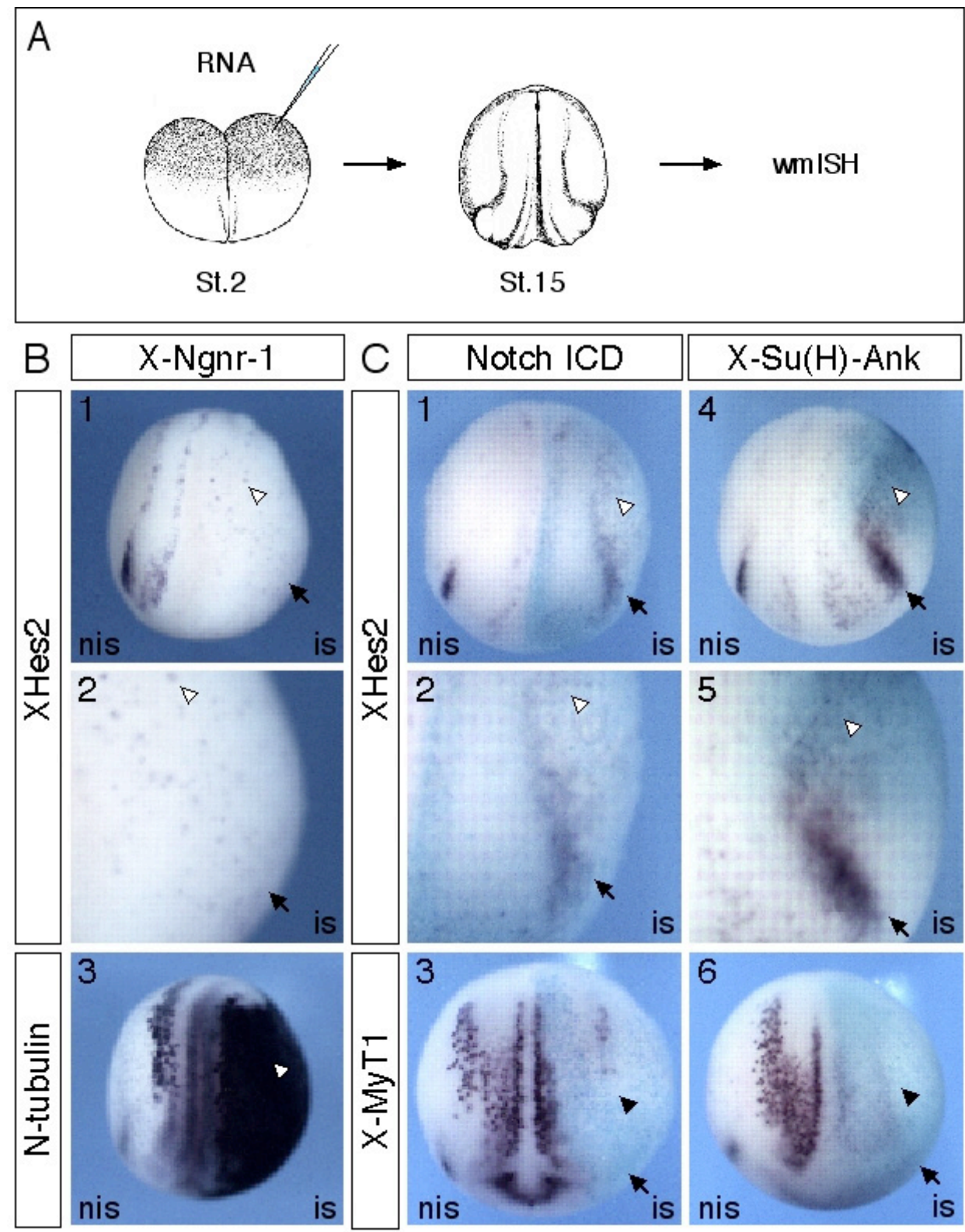

\section{Abb.2-9: X-Ngnr-1 und Notch regulieren die XHes2-Expression zelltypabhängig in Xenopus- Embryonen.}

Effekte der X-Ngnr-1-Überexpression und der ektopischen Aktivierung des Notch-Signalwegs auf die XHes2Expression in Xenopus laevis-Embryonen analysiert mittels wmISH. (A) Schematische Darstellung der experimentellen Strategie. Verschiedene RNAs (siehe 9B) wurden im animalen, polnahen Bereich in eine Blastomere des Zwei-Zell-Stadiums (St.2) von Xenopus laevis-Embryonen injiziert. Diese wurden bis zum Stadium 14/15 kultiviert und mittels wmISH analysiert. (B) Exogenes X-Ngnr-1, das die neuronale Differenzierung fördert und $\mathrm{N}$-tubulin ektopisch aktiviert (B3; Aktivitätskontrolle), unterdrückt einerseits die endogene XHes2-Expression, aktiviert andererseits aber auch die XHes2-Transkription in einzelnen Zellen im Ektoderm und im Neuroektoderm (B1,2). (C) Die ektopische Aktivierung des Notch-Signalwegs durch NotchICD und $\mathrm{X}-\mathrm{Su}(\mathrm{H})$-Ank, die die neuronale Differenzierung hemmt und die Expression von $X-M y T-1$ reprimiert (C3,6; Aktivitätskontrollen), bewirkt eine schwache ektopische Expression nur im Grenzbereich von Neuroektoderm und Ektoderm $(C 1,2,4,5)$. (B,C) Die injizierten RNAs und deren Mengen sind jeweils über den Fotos und die untersuchten Genexpressionen jeweils links der Fotos angegeben. Die Embryonen sind wie folgt orientiert: dorsale Aufsicht, anterior ist unten. Teilbereiche der injizierten Seiten $(B 1, C 1, C 4)$ sind vergrößert dargestellt (B2,C2,C4). Abkürzungen und Symbole: is, injizierte Seite; nis, nicht-injizierte Seite; schwarzer Pfeil, Ohrplakode $(B 1,2, C 1,2,4,5)$ bzw. trigeminale Plakode $(C 3,6)$; schwarze Pfeilspitze, Expressionsdomäne differenzierender bzw. differenzierter sensorischer Neuronen; weiße Pfeilspitze, ektopische Expression. 


\subsubsection{Funktionsanalyse von XHes2}

\section{Untersuchungen zur Funktion von XHes2 während der Neurogenese}

XHes2 wird, wie auch einige andere bHLH-O-Gene, in Xenopus laevis während der Entwicklung des Nervensystems exprimiert. Funktionelle Analysen haben gezeigt, dass einige dieser bHLH-O-Proteine, wie z.B. ESR1, ESR6, ESR7 und XHRT1, hemmend auf die Neurogenese wirken, während das bHLH-O-Protein XHes6 die Differenzierung von Neuronen begünstigt (Koyano-Nakagawa et al., 2000; Schneider et al., 2001; Chalmers et al., 2002; Taelman et al., 2004). Um aufzuklären, welche Rolle XHes2 bei der neuronalen Differenzierung spielt, wurden XHes2-Varianten in Xenopus-Embryonen überexprimiert und die Effekte auf die Neurogenese untersucht. Weiterhin wurde die XHes2Proteinexpression gezielt blockiert und die Auswirkungen auf die neuronale Differenzierung analysiert.

\subsubsection{1 Überexpression von XHes2-Varianten in Xenopus-Embryonen}

Für die Überexpressionsstudien wurden verschiedene XHes2-Konstrukte hergestellt, die sowohl Aufschluß über die Funktion des natürlich vorkommenden XHes2-Proteins, als auch über die Bedeutung einzelner Proteindomänen geben sollten (Abb.2-10).

Um die Wildtyp-Form von XHes2 in embryonalen Xenopus-Zellen exprimieren zu können, wurde zunächst der gesamte offene Leserahmen des isolierten XHes2-cDNA-Klons ohne 5'- und 3'-UTR-Sequenzen in den Expressionsvektor pCS2+ kloniert.

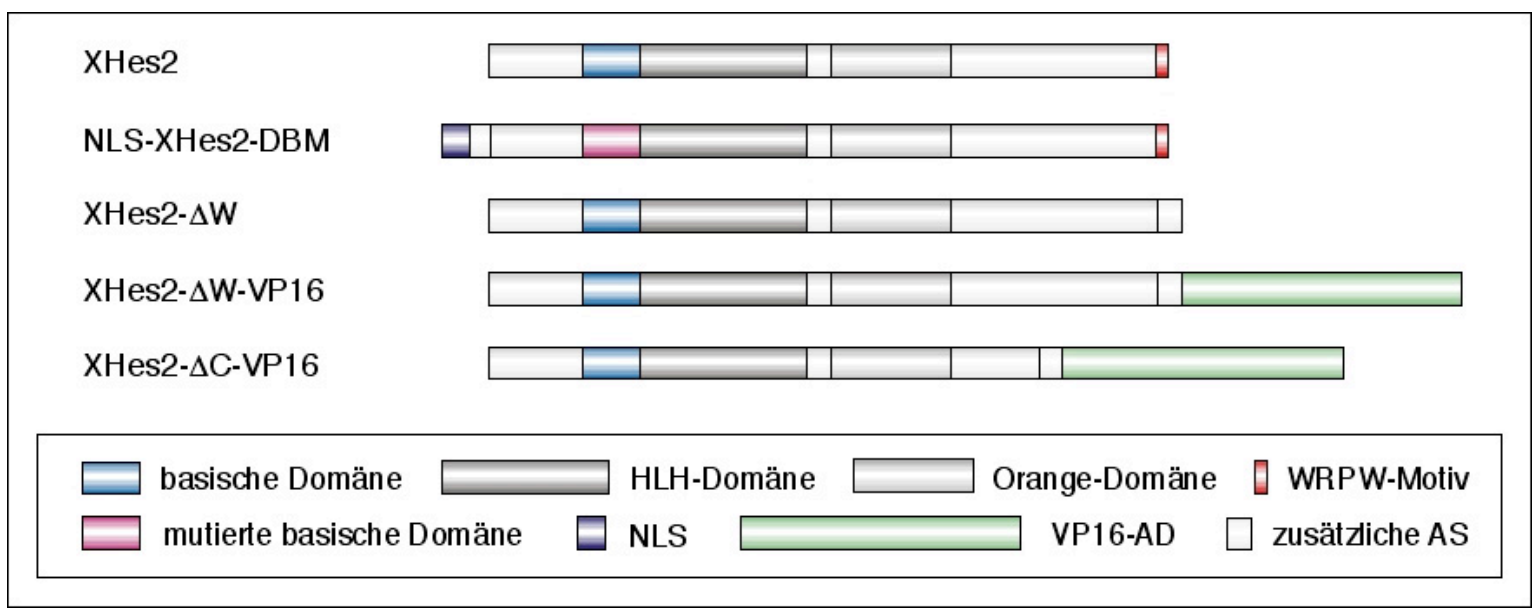

Abb.2-10: XHes2-Varianten für Überexpressionsstudien.

Schematische Darstellung der erzeugten XHes2-Konstrukte für die funktionellen Analysen. Im Gegensatz zum Wildtyp-Protein XHes2 trägt die DNA-Bindungsmutante NLS-XHes2-DBM, die ein zusätzliches Kernlokalisierungssignal (NLS) am N-Terminus besitzt, Mutationen in der basischen Domäne $\left({ }^{36}\right.$ MEKRRRARIN ${ }^{45}>{ }^{36}$ MKEEEEAEID $\left.{ }^{45}\right)$. In XHes2- $\Delta$ W fehlt das WRPW-Motiv, das für die Bindung der Groucho-Corepressoren notwendig ist. Die VP16-Transaktivierungsdomäne (AD) ersetzt in XHes2- $\Delta$ W-VP16 das WRPW-Motiv und in XHes2- $\Delta$ C-VP16 einen größeren C-terminalen Bereich. Die verschiedenen, farbig hervorgehoben Domänen der XHes2-Varianten sind unterhalb der Konstrukte aufgeführt. 
Zur Charakterisierung der Funktion einzelner Proteindomänen wurden diese entweder mutiert oder deletiert. Für mehrere Xenopus bHLH-O-Proteine konnte gezeigt werden, dass Deletionen oder Mutationen in der basischen Domäne einen Funktionsverlust (Koyano-Nakagawa et al., 2000; Schneider et al., 2001; Umbhauer et al., 2001; Taelman et al., 2004) oder einen dominant-negativen Effekt (Deblandre et al., 1999) verursachen können. Um zu überprüfen, ob die DNA-Bindung für die Funktion von XHes2 notwendig ist, wurden innerhalb der basischen Domäne mehrere basische Aminosäuren $\left({ }^{36}\right.$ MEKRRRARIN $\left.{ }^{45}\right)$ durch saure Aminosäuren $\left({ }^{36}\right.$ MKEEEEAEID $\left.{ }^{45}\right)$ ersetzt (XHes2-DBM), entsprechend der Mutationen in der DNA-Bindungsmutante von ESR6e (Deblandre et al., 1999). Da basische Aminosäuren innerhalb der basischen Domäne vermutlich auch für die Kernlokalisierung der bHLH-O-Proteine von Bedeutung sind, wurde die XHes2-DNABindungsmutante am Aminoende mit einem klassischen Kernlokalisierungssignal fusioniert (NLS-XHes2-DBM), um den Kernimport weiterhin zu gewährleisten. Für manche Funktionen von Hairy und $\mathrm{E}(\mathrm{spl})$-verwandten bHLH-O-Proteinen wird weiterhin das WRPW-Motiv benötigt, über das Groucho-Corepressoren gebunden werden (Schneider et al., 2001; Cossins et al., 2002). Um die Bedeutung des WRPW-Motivs für die Funktion von XHes2 analysieren zu können, wurde das Tetrapeptid-Motiv deletiert (XHes2- $\Delta W$ ).

bHLH-O-Proteine mit WRPW-Motiv sind in der Lage, die Transkription verschiedenster Gene zu reprimieren, indem sie an DNA binden und Corepressoren rekrutieren können (Barolo und Levine, 1997; Übersichtsartikel: Davis und Turner, 2001; Iso et al., 2003). Der Austausch der Repressionsdomäne durch die VP16-Transaktivierungsdomäne verwandelt einen vermeintlichen Transkriptionsrepressor in einen Transkriptionsaktivator (Sadowski et al., 1988), der bei Vorhandensein aller notwendigen Cofaktoren in der Lage sein sollte, die Transkription der Gene zu aktivieren, die normalerweise reprimiert werden. Zur Identifizierung der Zielgene von XHes2 wurden daher zwei VP16-Konstrukte hergestellt, die die Funktion von XHes2 umkehren sollten. Da bisher nur das WRPW-Motiv als Corepressor-bindende Region in Hairy und $\mathrm{E}(\mathrm{spl})$-verwandten bHLH-O-Proteinen identifiziert werden konnte, wurde dieses im XHes2-Protein durch die VP16Transaktivierungsdomäne ersetzt (XHes2- $\Delta \mathrm{W}$-VP16). Aufgrund möglicher weiterer Bereiche mit reprimierender Funktion in der C-terminalen Region (Übersichtsartikel: Davis und Turner, 2001; Iso et al., 2003) wurde in einem zweiten VP16-Konstrukt ein größerer C-terminaler Bereich von XHes2 einschließlich des WRPW-Motivs gegen die VP16Transaktivierungsdomäne ausgetauscht (XHes2- $\triangle \mathrm{C}$-VP16).

Diese XHes2-Varianten wurden in Xenopus-Embryonen überexprimiert und die Effekte auf die Neurogenese mittels wmISH in Embryonen und mittels RT-PCR in animalen Kappen untersucht. 


\subsection{Effekte der XHes2-Varianten in frühen Neurulastadien}

Da die ersten Neuronen in Xenopus bereits zu Beginn der Neurulation entstehen, wurden die Effekte der Überexpression von XHes2-Varianten auf die Neurogenese zunächst im offenen Neuralplattenstadium mittels wmISH analysiert (Abb.2-11, Tab.2-2).

Die Auswirkung einer ektopischen Expression von XHes2 und seiner Varianten auf die Expression von $X$-Ngnr-1 sollte die Frage beantworten, ob XHes2 die primäre Neurogenese bereits auf der Ebene der neuronalen Determinierung positiv oder negativ regulieren kann. Die Ergebnisse zeigten, dass durch die Überexpression von XHes2 die Transkription von X-Ngnr-1 in St.15-Embryonen reprimiert wird (Abb.2-11B1). Dieser Effekt war aufgrund des gewählten Injektionsortes vorwiegend in der anterioren Neuralplatte zu beobachten und betraf damit die profundal-trigeminale Plakode, sowie Domänen im späteren Gehirn und anterioren Rückenmark. XHes2-Varianten, die Mutationen in der DNA-Bindungsdomäne besaßen (NLS-XHes2-DBM) oder denen das Groucho-Corepressor-Motiv fehlte (XHes2- $\Delta \mathrm{W})$, waren dagegen nicht in der Lage, die Transkription von $X$-Ngnr-1 negativ zu regulieren (Abb.2-11B2,3). Somit scheint XHes2 für die Hemmung der X-Ngnr-1-Expression beide Motive zu benötigen, XHes2 muß einerseits an DNA binden und andererseits mit dem Corepressor Groucho interagieren können. Um zu untersuchen, inwieweit der Austausch der Groucho-Corepressor-Bindungsdomäne gegen die VP16-Transaktivierungsdomäne die Funktion von XHes2 verändert, wurde der Effekt von XHes2- $\Delta$ W-VP16 auf $X$-Ngnr-1 analysiert. XHes2- $\Delta$ W-VP16 induzierte in St.15Embryonen eine ektopische $X$-Ngnr-1-Expression im anterioren Ektoderm, die Expression innerhalb der Neuralplatte, vorwiegend im anterioren Anteil, war jedoch gehemmt (Abb.211B4). Wurde XHes2- $\Delta \mathrm{W}$-VP16 durch Injektion in eine animale, ventrale Blastomere vorwiegend im Ektoderm und in der posterioren Neuralplatte überexprimiert, kam es dort zur ektopischen Expression von X-Ngnr-1 (Abb.2-11B5). Diese Daten zeigen, dass XHes2- $\Delta$ W-VP16, zumindest in spezifischen Regionen des Embryos, die X-Ngnr-1Transkription aktivieren kann.

Um zu überprüfen, in welchem Maße die Differenzierung der primären Neuronen von der Überexpression der XHes2-Varianten beeinflußt werden kann, wurden die Effekte auf die $N$-tubulin-Expression beurteilt. In XHes2-überexprimierenden Embryonen war die Anzahl der N-tubulin-positiven Zellen eindeutig reduziert und die Stärke und Ausbreitung dieser Reduktion bzw. Hemmung größer als bei X-Ngnr-1 (Abb.2-11B6). Während die Mutation der DNA-Bindungsdomäne die Hemmung der $N$-tubulin-Expression verhinderte (Abb.211B7), hatte die Deletion des WRPW-Motivs eine Reduktion N-tubulin-positiver Zellen zur Folge, wenn auch in der Mehrzahl der analysierten Embryonen etwas weniger ausgeprägt im Vergleich zur XHes2-Wildtypform (Abb.2-11B8). Somit ist die DNA-Bindung für die 
Inhibition der N-tubulin-Transkription durch XHes2 notwendig, das WRPW-Motiv hingegen nicht. Die Überexpression von XHes2- $\Delta$ W-VP16 bewirkte wie XHes2 eine starke Reduktion der $N$-tubulin-Expression, ektopische $N$-tubulin-positive Zellen waren dagegen nicht vorhanden (Abb.2-11B9). Das Fehlen ektopischer Neuronen im frühen Neurulastadium trotz XHes2- $\Delta$ W-VP16-induzierter ektopischer X-Ngnr-1-Expression könnte auf eine Differenzierungsverzögerung zurückzuführen sein.

Die neurale und neuronale Differenzierung kann durch eine Vielzahl von Faktoren gehemmt werden. Neben der Aktivierung des Notch-Signalwegs und den dadurch induzierten bHLH-O-Proteinen, sind auch einige Sox-Proteine daran beteiligt, die Differenzierung von Neuronen zu verhindern und undifferenzierte Vorläuferzellen zu erhalten, indem sie der Aktivität proneuraler Proteine entgegenwirken (Bylund et al., 2003). Daher schien es interessant, die Effekte auf die Expression von XSox3 (Penzel et al., 1997) zu betrachten. Und tatsächlich resultierte die Überexpression von XHes2- $\Delta \mathrm{W}$ VP16 in einer starken Transkriptionsaktivierung von XSox3 im Ektoderm (Abb.211B13,14), meistens einhergehend mit einer leicht verbreiterten Neuralplattenexpression (Abb.2-11B13). Ektopisches XHes2 führte ebenfalls zu einer leichten Expansion der $X$ Sox3- Neuralplattenexpression, ohne die XSox3-Expressionsstärke zu beeinflussen; die Expression in der Plakodenregion war dagegen stark reduziert, aber nie vollständig gehemmt (Abb.2-11B10). Sowohl NLS-XHes2-DBM als auch XHes2- $\Delta \mathrm{W}$ hatten keine Auswirkung auf die XSox3-Expression (Abb.2-11B11,12), was darauf hindeutet, dass DNA-Bindung und das WRPW-Motiv für die Hemmung von $X$ Sox3 in der Plakodenregion notwendig sind. Somit ist bezüglich der Plakodenexpression in anterioren, ektodermalen Zellen ein gegenläufiger Effekt infolge der Überexpression von XHes2 und XHes2- $\Delta \mathrm{W}$ VP16 zu beobachten, während die Expansion der Neuralplatte bei beiden XHes2Varianten auftritt.

Zusammenfassend läßt sich sagen, dass XHes2 die primäre Neurogenese hemmen kann, aber auch einen inhibitorischen Effekt auf die frühe Plakodenentwicklung hat. Weiterhin lassen die Daten vermuten, dass die Regulation von X-Ngnr-1 und XSox3 durch XHes2 innerhalb und außerhalb der Neuralplatte von unterschiedlichen Faktoren beeinflußt werden kann. 


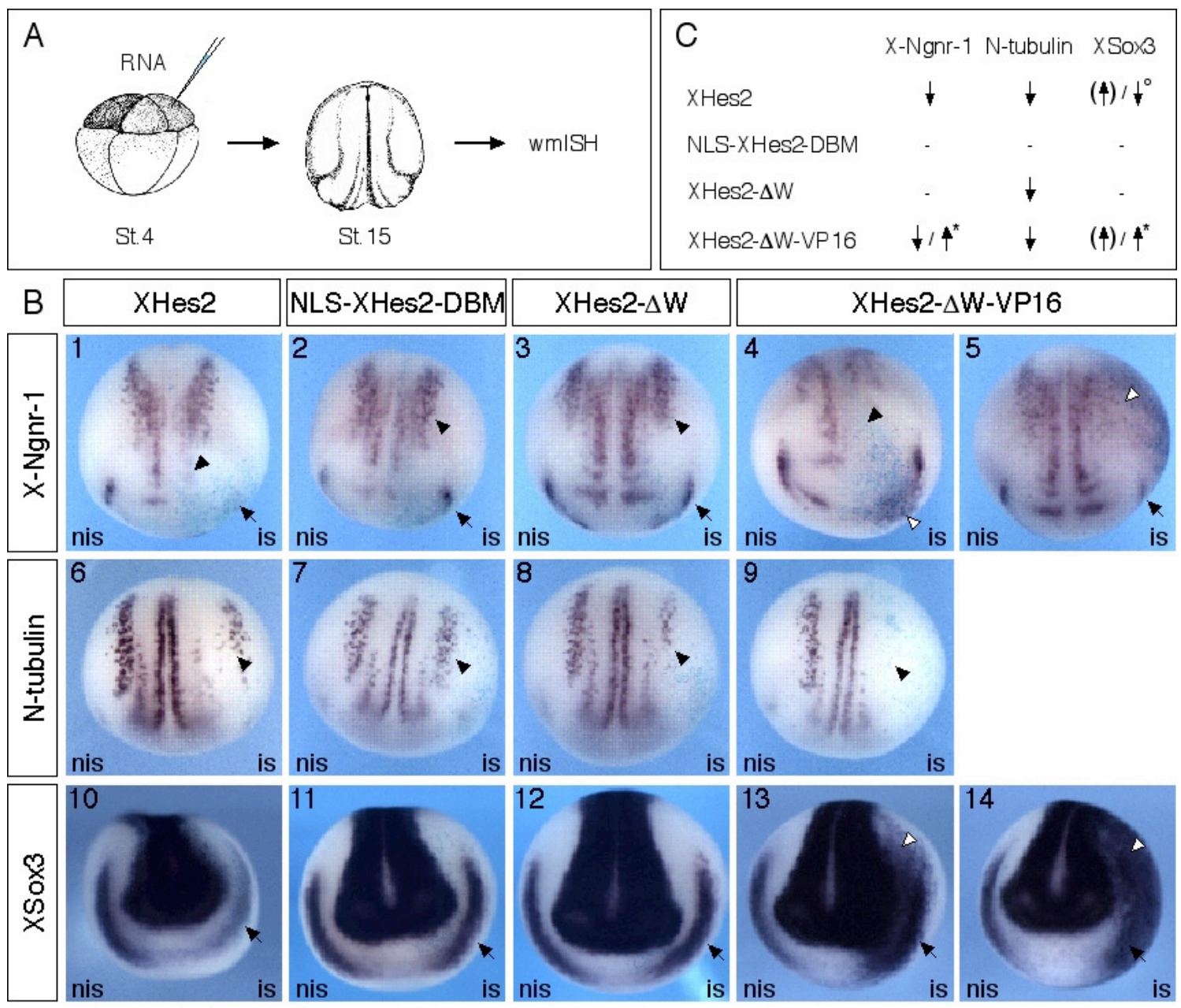

Abb.2-11: XHes2 hemmt primäre Neurogenese und Plakodenentwicklung in Xenopus-Embryonen.

Effekte von XHes2-Varianten auf die Expression von X-Ngnr-1, N-tubulin und XSox3 im offenen Neuralplattenstadium (St.14/15) von Xenopus laevis-Embryonen analysiert mittels wmISH. (A) Schematische Darstellung der experimentellen Strategie. Verschiedene RNAs (siehe 11B) wurden in die animale, dorsale Blastomere des Acht-Zell-Stadiums (St.4) von Xenopus laevis-Embryonen injiziert. Diese wurden bis zum Stadium 14/15 kultiviert und mittels wmISH analysiert. (B) wmISH-Analyse nach Überexpression von XHes2Varianten. XHes2 hemmt die Expression von X-Ngnr-1 (1) und $\mathrm{N}$-tubulin (6) einhergehend mit einer leichten Expansion der Neuralplatte. Die XSox3-Expression ist hingegen nur in der Plakodenregion reduziert, während sie in der Neuralplatte in einer leicht verbreiterten Domäne erhalten bleibt (10). NLS-XHes2-DBM beeinflußt keine der drei untersuchten Expressionen $(2,7,11)$. XHes2- $\Delta \mathrm{W}$ hat keinen Effekt auf die Expression von $X$ Ngnr-1 (3) und XSox3 (12), bewirkt jedoch eine Reduktion N-tubulin-positiver Zellen (8). XHes2- $\Delta$ W-VP16 reprimiert die Transkription von X-Ngnr-1 (4) und N-tubulin (9) innerhalb der Neuralplatte und bedingt eine verbreiterte XSox3-Expressionsdomäne (13), außerdem sind in der ektodermalen Region anterior zur profundal-trigeminalen Plakode X-Ngnr-1-positive Zellen (4) und im ektodermalen Bereich um die Plakodenregion XSox3-positive Zellen vorhanden. Wird XHes2- $\Delta$ W-VP16 durch Injektion in eine animale, ventrale Blastomere vorwiegend im Ektoderm überexprimiert, dann kommt es dort zur ektopischen Expression von X-Ngnr-1 (5) und XSox3 (14). (C) Zusammenfassung der durch die Überexpression von XHes2-Varianten erzielten Effekte in frühen Neurulastadien. Die injizierten RNAs sind jeweils über den Fotos und die untersuchten Genexpressionen jeweils links der Fotos angegeben. Die Embryonen sind wie folgt orientiert: (19) dorsale Aufsicht, anterior unten; (10-14) anteriore Aufsicht, dorsal oben. Abkürzungen und Symbole: nis, nicht-injizierte Seite; is, injizierte Seite; schwarzer Pfeil, profundal-trigeminale Plakode $(1-3,5)$ bzw. Plakodenregion (10-14) in anteriorer Neuralplatte; weiße Pfeilspitze, ektopische Expression; schwarze Pfeilspitze, primäre Neuronen in posteriorer Neuralplatte; -, unveränderte Expression; $\downarrow$, reduzierte endogene Expression; $\downarrow^{\circ}$, Reduktion nur in plakodaler Expressionsdomäne; $(\uparrow)$, leicht verbreiterte Expressionsdomäne innerhalb der Neuralplatte; $\uparrow^{*}$, ektopische Expression im Ektoderm. 


\begin{tabular}{|c|c|c|c|c|c|}
\hline injizierte RNA & $\mathrm{nLacZ}$ & XHes2 & NLS-XHes2-DBM & XHes2- $\Delta \mathrm{W}$ & XHes2- $\Delta$ W-VP16 \\
\hline Menge (pg) & 40 & 10 & 10 & 10 & 10 \\
\hline injizierte Zelle & $1 / 8 ;$ ad & $1 / 8 ;$ ad & $1 / 8 ;$ ad & $1 / 8 ;$ ad & $1 / 8 ;$ ad \\
\hline wmISH-Stadium & 14 & 14 & 14 & 14 & 14 \\
\hline Anzahl X-Ngnr-1 & 14 & 9 & 15 & 13 & 19 \\
$=/ \downarrow / \uparrow(\%)$ & $93 / 7 / 0$ & $11 / 89 / 0$ & $80 / 20 / 0$ & $38,5 /(38,5) /(23)$ & $0 / 32 / 100^{*}$ \\
\hline $\begin{array}{c}\text { Anzahl N-tubulin } \\
=/ \downarrow / \uparrow(\%)\end{array}$ & 19 & 16 & 11 & 11 & 15 \\
\hline $\begin{array}{c}\text { Anzahl XSox3 } \\
=/ \downarrow / \uparrow(\%)\end{array}$ & $79 / 16 / 5$ & $12,5 / 87,5 / 0$ & $64 / 36 / 0$ & $9 / 91 / 0$ & $0 / 100 / 0$ \\
\hline
\end{tabular}

Tab.2-2: Effekte überexprimierter XHes2-Varianten auf die primäre Neurogenese. Abkürzungen und Symbole: Anzahl X-Ngnr-1, Anzahl der mittels wmISH (X-Ngnr-1 Expression) analysierten Embryonen; =, Expression unverändert, $\downarrow$, weniger bis keine positiven Zellen in Expressionsdomäne; $\uparrow$, mehr positive Zellen in Expressionsdomäne; a, animal, d, dorsal, n.a., nicht analysiert; ${ }^{*}$, ektopisch im Ektoderm; ${ }^{\circ}$, Reduktion nur in plakodaler Expressionsdomäne; ", Expression normal bis auf schwache Expansion der anterioren Neuralplatte in Richtung der Plakodenregion; ${ }^{\circ}$, schmalere Neuralplattenexpression; ( ), schwacher Effekt. Bei mehr als 100\% zeigt ein Teil der Embryonen eine Kombination von Reduktion im Neuroektoderm und ektopische Expression im Ektoderm. XHes2 und XHes2-AW-VP16 injizierte Embryonen zeigen eine leichte Expansion der Neuralplatte. 


\subsection{Effekte von XHes2-AC-VP16 in ektodermalen Xenopus-Explantaten}

Um einerseits herauszufinden, welche weiteren Gene neben X-Ngnr-1 und XSox3 von XHes2 infolge einer aktiven Transkriptionsrepression reguliert werden können, und um andererseits der Frage nachzugehen, ob ektodermale Zellen, die eine als Transkriptionsaktivator fungierende XHes2-Variante überexprimieren, zu Neuronen differenzieren, wurden die Effekte der Überexpression von XHes2- $\Delta$ C-VP16 auf die Genexpression in ektodermalen Explantaten verschiedener Entwicklungsstadien mittels RT-PCR untersucht (Abb.2-12). Neben X-Ngnr-1 und N-tubulin wurden weitere Regulatoren der Neurogenese, aber auch der Myogenese betrachtet.

In animalen Kappen, die bis zum Stadium 13 kultiviert wurden, konnte, wie in den frühen Neurulastadien, infolge der Überexpression von XHes2- $\Delta$ C-VP16 eine Transkriptionsaktivierung von $X$-Ngnr-1, nicht aber von $N$-tubulin nachgewiesen werden. Außer der Expression von $X$-Ngnr-1 wurde aber auch die Expression von NeuroD und ESR1 stimuliert, die beide ebenfalls an der neuronalen Determinierung beteiligt sind und diese positiv bzw. negativ regulieren (Lee et al., 1995; Schneider et al., 2001). Somit stellen NeuroD und ESR1 vermutlich weitere durch XHes2 regulierte Zielgene dar, die allerdings beide auch durch X-Ngnr-1 induziert werden können (Ma et al., 1996; KoyanoNakagawa et al., 1999; Perron et al., 1999; Talikka et al., 2002).

Die Transkription von Xath3, das bei der neuronalen Differenzierung von Bedeutung ist (Perron et al., 1999), wurde erst in Explantaten des Stadium 22 durch XHes2- $\Delta$ C-VP16 aktiviert, was auf die Expression von $X-N g n r-1$ und NeuroD zurückzuführen sein wird und auf eine indirekte Regulation durch XHes2 hindeutet.

Erst nach längerer Kultivierung der Explantate bis zum Stadium 31 konnte schließlich, einhergehend mit der Abnahme des ESR1-Expressionsniveaus bei nahezu unveränderter Expression von $X-N g n r-1$ und NeuroD, eine signifikante Transkriptionsaktivierung von $N$ tubulin festgestellt werden. Diese Daten lassen vermuten, dass die neuronale Differenzierung im XHes2- $\Delta$ C-VP16 exprimierenden animalen Kappenektoderm durch die Aktivierung negativer Regulatoren, wie ESR1, verzögert wird.

Um zu überprüfen, ob XHes2- $\Delta$ C-VP16 neben Regulatoren der Neurogenese auch andere Faktoren in den Explantaten aktivieren kann, wurde das bHLH-Protein MyoD analysiert, das die frühe Myogenese reguliert (Hopwood et al., 1989). Eine Aktivierung der MyoD-Transkription konnte in den Explantaten jedoch nicht nachgewiesen werden. Somit scheint XHes2- $\triangle$ C-VP16 in ektodermalen Explantaten in der Lage zu sein, die Expression von Regulatoren der Neurogenese, aber nicht der Myogenese auf Transkriptionsebene zu fördern. 


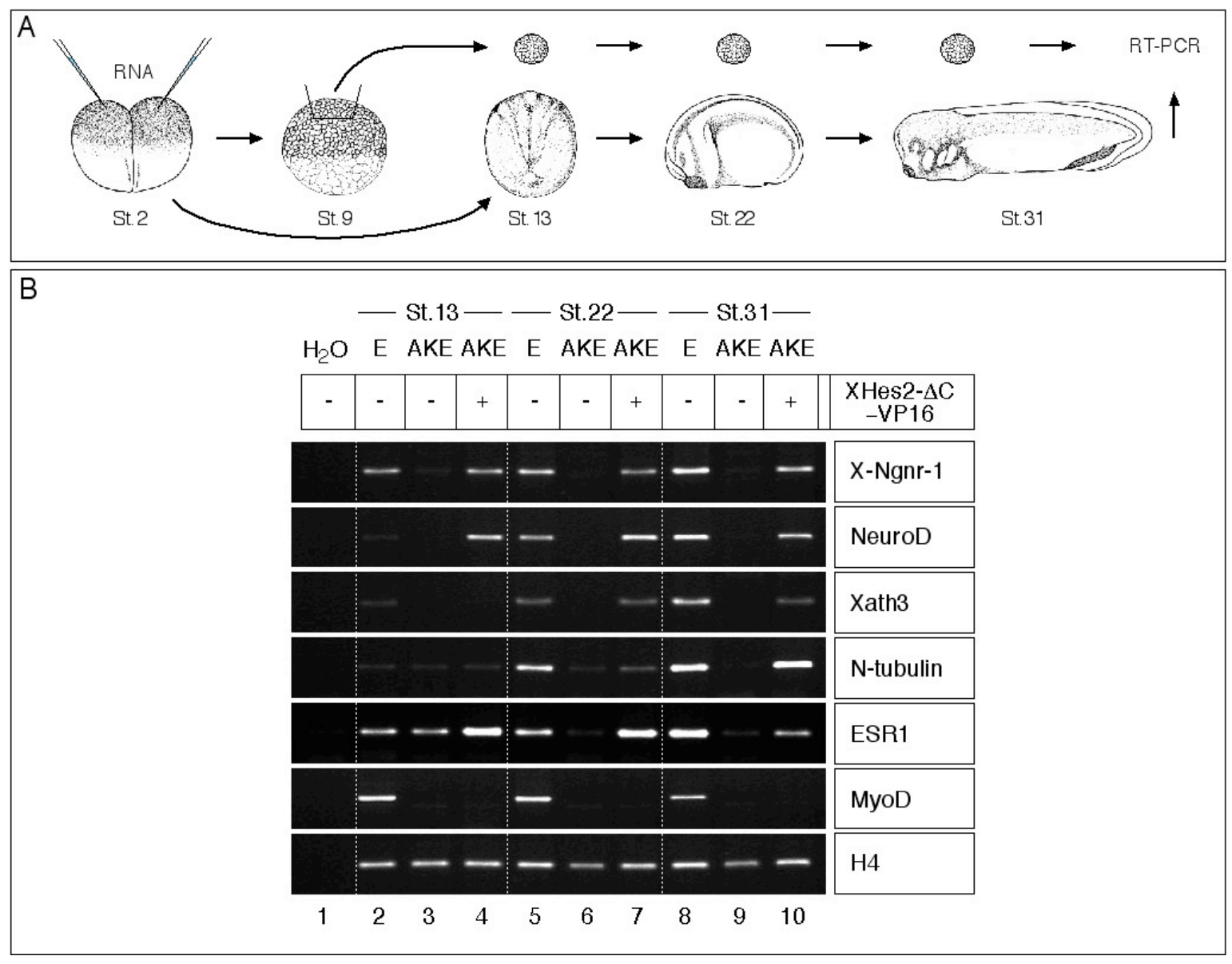

Abb.2-12: XHes2-AC-VP16 aktiviert die Transkription positiver und negativer neuronaler bHLH-Gene in frühen animalen Kappen, induziert ektopische Neuronen aber erst in späten animalen Kappen.

Effekte der Überexpression von XHes2- $\Delta$ C-VP16 auf die Genexpression im AKE verschiedener Stadien analysiert mittels semiquantitativer RT-PCR. (A) Schematische Darstellung der experimentellen Strategie. RNA (siehe 12B) wurde im animalen, polnahen Bereich in beide Blastomeren des Zwei-Zell-Stadiums (St.2) von Xenopus laevis-Embryonen injiziert, animale Kappen wurden im Stadium 9 (St.9) isoliert und solange kultiviert bis nicht-injizierte Kontrollembryonen das Stadium 13, 22 bzw. 31 (St.13, 22, 31) erreichten. Die aus den Explantaten und Kontrollembryonen gewonnenen RNA-Präparationen wurden dann mittels semiquantitativer RT-PCR analysiert. (B) RT-PCR-Analyse. Die Überexpression von XHes2- $\Delta$ C-VP16 führt bereits in St.13-Explantaten (AKE) zur Transkriptionsaktivierung von X-Ngnr-1, NeuroD und ESR1 (Spur 4 vs.3), während Xath3 erst in St.22-Explantaten exprimiert wird (Spur 7 vs. 6). Eine deutliche Erhöhung des Expressionsniveaus von $\mathrm{N}$-tubulin wird erst nach längerer Kultivierung in St.31-Explantaten erreicht, die andererseits eine Abnahme der ESR1-Expression aufweisen (Spur 10 vs. 9). MyoD, ein bHLH-Regulator der frühen Myogenese, wird in den Explantaten nicht exprimiert (Spur 4/7/10 vs. 3/6/9). Die injizierten RNAs sind über den jeweiligen DNA-Spuren angegeben. Wasser $\left(\mathrm{H}_{2} \mathrm{O}\right)$ wurde anstelle von RNA als Negativkontrolle (Spur 1) und Stadium 13, 22 bzw. 31 RNA als Positivkontrolle (Spur 2,5,8) eingesetzt. Alle RNAPräparationen sind frei von Verunreinigungen mit genomischer DNA (nicht gezeigt). Zur Überprüfung der eingesetzten RNA-Menge wurde die Expression von Histon $\mathrm{H} 4$ analysiert. XHes2- $\Delta$ C-VP16 injizierte animale Kappen wurden mit nicht-injizierten Explantaten der entsprechenden Stadien verglichen. RNA/Embryo: 25 pg XHes2- $\triangle$ C-VP16. RT-PCR-Primer/Produktlängen ESR1: ESR1 RT1F/ESR1 RT1R/225bp, Histon H4: H4_RTF/H4_RTR/188bp, MyoD: MyoD_RTF/MyoD_RTR/291bp, NeuroD: NeuroD_RTF/NeuroD_RTR/238bp, N-tubulin: N-tubulin_RTF/N-tubulin_RTR/250bp, XAth3: Xath3_RT1F/Xath3_RT1R/250bp, X-Ngnr-1: X-Ngnr1_RTF/X-Ngnr-1_RTTR/334bp.

Auch Gene, die wie Pax6 und $R x$ für die frühe Augenentwicklung oder wie Pax8 für die die frühe Innenohrentwicklung wichtig sind (Casarosa et al., 1997; Hirsch und Harris, 1997; Mathers et al., 1997; Carroll und Vize, 1999; Heller und Brändli, 1999), konnten durch Überexpression von XHes2- $\Delta$ C-VP16 in animalen Kappen nicht induziert werden (Daten nicht gezeigt). 


\subsection{Effekte von XHes2 und XHes2-AW-VP16 in späten Neurulastadien}

Die erst in älteren animalen Kappen auftretende ektopische Aktivierung der $\mathrm{N}$-tubulinTranskription durch XHes2- $\Delta \mathrm{W}$-VP16 unterstützte die Hypothese, dass die ektopische neuronale Differenzierung der X-Ngnr-1-positiven Zellen in frühen Neurulastadien inhibiert wird, und warf die Frage auf, ob in älteren Embryonen ektopische Neuronen durch XHes2- $\Delta$ W-VP16 induziert werden könnten. Daher wurden die Effekte von XHes2 und XHes2- $\Delta$ W-VP16 auf die Expression neuronaler Gene mittels wmISH im Stadium 24 analysiert, in dem Neuronen außer im Neuralrohr auch in weiteren Domänen, wie z.B. der sich ausbildenden Retina, entstehen (Abb.2-13, Tab.2-3).

Wie auch in St.15-Embryonen wurde die Transkription von X-Ngnr-1 in St.24-Embryonen durch die Überexpression von XHes2 reprimiert (Abb.2-13B1,2). XHes2- $\Delta$ W-VP16 verursacht im Neuroektoderm, wie XHes2, zwar zum größten Teil eine Verminderung $X$ Ngnr-1-positiver Zellen, jedoch zeigen einige der Embryonen eine ektopische Expression von X-Ngnr-1 im Ektoderm und posterioren Neuralrohr (Abb.2-13B3,4), wie zuvor bereits in St.15-Embryonen beobachtet werden konnte. Der geringere prozentuale Anteil an Embryonen mit ektopischer X-Ngnr-1-Expression im Stadium 24 gegenüber Stadium 15 könnte auf die über die Zeit durch Degradierung abnehmende XHes2- $\Delta$ W-VP16Konzentration in den injizierten Embryonen zurückzuführen sein.

Die Induktion der NeuroD-Expression durch XHes2- $\Delta \mathrm{W}$-VP16 in ektodermalen Explantaten ließ vermuten, dass NeuroD auch im Embryo durch XHes2-Varianten reguliert werden kann. Und tatsächlich konnte diese Annahme bestätigt werden. XHes2$\Delta$ W-VP16 war auch in St.24-Embryonen in der Lage, die NeuroD-Transkription ektopisch im Ektoderm zu aktivieren. Die starke ektopische NeuroD-Expression war jedoch nicht so gleichmäßig wie $X-N g n r-1$ in nahezu allen ektodermalen Zellen zu finden, sondern eher auf isolierte Zellcluster oder einzelne Zellen begrenzt (Abb.2-13B7,8). Durch die Überexpression von XHes2 wurde die endogene Expression von NeuroD, wie die von $X$ Ngnr-1, gehemmt (Abb.2-13B5,6).

Während N-tubulin im Gegensatz zu X-Ngnr-1 in St.15-Embryonen durch XHes2- $\Delta$ WVP16 nicht ektopisch aktiviert wurde, konnten in St.24-Embryonen infolge der XHes2- $\Delta \mathrm{W}$ VP16-Überexpression N-tubulin-positive Zellen in Clustern verschiedener Größe verstreut im Ektoderm detektiert werden (Abb.2-13B11,12). Bei einigen Embryonen war zusätzlich die endogene $N$-tubulin-Expression leicht reduziert, während diese durch ektopisches XHes2 fast vollständig gehemmt wurde (Abb.2-13B9,10). Damit scheint XHes2- $\Delta$ W-VP16 nicht nur in den ektodermalen Explantaten, sondern auch im Ektoderm vollständiger Embryonen in der Lage zu sein, ektopische Neuronen zu induzieren. Diese erscheinen 
jedoch später und in geringerer Dichte als die durch X-Ngnr-1 induzierten ektopischen Neuronen. 


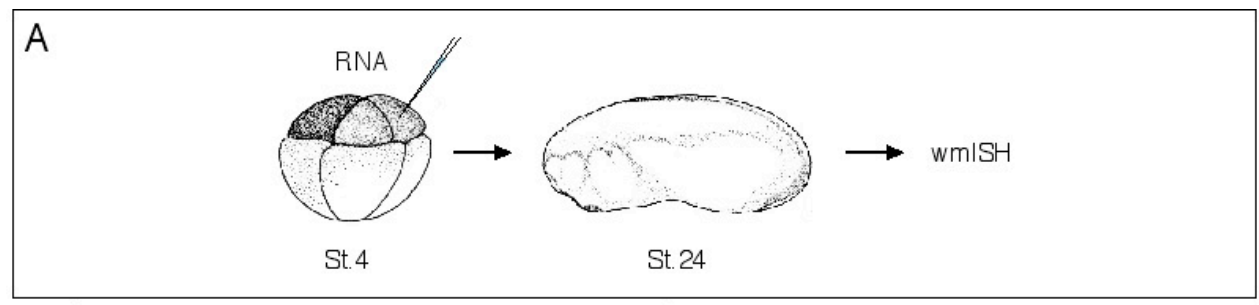

B $\quad$ XHes2 $\quad$ XHes2- $\triangle$ W-VP16
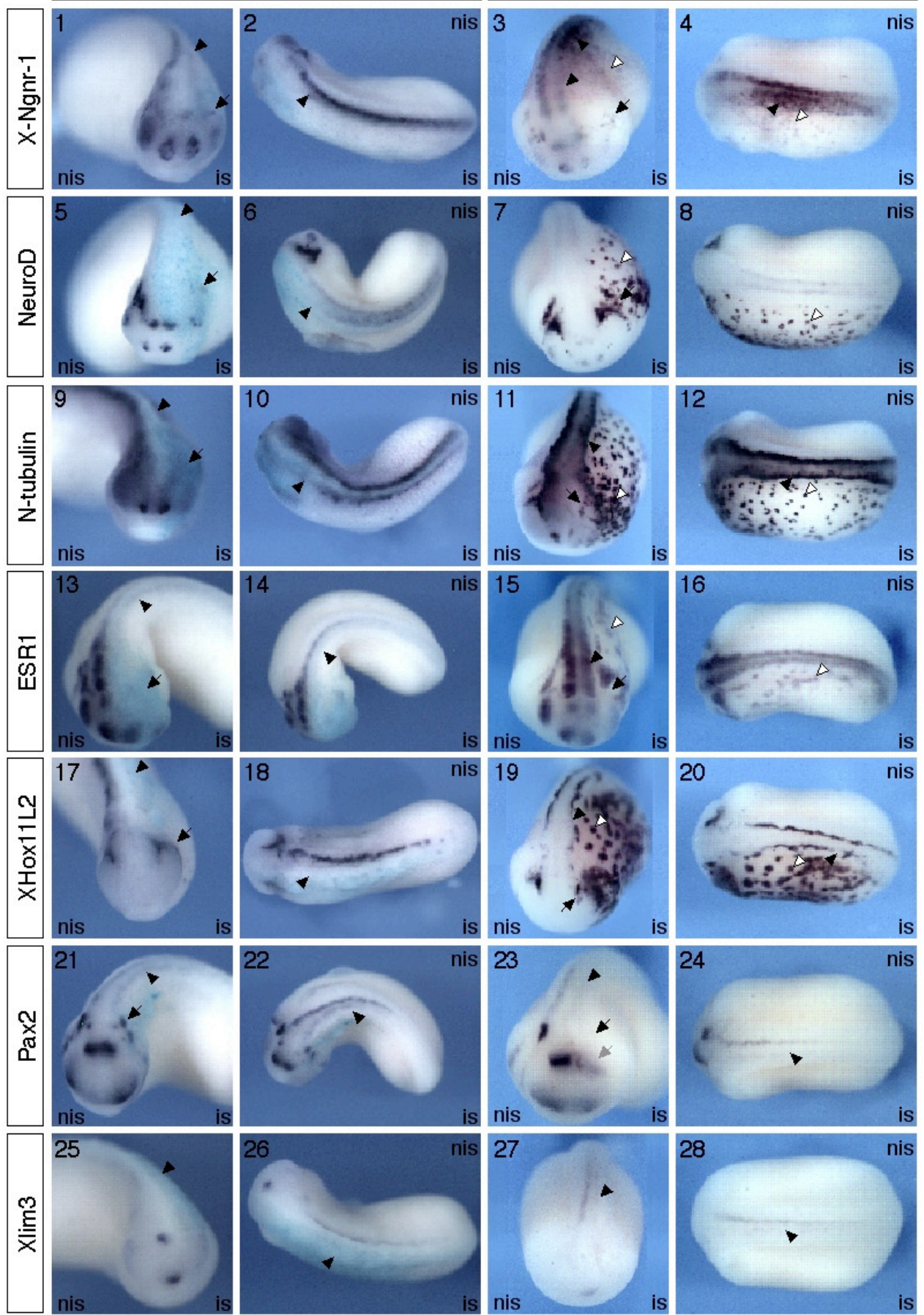


\begin{abstract}
Abb.2-13: In späten Neurulastadien wird die Neurogenese durch die Überexpression von XHes2 gehemmt, während XHes2-AW-VP16 ektopische sensorische Neuronen im Ektoderm induzieren kann. Auswirkungen von XHes2 und XHes2- $\Delta$ W-VP16 auf die Expression allgemeiner und spezifischer neuronaler Marker nach Neuralrohrschluß in St.24-Embryonen analysiert mittels wmISH. (A) Schematische Darstellung der experimentellen Strategie. Verschiedene RNAs (siehe 13B) wurden in die animale, dorsale Blastomere des Acht-Zell-Stadiums (St.4) von Xenopus laevis-Embryonen injiziert. Diese wurden bis zum Stadium 24 kultiviert und mittels wmISH analysiert. (B) wmISH-Analyse nach Überexpression von XHes2 und XHes2- $\Delta \mathrm{W}$ VP16. XHes2 hemmt nicht nur die Expression von X-Ngnr-1 $(1,2)$, NeuroD $(5,6)$ und $N$-tubulin $(9,10)$, sondern auch die von ESR1 $(13,14)$, XHox11L2 $(17,18)$, Pax2 $(21,22)$ und Xlim3 $(25,26)$ in St.24-Embryonen. XHes2$\Delta$ W-VP16 aktiviert einerseits die Transkription von X-Ngnr-1 (3,4), NeuroD $(7,8), N$-tubulin $(11,12)$, ESR1 $(15,16)$ und XHox11L2 $(19,20)$ ektopisch im Ektoderm von St.24-Embryonen, reprimiert aber andererseits auch die endogenen Expressionsdomänen dieser Gene. Der Interneuronen-Marker Pax2 $(23,24)$ und der Motorneuronenmarker Xlim3 $(27,28)$ werden durch XHes2- $\Delta$ W-VP16 gehemmt, anders als der sensorische Neuronenmarker $X H o x 11 L 2$ werden sie jedoch nicht ektopisch im Ektoderm exprimiert. Die injizierten RNAs sind jeweils über den Fotos und die untersuchten Genexpressionen jeweils links der Fotos angegeben. Die Embryonen sind wie folgt orientiert: (alle ungeraden Zahlen) anteriore Aufsicht, dorsal oben; (alle geraden Zahlen) dorsale Aufsicht, anterior links. Abkürzungen und Symbole: nis, nicht-injizierte Seite; is, injizierte Seite; schwarzer Pfeil, anteriore Expressionsdomänen (profundal-trigeminale Plakode, Hirn, Ohrplakode); weiße Pfeilspitze, ektopische Expression; schwarze Pfeilspitze, Expression in Rückenmark oder Hinterhirn.
\end{abstract}

Um zu testen, ob die zeitliche Verzögerung der neuronalen Differenzierung wie in den Explantaten mit einer Transkriptionsaktivierung von negativen Determinationsfaktoren, wie z.B. ESR1, einhergeht, wurden die Effekte auf die Expression von ESR1 analysiert. Während ESR1, wie X-Ngnr-1 und N-tubulin, durch XHes2 reprimiert werden konnte (Abb.2-13B13,14), führte die Überexpression von XHes2- $\Delta \mathrm{W}-\mathrm{VP16}$ wie in den Explantaten zur ektopischen Expression von ESR1 in ektodermalen Zellen, häufig einhergehend mit einer Repression der eigentlichen Expressionsdomänen (Abb.213B15,16). Ähnliche Effekte wurden für XHairy1 beobachtet (Tab.2-3). Da die Expressionstärke von ESR1 in den ektodermalen Zellen jedoch nicht so hoch ist, wie die von NeuroD oder N-tubulin, und auch weniger Zellen betroffen zu sein scheinen, könnte ein Übergewicht an proneuralen Faktoren gegenüber negativen Regulatoren im Stadium 24 die Differenzierung der Neuronen erklären.

Zur näheren Bestimmung des Subtyps der durch XHes2- $\Delta$ W-VP16 induzierten Neuronen wurden die Effekte auf die Expression von XHox11L2 (Patterson und Krieg, 1999), Pax2 (Heller und Brändli, 1997) und Xlim3 (Taira et al., 1993) untersucht, die jeweils Marker für sensorische Neuronen, Interneuronen und Motorneuronen darstellen. Während XHes2 und XHes2- $\triangle \mathrm{W}$-VP16 in der Lage waren, die endogene Transkription von allen drei Neuronen-spezifischen Genen zu hemmen, konnte XHes2- $\Delta$ W-VP16 nur die XHox11L2Expression, die endogen in sensorischen Hirnganglien und Rohon-Beard-Neuronen zu finden ist, ektopisch im Ektoderm stimulieren (Abb.2-13B17-28). Somit weisen die durch XHes2- $\Delta$ W-VP16 induzierten Neuronen mit der XHox11L2-Expression ein typisches Merkmal sensorischer Neuronen auf.

Zusammengenommen sprechen die Ergebnisse der Überexpression der XHes2-Varianten in Xenopus-Embryonen für eine negative Regulation der Neurogenese durch XHes2, das vermutlich die Expression, und vielleicht auch die Funktion verschiedener, für die neuronale Differenzierung wichtiger Faktoren blockieren kann. 


\begin{tabular}{|c|c|c|c|c|c|}
\hline injizierte RNA & XHes2 & XHes2- $\Delta$ W-VP16 & injizierte RNA & XHes2 & XHes2- $\Delta$ W-VP16 \\
\hline Menge (pg) & 10 & 10 & Menge (pg) & 10 & 10 \\
\hline injizierte Zelle & 1/8; ad & 1/8; ad & injizierte Zelle & 1/8; ad & 1/8; ad \\
\hline wmISH-Stadium & 24 & 24 & wmISH-Stadium & 24 & 24 \\
\hline $\begin{array}{l}\text { Anzahl X-Ngnr-1 } \\
=/ \downarrow / \uparrow(\%)\end{array}$ & $\begin{array}{c}14 \\
7 / 93 / 0\end{array}$ & $\begin{array}{c}14 \\
0 / 71 / 29^{*}\end{array}$ & $\begin{array}{l}\text { Anzahl Hox11L2 } \\
=/ \downarrow / \uparrow(\%)\end{array}$ & $\begin{array}{c}13 \\
0 / 100 / 0\end{array}$ & $\begin{array}{c}13 \\
0 / 0 / 100^{*}\end{array}$ \\
\hline $\begin{array}{l}\text { Anzahl NeuroD } \\
=/ \downarrow / \uparrow(\%)\end{array}$ & $\begin{array}{c}22 \\
0 / 100 / 0\end{array}$ & $\begin{array}{c}25 \\
0 / 0 / 100^{*}\end{array}$ & $\begin{array}{l}\text { Anzahl Pax2 } \\
=/ \downarrow / \uparrow(\%)\end{array}$ & $\begin{array}{c}26 \\
15 / 85 / 0\end{array}$ & $\begin{array}{c}24 \\
8 / 92 / 0\end{array}$ \\
\hline $\begin{array}{l}\text { Anzahl N-tubulin } \\
=/ \downarrow / \uparrow(\%)\end{array}$ & $\begin{array}{c}13 \\
15 / 85 / 0\end{array}$ & $\begin{array}{c}13 \\
0 / 15 / 85^{*}\end{array}$ & $\begin{array}{l}\text { Anzahl Xlim3 } \\
=/ \downarrow / \uparrow(\%)\end{array}$ & $\begin{array}{c}12 \\
8 / 92 / 0\end{array}$ & $\begin{array}{c}14 \\
36 / 64 / 0\end{array}$ \\
\hline $\begin{array}{l}\text { Anzahl ESR1 } \\
=/ \downarrow / \uparrow(\%)\end{array}$ & $\begin{array}{c}20 \\
10 / 90 / 0\end{array}$ & $\begin{array}{c}13 \\
0 / 0 / 100^{*}\end{array}$ & $\begin{array}{l}\text { Anzahl Hairy1 } \\
=/ \downarrow / \uparrow(\%)\end{array}$ & $\begin{array}{c}10 \\
0 / 100 / 0\end{array}$ & $\begin{array}{c}24 \\
0 / 0 / 100^{*}\end{array}$ \\
\hline
\end{tabular}

Tab.2-3: Effekte überexprimierter XHes2-Varianten in St.24-Embryonen. Abkürzungen und Symbole: Anzahl X-Ngnr-1, Anzahl der mittels wmISH (X-Ngnr-1 Expression) analysierten Embryonen; =, Expression unverändert; $\downarrow$, weniger bis keine positiven Zellen in Expressionsdomäne; $\uparrow$, mehr positive Zellen in Expressionsdomäne; a, animal; d, dorsal; *, ektopisch im Ektoderm. 


\subsubsection{2 Überexpression von induzierbaren XHes2-Varianten in Xenopus-Embryonen}

In den zuvor beschriebenen funktionellen Analysen wurde synthetische RNA der verschiedenen XHes2-Varianten während der ersten Furchungsteilungen injiziert, woraufhin die entsprechenden Proteine in vivo synthetisiert werden konnten und bereits in in frühen Entwicklungsstadien in aktiver Form vorhanden waren. Um den Zeitpunkt der Aktivierung von XHes2-Varianten in Xenopus-Embryonen regulieren zu können, wurden Glucocorticoid-induzierbare XHes2-Varianten erzeugt, indem die XHes2-Varianten carboxyterminal mit der Liganden-bindenden Domäne des humanen Glucocorticoidrezeptors fusioniert wurden (Abb.2-14) (Kolm und Sive, 1995). Die überexprimierten Fusionsproteine sind ohne Hormon inaktiv, da die Liganden-bindende Domäne funktionelle Domänen blockiert und die Fusionsproteine durch Bindung an Cytoskelett-assoziierte Hitzeschockproteine im Cytoplasma zurückhält. In Anwesenheit von Glucocorticoiden, wie z.B. Dexamethason, wird durch deren Bindung an die Liganden-bindende Domäne eine Konformationsänderung verursacht, die eine Freisetzung der Fusionsproteine und der funktionellen Domänen im Cytoplasma bewirkt und dadurch die ursprüngliche Funktion der Proteine wieder freigibt (Mattioni et al., 1994).

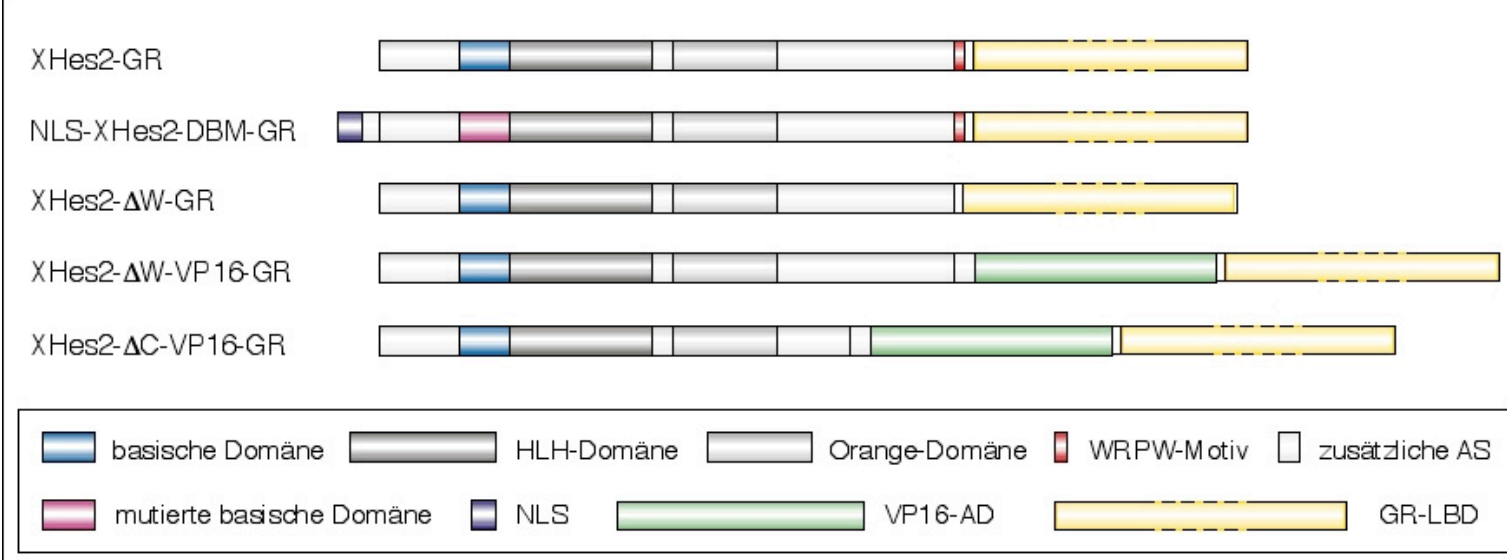

Abb.2-14: Induzierbare XHes2-Varianten für Überexpressionsstudien.

Schematische Darstellung der Dexamethason-induzierbaren XHes2-Konstrukte für die funktionellen Analysen. Die XHes2-Varianten (siehe auch Abb.2-10) enthalten an ihrem C-Terminus die Liganden-bindende Domäne des humanen Glucocorticoidrezeptors (GR). Die verschiedenen Domänen der XHes2-Varianten sind, wie unter den Konstrukten dargestellt, farbig hervorgehoben.

Die induzierbaren XHes2-Varianten wurden zur funktionellen Analyse von XHes2 bei der neuralen Differenzierung späterer Entwicklungsprozesse, wie z.B. der frühen Retinogenese, eingesetzt. Dazu wurden sie in Xenopus-Embryonen überexprimiert und in Midneurulastadien durch Dexamethason induziert. Die Effekte auf Regulatoren der Neurogenese wurden mittels wmISH in Embryonen und mittels RT-PCR in animalen Kappen untersucht. 


\subsection{Effekte der induzierbaren XHes2-Varianten in frühen Schwanzknospenstadien}

Um die Funktion von XHes2 in späteren Entwicklungsstadien, besonders hinsichtlich der frühen Retinogenese, zu analysieren, wurden die Effekte von im Midneurulastadium induzierten XHes2-Varianten auf die Expression von NeuroD und Pax2 in frühen Schwanzknospenstadien mittels wmISH analysiert (Abb.2-15, Tab.2-4). NeuroD schien zur Beurteilung der Effekte auf die spätere Neurogenese interessant, da es u.a. in differenzierenden Retinoblasten der undifferenzierten neuralen Retina exprimiert wird (Kanekar et al., 1997); auch XHes2 wird in der undifferenzierten Retina exprimiert. Zudem wurde die NeuroD-Transkription in Neurulastadien durch ektopisches XHes2 reprimiert und durch ektopisches XHes2- $\Delta$ W-VP16 aktiviert. Pax2, das, ähnlich wie XHes2, u.a. in der dorsalen Ohrplakode exprimiert wird (Heller und Brändli, 1997), wurde dagegen sowohl durch die Überexpression von XHes2 als auch durch ektopisches XHes2- $\Delta \mathrm{W}$ VP16 in Neurulastadien gehemmt und zeigte somit ein von NeuroD abweichendes Verhalten in der Transkriptionsregulation durch XHes2.

Die Induktion von XHes2-GR im Stadium 17 resultierte unerwarteterweise in keiner signifikanten Veränderung der NeuroD-Expression im Stadium 26 (Abb.2-15B1,2). Allerdings zeigte ein kleiner prozentualer Anteil der induzierten und der nicht-induzierten Embryonen eine Reduktion NeuroD-positiver Zellen auf der injizierten Seite, was auf eine unvollständige Inaktivierung des Fusionsproteins zurückzuführen sein wird (Tab.2-4). Ähnliche Ergebnisse wurden in Embryonen beobachtet, die im Stadium 30 analysiert wurden (Daten nicht gezeigt). Selbst bei früherer Induktion von XHes2-GR im Stadium 11 konnte nur in ungefähr der Hälfte der Embryonen im Stadium 30 eine vorwiegend partielle Reduktion der NeuroD-Expressionsdomänen beobachtet werden (Daten nicht gezeigt). Auch die Expression von Pax2 wies infolge der Induktion von XHes2-GR im Stadium 17, wie die von NeuroD, keinerlei Veränderungen im Stadium 26 auf (Abb.2-15C1,2). Diese Daten sprechen gegen eine Repression von NeuroD und Pax2 durch im Stadium 17 induziertes XHes2-GR in der Retina früher Schwanzknospenstadien. Die Überexpression von induziertem NLS-XHes2-DBM-GR hatte, wie XHes2-GR, keinen Einfluß auf die NeuroD-Transkription (Abb.2-15B5,6). Dies konnte jedoch nicht interpretiert werden, da bei der Induktion von XHes2-GR kein Effekt beobachtet wurde.

Im Gegensatz dazu bedingte die Induktion von XHes2- $\Delta$ W-GR und XHes2- $\Delta$ W-VP16-GR im Stadium 17 eine deutliche Veränderung der NeuroD-Expression in frühen Schwanzknospenstadien. Infolge der Induktion von XHes2- $\Delta$ W-GR war die Anzahl NeuroD-positiver Zellen innerhalb der Expressionsdomänen deutlich erhöht (Abb.2- 
15B7,8), was darauf hindeutet, dass aktives, ektopisches XHes2- $\Delta \mathrm{W}$-GR durch das Fehlen des WPRW-Motivs eine endogene Repression der NeuroD-Transkription in der 


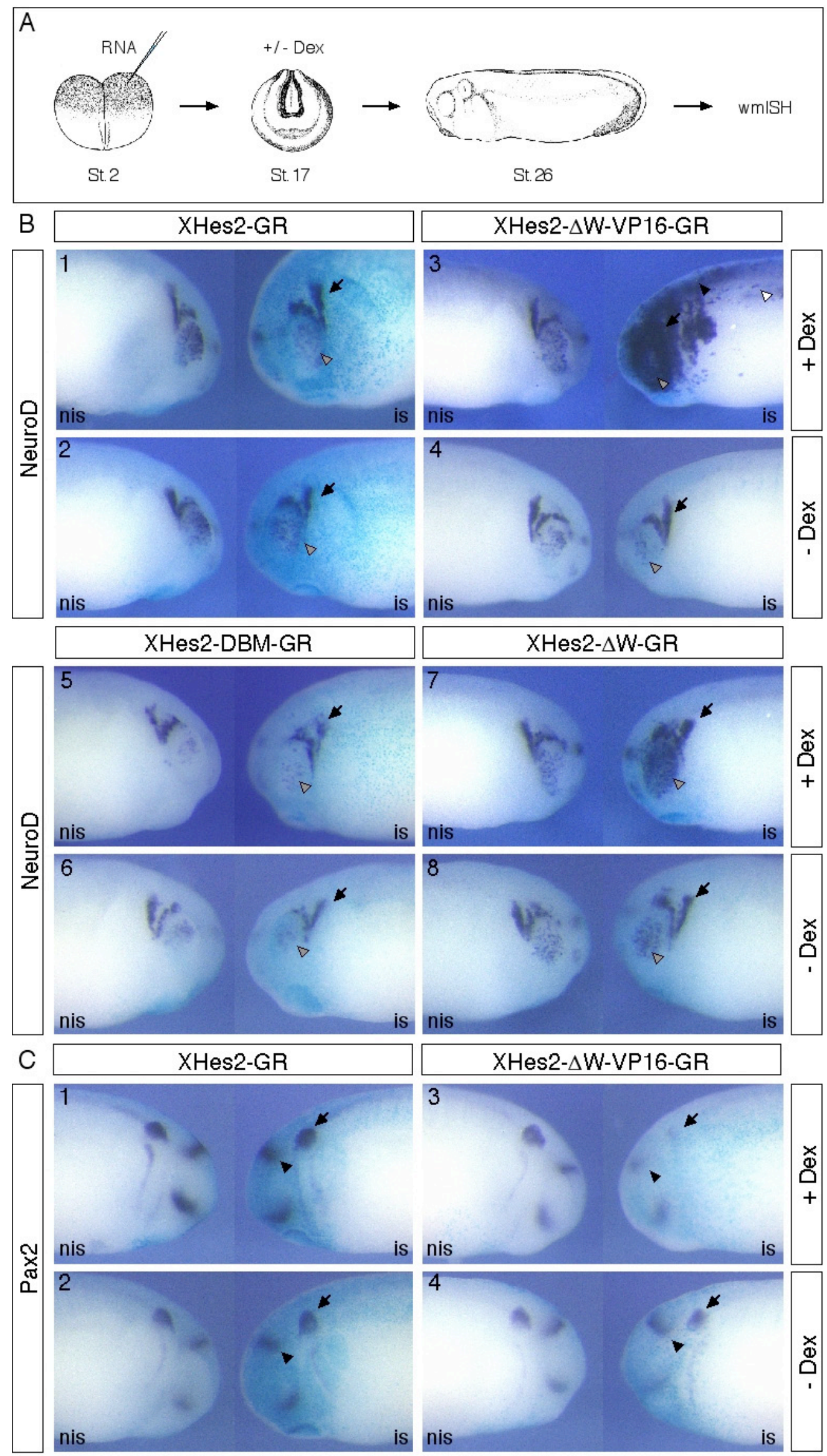


Abb.2-15: Die Induktion von XHes2-AW-VP16-GR im späten Neuralfaltenstadium aktiviert die NeuroDTranskription ektopisch und reprimiert die Pax2-Transkription in frühen Schwanzknospenstadien.

Auswirkungen von in St.17 induzierten XHes2-Varianten auf die Expression von NeuroD und Pax2 in St.26Embryonen analysiert mittels wmISH. (A) Schematische Darstellung der experimentellen Strategie. Verschiedene RNAs (siehe 15B) wurden im animalen, polnahen Bereich in eine Blastomere des Zwei-ZellStadiums (St.2) von Xenopus laevis-Embryonen injiziert. Im St.17 wurde zu der Hälfte der injizierten Embryonen Dexamethason zur Induktion der Fusionsproteine hinzugefügt, während die andere Hälfte unbehandelt blieb. Induzierte und nicht-induzierte Embryonen wurden dann bis zum Erreichen des Stadiums 26 kultiviert und mittels wmISH analysiert. $(B, C)$ wmISH-Analyse nach Überexpression Hormon-induzierbarer XHes2-Varianten. (B)NeuroD-Expression. (1) Bei Induktion von XHes2-GR im Stadium 17 ist die Expression von NeuroD unverändert. (3) Induziertes XHes2- $\Delta$ W-VP16-GR aktiviert die NeuroD-Transkription ektopisch in ZNS, Neuralleisten und Ektoderm. (5) Die Induktion von NLS-XHes2-DBM-GR hat keinen Einfluß auf NeuroD. (7) Induziertes XHes2- $\Delta \mathrm{W}$-GR erhöht die Dichte NeuroD-positver Zellen innerhalb der Expressionsdomänen. (B2,4,6,8) Ohne Dexamethason-kultivierte Embryonen zeigen keine Veränderung der NeuroD-Expression. (C) Pax2-Expression. (1) In St.17 induziertes XHes2-GR hat keinen Einfluß auf das Pax2-Expressionsmuster. (3) Die Induktion von XHes2- $\Delta$ W-VP16-GR blockiert die Transkription von Pax2. $(\mathrm{C} 2,4)$ Ohne Dexamethason-kultivierte Embryonen zeigen keine Veränderung der Pax2-Expression. Die injizierten RNAs sind jeweils über den Fotos und die untersuchten Genexpressionen jeweils links der Fotos angegeben. Ob die Embryonen mit Dexamethason (+Dex) oder ohne (-Dex) als Vergleichspool kultiviert wurden, ist rechts der Fotos dargestellt. Die Embryonen sind wie folgt orientiert: Seitenansicht, dorsal oben. Abkürzungen und Symbole: nis, nicht-injizierte Seite; is, injizierte Seite; schwarzer Pfeil, Trigeminus (B) oder Ohrvesikel (C); graue Pfeilspitze, Retina; schwarze Pfeilspitze, ektopische Expression in Hirn und Rückenmark (B) oder Expression in Mittel-/Hinterhirn-Grenze (C); weiße Pfeilspitze, ektopische Expression in Epidermis.

\begin{tabular}{|c|c|c|c|c|}
\hline injizierte RNA & XHes2-GR & NLS-XHes2-DBM-GR & XHes2- $\Delta$ W-GR & XHes2- $\Delta$ W-VP16-GR \\
\hline Menge (pg) & 50 & 50 & 50 & 50 \\
\hline injizierte Zelle & $1 / 2 ; a$ & $1 / 2 ; a$ & $1 / 2 ; a$ & $1 / 2 ; a$ \\
\hline wmISH-Stadium & 26 & 26 & 26 & 26 \\
\hline $\begin{array}{c}\text { + Dex Anzahl NeuroD } \\
=/ \downarrow / \uparrow(\%)\end{array}$ & $\begin{array}{c}16 \\
75 / 25 / 0\end{array}$ & $\begin{array}{c}12 \\
100 / 0 / 0\end{array}$ & $\begin{array}{c}24 \\
4 / 0 / 96\end{array}$ & $\begin{array}{c}26 \\
0 / 0 / 100^{*}\end{array}$ \\
\hline $\begin{array}{c}\text { - Dex Anzahl NeuroD } \\
=/ \downarrow / \uparrow(\%)\end{array}$ & $\begin{array}{c}15 \\
80 / 20 / 0\end{array}$ & $\begin{array}{c}12 \\
100 / 0 / 0\end{array}$ & $\begin{array}{c}18 \\
83 / 11 / 6\end{array}$ & $\begin{array}{c}13 \\
100 / 0 / 0\end{array}$ \\
\hline $\begin{array}{c}\text { + Dex Anzahl Pax2 } \\
=/ \downarrow / \uparrow(\%)\end{array}$ & $\begin{array}{c}18 \\
100 / 0 / 0\end{array}$ & n.a. & n.a. & $\begin{array}{c}14 \\
0 / 100 / 0\end{array}$ \\
\hline $\begin{array}{c}\text { - Dex Anzahl Pax2 } \\
=/ \downarrow / \uparrow(\%)\end{array}$ & $\begin{array}{c}12 \\
100 / 0 / 0\end{array}$ & n.a. & n.a. & $\begin{array}{c}20 \\
100 / 0 / 0\end{array}$ \\
\hline
\end{tabular}

Tab.2-4: Effekte überexprimierter induzierbarer XHes2-Varianten in St.26-Embryonen. Abkürzungen und Symbole: St., Stadium; +Dex, Induktion mit Dexamethason; -Dex, keine Induktion mit Dexamethason; Anzahl NeuroD, Anzahl der mittels wmISH (NeuroD-Expression) analysierten Embryonen; =, Expression unverändert; $\downarrow$, weniger bis keine positiven Zellen in Expressionsdomäne; $\uparrow$, mehr positive Zellen in Expressionsdomäne; a, animal; n.a., nicht analysiert; *, ektopische Expression in Neuroektoderm und Ektoderm.

undifferenzierten Retina unterbinden kann. Induziertes XHes2- $\Delta$ W-VP16-GR war fähig, die NeuroD-Transkription ektopisch in nahezu allen Zellen neuroektodermaler und ektodermaler Derivate, wie ZNS, Augen, Neuralleisten und Epidermis, zu aktivieren (Abb.2-15B3,4). Dies zeigt, dass die ektopische Expression von NeuroD durch antimorphe XHes2-Varianten, wie XHes2- $\Delta$ W-VP16, nicht nur auf das Ektoderm begrenzt ist. Die Pax2-Transkription wurde hingegen durch im Stadium 17 induziertes XHes2- $\Delta \mathrm{W}$ VP16-GR in frühen Schwanzknospenstadien reprimiert (Abb.2-15C3,4), was auf einen anderen Regulationsmechanismus durch XHes2 hinweist.

Da diese Effekte auf die NeuroD- bzw. Pax2-Expression im Widerspruch zu den oben beschriebenen Ergebnissen mit der XHes2-GR-Variante stehen, sind weitere Experimente notwendig, um zu klären, ob die Induktion von überexprimiertem XHes2-GR im Stadium 17 tatsächlich keinen Effekt auf die NeuroD- und Pax2-Expression im Stadium 
26 hat und, wenn dies zutrifft, bis zu welchem Induktionsstadium eine Repression von NeuroD und Pax2 möglich ist.

\subsection{Effekte von induzierbarem XHes2-AC-VP16-GR in ektodermalen Explantaten}

Die simultane Transkriptionsaktivierung von X-Ngnr-1, NeuroD und ESR1 durch Überexpression von XHes2- $\triangle$ C-VP16 in ektodermalen Explantaten ließ die Frage aufkommen, ob diese Gene direkt durch XHes2- $\Delta$ C-VP16 induziert werden können und somit XHes2-Zielgene darstellen. Aufgrund der Expression von XHes2 in verschiedenen Plakoden schien es ferner interessant, zu hinterfragen, ob die Induktion dieser Gene auch in älterem, bereits differenzierendem Ektoderm möglich ist. Um diesen Fragen nachzugehen, wurden die Auswirkungen der Dexamethason-Induktion von überexprimiertem XHes2- $\Delta$ C-VP16-GR im Stadium 16 auf die Genexpression in ektodermalen Explantaten nach verschieden langer Kultivierung mittels RT-PCR untersucht (Abb.2-16).

Bereits 3 Stunden nach Dexamethason-Zugabe wurde im XHes2- $\Delta$ C-VP16-GR überexprimierenden animalen Kappenektoderm die Transkription von $X-N g n r-1$, NeuroD und ESR1 aktiviert, während Xath3 und $N$-tubulin erst nach 18 Stunden exprimiert wurden. MyoD-Transkripte waren in den Explantaten nicht nachweisbar. Diese Ergebisse zeigen, dass XHes2- $\triangle$ C-VP16-GR bereits kurz nach Induktion die Transkription von $X$ Ngnr-1, NeuroD und ESR1 ektopisch in ektodermalen Explantaten aktivieren kann, was darauf hindeutet, dass alle drei Gene direkte XHes2-Zielgene sind. Der endgültige Beweis durch eine Verkürzung der Induktionsdauer bzw. durch die Hemmung der Proteinsynthese steht allerdings noch aus, da NeuroD und vermutlich auch ESR1, im Gegensatz zu Xath3 und N-tubulin, direkt durch X-Ngnr-1 induziert werden können. Interessanterweise ist XHes2- $\Delta$ C-VP16-GR somit fähig, die Transkription von $X$-Ngnr-1, NeuroD und ESR1 nicht nur im undifferenzierten Ektoderm, sondern selbst im differenzierenden Ektoderm zu aktivieren. 


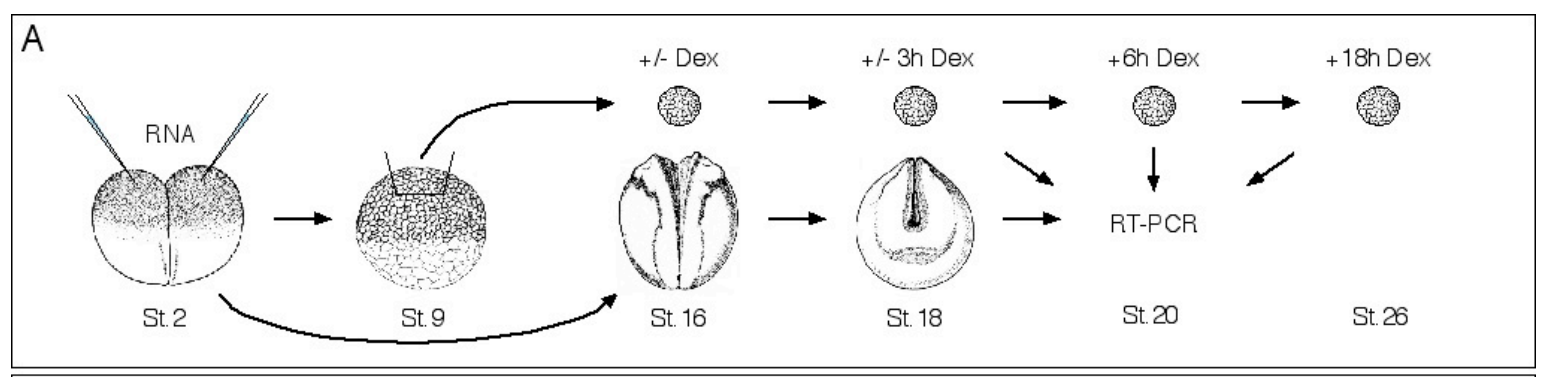

B

$\mathrm{H}_{2} \mathrm{O}$ E
\begin{tabular}{|c|c|c|c|c|c|l|}
\hline- & - & + & + & + & + & XHes2- $\Delta$ C-VP16-GR \\
\hline- & - & - & + & + & + & Dexamethason \\
\hline- & 3 & 3 & 3 & 6 & 18 & Inkubationszeit (h) \\
\hline
\end{tabular}

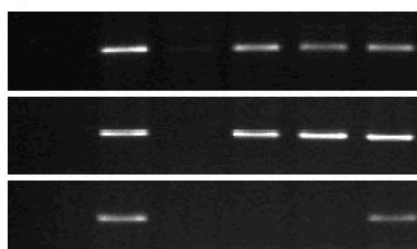

X-Ngnr-1

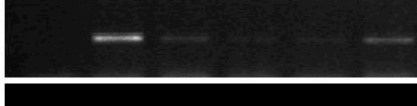

NeuroD

Xath3

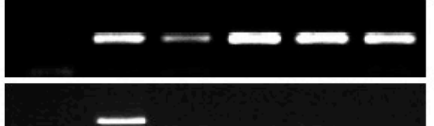

N-tubulin

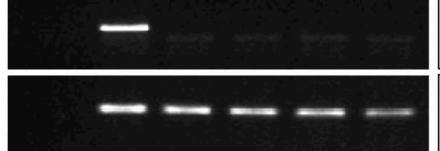

ESR1

MyoD

Histon $\mathrm{H} 4$

$\begin{array}{llllll}1 & 2 & 3 & 4 & 5 & 6\end{array}$

Abb.2-16: XHes2-AC-VP16-GR aktiviert bereits kurz nach Induktion die Transkription von X-Ngnr-1, NeuroD und $E S R 1$ in ektodermalen Explantaten.

Auswirkungen der Induktion von XHes2- $\Delta$ C-VP16-GR auf die Genexpression in unterschiedlich lang kultivierten animalen Kappen analysiert mittels semiquantitativer RT-PCR. (A) Schematische Darstellung der experimentellen Strategie. RNA (siehe 16B) wurde im animalen, polnahen Bereich in beide Blastomeren des Zwei-Zell-Stadiums (St.2) von Xenopus laevis-Embryonen injiziert, animale Kappen wurden im Stadium 9 (St.9) isoliert und solange kultiviert bis nicht-injizierte Kontrollembryonen das Stadium 16 (St.16) erreichten. Ein Viertel der Explantate wurde dann für drei weitere Stunden bei $18^{\circ} \mathrm{C}$ kultiviert, während zu den anderen drei Viertel der animalen Kappen Dexamethason zur Induktion der Fusionsproteine hinzugefügt wurde. Nach einer Inkubation von 3, 6 und 18 Stunden $(\mathrm{h})$ bei $18^{\circ} \mathrm{C}$ wurden die Hormon-behandelten Explantate für die RNA-Präparation gesammelt. Kontrollembryonen hatten zu diesen Zeitpunkten Stadium 18, 20 und 26 erreicht. Die aus den Explantaten (AKE) und Kontrollembryonen (E) gewonnenen RNA-Präparationen wurden dann mittels RT-PCR analysiert. (B) RT-PCR-Analyse. 3 Stunden nach Dexamethason-Zugabe wird im XHes2- $\triangle$ C-VP16-GR überexprimierendem AKE die Transkription von X-Ngnr-1, NeuroD und ESR1 aktiviert (Spur 4 vs. 3), während Xath3 und $N$-tubulin erst nach 18 Stunden exprimiert werden (Spur 6 vs. 3). MyoDTranskripte sind in den Explantaten nicht nachweisbar (Spur 4-6 vs. 3). Die injizierten RNAs sind über den jeweiligen DNA-Spuren angegeben. Wasser $\left(\mathrm{H}_{2} \mathrm{O}\right)$ wurde anstelle von RNA als Negativkontrolle (Spur 1) und Stadium 18 RNA als Positivkontrolle (Spur 2) eingesetzt. Alle RNA-Präparationen sind frei von Verunreinigungen mit genomischer DNA (nicht gezeigt). Zur Überprüfung der eingesetzten RNA-Menge wurde die Expression von Histon $\mathrm{H} 4$ analysiert. Dexamethason-induzierte XHes2- $\Delta$ C-VP16-GR injizierte animale Kappen wurden mit injizierten, aber nicht induzierten Explantaten verglichen. RNA/Embryo: 25pg XHes2- $\Delta$ CVP16-GR. RT-PCR Primer/Produktlängen ESR1: ESR1_RT1F/ESR1_RT1R/225bp, Histon H4: H4_RTF/H4_RTR/188bp, MyoD: MyoD_RTF/MyoD_RTR/291bp, NeuroD: NeuroD_RTF/NeuroD_RTR/238bp, N-tubulin: N-tubulin_RTF/N-tubulin_RTR/250bp, Xath3: Xath3_RT1F/Xath3_RT1R/250bp, X-Ngnr-1: X-Ngnr1_RTF/X-Ngnr-1_RT̄R/334bp. 


\subsubsection{3 Überexpression von XHes2 und X-Ngnr-1 bzw. NeuroD in Xenopus- Embryonen}

Die bisher erhaltenen Daten zeigen, dass ektopisches XHes2 die Transkription von $X$ Ngnr-1 und seiner Zielgene reprimiert. Da aber, aufgrund der gleichzeitigen Aktivierung von NeuroD und $X$-Ngnr-1 durch induzierbares XHes2- $\Delta$ W-VP16-GR in ektodermalen Explantaten, neben $X$-Ngnr-1 auch NeuroD ein direktes Zielgen von XHes2 sein könnte, stellte sich die Frage, ob XHes2, wie andere bHLH-O-Proteine (Schneider et al., 2001; Chalmers et al., 2002; Taelman et al., 2004), die Neurogenese auch unterhalb von $X$ Ngnr-1 hemmen kann. Um die Ebenen unterhalb der X-Ngnr-1-Transkription genauer zu beleuchten, wurde XHes2 zusammen mit X-Ngnr-1 oder NeuroD in Xenopus-Embryonen überexprimiert und der Einfluß von XHes2 auf die Aktivitäten der beiden proneuralen Faktoren mittels wmISH analysiert (Abb.2-17, Tab.2-5).

Als erstes wurden die Auswirkungen von XHes2 auf die Aktivität von X-Ngnr-1 im Hinblick auf die $N$-tubulin-Expression untersucht. Die Fähigkeit von X-Ngnr-1, $N$-tubulin ektopisch zu induzieren (Abb.2-17B1), konnte durch die Coexpression von XHes2 abhängig von der injizierten XHes2-RNA-Menge entweder partiell (Abb.2-17B2) oder komplett (Abb.217B3) unterdrückt werden. Somit ist XHes2 in der Lage, die Aktivität von X-Ngnr-1, die in der Induktion $\mathrm{N}$-tubulin-positiver Zellen besteht, zu blockieren.

Da die N-tubulin-Expression nicht direkt durch X-Ngnr-1 stimuliert wird, wohl aber die NeuroD-Expression (Perron et al., 1999), wurde der Effekt von XHes2 auf die Aktivität von X-Ngnr-1 anhand von NeuroD beurteilt. Auch die Aktivierung der NeuroD-Transkription durch ektopisches X-Ngnr-1 (Abb.2-17C1) konnte durch coexprimiertes XHes2 vollständig unterbunden werden, genauso wie die endogene NeuroD-Transkription (Abb.2-17C2), die durch XHes2 allein ebenfalls reprimiert wurde (Abb.2-17C3). Diese Ergebnisse legen nahe, dass die Neurogenese auch auf der Ebene der NeuroD-Transkription durch XHes2 gehemmt wird. Ob dies nur durch eine direkte Bindung von XHes2 in Form eines Homodimers an den Promoter, vielleicht sogar in Konkurrenz zu X-Ngnr-1, geschieht, oder durch eine direkte Protein-Protein-Wechselwirkung von XHes2 und X-Ngnr-1, bleibt zu klären.

Da die N-tubulin-Expression nicht nur durch X-Ngnr-1, sondern auch durch NeuroD stimuliert werden kann, wurden die Auswirkungen von XHes2 auf die Aktivität von NeuroD hinsichtlich der $N$-tubulin-Transkription analysiert. Die ektopische Induktion von $N$-tubulin infolge der NeuroD-Überexpression (Abb.2-17D1) konnte durch gleichzeitig überexprimiertes XHes2 vollständig blockiert werden (Abb.2-17D2,3). Mit zunehmender XHes2-RNA-Menge wurde auch die endogene $N$-tubulin-Transkription verstärkt reprimiert 
(Abb.2-17D3, Tab.2-5). Diese Daten zeigen, dass XHes2 ebenfalls der $\mathrm{N}$-tubulin induzierenden Aktivität von NeuroD entgegenwirken kann.

Zusammenfassend läßt sich sagen, dass XHes2 die Neurogenese nicht nur durch die Repression der X-Ngnr-1-Transkription hemmen kann, sondern ebenfalls in der Lage ist, die Aktivität von X-Ngnr-1, Z.B durch Repression der NeuroD-Transkription, und von NeuroD zu blockieren.

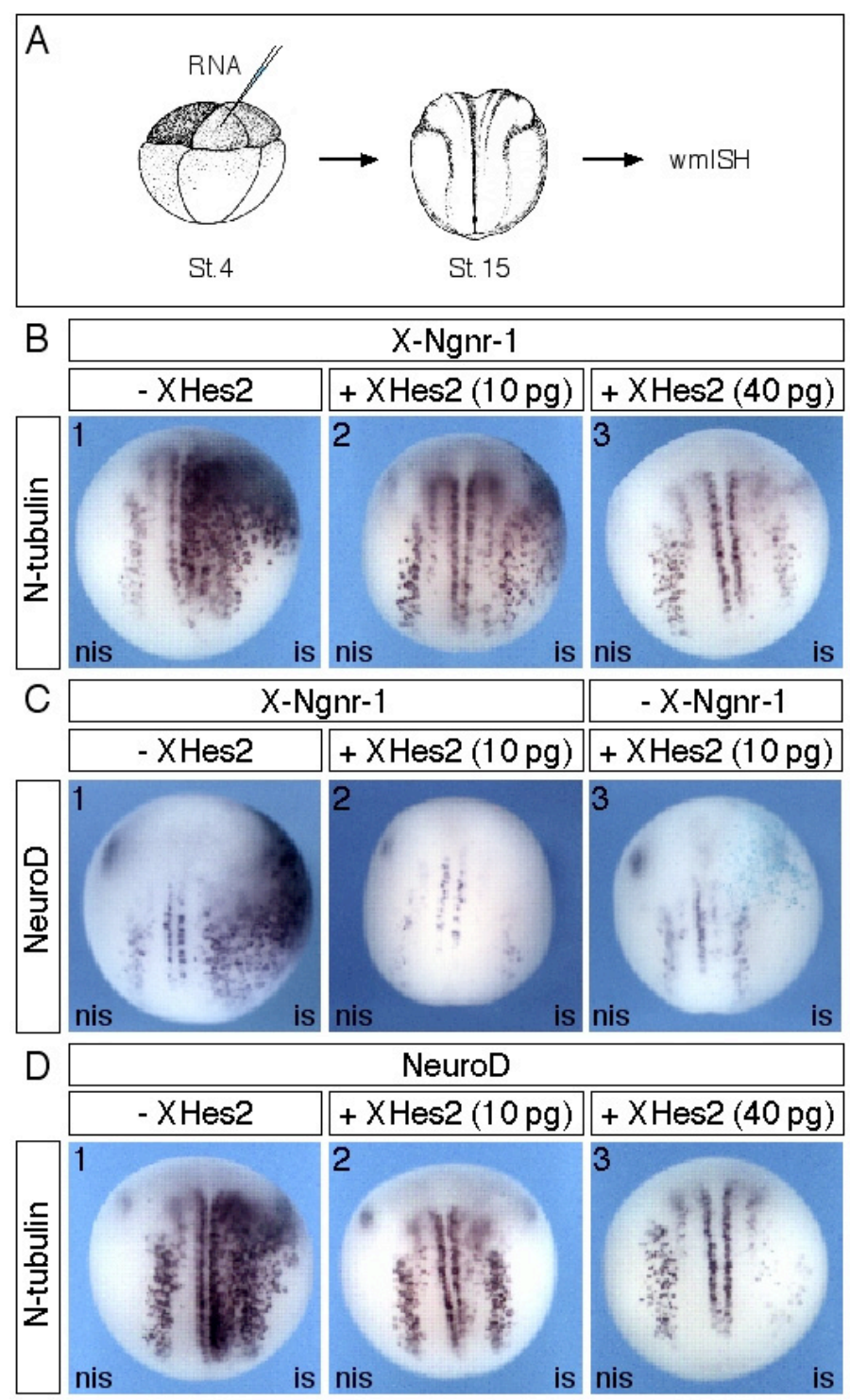

Abb.2-17: XHes2 hemmt die Aktivität von X-Ngnr-1 und NeuroD in frühen Neurulastadien.

Auswirkungen von XHes2 auf die Aktivität von X-Ngnr-1 und NeuroD, speziell die ektopische Expression von $\mathrm{N}$-tubulin und NeuroD, im offenen Neuralplattenstadium (St.14/15) von Xenopus laevis-Embryonen analysiert mittels wmISH. (A) Schematische Darstellung der experimentellen Strategie. Verschiedene RNAs (siehe 17B) wurden in die animale, dorsale Blastomere des Acht-Zell-Stadiums (St.4) von Xenopus laevis-Embryonen injiziert. Diese wurden bis zum Stadium 14/15 kultiviert und mittels wmISH analysiert. (B-D) wmISH-Analyse nach Überexpression von X-Ngnr-1 bzw. NeuroD und XHes2. (B,D) Effekte auf die N-tubulin-Expression. XHes2 reduziert konzentrationsabhängig die Anzahl und Dichte der durch X-Ngnr-1 und NeuroD induzierten $N$-tubulin-positiven Zellen bis hin zur kompletten Hemmung der ektopischen X-Ngnr-1 und NeuroD-Aktivität, sowie der endogenen $\mathrm{N}$-tubulin-Expression. (C) Effekte auf die NeuroD-Expression. $(\mathrm{C} 1,2)$ XHes2 reprimiert die durch X-Ngnr-1 aktivierte NeuroD-Transkription, nicht nur die exogene, sondern auch die endogene. (C3) XHes2 hemmt die endogene NeuroD-Expression. Die injizierten RNAs, teilweise mit Angabe der injizierten Menge, sind jeweils über den Fotos und die untersuchten Genexpressionen jeweils links der Fotos angegeben. Die Embryonen sind wie folgt orientiert: dorsale Aufsicht, anterior oben. Abkürzungen und Symbole: is, injizierte Seite; nis, nicht-injizierte Seite. 


\begin{tabular}{|c|c|c|c|c|c|c|c|}
\hline injizierte RNA & XHes2 & X-Ngnr-1 & $\begin{array}{l}\text { X-Ngnr-1 } \\
+ \text { XHes2 }\end{array}$ & $\begin{array}{l}\text { X-Ngnr-1 } \\
+ \text { XHes2 }\end{array}$ & NeuroD & $\begin{array}{l}\text { NeuroD } \\
+ \text { XHes2 }\end{array}$ & $\begin{array}{l}\text { NeuroD } \\
+ \text { XHes2 }\end{array}$ \\
\hline Menge (pg) & 10 & 10 & $10+10$ & $10+40$ & 100 & $100+10$ & $100+40$ \\
\hline injizierte Zelle & $1 / 8 ; \mathrm{ad}$ & $1 / 8 ; \mathrm{ad}$ & $1 / 8 ; \mathrm{ad}$ & $1 / 8 ; \mathrm{ad}$ & $1 / 8 ; a d$ & $1 / 8 ; \mathrm{ad}$ & $1 / 8 ; \mathrm{ad}$ \\
\hline wmISH-Stadium & 14 & 14 & 14 & 14 & 14 & 14 & 14 \\
\hline $\begin{array}{l}\text { Anzahl N-tubulin } \\
=/ \downarrow / \uparrow(\%)\end{array}$ & $\begin{array}{c}16^{12} \\
12,5 / 87,5 / 0\end{array}$ & $\begin{array}{c}19^{11} \\
0 / 0 / 100^{*}\end{array}$ & $\begin{array}{c}17 \\
33 / 28 / 39^{*}\end{array}$ & $\begin{array}{c}17 \\
70 / 29 / 0\end{array}$ & $\begin{array}{c}19 \\
5 / 0 / 95^{\star}\end{array}$ & $\begin{array}{c}20 \\
50 / 50 / 0\end{array}$ & $\begin{array}{c}17 \\
6 / 94 / 0\end{array}$ \\
\hline $\begin{array}{l}\text { Anzahl NeuroD } \\
=/ \downarrow / \uparrow(\%)\end{array}$ & $\begin{array}{c}12 \\
0 / 100 / 0\end{array}$ & $\begin{array}{c}15 \\
7 / 0 / 93^{*}\end{array}$ & $\begin{array}{c}11 \\
9 / 91 / 0\end{array}$ & $\begin{array}{c}7 \\
0 / 100 / 0\end{array}$ & n.a. & n.a. & n.a. \\
\hline
\end{tabular}

Tab.2-5: Effekte von XHes2 auf die Aktivität von X-Ngnr-1 und NeuroD in Embryonen. Abkürzungen und Symbole: Anzahl N-tubulin, Anzahl der mittels wmISH (N-tubulin Expression) analysierten Embryonen; =, Expression unverändert; $\downarrow$, weniger bis keine positiven Zellen in Expressionsdomäne; $\uparrow$, mehr positive Zellen in Expressionsdomäne; a, animal; $d$, dorsal; n.a., nicht analysiert; ${ }^{\mathrm{T}}{ }^{\mathrm{T} 2}$, entspricht der jeweiligen Analyse aus Tabelle 1 bzw. Tabelle 2; ${ }^{*}$, ektopisch in Neuroektoderm und Ektoderm. 


\subsubsection{Gezielte Hemmung der XHes2-Proteinsynthese in Xenopus-Embryonen}

Überexpressionsstudien von Protein-Varianten in Xenopus-Embryonen geben Aufschluß über die Aktivität des Proteins im untersuchten Entwicklungskontext, jedoch sind aufgrund des Vorkommens verwandter Proteine mit gleicher oder überlappender Funktion unspezifische Effekte nicht auszuschließen. Die gezielte Translationshemmung eines Proteins durch Mikroinjektion spezifischer antisense-Morpholino-Oligonukleotide in Xenopus-Embryonen stellt hingegen eine neuere und spezifischere Methode der Funktionsanalyse dar (Heasman, 2002) und wurde daher auch für erste weitere Untersuchungen zur Funktion von XHes2 eingesetzt.

Für die gezielte Hemmung der XHes2-Proteinsynthese wurde ein XHes2-spezifisches antisense-Morpholino-Oligonukleotid (XHes2-MO) eingesetzt, das an die 5'-UTR der XHes2-mRNA bindet (Abb.2-18A). Die Wirksamkeit und Spezifität dieses MorpholinoOligonukleotids wurde in vitro in einem Retikulocyten-Transkriptions-/Translationssystem überprüft (Abb.2-18B,C). XHes2-MO konnte im Gegensatz zu einem Standard-KontrollMorpholino-Oligonukleotid (KoMO) oder einem ESR9-spezifischen MorpholinoOligonukleotid (ESR9-MO) die Proteinsynthese von XHes2 konzentrationsabhängig hemmen (Abb.2-18B). Die Translation von ESR9 wurde hingegen durch XHes2-MO nicht blockiert (Abb.2-18C). Diese Daten zeigen, dass XHes2-MO in vitro die Proteinsynthese von XHes2 spezifisch hemmen kann.

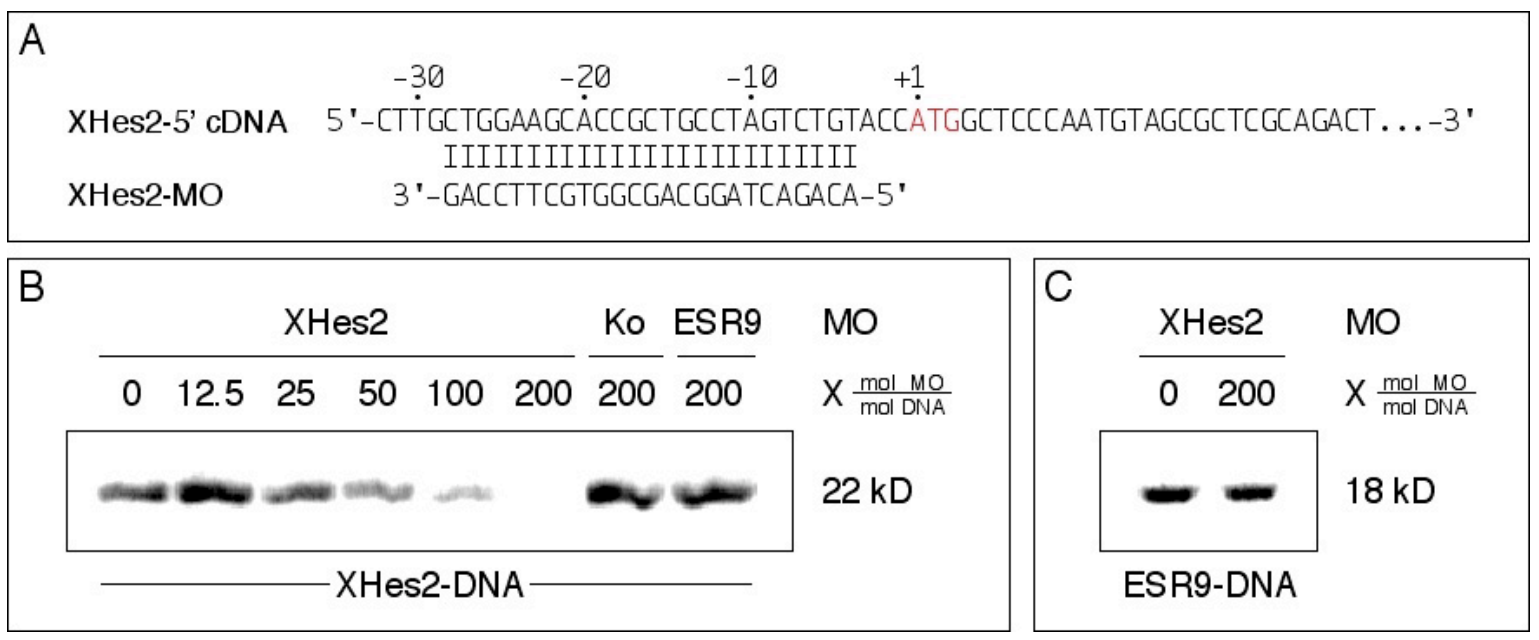

Abb.2-18: XHes2-MO bewirkt eine spezifische Hemmung der XHes2-Translation in vitro.

(A) Darstellung des XHes2-MO revers komplementären Bereichs in der XHes2-cDNA. Das XHes2-MO bindet (I) vor dem Startcodon (rot hervorgehoben) in der 5'-UTR von XHes2. Positionen in der translatierten Region sind mit positiven Zahlen, Positionen in der 5'-untranslatierten Region mit negativen Zahlen angegeben. (B,C) SDS-PAGE-Analyse der in vitro Transkription und Translation ( ${ }^{35}$ S-Met-Markierung) mit und ohne MOs . Die verwendete Plasmid-DNA ist unterhalb der Protein-Spuren angegeben, die eingesetzten MOs und deren relatives molares Verhältnis $(X)$ zur Plasmid-DNA sind oberhalb der Protein-Spuren dargestellt. Das Molekulargewicht der Proteine ist rechts zu finden. (B) Die in vitro Translation von XHes2 kann durch XHes2$\mathrm{MO}$, nicht aber durch ein Standard-Kontroll-MO (KoMO) oder ESR9-MO spezifisch und konzentrationsabhängig gehemmt werden. (C) Das XHes2-MO hat keinen Einfluß auf die in vitro Translation von ESR9. 
Das XHes2-spezifische Morpholino-Oligonukleotid wurde zur Blockierung der XHes2Funktion, genauer zur Hemmung der XHes2-Translation, in Xenopus-Embryonen injiziert, gefolgt von der Analyse der Auswirkungen auf die neuronale Differenzierung mittels wmISH.

\subsection{Effekte von XHes2-MO in frühen Neurulastadien}

XHes2 wird in frühen Neurulastadien nicht in den typischen Domänen der primären Neurogenese exprimiert, wie z.B. ESR1 (Abb.2-7A13), sondern nur in bestimmten lateralen und medialen Zellpopulationen im dorsalen Ektoderm und zwar erst zu einem Zeitpunkt, wenn die ersten Neuronen bereits differenzieren (Abb.2-5F,G). Dies deutet darauf hin, dass XHes2 keine generelle Rolle bei der Selektion zukünftiger primärer Neuronen spielt, die durch die Notch-vermittelte laterale Hemmung kontrolliert wird. Da aber in früheren Stadien XHes2-Transkripte im animalen Ektoderm vorhanden sind (Abb.2-5C,E), aus dem neuroektodermale Zellen entstehen, schien es interessant, die Effekte der Injektion von XHes2-MO auf die primäre Neurogenese in Xenopus-Embryonen mittels wmISH zu untersuchen (Abb.2-19, Tab.2-6). Wie bei der Überexpression der XHes2-Varianten wurden $X$-Ngnr-1, N-tubulin und XSox3 analysiert.

Infolge der Injektion des XHes2-spezifischen antisense-Morpholino-Oligonukleotids war die Expression von $X$-Ngnr-1 weder signifikant reduziert, noch verstärkt, aber erinnerte hinsichtlich der Form und Größe der trigeminalen Plakode und des größeren Abstands der lateralen, posterioren Expressionsdomäne zur Mittellinie an das X-Ngnr-1Expressionsmuster eines jüngeren Entwicklungsstadiums (Abb.2-19B2). Das injizierte Standard-Kontroll-Morpholino-Oligonukleotid hatte dagegen keinen Effekt auf X-Ngnr-1 (Abb.2-19B1), bedingte jedoch in einigen Embryonen eine leichte Reduktion der Anzahl $N$-tubulin-positiver Zellen und der N-tubulin-Expressionsstärke (Abb.2-19B3). Der gleiche, aber weitaus stärker ausgeprägtere Effekt auf $\mathrm{N}$-tubulin konnte in XHes2-MO-injizierten Embryonen beobachtet werden (Abb.2-19B). Die Tatsache, dass die einzelnen $N$-tubulinExpressionsdomänen an sich aber immer vorhanden waren, deutet darauf hin, dass die neuronale Entwicklung auf der XHes2MO-injizierten Seite deutlich verlangsamt stattfindet. Die verbreiterte $X$ Sox3-Neuralplattenexpression und die kleinere, aber nie komplett reprimierte plakodale $X$ Sox3-Expression infolge der Injektion von XHes2-MO (Abb.219B6) könnte ebenfalls auf eine verlangsamte neurale Entwicklung zurückzuführen sein. In Kontroll-Morpholino-injizierten Embyonen war die XSox3-Expression unverändert (Abb.2-19B5). Diese Daten zugrundelegend hat die Injektion von XHes2-MO keinen dramatischen Einfluß auf die primäre Neurogenese, aber bedingt eine verlangsamte neurale und neuronale Entwicklung. 


\begin{tabular}{|c|c|c|}
\hline injiziertes MO & KoMO & XHes2MO \\
\hline Menge (ng) & 20 & 20 \\
\hline injizierte Zelle & $1 / 2 ; a$ & $1 / 2 ; a$ \\
\hline wmISH-Stadium & 14 & 14 \\
\hline Anzahl X-Ngnr-1 & 12 & 17 \\
$=/ \downarrow / \uparrow(\%)$ & $83 / 17 / 0$ & $6 / 12 / 82^{\wedge}$ \\
\hline Anzahl N-tubulin & 13 & 16 \\
$=/ \downarrow / \uparrow(\%)$ & $69 / 31 / 0$ & $0 / 100 / 0$ \\
\hline Anzahl XSox3 & 16 & 20 \\
$=/ \downarrow / \uparrow(\%)$ & $81 / 6^{`} / 13^{*}$ & $0 / 100^{\circ} / 0$ \\
\hline
\end{tabular}

Tab.2-6: Effekte der XHes2-MO-Injektion auf die neurale und neuronale Entwicklung.

Abkürzungen und Symbole: MO, Morpholino-Oligonukleotid; Anzahl X-Ngnr-1, Anzahl der mittels wmISH (XNgnr-1 Expression) analysierten Embryonen; =, Expression unverändert; $\downarrow$, weniger positive Zellen in Expressionsdomäne (keine komplette Hemmung); $\uparrow$, mehr positive Zellen in Expressionsdomäne, KoMO, Standard-Kontroll-MO; a, animal; $\uparrow \wedge$, laterale Expressionsdomäne in posteriorer Neuralplatte auf der injizierten Seite hat einen größeren Abstand zur Mittellinie als auf der nicht-injizierten Seite und plakodale Expressionsdomäne ist größer, damit ähnelt die Expression der in jüngeren Stadien; $\downarrow$ ', nur schwache Reduktion in Plakodenregion; $\uparrow$ “, verbreiterte Neuralplattenexpression; $\downarrow \circ$, verkleinerte, aber nie vollständig reprimierte plakodale Expressionsdomäne einhergehend mit verbreiterter Neuralplattenexpression.
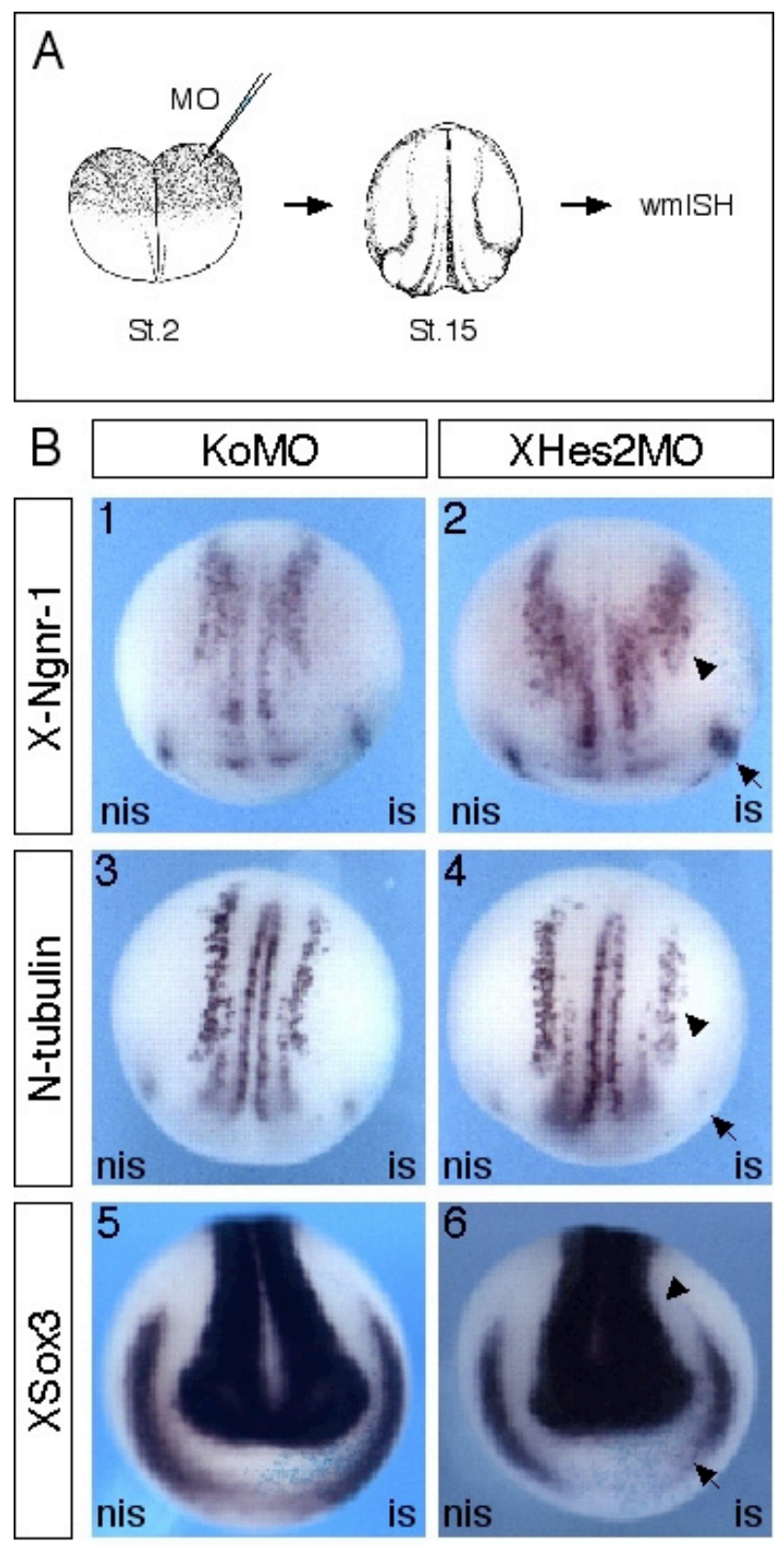

Abb.2-19: XHes2-MO verzögert die neurale und neuronale Entwicklung in Xenopus-Embryonen.

Auswirkungen der XHes2-MO-Injektion auf die Expression von $X$-Ngnr-1, $\mathrm{N}$-tubulin und $X$ Sox3 im offenen Neuralplattenstadium $(14 / 15)$ von Xenopus laevis-Embryonen analysiert mittels wmISH. (A) Schematische Darstellung der experimentellen Strategie. MOs (siehe 19B) wurden im animalen, polnahen Bereich in eine Blastomere des Zwei-Zell-Stadiums (St.2) von Xenopus laevis-Embryonen injiziert. Diese wurden bis zum Stadium 14/15 kultiviert und mittels wmISH analysiert. (B) wmISH-Analyse nach Injektion von KoMO und XHes2MO. Die XHes2-MO-Injektion bedingt eine Reduktion $N$-tubulin-positiver Zellen (4), sowie ein $X$ Ngnr-1-Expressionsmuster, das einem etwas früheren Stadium ähnelt (2). Die plakodale $X$ Sox3-Expressionsdomäne ist nach XHes2-MO-Injektion insgesamt kleiner, während die XSox3Expressionsdomäne innerhalb der Neuralplatte verbreitert ist (6). Die Expressionsmuster von X-Ngnr-1 und $X$ Sox3 sind infolge der KoMO-Injektion weitgehend unverändert $(1,5)$, die Anzahl $N$ tubulin-positiver Zellen ist leicht reduziert (3). Die injizierten MOs sind jeweils über den Fotos und die untersuchten Genexpressionen jeweils links der Fotos angegeben. Die Embryonen sind wie folgt orientiert: (B1-4) dorsale Aufsicht, anterior unten; (B5,6) anteriore Aufsicht, dorsal oben. Abkürzungen und Symbole: is, injizierte Seite; nis, nicht-injizierte Seite; schwarzer Pfeil, profundal-trigeminale Plakode $(B 2,4)$ bzw.Plakodenregion (B6) in anteriorer Neuralplatte; schwarze Pfeilspitze, primäre Neuronen in posteriorer Neuralplatte $(B 2,4)$ bzw. Neuralplatte (B6). 


\subsection{Effekte von XHes2-MO in späten Neurulastadien}

Um zu überprüfen, ob XHes2 eine Rolle bei der Regulation von NeuroD und Pax2 spielt, wie es die Überexpressionsstudien vermuten lassen, wurden die Auswirkungen der Injektion von XHes2-MO auf die Expression von NeuroD und Pax2 in späten Neurulastadien mittels wmISH analysiert (Abb.2-20, Tab.2-7).

Infolge der XHes2-MO-Injektion konnte sowohl eine verstärkte NeuroD-Expression im Neuralrohr als auch eine diffusere, weniger abgegrenzte NeuroD-Expression mit zusätzlichen positiven Zellen im Bereich der profundalen und trigeminalen Plakoden beobachtet werden (Abb.2-20C1-3). In KoMO-injizierten Embryonen war NeuroD unverändert (Abb.2-20B1-3). Die Aktivierung der NeuroD-Transkription durch die endogene Hemmung der XHes2-Proteinsynthese legt nahe, dass XHes2 die NeuroDExpression negativ reguliert. Im Gegensatz dazu war die Pax2-Expression durch XHes2MO im Neuralrohr und in der Ohrplakode stark reduziert bis komplett gehemmt (Abb.220E1-3). Die Injektion des Kontroll-Morpholinos hatte hingegen keinen Effekt auf Pax2 (Abb.2-20D1-3). Die negative Regulation der Pax2-Expression durch die endogene Hemmung der XHes2-Proteinsynthese läßt vermuten, dass XHes2 für die Transkription von Pax2 notwendig ist. Ähnlich wie in frühen Neurulastadien konnte auch in späten Neurulastadien infolge der XHes2-MO-Injektion, nicht aber infolge der KoMO-Injektion, eine langsamere Entwicklung festgestellt werden, die sich durch ein nur unvollständig geschlossenes Neuralrohr im Stadium 24 auszeichnete. Die deutlich verlangsamte Neurulation könnte auf die Notwendigkeit von XHes2 für die normale rechtzeitige, stadientypische Entwicklung des Neuroektoderms hindeuten.

\begin{tabular}{|c|c|c|c|c|}
\hline injiziertes MO & KoMO & XHes2MO & KoMO & XHes2MO \\
\hline Menge (ng) & 20 & 20 & 5 & 5 \\
\hline injizierte Zelle & $1 / 2 ; a$ & $1 / 2 ; a$ & $1 / 2 ; a$ & $1 / 2 ; a$ \\
\hline wmISH-Stadium & 24 & 24 & $25-26$ & $25-26$ \\
\hline $\begin{array}{l}\text { Anzahl NeuroD } \\
=/ \downarrow / \uparrow(\%)\end{array}$ & $\begin{array}{c}9 \\
78 / 22 / 0\end{array}$ & $\begin{array}{c}22 \\
18 / 0 / 82^{\wedge}\end{array}$ & $\begin{array}{c}7 \\
100 / 0 / 0\end{array}$ & $\begin{array}{c}15 \\
100 / 0 / 0\end{array}$ \\
\hline $\begin{array}{l}\text { Anzahl Pax2 } \\
=/ \downarrow / \uparrow(\%)\end{array}$ & $\begin{array}{c}8 \\
100 / 0 / 0 \\
\end{array}$ & $\begin{array}{c}20 \\
25 / 75^{\circ} / 0\end{array}$ & $\begin{array}{c}10 \\
100 / 0 / 0\end{array}$ & $\begin{array}{c}15 \\
100 / 0 / 0\end{array}$ \\
\hline
\end{tabular}

Tab.2-7: Effekte der XHes2-MO-Injektion in St.24-Embryonen. Abkürzungen und Symbole: MO, Morpholino-Oligonukleotid; Anzahl NeuroD, Anzahl der mittels wmISH (NeuroD-Expression) analysierten Embryonen; =, Expression unverändert; $\downarrow$, weniger bis keine positiven Zellen in Expressionsdomänen; $\uparrow$, mehr positive Zellen in Expressionsdomänen; KoMO, Standard-Kontroll-MO; a, animal; ^, diffusere Expression mit zusätzlichen positiven Zellen im Bereich der profundalen und trigeminalen Plakode, sowie verstärkte Expression im Neuralrohr, das nicht vollständig geschlossen ist; ${ }^{\circ}$, Reduktion von positiven Zellen vorwiegend in Ohrplakode und Neuralrohr (60/75\%), selten auch im Grenzbereich von Mittelhirn zu Hinterhirn $(15 / 75 \%)$. 

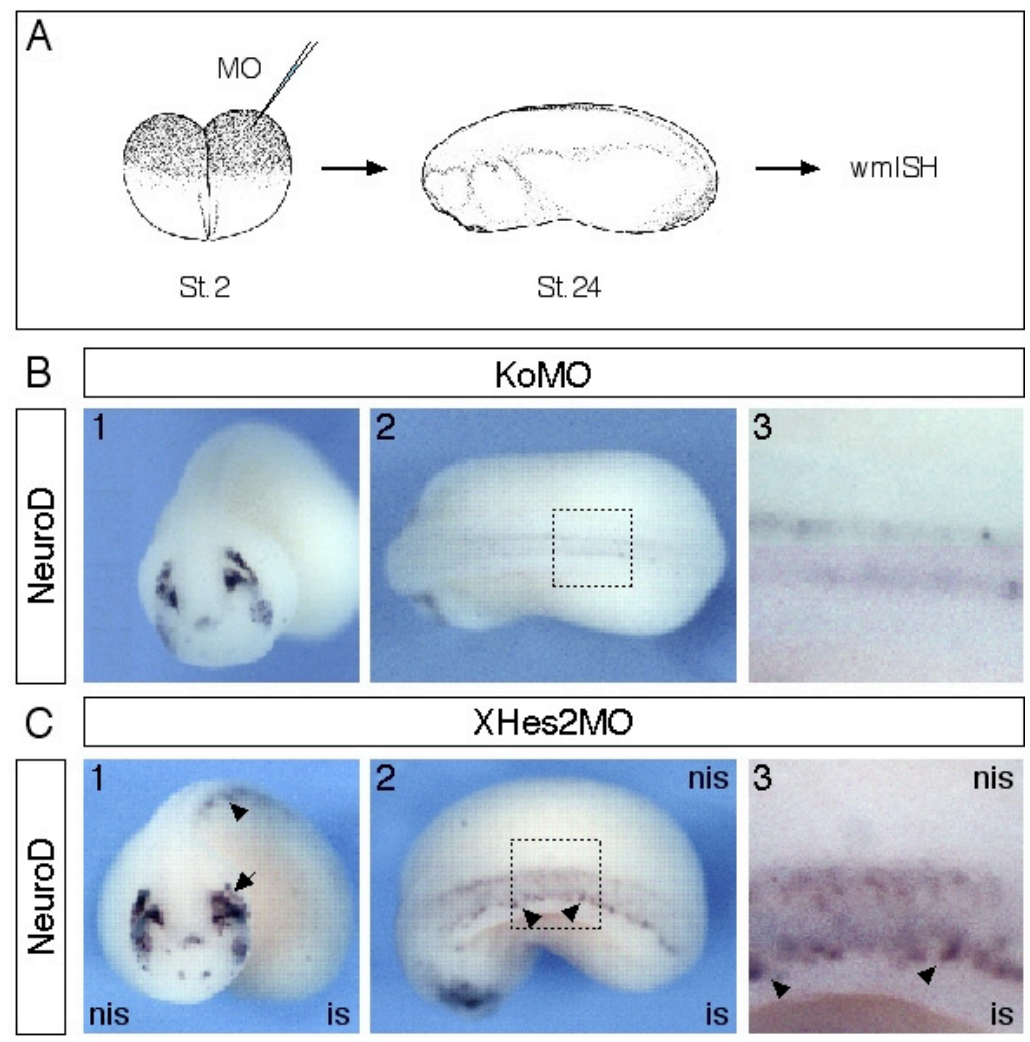

D
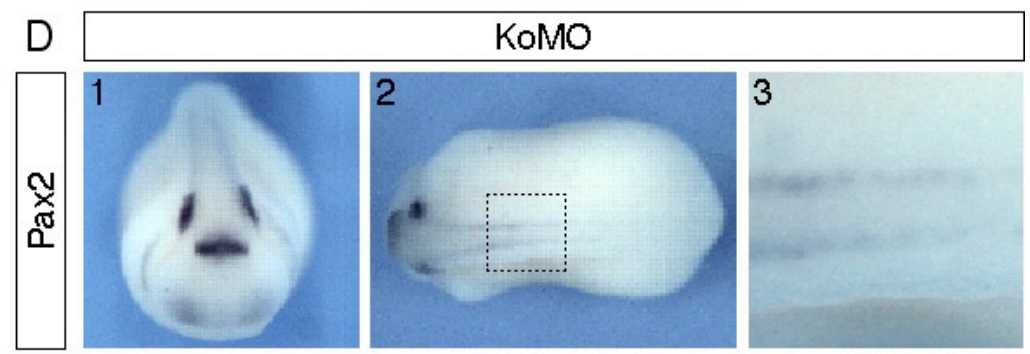

$\mathrm{E}$

XHes2MO
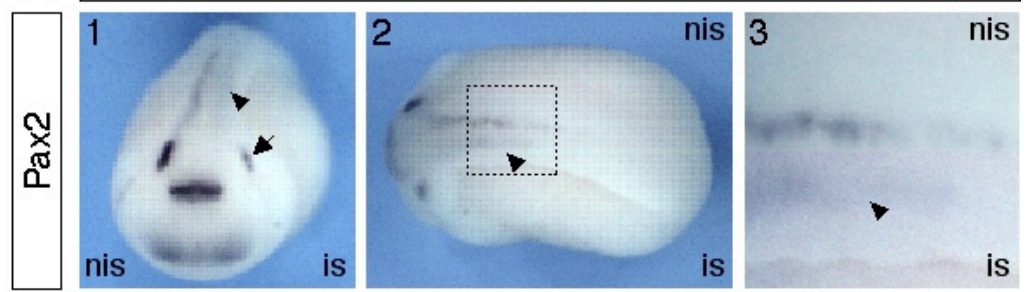

Abb.2-20: XHes2-MO hat einen positiven Effekt auf die NeuroD-Expression und einen negativen Effekt auf die Pax2-Expression meist einhergehend mit einem unvollständig geschlossenen Neuralrohr.

Auswirkungen der XHes2-MO-Injektion auf die Expression von NeuroD und Pax2 in St.24-Embryonen analysiert mittels wmISH. (A) Schematische Darstellung der experimentellen Strategie. MOs (siehe 20B-E) wurden im animalen, polnahen Bereich in eine Blastomere des Zwei-Zell-Stadiums (St.2) von Xenopus laevisEmbryonen injiziert. Diese wurden bis zum Stadium 24 kultiviert und mittels wmISH analysiert. (B-E) wmISHAnalyse nach Injektion von KoMO und XHes2-MO. Die Injektion von XHes2-MO resultiert in einer diffuseren, weniger abgegrenzten NeuroD-Expression mit zusätzlichen positiven Zellen im Bereich der profundalen und trigeminalen Plakoden, sowie einer verstärkte NeuroD-Expression im nicht vollständig geschlossenen Neuralrohr (C1-3). Die Pax2-Expression ist infolge der XHes2-MO-Injektion in Ohrplakode und Neuralrohr stark reduziert bis komplett gehemmt (E1-3). In KoMO-injizierten Embryonen ist die Expression von NeuroD (B1-3) und Pax2 (D1-3) unverändert. Die injizierten MOs sind jeweils über den Fotos und die untersuchten Genexpressionen jeweils links der Fotos angegeben. Die Embryonen sind wie folgt orientiert: (B-E1) anteriore Aufsicht, dorsal oben; (B-E2,3) dorsale Aufsicht, anterior links. Quadrate (B-E2) zeigen den jeweiligen Bildausschnitt, der vergrößert dargestellt ist (B-E3). Abkürzungen und Symbole: nis, nicht-injizierte Seite; is, injizierte Seite; schwarzer Pfeil, profundal-trigeminale Plakode (C1) bzw. Ohrplakode (E1); schwarze Pfeilspitze, Neuralrohr (C,E1-3). 


\subsection{Charakterisierung der Xenopus-bHLH-O-Proteine ESR8, ESR9 und ESR10}

Die während meiner Diplomarbeit durchgeführte Expressionsmuster-Durchmusterung einer embryonalen Xenopus-Schwanzspitzen-cDNA-Bank führte zur Identifizierung eines neuen Säuger-Hes5-ähnlichen bHLH-O-Gens, ESR8 (ehemals XTT182: Xairy), das außer in Regionen der Somitogenese vor allem in proneuronalen Domänen exprimiert wird und durch Notch und Neurogenin induzierbar ist. Die weitere funktionelle Charakterisierung von ESR8 zeigte, dass die ektopische Expression von ESR8, ähnlich der ektopischen Aktivierung des Notch-Signalwegs, die Transkription von Genen, die bei der neuronalen Differenzierung von Bedeutung sind, reprimiert (Sölter, 1999). Zur selben Zeit wurden bei der Expressionsmuster-Durchmusterung einer embryonalen Xenopus-Neurula-cDNABank zwei weitere Säuger-Hes5-ähnliche und durch Notch-induzierbare bHLH-O-Gene, ESR9 (ehemals 8C9) und ESR10 (ehemals 11A10), identifiziert, die, wie ESR8, in Regionen der Neurogenese und Somitogenese exprimiert werden (Gawantka et al., 1998; Li et al., 2003). Die Existenz dieser drei sehr ähnlichen bHLH-O-Gene ließ die Frage nach Gemeinsamkeiten und Unterschieden aufkommen. Daher wurde im Rahmen dieser Arbeit nicht nur die funktionelle Analyse von ESR8 während der Neurogenese fortgesetzt, sondern auch eine vergleichende Charakterisierung von ESR8, ESR9 und ESR10 durchgeführt.

\subsubsection{Strukturanalysen Säuger-Hes5-ähnlicher Proteine aus Xenopus}

\subsubsection{Sequenzvergleich von Säuger-Hes5-ähnlichen Proteinen aus Xenopus}

Wie bereits erwähnt, existieren in Xenopus laevis mehrere verschiedene bHLH-OProteine, die am ehesten dem Hes5-Protein aus Säugern ähneln (Abb.2-1, Abb.7-1, Tab.7-1,3) und damit der Vertebraten-Hes5-Gruppe angehören (Li et al., 2003). Neben ESR8, ESR9 und ESR10 zählen auch ESR1, ESR2, ESR3/7, ESR6 und ESR11 zu den insgesamt acht Mitgliedern der Hes5-Gruppe aus Xenopus laevis (Wettstein et al., 1997; Perron et al., 1998; Gawantka et al, 1998; Deblandre et al., 1999; Jen et al., 1999; Sölter,1999; Koyano-Nakagawa et al., 2000; Li et al., 2003). Ein jedes dieser Proteine konnte mittels Datenbanksuche ebenfalls im diploiden Xenopus tropicalis identifiziert werden (Abb.7-1, Tab.7-2), was darauf hindeutet, dass es sich bei den acht Hes5ähnlichen Proteinen nicht um Allelvarianten im tetraploiden Xenopus laevis handelt.

Um die Sequenzähnlichkeit der Hes5-verwandten Proteine aus Xenopus und Säugern genauer zu untersuchen, wurde das Hes5-Protein aus der Maus mit dem humanen Hes5Protein und den Mitgliedern der Hes5-Gruppe aus Xenopus laevis verglichen (Abb.2-21). 
Wie Hes5 aus Säugern, besitzen alle Hes5-ähnlichen Proteine aus Xenopus laevis zusätzlich zu den konservierten bHLH- und Orange-Domänen ein Prolin an Position 8 der basischen Domäne und ein WRPW-Motiv, über das Groucho-Corepressoren rekrutiert werden können (Abb.2-21A). Außerhalb dieser Domänen sind keine weiteren konservierten Regionen vorhanden und in keinem der Hes5-ähnlichen Proteine aus Xenopus laevis ist die carboxyterminale Region Prolin- und Polyalanin-reich, wie in den Hes5-Proteinen aus Maus und Mensch. Aufgrund des Fehlens der für Hairy-Proteine charakteristischen HC-Domäne zwischen Orange-Domäne und WRPW-Motiv (Davis und Turner, 2001) und einer Gesamtlänge von weniger als 170 Aminosäuren, zählen die Mitglieder der Vertebraten-Hes5-Gruppe somit zur E(spl)-Unterfamilie von bHLH-OProteinen.

Die verschiedenen Hes5-ähnlichen Proteine aus Xenopus laevis sind unterschiedlich nah mit Hes5 aus Maus und Mensch verwandt (Abb.2-21B, Abb.7-1, Abb.7-6). Die größte Ähnlichkeit zu Maus-Hes5 bezogen auf die Gesamtproteine, sowie auf die bHLH- und Orange-Domänen, zeigt ESR1. Auch ESR7 und ESR11 besitzen, vor allem in der bHLHDomäne, eine stärkere Homologie zu Maus-Hes5 als die übrigen Xenopus-Mitglieder der Hes5-Gruppe.

Aufgrund der Ähnlichkeiten der Xenopus-Mitglieder der Hes5-Gruppe untereinander lassen sich zum Teil Untergruppen bilden (Abb.2-21, Abb.7-1, Abb.7-6). Am engsten untereinander verwandt sind ESR8, ESR9 und ESR10, wobei sich ESR9 und ESR10 untereinander stärker ähneln, allerdings steht ESR8 ESR10 näher als ESR9 (siehe auch Abb.2-22, Abb.7-7,8). ESR2 weist größere Sequenzunterschiede auf, ist aber ESR8 am ähnlichsten. ESR1, ESR7 und ESR11 sind untereinander nicht so eng verwandt wie ESR8, ESR9 und ESR10, aber bezogen auf Gesamtprotein und bHLH-Domäne steht ESR7 ESR1 am nächsten, während ESR11 am ehesten ESR7 ähnelt. ESR6 unterscheidet sich stärker von den übrigen Xenopus-Hes5-ähnlichen Proteinen, ist aber am ehesten mit ESR1 verwandt. 


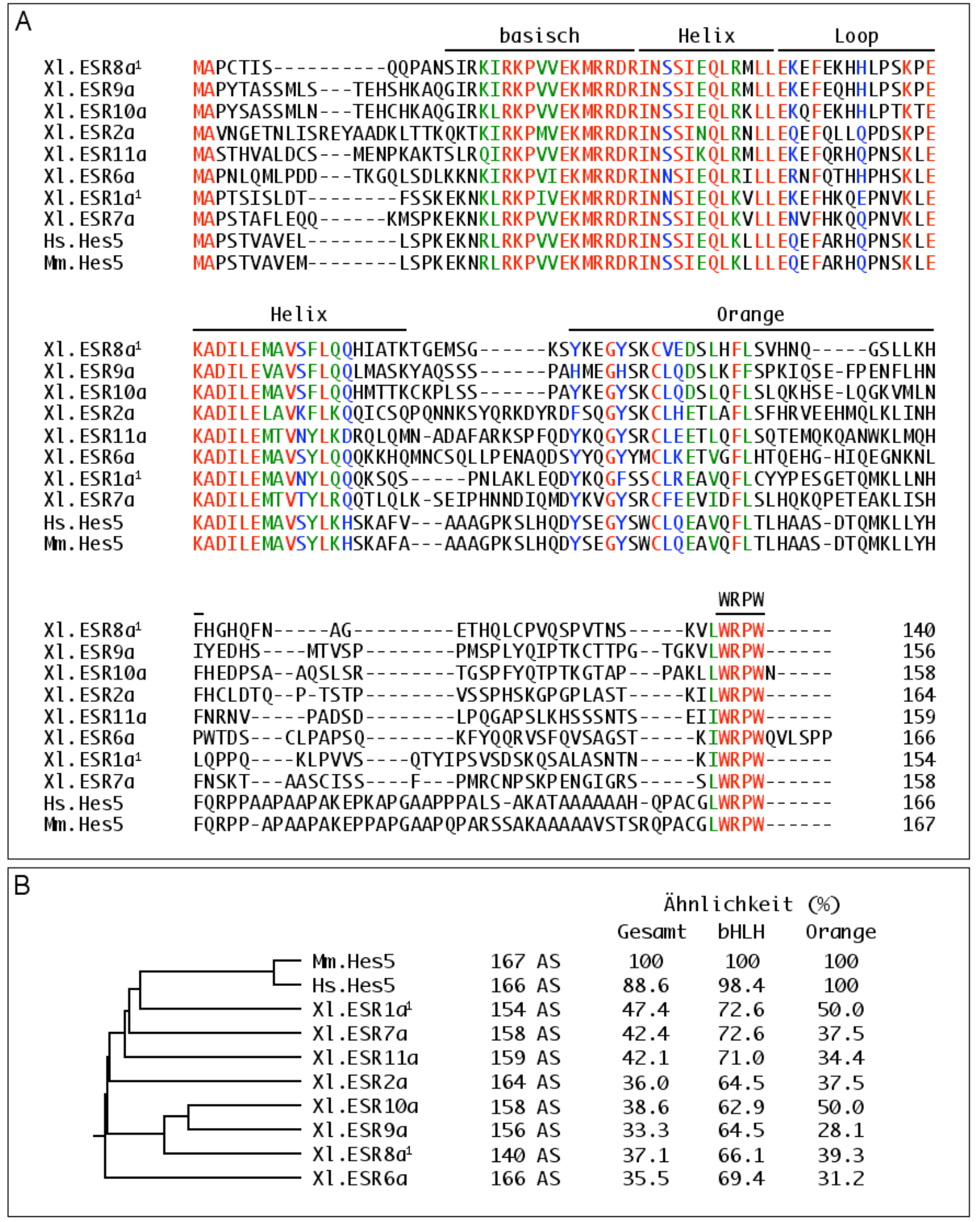

Abb.2-21: In Xenopus laevis existieren acht verschiedene Maus-Hes5-ähnliche Proteine.

(A) Sequenzvergleich von Hes5-ähnlichen Proteinen aus Xenopus laevis und Hes5-Proteinen aus Säugern. bHLH- und Orange-Domänen (Davis und Turner, 2001) sind durch Balken gekennzeichnet. Alle Proteine enthalten ein WRPW-Motif, ein konserviertes Prolin an Position 8 der basischen Domäne, sowie eine relativ kurze carboxyterminale Region ohne HC-Domäne und gehören daher zu den E(spl)-verwandten Proteinen. Der Grad der Aminosäurekonservierung ist wie folgt dargestellt: rot, identisch; grün, starke Ähnlichlichkeit; blau, schwache Ähnlichkeit; Bindestriche (-), fehlende Aminosäuren. (B) Sequenzähnlichkeiten zwischen Maus-Hes5 und Hes5-Proteinen aus Xenopus laevis und Mensch. ESR1 ist Hes5 aus Säugern ähnlicher als die übrigen Xenopus-Mitglieder der Hes5-Gruppe. ESR8, ESR9 und ESR10 sind eng miteinander verwandt. Der phylogenetische Stammbaum basiert auf einem Vergleich der Gesamtproteine. Die DatenbankZugriffsnummern befinden sich im Anhang (Abb.7-1). Abkürzungen: AS, Aminosäuren; Hs., Homo sapiens; Mm., Mus musculus; XI., Xenopus laevis. 


\subsubsection{Sequenzvergleich alleler Varianten von ESR8, ESR9 und ESR10 aus Xenopus}

Die Ähnlichkeit der Proteinsequenzen von ESR8, ESR9 und ESR10 aus Xenopus laevis warf die Frage auf, wie konserviert diese Proteine untereinander und in Xenopus tropicalis sind. Für die Analyse dieser verwandtschaftlichen Beziehungen wurden die identifizierten Allelvarianten von ESR8, ESR9 und ESR10 aus Xenopus laevis und aus Xenopus tropicalis miteinander verglichen (Abb.2-22, Abb.7-1,7,8, Tab.7-1,2,3).

Die enge Verwandtschaft der Xenopus-bHLH-O-Proteine ESR8, ESR9 und ESR10 zeigt sich durch die Konservierung von bHLH- und Orange-Domänen, sowie der an diese Domänen und an das WRPW-Motiv angrenzenden Aminosäuren (Abb.2-22A). Auch in den N-terminalen und C-terminalen Regionen der Proteine sind einzelne Aminosäuren konserviert.

Der bisherigen Datenbanksuche zufolge konnten neben den bekannten allelen Versionen von ESR8 und ESR10, die in dieser Arbeit mit ESR8a und ESR10a bezeichnet werden, jeweils keine weiteren Allelvarianten im tetraploiden Xenopus laevis identifiziert werden. Im diploiden Xenopus tropicalis existieren ein ESR8a-orthologes Protein, ESR8, und ein ESR10a-orthologes Protein, ESR10, mit einer Gesamtprotein-Ähnlichkeit zu den jeweiligen Proteinen aus Xenopus laevis von 84,3\% bzw. 77,2\% (Abb.2-22B). Für ESR9 wurden außer der publizierten Sequenz, hier mit ESR9a benannt, zwei weitere allele Varianten, ESR9b und ESR9c, identifiziert, die jeweils eine Gesamtprotein-Ähnlichkeit von $77,0 \%$ bzw. 81,2\% besitzen, während die von ESR10a zu ESR9a 63,5\% beträgt. Die Existenz von mindestens drei ESR9-Allelvarianten in Xenopus laevis könnte auf eine Genduplikation hinweisen. Und tatsächlich wurden in Xenopus tropicalis zwei ESR9ähnliche Proteine, ESR9A und ESR9B, mit einer Gesamtprotein-Ähnlichkeit zu ESR9a von $77.0 \%$ bzw. 78,7\% gefunden. Das Vorkommen von zwei ESR9-ähnlichen Proteinen im diploiden Xenopus tropicalis deutet ebenfalls auf eine Genduplikation hin. Diese Annahme wird zusätzlich durch die Existenz eines BAC-Klons (GenBank-Zugangsnr. AC151464) bestärkt, der die genomische Sequenz von ESR10, ESR9B und ESR9A in der angegebenen Reihenfolge enthält (siehe auch Tab.7-2). Allerdings weist ESR9B einen Aminosäureaustausch im carboxyterminalen WRPW-Motiv auf, und zwar ist das zweite Trypthophan (W) durch ein Phenylalanin (F) ersetzt (Abb.2-22A). Auch das Hairy-Protein aus der Spinne Cupiennius salei $(\mathrm{Cs}-\mathrm{H})$ besitzt ein solches WRPF-Motiv (Damen et al., 2000). Ob dieser Aminosäureaustausch die Interaktion mit Groucho-Proteinen beeinflußt, ist unbekannt. Das sehr ähnliche carboxyterminale WRPY-Motiv der Runt-DomänenProteine ist für die Groucho-abhängige Repression in Drosophila erforderlich (Aronson et 
al., 1997). Dies läßt vermuten, dass das WRPF-Motiv ebenfalls, wie die Tetrapeptide WRPW und WRPY, Groucho-Proteine rekrutieren kann.

Obwohl ESR8 eng mit ESR9 und ESR10 verwandt ist, zeigen sich dennoch einige Unterschiede in der Aminosäurenzusammensetzung von ESR8 zu den sich untereinander stärker ähnelnen ESR9 und ESR10, vor allem im N- und C-terminalen Bereich, was eine geringere Gesamtprotein-Ähnlichkeit von ESR8 gegenüber ESR9 und ESR10 bedingt (Abb.2-22, Abb.7-7,8).

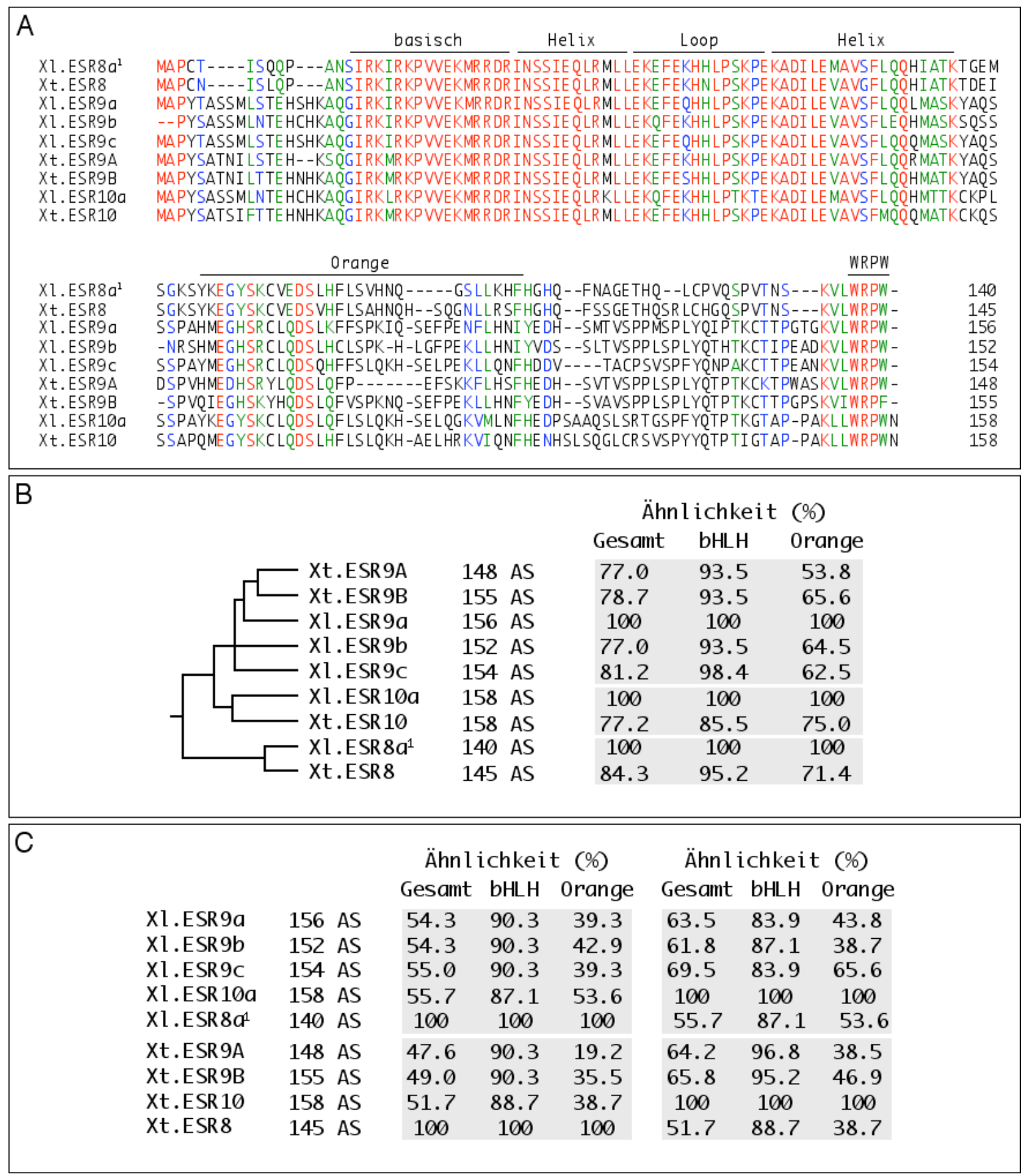

Abb.2-22: Die Xenopus-Hes5-ähnlichen Proteine ESR8, ESR9 und ESR10 sind evolutionär eng verwandt.

(A) Sequenzvergleich von ESR8, ESR9 und ESR10 aus Xenopus laevis und Xenopus tropicalis. bHLH- und Orange-Domänen (Davis und Turner, 2001) und das WRPW-Motif sind durch Balken gekennzeichnet. Der Grad der Aminosäurekonservierung ist wie folgt dargestellt: rot, identisch; grün, starke Ähnlichlichkeit; blau, 
schwache Ähnlichkeit; Bindestriche (-), fehlende Aminosäuren. (B,C) Sequenzähnlichkeiten zwischen ESR8, ESR9 und ESR10 aus Xenopus laevis und Xenopus tropicalis. Der phylogenetische Stammbaum basiert auf einem Vergleich der Gesamtproteine. Die Datenbank-Zugriffsnummern befinden sich im Anhang (Abb.7-1). Abkürzungen: AS, Aminosäuren; XI., Xenopus laevis; Xt., Xenopus tropicalis. 


\subsubsection{Untersuchungen zur Expression von ESR8, ESR9 und ESR10 in Xenopus laevis}

Während der Embryonalentwicklung von Xenopus laevis werden neben ESR8, auch ESR9 und ESR10 ähnlich wie ESR1 in proneuronalen Domänen exprimiert (Gawantka et al., 1998; Sölter, 1999; Schneider et al., 2001; Li et al., 2003). Um Gemeinsamkeiten und Unterschiede in der Expression von ESR8, ESR9 und ESR10 untereinander, aber auch im Vergleich zur Expression von ESR1 aufzudecken, wurde eine vergleichende Expressionsanalyse von ESR8, ESR9, ESR10 und ESR1 in Xenopus laevis durchgeführt.

\subsubsection{Expressionsanalyse von ESR8, ESR9 und ESR10 während der Embryogenese}

Um einerseits die Beobachtung zu überprüfen, dass ESR8, ESR9 und ESR10 ein sehr ähnliches, wenn nicht weitgehend identisches Expressionsmuster, vor allem in den Regionen des Embryos, in denen Neuronen entstehen, aufweisen und um andererseits die Expression dieser drei Gene mit der von ESR1 zu vergleichen, wurde die Expression von ESR8, ESR9, ESR10 und ESR1 in verschiedenen Embryonalstadien von Xenopus laevis mittels wmISH untersucht (Abb.2-23A-H).

Im frühen Neurulastadium werden ESR8, ESR9 und ESR10 tatsächlich genauso wie ESR1 in den Regionen der primären Neurogenese in der posterioren Neuralplatte, im ventralen Vorderhirn und in den trigeminalen Plakoden exprimiert (Abb.2-23A-D). Auch im Stadium 39 sind keine grundlegenden Unterschiede der vier Gene hinsichtlich ihrer Expression im sich entwickelnden Gehirn und in der ciliären Marginalzone der Retina zu erkennen (Abb.2-23E-H). Außerdem konnten Transkripte von ESR8, ESR9, ESR10 und ESR1 im Stadium $39 \mathrm{im}$ Seitenliniensystem, sowie im dorsalen und ventralen Anteil des Pankreas detektiert werden. Allerdings ist das ESR1-Signal im Pankreas sehr schwach.

Neben diesen Gemeinsamkeiten in der Expression im Neuroektoderm und seinen Derivaten gibt es allerdings auch Unterschiede. So sind ESR1-Transkripte nur im posterioren präsomitischen Mesoderm von Neurulastadien nachweisbar, die Expressionsdomänen von ESR8, ESR9 und ESR10 im präsomitischen Mesoderm umfassen einen größeren, sich weiter anterior ausdehnenden Bereich (Abb.2-23A-D) und variieren leicht, was auf eine zyklische Expression sowohl von ESR8 als auch von ESR9 und ESR10 (Li et al., 2003) hindeutet. In frühen Neurulastadien konnte zudem im Bereich der posterioren Mittellinie eine schwache Expression von ESR8, nicht aber von ESR9, ESR10 und ESR1 detektiert werden (Abb.2-23A-D). 
Zusammenfassend läßt sich sagen, dass ESR8, ESR9 und ESR10 sich nicht wesentlich hinsichtlich ihrer Expressionsmerkmale unterscheiden. Außerdem überlappen viele der Expressionsdomänen dieser drei Gene mit denen von ESR1.

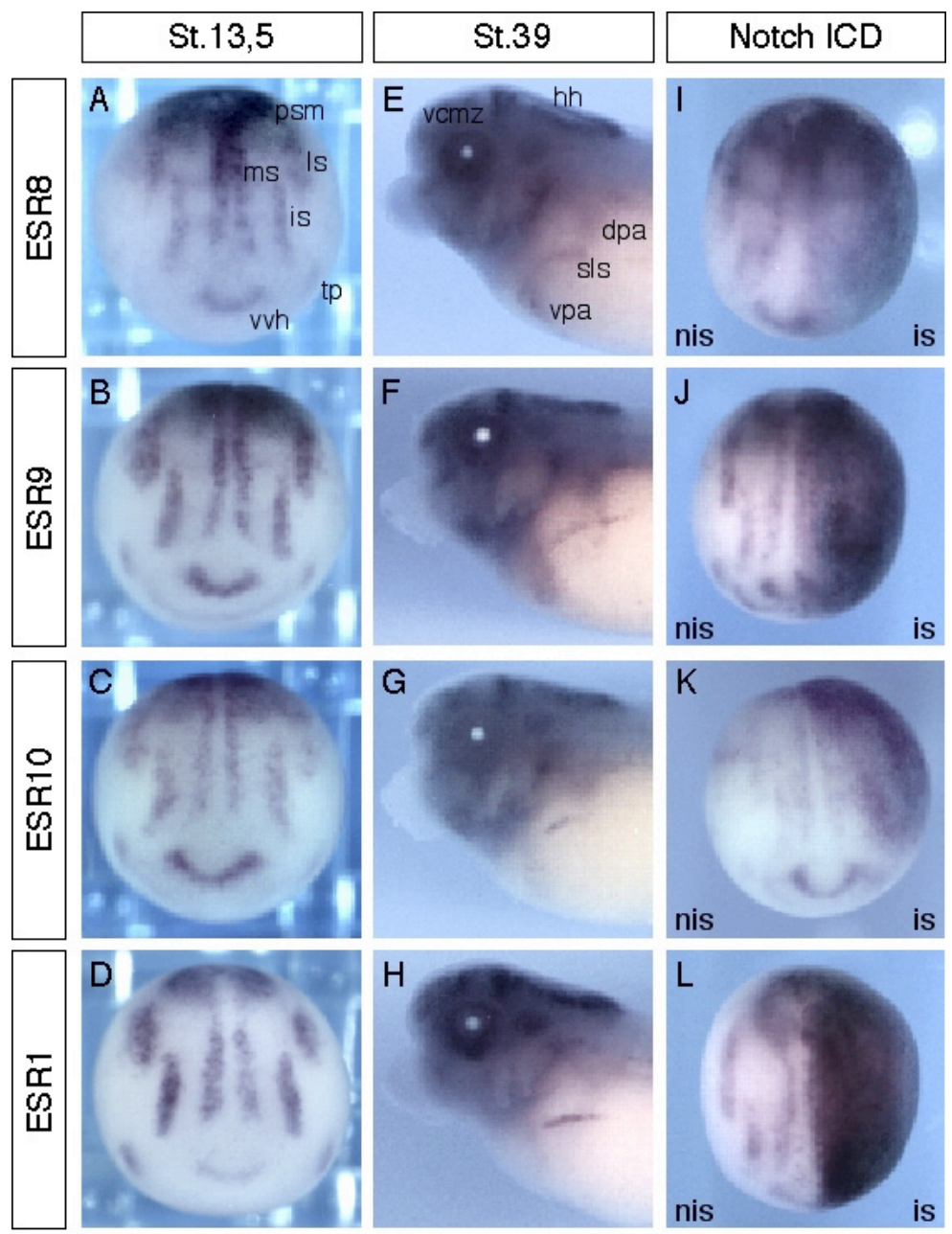

Abb.2-23: Die Notch-Zielgene ESR8, ESR9 und ESR10 werden während der Embryogenese von Xenopus laevis in proneuronalen Domänen, aber auch in entstehenden Somiten und im Pankreas exprimiert.

(A-H) Vergleichende Expressionsanalyse von ESR8, ESR9, ESR10 und ESR1 während der Neurogenese von Xenopus laevis mittels wmISH. (I-L) Effekte der ektopischen Aktivierung des Notch-Signalwegs auf die Expression von ESR8, ESR9, ESR10 und ESR1 in Xenopus laevis-Embryonen analysiert mittels wmISH. Notch-ICD-RNA wurde im animalen, polnahen Bereich in eine Blastomere des Zwei-Zell-Stadiums (St.2) von Xenopus laevis-Embryonen injiziert. Diese wurden bis zum Stadium 14/15 kultiviert und mittels wmISH analysiert (schematische Darstellung der experimentellen Strategie s. Abb.2-9A, Notch-ICD-Aktivitätskontrolle s. Abb.2-9C3). Ektopisches Notch-ICD, das die neuronale Differenzierung hemmt und die Expression von $X$ MyT-1 reprimiert (Abb.2-9C3; Aktivitätskontrolle), bewirkt eine ektopische Expression von ESR8, ESR9, ESR10 und ESR1 im Neuroektoderm und Ektoderm. (A-L) Die Embryonalstadien und injizierten RNAs sind über den Fotos und die untersuchten Genexpressionen jeweils links der Fotos angegeben. Die Embryonen sind wie folgt orientiert: (A-D,I-L) dorsale Ansicht, anterior unten; (E-H) laterale Ansicht, anterior links. Abkürzungen: dpa, dorsaler Pankreas; eso, entstehende Somiten; hh, Hinterhirn; is, intermediärer Streifen späterer Interneuronen oder injizierte Seite; Is, lateraler Streifen späterer sensorischer Neuronen; ms, medialer Streifen späterer Motorneuronen; nis, nicht-injizierte Seite; psm, präsomitisches Mesoderm; sls, Seitenliniensystem; tp, trigeminale Plakode; vcmz, ciliäre Marginalzone mit sich teilenden Vorläuferzellen; vpa, ventraler Pankreas; vvh, ventrales Vorderhirn. Anmerkung: $(D, H)$ sind identisch mit $(A b b .2-7 A 13,16)$. 
Zur Charakterisierung der zeitlichen Expression von ESR8, ESR9 und ESR10, sowie von ESR1 während der Embryonalentwicklung wurde eine semiquantitative RT-PCR-Analyse auf Gesamt-RNA verschiedener Embryonalstadien von Xenopus laevis (Nieuwkoop und Faber, 1994) durchgeführt (Abb.2-24).

ESR1-Transkripte sind während der gesamten Embryonalentwicklung vorhanden, mit dem niedrigsten Expressionsniveau in Stadium 8 und 9 und einer verstärkten Expression ab der Neurulation (Stadium 13 und folgende). Transkripte von ESR8, ESR9 und ESR10 sind erst ab dem Midblastulastadium (Stadium 8) mit Einsetzen der zygotischen Transkription detektierbar. Die Expression von ESR9 wird allerdings weitaus schwächer als die von ESR8 und ESR10 induziert. Die Expressionsstärke von ESR9 nimmt erst während der Gastrulation (Stadium 11) zu und erreicht während der Neurulation ihr Maximum. Das Expressionsniveau von ESR10 ist dagegen während der Embryogenese relativ konstant mit einer etwas schwächeren Expression vor der Neurulation. ESR8 wird ebenfalls ohne stärkere Schwankungen der Expressionsstärke in den verschiedenen Stadien exprimiert, wird jedoch in früheren Stadien etwas stärker exprimiert als in den späteren Stadien. Somit unterscheidet sich ESR1 von ESR8, ESR9 und ESR10 hinsichtlich der zeitlichen Expression vorwiegend durch das Vorhandensein maternaler ESR1-Transkripte. ESR8, ESR9 und ESR10 unterscheiden sich hingegen nur in den Expressionsniveaus in den Blastulastadien.

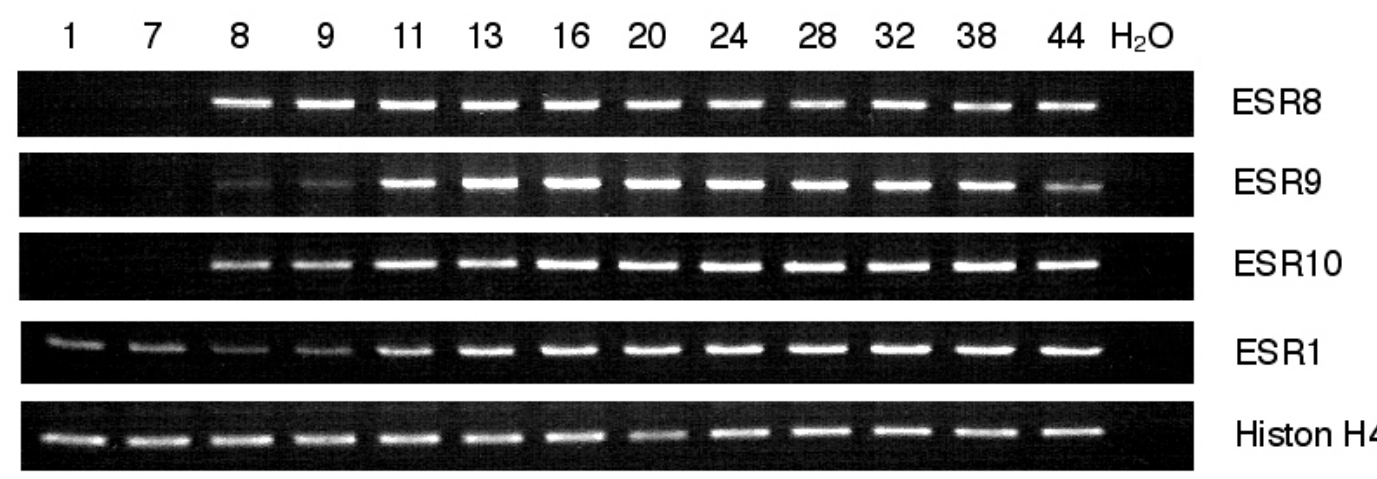

Abb.2-24: ESR8, ESR9 und ESR10 werden ab dem Midblastulastadium in Xenopus laevis exprimiert. Zeitliche Expressionsanalyse von ESR8, ESR9, ESR10 und ESR1 in Embryonalstadien von Xenopus laevis mittels semiquantitativer RT-PCR. Die Stadien der eingesetzten Gesamt-RNA-Präparationen sind über den jeweiligen DNA-Spuren angegeben. Um DNA-/RNA Kontaminationen der RT-PCR Reagenzien auszuschließen, wurde eine Kontrollreaktion durchgeführt bei der Wasser $\left(\mathrm{H}_{2} \mathrm{O}\right)$ anstelle von Stadien-RNA verwendet wurde. Alle RNA-Präparationen sind frei von Verunreinigungen mit genomischer DNA (nicht gezeigt). Zur Überprüfung der für die cDNA-Synthese eingesetzten RNA-Menge wurde die Expression von Histon $\mathrm{H} 4$ analysiert. RT-PCR Primer/Produktlängen Histon H4: H4_RTF/H4_RTR/188bp, ESR1: ESR1_RT1F/ESR1_RT1R/225bp, ESR8: ESR8_RT1F/ESR8_RT1R/185bp, ESR9: ESR9_RT1F/ ESR9_RT1R/212bp, ESR10: ESR10_RT1F/ESR10_RT1R/212bp. Maternale Transkripte sind nur von ESR1 nachweisbar (Stadium 1 und 7). Mit einsetzender zygotischer Transkription im Midblastulastadium (Stadium 8) werden ESR8 und ESR10 exprimiert, die Expression von ESR9 wird ebenfalls induziert, aber weitaus schwächer als die von ESR8 und ESR10. Erst während der Gastrulation (Stadium 11) nimmt die Expressionsstärke von ESR9 zu, und auch ESR1 wird zunehmend stärker transkribiert. Alle untersuchten Gene werden während der weiteren Embryogenese bis hin zum Kaulquappenstadium (Stadium 44) exprimiert. 


\subsubsection{Räumliche Expressionsanalyse von ESR8, ESR9 und ESR10 im adulten Frosch}

Zusätzlich zur Expressionsanalyse von ESR8, ESR9 und ESR10, sowie von ESR1 während der Embryogenese, wurde die räumliche Expression dieser Gene im adulten Tier mittels semiquantitativer RT-PCR auf Gesamt-RNA verschiedener adulter Organe von Xenopus laevis untersucht (Abb.2-25).

ESR1 wird als einziges der vier untersuchten Gene in nahezu allen adulten Organen, allerdings unterschiedlich stark exprimiert. Wie ESR1 werden auch ESR8, ESR9 und ESR10 im adulten Auge und Gehirn transkribiert, in den übrigen Organen unterscheiden sie sich hinsichtlich ihrer Expression sowohl von ESR1 als auch untereinander. Während ESR9-Transkripte ausschließlich in Auge und Gehirn detektiert werden konnten, wurden geringe Mengen an ESR10-Transkripten ebenfalls in der adulten Haut und Milz gefunden. Im Gegensatz zu ESR9 und ESR10 konnten für ESR8 signifikante Expressionsniveaus auch in Lunge, Milz, Skelettmuskel, Dünndarm und Hoden nachgewiesen werden. Somit unterscheidet sich die ESR8-Expression von der ESR9- und ESR10-Expression im adulten Tier im wesentlichen durch die Expression in zusätzlichen Organen, die nicht vorwiegend neuroektodermalen Ursprungs wie Auge und Gehirn sind, sondern vielmehr mesodermaler und endodermaler Herkunft.

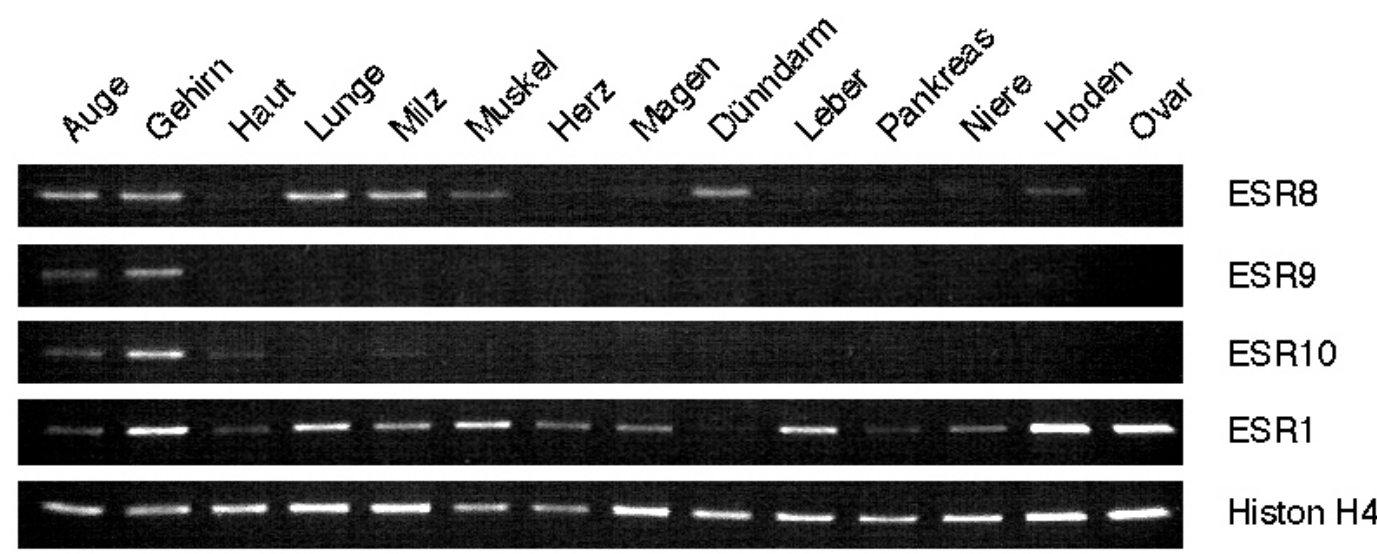

Abb.2-25: ESR8, ESR9 und ESR10 werden im adulten Gehirn und Auge von Xenopus laevis exprimiert. Expressionsanalyse von ESR8, ESR9, ESR10 und ESR1 in adulten Organen von Xenopus laevis mittels semiquantitativer RT-PCR. Die untersuchten Organe sind über den jeweiligen DNA-Spuren angegeben. Um DNA-und RNA-Kontaminationen der RT-PCR Reagenzien auszuschließen, wurde eine Kontrollreaktion durchgeführt bei der Wasser $\left(\mathrm{H}_{2} \mathrm{O}\right)$ anstelle von RNA aus Organen verwendet wurde (s. Abb.2-24). Alle RNAPräparationen sind frei von Verunreinigungen mit genomischer DNA (nicht gezeigt). Zur Überprüfung der für die cDNA-Synthese eingesetzten RNA-Menge wurde die Expression von Histon H4 analysiert. RT-PCR Primer/Produktlängen Histon H4: H4_RTF/H4_RTR/188bp, ESR1: ESR1_RT1F/ESR1_RT1R/225bp, ESR8: ESR8_RT1F/ESR8_RT1R/185bp, ESR9: ESR9_RT1F/ESR9_RT1R/212bp, ESR 10: ESR10_RT1F/ ESR10_RT1R/212bp. Während ESR1 in nahezu allen Organen exprimiert wird, werden ESR8, ESR9 und ESR10 im Gehirn und Auge transkribiert, ESR8-Transkripte sind zusätzlich in Lunge, Milz, Muskel, Dünndarm und Hoden vorhanden, ESR10-Transkripte in sehr geringem Anteil auch in Haut und Milz. 


\subsubsection{Regulation der Expression von ESR8, ESR9 und ESR10 durch den Notch- Signalweg}

Aufgrund ihrer X-Delta-1-ähnlichen Expressionsmuster während der Embryogenese zählen ESR8, ESR9 und ESR10 wie ESR1 zu der X-Delta-1-Synexpressionsgruppe (Gawantka et al., 1998), was einen Zusammenhang mit dem Delta-Notch-Signalweg nahelegt, der eine bedeutende Rolle bei der Hemmung der primären neuronalen Differenzierung in Xenopus-Embryonen spielt (Chitnis et al., 1995). In verschiedenen Arbeiten konnte gezeigt werden, dass neben ESR1 auch ESR8, sowie ESR9 und ESR10 durch die Aktivierung des Notch-Signalwegs induziert werden und somit Notch-Zielgene sind (Wettstein et al., 1997; Gawantka et al., 1998; Sölter,1999; Bellefroid, persönliche Mitteilung). Um dies unter einheitlichen Versuchsbedingungen zu kontrollieren, wurden Komponenten des Notch-Signalwegs in Xenopus-Embryonen überexprimiert und die Effekte auf die Transkription von ESR8, ESR9, ESR10 und ESR1 mittels wmISH in frühen Neurulastadien untersucht (Abb.2-23I-L; Tab.2-8).

Die ektopische Aktivierung des Notch-Signalwegs durch die Überexpression von NotchICD, einer konstitutiv-aktiven Form des X-Notch-1-Rezeptors (Coffman et al., 1993), bewirkte eine ektopische Transkriptionsaktivierung von ESR8, ESR9, ESR10 und ESR1 im Neuroektoderm und Ektoderm von frühen Neurulastadien (Abb.2-23I-L; Tab.2-8). Auch ektopisches $\mathrm{X}$-Su(H)-Ank, eine konstitutiv-aktive Form von X-Su(H) (Wettstein et al., 1997), induzierte ESR8, ESR9 und ESR10 ektopisch im Neuroektoderm und Ektoderm (Tab.2-8). In animalen Kappenexperimenten konnte die Transkriptionsaktivierung von ESR8, ESR9, ESR10 und ESR1 durch Notch-ICD ebenfalls nachgewiesen werden (Daten nicht gezeigt). Diese Ergebnisse bestätigen, dass ESR8, ESR9 und ESR10, sowie ESR1 Notch-Zielgene sind.

\begin{tabular}{|c|c|c|}
\hline Injizierte RNA & Notch ICD & X-Su(H)-Ank \\
\hline Menge (pg) & 100 & 200 \\
\hline injizierte Zelle & $1 / 2, a$ & $1 / 2, a$ \\
\hline wmISH-Stadium & 14 & 14 \\
\hline Anzahl ESR8 & 27 & 23 \\
$=/ \downarrow / \uparrow(\%)$ & $0 / 0 / 100^{*}$ & $0 / 0 / 100^{*}$ \\
\hline Anzahl ESR9 & 18 & 12 \\
$=/ \downarrow / \uparrow(\%)$ & $0 / 0 / 100^{*}$ & $0 / 0 / 100^{*}$ \\
\hline Anzahl ESR10 & 17 & 9 \\
$=/ \downarrow / \uparrow(\%)$ & $0 / 0 / 100^{*}$ & $0 / 0 / 100^{*}$ \\
\hline Anzahl ESR1 & 12 & $n . a$. \\
$=/ \downarrow / \uparrow(\%)$ & $0 / 0 / 100^{*}$ & 10 \\
\hline Anzahl X-MyT-1 & 11 & $20 / 80 / 0$ \\
$=/ \downarrow / \uparrow(\%)$ & $0 / 100 / 0$ & \\
\hline
\end{tabular}

Tab.2-8: Einfluß der Notch-Aktivierung auf die Expression von ESR8, ESR9, ESR10 und ESR1 in Embryonen. Abkürzungen und Symbole: Anzahl ESR8, Anzahl der mittels wmISH (ESR8 Expression) analysierten Embryonen; =, Expression unverändert; $\downarrow$, weniger bis keine positiven Zellen in Expressionsdomäne; $\uparrow$, mehr positive Zellen in Expressionsdomäne; a, animal; n.a., nicht analysiert; *, ektopisch in Neuroektoderm und Ektoderm; T1 entspricht der jeweiligen Analyse aus Tahalln 1 


\subsubsection{Funktionsanalysen von ESR8, ESR9 und ESR10 während der Neurogenese}

Die Expression von ESR8, ESR9 und ESR10 in proneuronalen Domänen während der Embryonalentwicklung von Xenopus laevis legt nahe, dass diese drei durch Notchinduzierbaren bHLH-O-Gene eine regulative Funktion bei der Ausbildung des Nervensystems übernehmen. Die hinsichtlich ihrer Proteinsequenz und Expression ähnlich exprimierten Notch-Zielgene ESR1 und ESR7 hemmen in Überexpressionsstudien, wie die Aktivierung des Notch-Signalwegs, die Differenzierung primärer Neuronen in Xenopus-Embryonen (Chitnis et al., 1995; Koyano-Nakagawa et al., 2000; Schneider et al., 2001). Erste Untersuchungen zur Funktion von ESR8 im Rahmen der Diplomarbeit hatten gezeigt, dass auch die Überexpression von ESR8 die primäre Neurogenese in Xenopus-Embryonen hemmt. Die neuronale Differenzierung konnte ebenso durch überexprimiertes ESR9 oder ESR10 verhindert werden (Eric Bellefroid, persönliche Mitteilung). In der vorliegenden Arbeit wurden diese ersten Experimente durch weitere ergänzt, um die Rolle von ESR8, ESR9 und ESR10 bei der neuronalen Differenzierung zu klären. Zum einen wurden induzierbare Varianten von ESR8, ESR9 und ESR10 in Xenopus-Embryonen überexprimiert und zum anderen wurde die Proteinexpression von ESR8, ESR9 und ESR10 in Xenopus-Embryonen gezielt blockiert, jeweils gefolgt von der Analyse der Auswirkungen auf die Neurogenese.

\subsubsection{1 Überexpression induzierbarer Varianten von ESR8, ESR9 und ESR10 in Xenopus-Embryonen}

In den ersten Experimenten zur Funktion von ESR8, ESR9 und ESR10 hatte sich herausgestellt, dass die Überexpression von ESR8, ESR9 und ESR10 ab dem Zwei-ZellStadium von Xenopus-Embryonen die Transkription von N-tubulin im offenen Neuralplattenstadium reprimiert, aber auch mit dem Auftreten von Gastrulationsdefekten und sekundären Achsen und einer starken Neuralplattenexpansion einhergeht. Um auszuschließen, dass die Hemmung der primären Neurogenese ein sekundärer Effekt ist, der auf Veränderungen der frühen Entwicklung zurückzuführen ist, wurden in den weiteren Überexpressionsstudien in Xenopus-Embryonen Glucocorticoid-induzierbare Varianten von ESR8, ESR9 und ESR10 verwendet, die eine kontrollierte Aktivierung der überexprimierten Proteine in Anwesenheit von Dexamethason ermöglichten. Zur Herstellung der induzierbaren Varianten wurden die zu analysierenden Proteine carboxyterminal mit der Liganden-bindenden Domäne des humanen Glucocorticoidrezeptors fusioniert (Abb.2-26) (Kolm und Sive, 1995). Zusätzlich zu den induzierbaren Wildtyp-Formen (ESR8-GR, ESR9-GR und ESR10-GR) wurden 
induzierbare DNA-Bindungsmutanten (ESR8-DBM-GR, ESR9-DBM-GR und ESR10DBM-GR) erzeugt, bei denen mehrere basische Aminosäuren $\left({ }^{22 / 29}\right.$ VEKMRRDRIN $\left.{ }^{31 / 38}\right)$ innerhalb der DNA-Bindungsdomäne durch saure Aminosäuren $\left({ }^{22 / 29} \mathrm{VREMEEDDID}^{31 / 38}\right)$ ersetzt wurden, entsprechend der Mutationen in der DNA-Bindungsmutante von ESR6e, die einen domimant-negativen Effekt auf die Differenzierung von Cilienzellen ausübt (Deblandre et al., 1999). Für andere Xenopus bHLH-O-Proteine konnte gezeigt werden, dass Deletionen oder Mutationen in der basischen Domäne auch einen Funktionsverlust verursachen können (Koyano-Nakagawa et al., 2000; Schneider et al., 2001; Umbhauer et al., 2001; Taelman et al., 2004).

Um die Funktion von ESR8, ESR9 und ESR10 während der primären Neurogenese zu analysieren, wurden die induzierbaren Varianten von ESR8, ESR9 und ESR10 in Xenopus-Embryonen überexprimiert, durch Dexamethason im Midgastrulastadium induziert und die Effekte auf die Neurogenese mittels wmISH in verschiedenen Embryonalstadien untersucht (Abb.2-27; Tab.2-9).

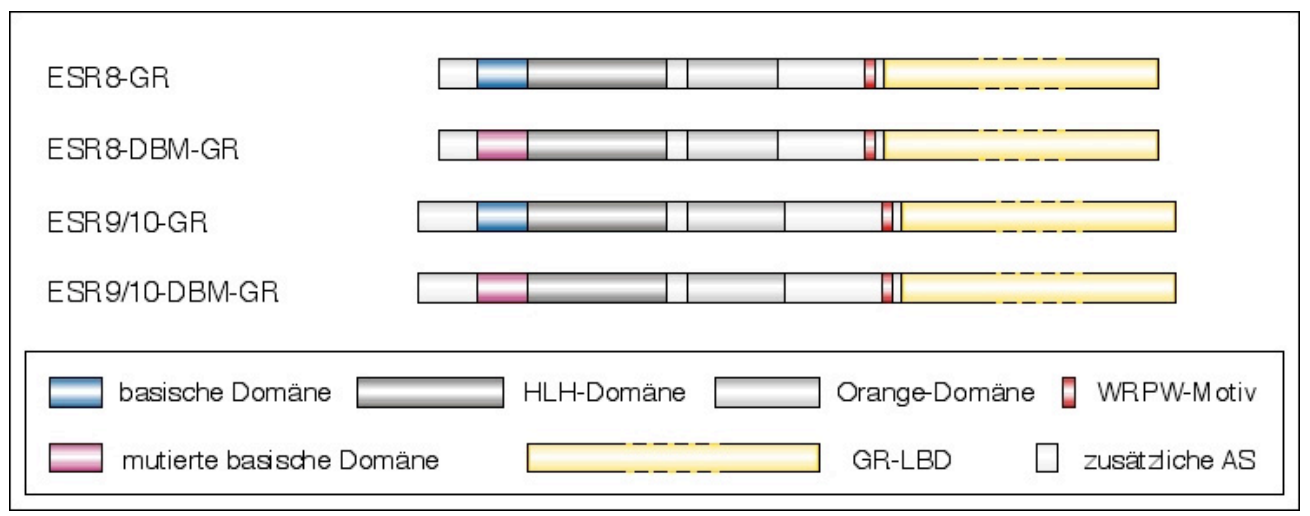

Abb.2-26: Induzierbare Varianten von ESR8, ESR9 und ESR10 für Überexpressionsstudien.

Schematische Darstellung der Dexamethason-induzierbaren Konstrukte von ESR8, ESR9 und ESR10 für die funktionellen Analysen. Die induzierbaren Varianten enthalten an ihrem C-Terminus die Liganden-bindende Domäne des humanen Glucocorticoidrezeptors (GR). Im Gegensatz zu den induzierbaren Wildtyp-Proteinen ESR8-GR, ESR9-GR und ESR10-GR tragen die DNA-Bindungsmutanten ESR8-DBM-GR, ESR9-DBM-GR und ESR10-DBM-GR Mutationen in der basischen Domäne (22/29 VEKMRRDRIN ${ }^{31 / 38}>$ ${ }^{22 / 29}$ VREMEEDDID ${ }^{31 / 38}$ ). Die verschiedenen Domänen der XHes2-Varianten sind, wie unter den Konstrukten dargestellt, farbig hervorgehoben.

\subsection{Effekte induzierbarer Varianten von ESR8, ESR9 und ESR10 auf die Neurogenese}

Da bereits frühere Experimente gezeigt hatten, dass eine im Zwei-Zell-Stadium von Xenopus-Embryonen überexprimierte und im Midgastrulastadium induzierte ESR8Variante, ESR8-GR, in der Lage war, die Transkription von $N$-tubulin im offenen Neuralplattenstadium zu reprimieren, stellte sich die Frage, ob auch die induzierbaren Varianten von ESR9 und ESR10 diese Fähigkeit besaßen, die primäre Neurogenese zu hemmen. Um dies zu beantworten, wurden ESR8-GR, ESR9-GR und ESR10-GR im 
Zwei-Zell-Stadium von Xenopus-Embryonen überexprimiert, im Midgastrulastadium durch Dexamethason induziert und die Effekte auf die Expression von $\mathrm{N}$-tubulin mittels wmISH im offenen Neuralplattenstadium analysiert (Abb.2-27A). Wie die Induktion von ESR8-GR bewirkte die Induktion von ESR9-GR und ESR10-GR im Stadium 11 eine deutliche Reduktion der Anzahl N-tubulin-positiver Zellen im Stadium 14 (Abb.2-27B4, Tab.2-9), was darauf hindeutet, dass ESR8, ESR9 und ESR10 die neuronale Differenzierung hemmen.

Um zu überprüfen, ob die Neurogenese bereits auf der Ebene der neuronalen Determinierung negativ reguliert wird, wurde die Auswirkung von im Midgastrulastadium induziertem ESR8-GR auf die X-Ngnr1-Transkription im offenen Neuralplattenstadium untersucht (Abb.2-27A). Da die X-Ngnr-1-Expression im Stadium 14 infolge der Induktion von ESR8-GR im Stadium 11 reprimiert war (Abb.2-27B1; Tab.2-9), kann ESR8 die neuronale Determinierung vermutlich durch die Transkriptionsrepression von $X$-Ngnr-1 verhindern.

Die Notwendigkeit der DNA-bindenden Domäne für verschiedene Funktionen von Xenopus-bHLH-O-Proteinen ließ die Frage aufkommen, welche Bedeutung die DNAbindende Domäne für die Funktion von ESR8, ESR9 und ESR10 während der Neurogenese besitzt. Daher wurden ESR8-DBM-GR, ESR9-DBM-GR und ESR10-DBMGR im Zwei-Zell-Stadium von Xenopus-Embryonen überexprimiert, im Midgastrulastadium durch Dexamethason induziert und zunächst die Effekte auf die Expression von $\mathrm{N}$-tubulin mittels wmISH im offenen Neuralplattenstadium analysiert (Abb.2-27A). Keine der induzierten DNA-Bindungsmutanten konnte die Anzahl N-tubulinpositiver Zellen im Stadium 14 in dem Maße reduzieren, wie das für die induzierten Wildtyp-Formen von ESR8, ESR9 und ESR10 im Stadium 14 beobachtet werden konnte (Abb.2-27B4,5; Tab.2-9). Ein dominant-negativer Effekt mit einer erhöhten Anzahl an $\mathrm{N}$ tubulin-positiven Zellen wurde in frühen Neurulastadien nicht erzielt.

Aufgrund der Fähigkeit von ESR8-GR, die X-Ngnr-1-Expression im frühen Neurulastadium zu hemmen, schien es weiterhin vielversprechend, den Einfluß von im Midgastrulastadium induziertem ESR8-DBM-GR auf die X-Ngnr-1-Expression im Stadium 14 und $19 \mathrm{zu}$ untersuchen (Abb.2-27A). Interessanterweise wurden in frühen und späteren Neurulastadien infolge der Induktion von ESR8-DBM-GR weitaus mehr X-Ngnr1-positive Zellen vorwiegend im Bereich der olfaktorischen und profundal-trigeminalen Plakoden, aber auch im sich einfaltenden Neuralrohr gefunden (Abb.2-27B2,3; Tab.2-9). Um herauszufinden, ob die zusätzlich neuronal-determinierten Zellen später die Fähigkeit zur Differenzierung besitzen, wurde der Effekt von im Midgastrulastadium induziertem ESR8-DBM-GR auf die Transkription von N-tubulin im Stadium 17/18, 21 und 26 analysiert (Abb.2-27A). Im Unterschied zum Stadium 14, in dem die N-tubulin-Expression 
weitgehend unverändert war (Abb.2-27B5), konnten im Stadium 17/18 und 21 infolge der ESR8-DBM-GR-Induktion zusätzliche N-tubulin-positive Zellen in den Regionen neuroektodermaler Herkunft detektiert werden, in denen die zusätzlichen X-Ngnr-1positiven Zellen lokalisiert waren, d.h. im Bereich der olfaktorischen und profundaltrigeminalen Plakoden und im sich einfaltenden Neuralrohr (Abb.2-27B7,8; Tab.2-9). Im Stadium 26 waren außerdem N-tubulin-positive Zellen im Augenvesikel vorhanden (Abb.2-27B10,11), der normalerweise in diesem Stadium noch nicht differenzierte, $N$ tubulin-negative Retinoblasten enthält. Im Midgastrulastadium induziertes ESR8-GR verursachte hingegen nicht nur im Stadium 14, sondern auch im Stadium 18 und 26, eine deutliche Repression der N-tubulin-Transkription (Abb.2-B6,9; Tab.2-9).

Diese Daten zeigen, dass ESR8-DBM-GR im Vergleich zu ESR8-GR bei Induktion im Stadium 11 einen dominant-negativen Effekt bezüglich der Repression der X-Ngnr-1- und $N$-tubulin-Transkription verursacht. Die neuronale Determinierung und die darauf folgende neuronale Differenzierung werden durch im Midgastrulastadium induziertes ESR8-DBMGR gefördert, während diese durch im Midgastrulastadium induziertes ESR8-GR gehemmt werden.

Der nicht in frühen, sondern erst in späteren Neurulastadien beobachtete dominantnegative Effekt bezüglich der $N$-tubulin-Expression deutet darauf hin, dass die Differenzierung der ersten Neuronen im Stadium 14 und vermutlich die vorausgehende neuronale Determinierung durch im Midgastrulastadium induziertes ESR8-DBM-GR nicht betroffen sind. Eine mögliche Erklärung dafür wäre, dass keine endogenen WildtypProteine, wie ESR8 oder ESR8-Bindungspartner, vorhanden sind, die durch die Anwesenheit der ESR8-DNA-Bindungsmutanten inaktiviert werden könnten, da bHLH-OProteine vorwiegend als Homo- bzw. Heterodimere agieren und die Transkription von Genen, wie z.B. X-Ngnr-1, reprimieren können. Erst die Inaktivierung endogener WildtypMoleküle, wie ESR8 oder ESR8-Bindungspartnern, durch ESR8-DNA-BindungsmutantenMonomere sollte in einem dominant-negativen Effekt hinsichtlich der Determinierung und nachfolgenden Differenzierung neuronaler Zellen innerhalb proneuraler Domänen resultieren, wie dies für X-Ngnr-1 ab Stadium 14 und für N-tubulin ab Stadium $17 \mathrm{zu}$ beobachten ist. Somit zeigen die Überexpressionsstudien mit der induzierbaren ESR8DNA-Bindungsmutante durch den Funktionsverlust die Notwendigkeit der DNA-bindenden Domäne für die Hemmung der neuronalen Determinierung und Differenzierung und unterstützen außerdem durch den dominant-negativen Effekt die Hypothese, dass das ESR8-Wildtyp-Protein die Neurogenese negativ reguliert.

Zusammengenommen sprechen die Ergebnisse der im Stadium 11 induzierten Varianten von ESR8, ESR9 und ESR10 dafür, dass ESR8, ESR9 und ESR10 während der Neurogenese die Anzahl von Neuronen im sich entwickelnden Nervensystem begrenzen. 

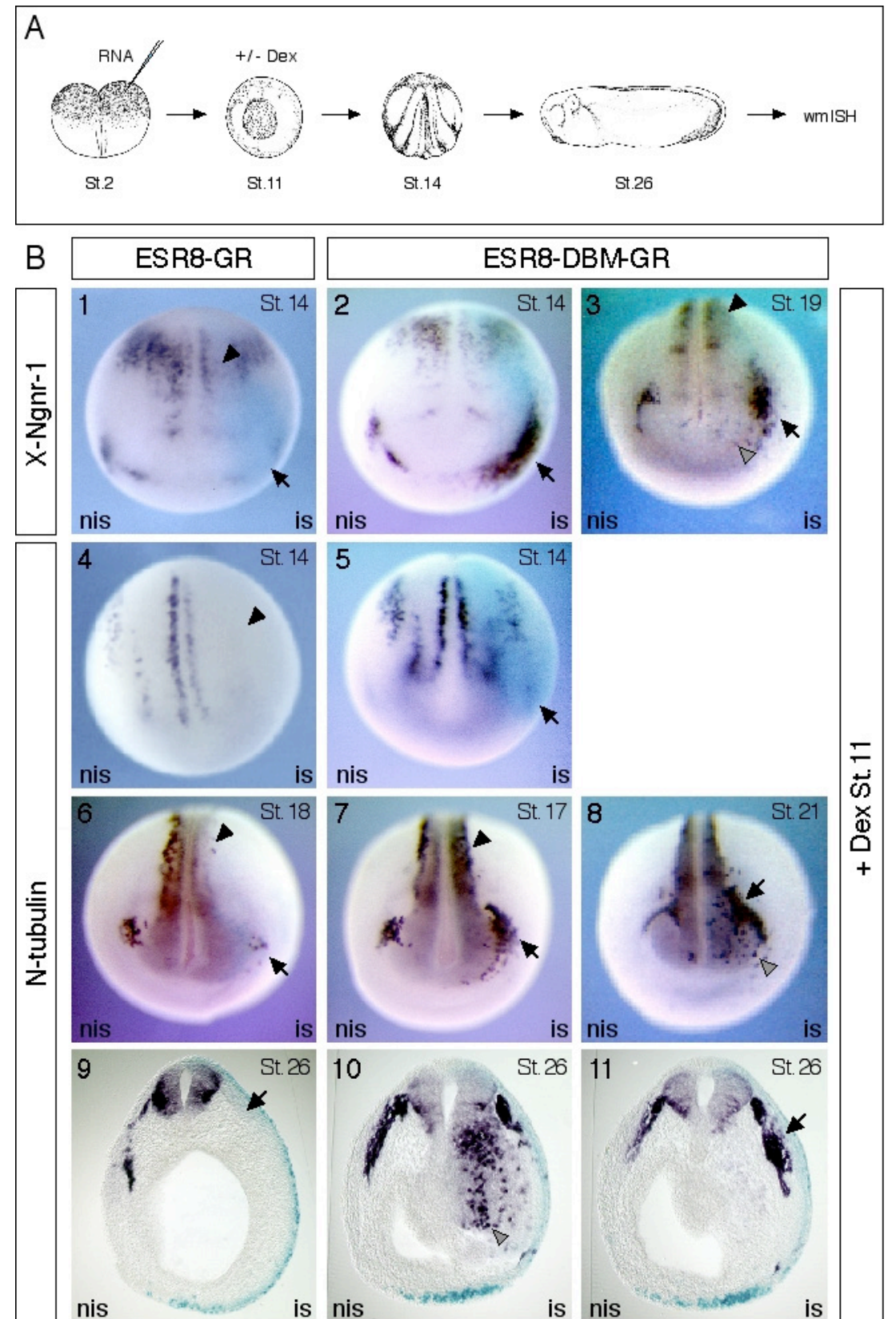

Abb.2-27: Die Neurogenese in Xenopus-Embryonen wird durch die Induktion von ESR8-GR und ESR8-DBMGR im Midgastrulastadium negativ bzw. positiv reguliert.

Auswirkungen von in St.11 induzierten ESR8-Varianten auf die Expression von X-Ngnr-1 und $\mathrm{N}$-tubulin in XenopusEmbryonen analysiert mittels wmISH. (A) Schematische Darstellung der experimentellen Strategie. Verschiedene RNAs (siehe 27B) wurden im animalen, polnahen Bereich in eine Blastomere des Zwei-Zell-Stadiums (St.2) von Xenopus laevis-Embryonen injiziert. Im St.11 wurde zu der Hälfte der injizierten Embryonen Dexamethason zur Induktion der Fusionsproteine hinzugefügt, während die andere Hälfte unbehandelt blieb. Induzierte und nichtinduzierte Embryonen wurden dann bis zum Erreichen des Stadiums 14, 17-21 und 26 kultiviert und mittels wmISH analysiert. (B) wmISH-Analyse nach Überexpression Hormon-induzierbarer ESR8-Varianten und Induktion im St.11. $(B 1,4,6,9)$ Im Stadium 11 induziertes ESR8-GR hemmt die Expression von $X$-Nngr-1 (1) und $N$-tubulin $(4,6,9)$ in den trigeminalen Plakoden bzw. Nerven (schwarze Pfeile) und in der posterioren Neuralplatte bzw. im Neuralrohr (schwarze Pfeilspitzen). (B2,3,5,7,8,10,11) Die Induktion von ESR8-DBM-GR im Stadium 11 bewirkt eine Aktivierung der Transkription von $X$-Nngr-1 $(2,3)$ und $N$-tubulin $(7,8,10,11)$ im Bereich der trigeminalen Plakoden bzw. Nerven (schwarze Pfeile) und im posterioren Neuralrohr (schwarze Pfeilspitzen), sowie in isolierten Zellen bzw. Zellgruppen der Augenvesikel (graue Pfeilspitzen); in St.14-Embryonen ist jedoch noch keine zusätzliche $N$-tubulin-Expression (5) in der trigeminalen Plakodenregion (schwarzer Pfeil) erkennbar. Ohne Dexamethason-kultivierte Embryonen wiesen keine signifikanten Veränderungen der Expression von X-Ngnr-1 und $N$-tubulin auf (nicht gezeigt). Die injizierten RNAs sind jeweils über den Fotos und die untersuchten Genexpressionen jeweils links der Fotos angegeben. Das Stadium der Induktion mit Dexamethason (+Dex St.11) ist rechts der Fotos dargestellt. Die Embryonen sind wie folgt orientiert: (B1-8) anteriore Ansicht, dorsal oben; (B9-11) $30 \mu \mathrm{m}$ Vibratom-Querschnitte auf Höhe des Trigeminus, dorsal oben. (B10,11) Aufeinanderfolgende Schnitte eines Embryos. Abkürzungen: is, injizierte Seite; nis, nicht-injizierte Seite; St., Stadium. 


\begin{tabular}{|c|c|c|}
\hline injizierte RNA & ESR8-GR & $\begin{array}{c}\text { ESR8-DBM- } \\
\text { GR }\end{array}$ \\
\hline Menge (pg) & $50 ; 100$ & $50 ; 100$ \\
\hline injizierte Zelle & $1 / 2 ; a$ & $1 / 2 ; a$ \\
\hline Induktion (St.) & 11 & 11 \\
\hline wmISH-Stadium & $14 / 15$ & $14 / 15$ \\
\hline $\begin{array}{c}+ \text { Dex } \\
\text { Anzahl N-tubulin } \\
=/ \downarrow / \uparrow(\%)\end{array}$ & $\begin{array}{c}45 ; 9 \\
11 / 89 / 0 ; \\
0 / 100 / 0\end{array}$ & $\begin{array}{c}82 \\
43 /(54) /(3)\end{array}$ \\
\hline $\begin{array}{c}\text { - Dex } \\
\text { Anzahl N-tubulin } \\
=/ \downarrow / \uparrow(\%)\end{array}$ & $\begin{array}{c}47 ; 9 \\
62 / 38 / 0 ; \\
78 / 22 / 0\end{array}$ & $\begin{array}{c}80 \\
73 /(27) / 0\end{array}$ \\
\hline wmISH-Stadium & 18 & 18 \\
\hline $\begin{array}{c}+ \text { Dex } \\
\text { Anzahl N-tubulin } \\
=/ \downarrow / \uparrow(\%)\end{array}$ & $\begin{array}{c}32 \\
22 / 78 / 0\end{array}$ & $\begin{array}{c}55 ; 21 \\
33 /(2) / 65 t ; \\
0 / 38 / 62\end{array}$ \\
\hline $\begin{array}{c}\text { - Dex } \\
\text { Anzahl N-tubulin } \\
=/ \downarrow / \uparrow(\%)\end{array}$ & $\begin{array}{c}27 \\
93 / 0 /(7)\end{array}$ & $\begin{array}{c}51 ; 18 \\
92 /(8) / 0 \\
100 / 0 / 0\end{array}$ \\
\hline wmISH-Stadium & 14 & 14 \\
\hline $\begin{array}{c}+ \text { Dex } \\
\text { Anzahl X-Ngnr-1 } \\
=/ \downarrow / \uparrow(\%)\end{array}$ & $\begin{array}{c}61 ; 30 \\
47 / 43 /(10) ; \\
7 / 93 / 0\end{array}$ & $\begin{array}{c}45 ; 23 \\
25 / 4 / 71 t \\
13 / 0 / 87\end{array}$ \\
\hline $\begin{array}{c}\text { - Dex } \\
\text { Anzahl X-Ngnr-1 } \\
=/ \downarrow / \uparrow(\%)\end{array}$ & $\begin{array}{c}70 ; 18 \\
90 / 10 / 0 \\
44 / 56 / 0\end{array}$ & $\begin{array}{c}45 ; 31 \\
98 / 0 / 2 ; \\
100 / 0 / 0\end{array}$ \\
\hline wmISH-Stadium & 18 & 18 \\
\hline $\begin{array}{c}\text { + Dex } \\
\text { Anzahl X-Ngnr-1 } \\
=/ \downarrow / \uparrow(\%)\end{array}$ & $\begin{array}{c}6 \\
0 /(83) / 17\end{array}$ & $\begin{array}{c}14 \\
0 / 0 / 100\end{array}$ \\
\hline $\begin{array}{c}\text { - Dex } \\
\text { Anzahl X-Ngnr-1 } \\
=/ \downarrow / \uparrow(\%)\end{array}$ & $\begin{array}{c}13 \\
100 / 0 / 0\end{array}$ & $\begin{array}{c}15 \\
93 / 0 /(7)\end{array}$ \\
\hline
\end{tabular}

Tab.2-9: Effekte überexprimierter induzierbarer Varianten von ESR8, ESR9 und ESR10 in Neurulastadien. Abkürzungen und Symbole: St., Stadium; +Dex, Induktion mit Dexamethason; -Dex, keine Induktion mit Dexamethason; Anzahl N-tubulin, Anzahl der mittels wmISH (N-tubulin-Expression) analysierten Embryonen; =, Expression unverändert; $\downarrow$, weniger bis keine positiven Zellen in Expressionsdomäne; $\uparrow$, mehr positive Zellen in Expressionsdomäne; ( ), schwacher Effekt; a, animal; t, trigeminale Plakode. 


\subsubsection{2 Überexpression von induzierbarem ESR8 und X-Ngnr-1 in Xenopus- Embryonen}

Die Beobachtung, dass im Midgastrulastadium induziertes ESR8-GR die neuronale Differenzierung bereits auf der Ebene der neuronalen Determinierung durch Repression der X-Ngnr-1-Transkription hemmen kann, die Repression von X-Ngnr-1-Zielgenen aber in vielen Fällen stärker war, führte zur der Frage, ob ESR8 die Neurogenese auch unterhalb von $X$-Ngnr-1 hemmen kann, wie es bereits für andere bHLH-O-Proteine beschrieben wurde (Schneider et al., 2001; Chalmers et al., 2002; Taelman et al., 2004). Um dies zu klären, wurde ESR8-GR zusammen mit X-Ngnr-1 im Zwei-Zell-Stadium von Xenopus-Embryonen überexprimiert, ESR8-GR im Midgastrulastadium durch Dexamethason induziert und der Einfluß von induziertem ESR8-GR auf die Aktivität von X-Ngnr-1, ektopisch die $N$-tubulin-Expression stimulieren zu können, mittels wmISH im offenen Neuralplattenstadium analysiert (Abb.2-28;Tab.2-10).

Ohne die Induktion von ESR8-GR resultierte die Überexpression von X-Ngnr-1 in einer starken ektopischen Expression von $\mathrm{N}$-tubulin im Ektoderm und Neuroektoderm (Abb.228B1,2). Im Midgastrulastadium induziertes ESR8-GR war hingegen sowohl in der Lage, die Anzahl und Dichte der durch X-Ngnr-1 ektopisch induzierten $N$-tubulin-positiven Zellen zu reduzieren bis hin zur nahezu kompletten Hemmung der ektopischen X-Ngnr-1Aktivität, als auch die endogene $N$-tubulin-Expression zu reprimieren (Abb.2-28B3,4). Die nur leicht verminderte X-Ngnr-1-Aktivität in ungefähr der Hälfte der Dexamethasonbehandelten Embryonen (Abb.2-28B3; Tab.2-10) könnte darauf zurückzuführen sein, dass diese Embryonen zum Zeitpunkt der Induktion bereits ein späteres Stadium erreicht hatten, in dem die ektopische neuronale Differenzierung infolge der X-Ngnr-1Überexpression im frühen Embryo bereits vor der ESR8-Induktion, nicht mehr durch induziertes ESR8-GR inhibierbar war. Insgesamt bestätigen die Ergebnisse die Annahme, dass ESR8 die neuronale Differenzierung auch unterhalb der X-Ngnr-1-Transkription durch Hemmung der X-Ngnr-1-Aktivität regulieren kann.

In weiteren Coexpressionsexperimenten mit nicht-induzierbaren Wildtyp-Formen von ESR8, ESR9 und ESR10 in animalen Kappen und in Xenopus-Embryonen konnte nachgewiesen werden, dass neben ESR8 auch ESR9 und ESR10 die N-tubulininduzierende Aktivität von X-Ngnr-1 blockieren können (Daten nicht gezeigt; Eric Bellefroid, persönliche Mitteilung). Welche für die neuronale Differenzierung verantwortlichen Faktoren durch ESR8, ESR9 und ESR10 negativ reguliert werden und welche Mechanismen zugrundeliegen, bleibt zu klären. 


\begin{tabular}{|c|c|c|c|}
\hline injizierte RNA & $\begin{array}{c}\text { X-Ngnr-1/ } \\
\text { ESR8-GR }\end{array}$ & X-Ngnr-1 & ESR8-GR \\
\hline Menge (pg) & $15 / 75$ & 15 & 75 \\
\hline injizierte Zelle & $1 / 2 ; \mathrm{a}$ & $1 / 2 ; \mathrm{a}$ & $1 / 2 ; \mathrm{a}$ \\
\hline wmISH-Stadium & 14 & 14 & 14 \\
\hline Induktion (St.) & 11 & - & 11 \\
\hline $\begin{array}{c}- \text { Dex } \\
\text { Anzahl N-tubulin } \\
=/ \downarrow / \uparrow(\%)\end{array}$ & $0 / 0 / 100^{* *}$ & $0 / 0 / 100^{* * *}$ & $47 / 53 / 0$ \\
\hline $\begin{array}{c}+ \text { Dex } \\
\text { Anzahl N-tubulin } \\
=/ \downarrow / \uparrow(\%)\end{array}$ & 58 & n.a. & 21 \\
\hline
\end{tabular}

Tab.2-10: Effekte von induzierbarem ESR8-GR auf die Aktivität von X-Ngnr-1 in Embryonen. Abkürzungen und Symbole: St., Stadium; + Dex, Dexamethason-Induktion; - Dex, keine Induktion mit Dexamethason; Anzahl N-tubulin, Anzahl der mittels wmISH (N-tubulin-Expression) analysierten Embryonen; =, Expression unverändert; $\downarrow$, weniger bis keine positiven Zellen in Expressionsdomäne; $\uparrow^{*{ }^{*} * *}$, zunehmende Anzahl positiver Zellen in Neuroektoderm und Ektoderm; a, animal; n.a., nicht analysiert.

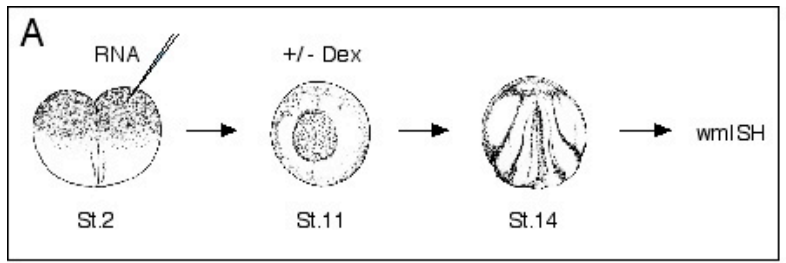

B
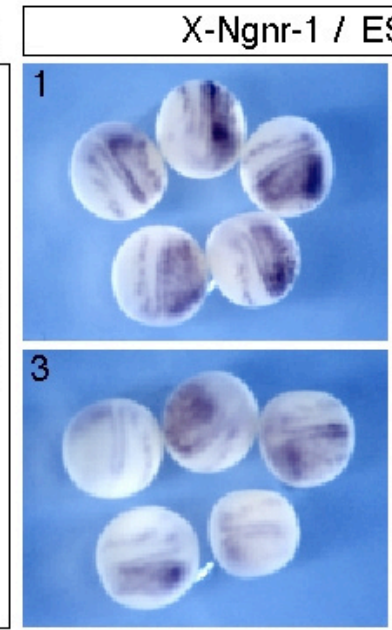

ESR8-GR
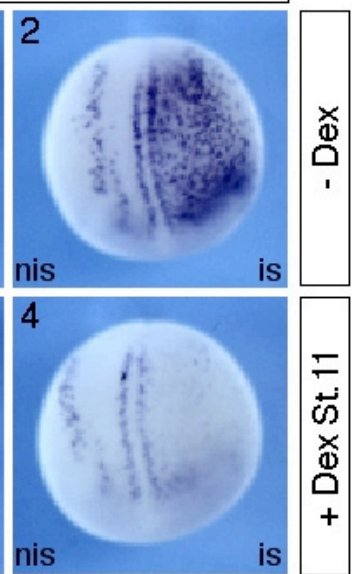

Abb.2-28: ESR8 hemmt die Aktivität von XNgnr-1 während der primären Neurogenese.

Auswirkungen von in St.11-induziertem ESR8GR auf die Aktivität von X-Ngnr-1, speziell die ektopische Expression von $N$-tubulin, im offenen Neuralplattenstadium (St.14/15) von Xenopus laevis-Embryonen analysiert mittels wmISH. (A) Schematische Darstellung der experimentellen Strategie. Verschiedene RNAs (siehe 28B) wurden im animalen, polnahen Bereich in eine Blastomere des Zwei-Zell-Stadiums (St.2) von Xenopus laevis-Embryonen injiziert. Im Stadium 11 (St.11) wurde zu der Hälfte der injizierten Embryonen Dexamethason zur Induktion der Fusionsproteine hinzugefügt, während die andere Hälfte unbehandelt blieb. Induzierte und nichtinduzierte Embryonen wurden dann bis zum Erreichen des Stadiums 14 kultiviert und mittels wmISH analysiert. (B) wmISH-Analyse nach Überexpression von X-Ngnr-1 und ESR8-GR. Die Induktion von ESR8-GR reduziert die Anzahl und Dichte der durch X-Ngnr-1 induzierten N-tubulinpositiven Zellen bis hin zur kompletten Hemmung der ektopischen X-Ngnr-1-Aktivität, sowie der endogenen $\mathrm{N}$-tubulin-Expression. Die injizierten RNAs sind jeweils über den Fotos und die untersuchten Genexpressionen jeweils links der Fotos angegeben. $\mathrm{Ob}$ die Embryonen mit Dexamethason (+Dex) oder ohne (-Dex) als Vergleichspool kultiviert wurden, ist rechts der Fotos dargestellt. Die Embryonen sind wie folgt orientiert: dorsale Aufsicht, $(\mathrm{B} 2,4)$ anterior unten. Abkürzungen und Symbole: is, injizierte Seite; nis, nicht-injizierte Seite. 


\subsubsection{Gezielte Hemmung der Proteinsynthese von ESR8, ESR9 und ESR10 in Xenopus-Embryonen}

Die Überexpression induzierbarer Varianten von ESR8, ESR9 und ESR10 zeigte, dass diese drei bHLH-O-Proteine die neuronale Differenzierung hemmen und somit vermutlich im Rahmen der Notch-vermittelten lateralen Hemmung an der Selektion zukünftiger primärer Neuronen beteiligt sind. Aufgrund der strukturellen Ähnlichkeit von ESR8, ESR9 und ESR10 untereinander und mit anderen nah verwandten bHLH-O-Proteinen können unspezifische Effekte auf die Neurogenese infolge ihrer Überexpression allerdings nicht ausgeschlossen werden. Um die Bedeutung jedes einzelnen dieser drei bHLH-O-Proteine für die Neurogenese zu untersuchen, wurde daher die Translation von ESR8, ESR9 und ESR10 in vivo gezielt durch Mikroinjektion spezifischer antisense-MorpholinoOligonukleotide in Xenopus-Embryonen (Heasman, 2002) gehemmt, gefolgt von der Analyse der Effekte auf die neuronale Differenzierung mittels wmISH.

Zur gezielten Hemmung der Proteinsynthese von ESR8, ESR9 und ESR10 wurden antisense-Morpholino-Oligonukleotide mit jeweils größt möglicher Spezifität (ESR8-MO, ESR9-MO und ESR10-MO) ausgewählt, die entsprechend ihrer Sequenz in der 5'-UTR der jeweiligen mRNA binden sollten (Abb.2-29A-C). Die Wirksamkeit und Spezifität dieser Morpholino-Oligonukleotide wurde in vitro in einem Retikulocyten-Transkriptions/Translationssystem überprüft (Abb.2-29D-F). In diesem in vitro-System konnte die in vitro Translation von ESR8 nur durch ESR8-MO, nicht aber durch ein Standard-Kontroll-MO (KoMO), ESR9-MO oder ESR10-MO spezifisch und konzentrationsabhängig gehemmt werden (Abb29D). Im Gegensatz dazu wurde die in vitro Translation von ESR9 nicht nur durch ESR9-MO, sondern auch durch ESR10-MO konzentrationsabhängig gehemmt, während ein Standard-Kontroll-MO (KoMO) oder ESR8-MO keinen Einfluß auf die ESR9Proteinsynthese besaßen (Abb.2-29E). Auch die in vitro Translation von ESR10 konnte durch ESR10-MO und ESR9-MO, nicht aber durch ein Standard-Kontroll-MO (KoMO) oder ESR8-MO konzentrationsabhängig gehemmt werden (Abb.2-29F). Somit ist nur ESR8-MO in der Lage eine spezifische Hemmung der ESR8-Translation in vitro zu bewirken. ESR9-MO und ESR10-MO hingegen können jeweils die Proteinsynthese sowohl von ESR9 als auch ESR10 hemmen, was vermutlich auf eine Kreuzhybridisierung der zu 80\% identischen Morpholino-Oligonukleotide zurückzuführen ist (Abb.2-29B,C). Da aufgrund der hohen Sequenzidentität der 5'-UTR und der sich anschließenden kodierenden Region von ESR9 und ESR10 keine spezifischeren MorpholinoOligonukleotide ausgewählt werden konnten, wurden die möglicherweise auch in vivo kreuzhybridisierenden ESR9-MO und ESR10-MO für die weitere Analyse verwendet. 


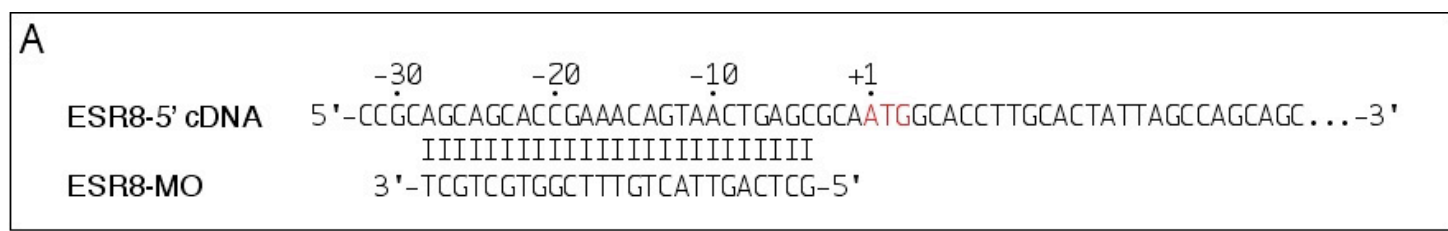

\begin{tabular}{|c|c|}
\hline \\
\hline \multicolumn{2}{|r|}{-20} \\
\hline ESR9-5' cDNA & $\begin{array}{l}5 \text { ' }-\ldots \text { AGCTCCATCÄCATCCCATTACCAGACAGAÄTGGCTCCTTACACTGCTAGCAGCATGC . ...-3' } \\
\text { IIIIIIIIIIIIIIIIIIIIIIIII }\end{array}$ \\
\hline ESR9-MO & 3'-AGGTAGTGTAGGGTAATGGTCTGTC-5' \\
\hline
\end{tabular}

\begin{tabular}{|c|c|}
\hline$C$ & -10 \\
\hline ESR10-5' cDNA & $\begin{array}{c}5^{\prime} \text { '-... AGCTCCATCÄTATCCACTTÁCTAAACAGGÄTGGCTCCTTACAGCGCTAGCAGCATGC ... -3' } \\
\text { IIIIIIIIIIIIIIIIIIIIIIIII }\end{array}$ \\
\hline ESR10-MO & 3' -AGGTAGTATAGGTGAATGATTTGTC-5 ' \\
\hline
\end{tabular}

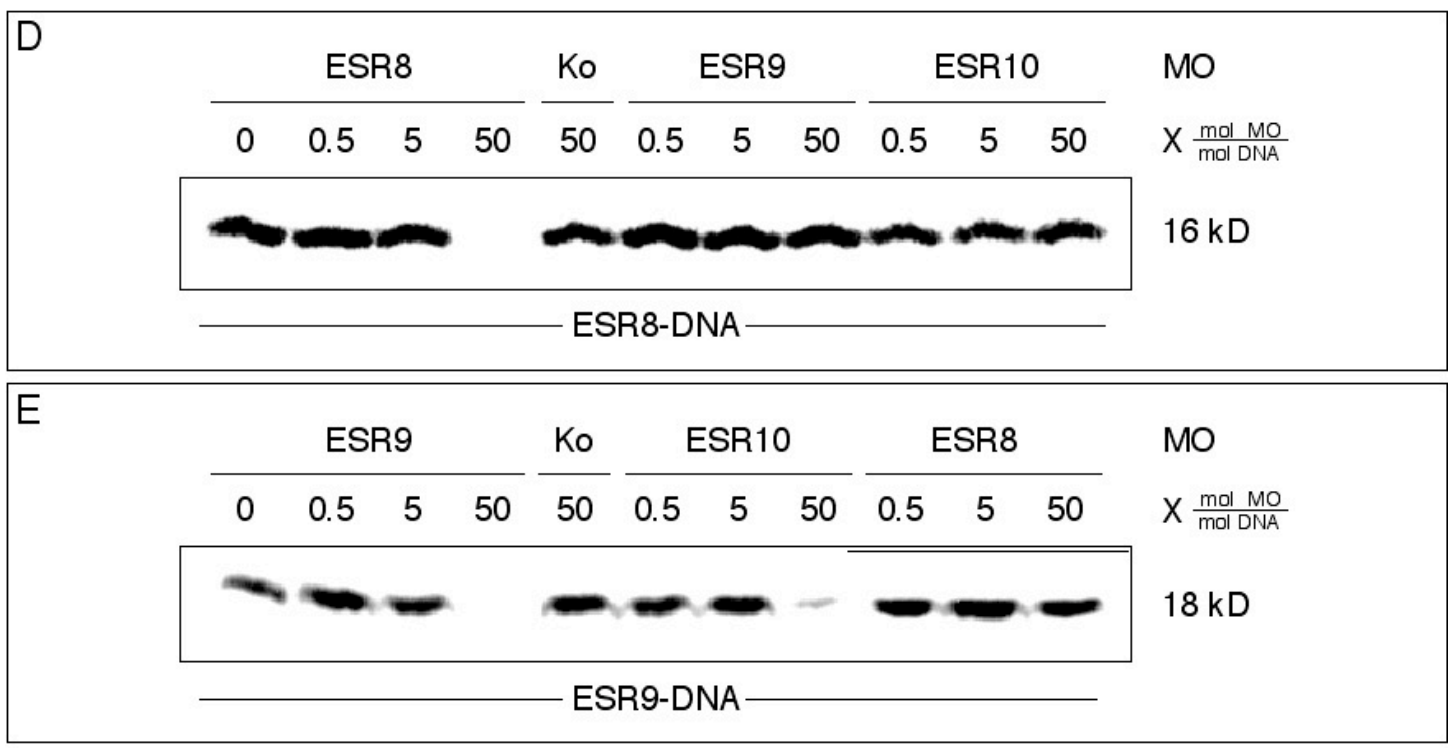

\begin{tabular}{|c|c|c|c|c|c|c|c|c|c|c|c|c|}
\hline $\mathrm{F}$ & \multicolumn{4}{|c|}{ ESR10 } & Ko & \multicolumn{3}{|c|}{ ESR9 } & \multicolumn{3}{|c|}{ ESR8 } & $\mathrm{MO}$ \\
\hline & 0 & 0.5 & 5 & 50 & 50 & 0.5 & 5 & 50 & 0.5 & 5 & 50 & $X \frac{\mathrm{mol} \mathrm{MO}}{\mathrm{mol} \mathrm{DNA}}$ \\
\hline & & & & & & & & & val & & & $18 \mathrm{kD}$ \\
\hline & & & & & $-F$ & $10-[$ & & & & & . & \\
\hline
\end{tabular}

Abb.2-29: ESR8-MO bewirkt eine spezifische Hemmung der ESR8-Translation in vitro, während ESR9MO und ESR10-MO jeweils die Proteinsynthese sowohl von ESR9 als auch ESR10 hemmen können. (A-C) Darstellung der zu den jeweiligen MOs revers komplementären Bereiche in den cDNAs von ESR8 (A), ESR9 (B) und ESR10 (C). Alle drei MOs binden (I) vor dem Startcodon (rot hervorgehoben) in der 5'-UTR der entsprechenden cDNAs. ESR9-MO und ESR10-MO unterscheiden sich voneinander nur in $20 \%(5 / 25)$ der Nukleotide (grün hervogehoben). Positionen in der translatierten Region sind mit positiven Zahlen, Positionen in der 5'-untranslatierten Region mit negativen Zahlen angegeben. (D-F) SDS-PAGE-Analyse der in vitro Transkription und Translation ( ${ }^{35}$ S-Met-Markierung) mit und ohne MOs . Die verwendeten Plasmid-DNAs sind unterhalb der Protein-Spuren angegeben, die eingesetzten MOs und deren relatives molares Verhältnis (X) zur Plasmid-DNA sind oberhalb der Protein-Spuren dargestellt. Das Molekulargewicht der Proteine ist rechts zu finden. (D) Die in vitro Translation von ESR8 kann durch ESR8-MO, nicht aber durch ein Standard-KontrollMO (KoMO), ESR9-MO oder ESR10-MO spezifisch und konzentrationsabhängig gehemmt werden. (E) Die in vitro Translation von ESR9 kann durch ESR9-MO und ESR10-MO, nicht aber durch ein Standard-Kontroll-MO (KoMO) oder ESR8-MO konzentrationsabhängig gehemmt werden. (F) Die in vitro Translation von ESR10 kann durch ESR10-MO und ESR9-MO, nicht aber durch ein Standard-Kontroll-MO (KoMO) oder ESR8-MO konzentrationsabhängig gehemmt werden. 


\subsection{Effekte von ESR8-MO, ESR9-MO und ESR10-MO auf die neuronale Differenzierung}

Um herauszufinden, welche Auswirkungen die Hemmung der Translation von ESR8, ESR9 und ESR10 auf die Embryonalentwicklung, speziell die neuronale Differenzierung hat, wurden ESR8-MO, ESR9-MO und ESR10-MO in Xenopus-Embryonen injiziert und die Effekte auf die N-tubulin-Expression mittels wmISH in verschiedenen Embryonalstadien untersucht (Abb.2-30; Tab.2-11).

Infolge der Mikroinjektion von 20 ng des jeweiligen Morpholino-Oligonukleotids pro Zelle bzw. Embryo wurde eine unterschiedlich starke Reduktion $\mathrm{N}$-tubulin positiver Zellen in St.15-Embryonen gefunden (Abb.2-30B; Tab.2-11). Die Anzahl N-tubulin-positiver Zellen wurde durch ESR8-MO verringert, allerdigs erinnerte die verbliebene $N$-tubulinExpression an ein früheres Entwicklungsstadium (Abb.2-30B1). ESR9-MO hemmte hingegen die Expression von $\mathrm{N}$-tubulin vollständig (Abb.2-30B3), während ESR10-MO einen etwas schwächeren Effekt als ESR9-MO hatte (Abb.2-30B2). Somit konnte infolge der Injektion vergleichbarer Mengen von ESR8-MO, ESR9-MO und ESR10-MO ein stärkerer Effekt bei geringerer Spezifität der Morpholino-Oligonukleotide, vermutlich aufgrund einer Kreuzhybridisierung von ESR9-MO und ESR10-MO, und bei höherer Anzahl alleler Varianten, möglicherweise infolge einer Genduplikation von ESR9 (siehe Abschnitt 2.3.1.2), beobachtet werden.

Im weiteren wurden die Auswirkungen von unterschiedlicher Mengen von ESR8-MO, ESR9-MO und ESR10-MO in späteren Entwicklungsstadien untersucht (Abb.2-30C; Tab.2-11). Dabei zeigte sich, dass die Injektion von 20ng ESR8-MO, 10ng ESR10-MO und 5ng ESR9-MO nicht unterscheidbare Phänotypen mit Veränderungen der neuralen und neuronalen Entwicklung im Stadium 18 und 30 zur Folge hatte (Abb.2-30C1-3,5-7). Geringere MO-Mengen hatten weitaus schwächere bis keine Effekte (Tab.2-11). Im Stadium 18 konnte eine deutliche Verzögerung der Neurulation beobachtet werden, die mit einer an ein jüngeres Stadium erinnernden $\mathrm{N}$-tubulin-Expression einherging (Abb.230C1-3). Während St.30-Embryonen äußerlich unauffällig waren (Abb.2-30C5-7a,b), zeigten Vibratom-Querschnitte des Gehirns dieser Embryonen eine deutliche Expansion des neuralen Gewebes begleitet von einer verringerten, sowie diffuseren N-tubulinExpression (Abb.2-30C5-7c). In den ESR9-MO injizierten Embryonen wurde außerdem eine verminderte $\mathrm{N}$-tubulin-Expression im Auge (Abb.2-30C7a,b) und eine veränderte Augenmorphologie (Abb.2-30C7d) festgestellt. Die Erhöhung der ESR9-MO-Dosis auf 10ng war ausreichend, um eine nahezu komplette Hemmung der $N$-tubulin-Expression im St.15 (Abb.2-30D1), St.18 (Abb.2-30C4) und St.30 (Abb.2-30C8) zu verursachen. Zudem 
war in St.30-Embryonen das Längenwachstum stark beeinträchtigt und verursachte eine Krümmung der Embryonen in Richtung der injizierten, kürzeren Seite (Abb.2-30C8a,b).

Der Versuch, den Effekt von ESR9-MO auf die primäre Neurogenese durch die Überexpression von ESR9 im Rahmen einer Funktionswiederherstellung abzuschwächen oder zu verhindern, war nicht erfolgreich (Abb.2-30D; Tab.2-11), was darauf hindeuten könnte, dass ESR9-MO unspezifisch die Synthese anderer Proteine, wie z.B. ESR10, hemmt oder/und dass eine Funktionswiederherstellung durch eine ubiquitäre und zeitlich nicht regulierte Proteinexpression nicht möglich ist.

Zusammenfassend läßt sich sagen, dass ESR8-MO, ESR9-MO und ESR10-MO, die eine Hemmung der Proteinsynthese von ESR8, ESR9 und ESR10 bewirken, in jeweils unterschiedlich starker Ausprägung die Neurulation verzögern, eine Expansion von neuralen Geweben bedingen und die Anzahl differenzierter Neuronen reduzieren.

Diese Ergebnisse zeigen, dass die Funktion der einzelnen, untereinander sehr ähnlichen bHLH-O-Proteine nicht durch andere Proteine kompensiert werden kann, und deuten darauf hin, dass definierte Proteinmengen von ESR8, ESR9 und ESR10 für eine normale Entwicklung und Abgrenzung des Neuroektoderms und seiner Derivate, und somit auch für die rechtzeitige, stadientypische Differenzierung primärer Neuronen benötigt werden. Diese mögliche weitere, die frühe Entwicklung betreffende Funktion von ESR8, ESR9 und ESR10 ist von den zuvor beschriebenen späteren Funktionen, wie der Hemmung der neuronalen Determinierung und Differenzierung, die bei Funktionsverlust, wie die im Midgastrulastadium induzierten DNA-Bindungsmutanten, eine erhöhte Anzahl differenzierter Neuronen hätten erwarten lassen, abzugrenzen. 


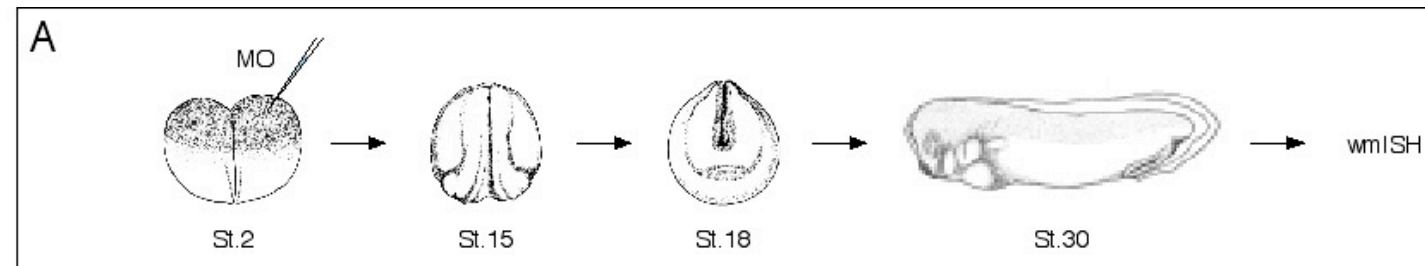

B ESR8MO (20ng) $\quad$ ESR10MO (20ng)
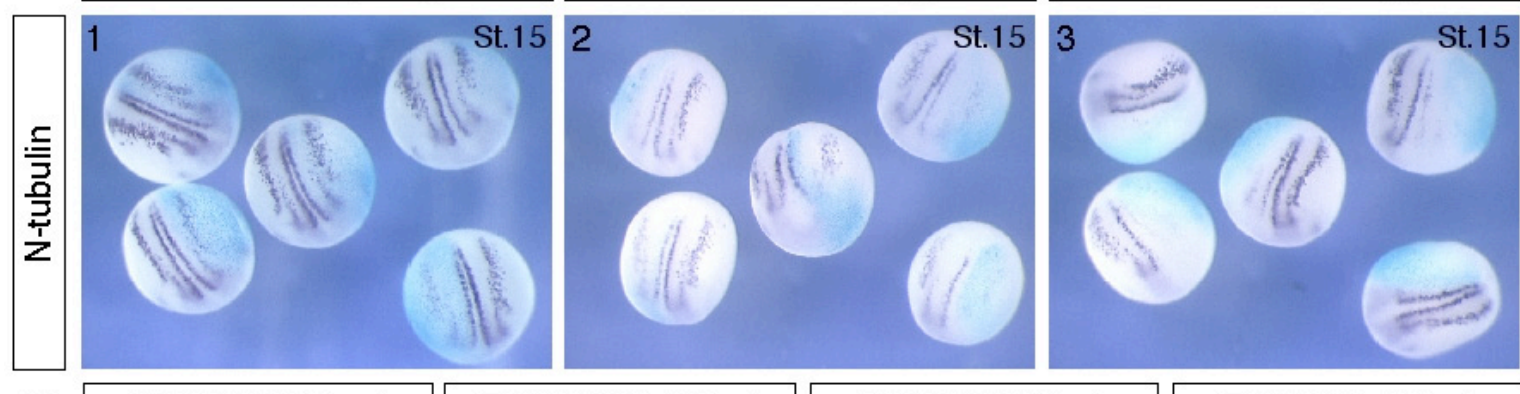

C ESR8MO (20ng)

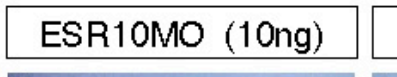

ESR9MO (5ng)
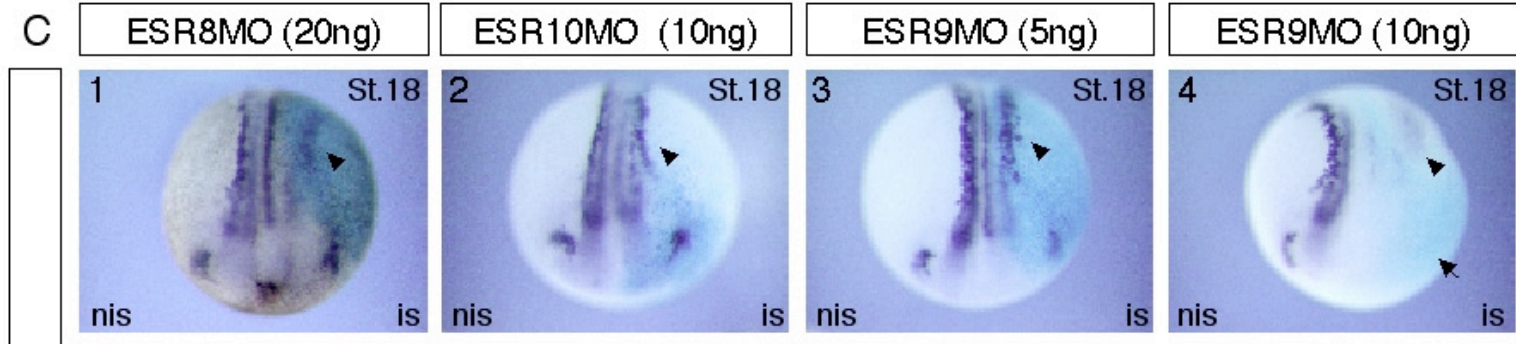

is nis

is nis
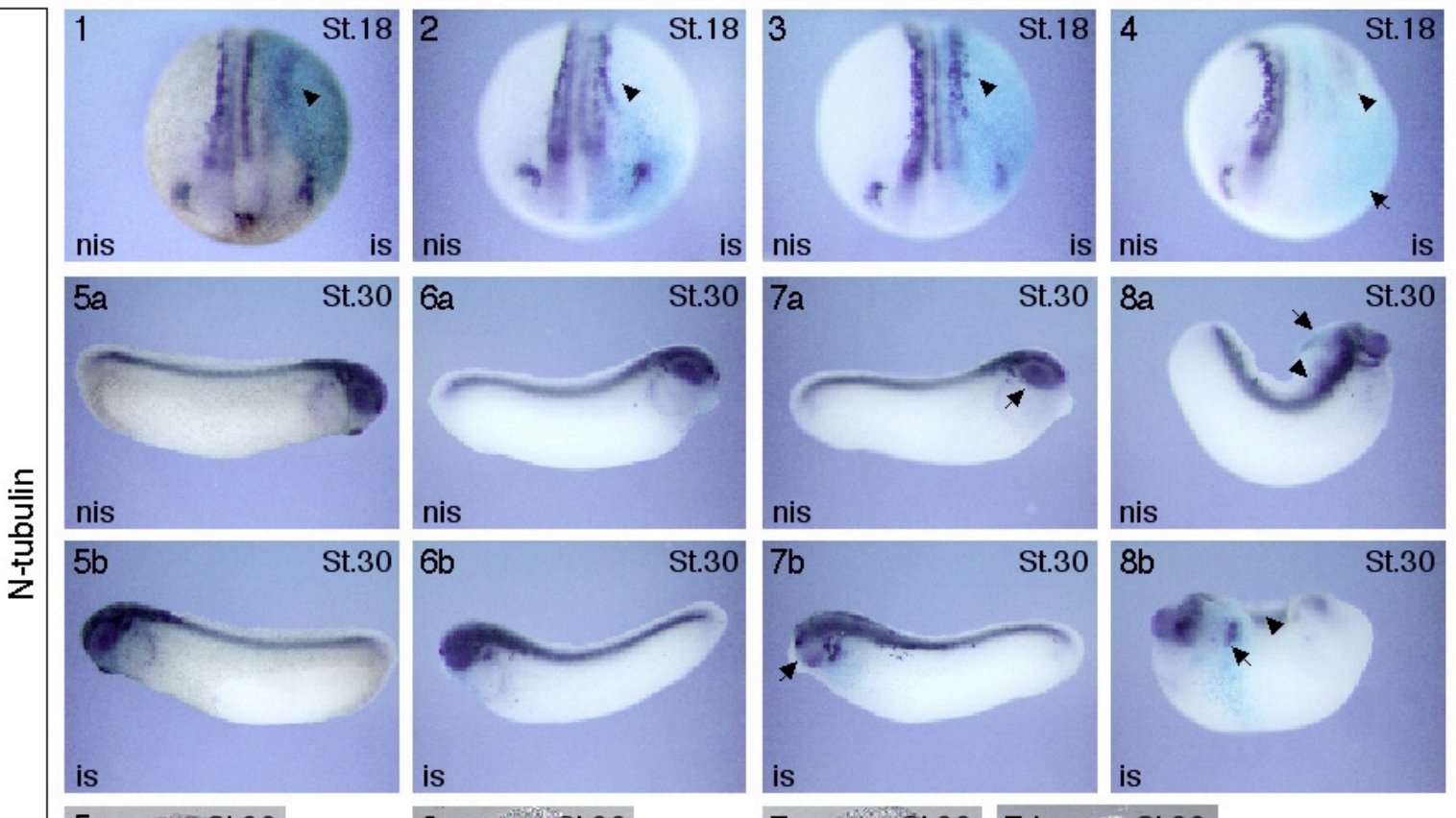

$8 b$

St.30
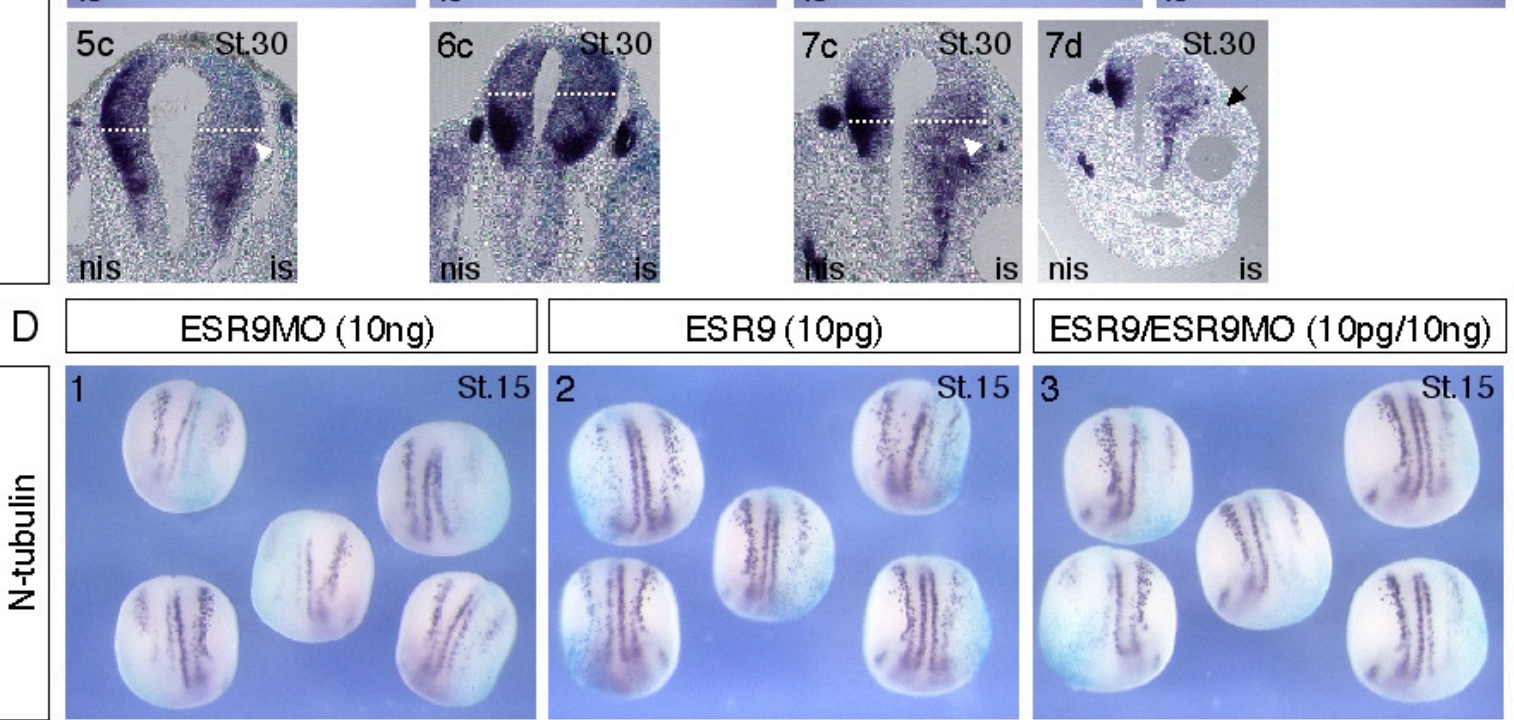
Abb.2-30: ESR8-MO, ESR9-MO und ESR10-MO verzögern die Neurulation, bedingen eine Expansion von neuralen Geweben und vermindern die neuronale Differenzierung.

Auswirkungen der Injektion von ESR8-MO, ESR9-MO und ESR10-MO auf die Expression von N-tubulin in Xenopus laevis-Embryonen analysiert mittels wmISH. (A) Schematische Darstellung der experimentellen Strategie. MOs (siehe 30B) wurden im animalen, polnahen Bereich in eine Blastomere des Zwei-ZellStadiums (St.2) von Xenopus laevis-Embryonen injiziert. Diese wurden bis zum Stadium 15, 18 oder 30 kultiviert und mittels wmISH analysiert. (B-D) wmISH-Analyse nach Injektion von ESR8-MO, ESR9-MO und ESR10-MO. (B) Jeweils gleiche Mengen der drei MOs (20ng/Embryo) bewirken eine unterschiedlich starke Reduktion $N$-tubulin positiver Zellen in St.15-Embryonen, wobei der Effekt von ESR8-MO (1) über ESR10-MO (2) zu ESR9-MO (3) zunimmt. (C1-3,5-7) Unterschiedliche Mengen von ESR8-MO (20ng), ESR9-MO (5ng) und ESR10-MO (10ng) haben ähnliche Veränderungen hinsichtlich der neuralen und neuronalen Entwicklung im St.18 und St.30 zur Folge. (C1-3) Die Einfaltung der Neuralplatte zur Bildung des Neuralrohres ist auf der MO-injizierten Seite gegenüber der nicht-injizierten Kontrollseite von St.18-Embryonen verzögert (besonders deutlich im anterioren Bereich), auch die $\mathrm{N}$-tubulin-Expression erinnert an ein jüngeres Stadium (schwarze Pfeilspitzen). (C5-7) Im St.30 sind äußerlich kaum Unterschiede zwischen injizierter und nicht-injizierter Seite erkennbar (C5-7a,b). In transversalen Schnitten auf Höhe des Mittelhirns wird allerdings infolge der MOInjektion eine deutliche Expansion des neuralen Gewebes sichtbar (weiße, gepunktete Linie), die von einer verringerten, sowie diffuseren $N$-tubulin-Expression begleitet wird (weiße Pfeilspitzen) (C5-7c). Die mit ESR9MO injizierten Embryonen zeigen zudem noch eine verminderte $N$-tubulin-Expression im Auge (C7a,b), sowie eine veränderte Augenmorphologie (C7d) (schwarze Pfeile). (C4,8) 10ng ESR9MO verursachen eine nahezu komplette Hemmung der N-tubulin-Expression im St.18 (C4) und St.30 (C8) (schwarze Pfeile und Pfeilspitzen), wobei die St.30-Embryonen insgesamt, vor allem aber auf der injizierten Seite stark verkürzt sind, was zu einer Krümmung führt (C8a,b). (D) Die Hemmung der N-tubulin-Transkription durch ESR9-MO (10ng) in St.15-Embryonen (D1) wird durch die Coinjektion von ESR9 (10pg), das die Anzahl N-tubulin positiver Zellen reduziert (D2), nicht beeinflußt (D3). Die injizierten MOs und RNAs und deren Mengen pro Embryo sind jeweils über den Fotos und die untersuchten Genexpressionen jeweils links der Fotos angegeben. Die Stadien sind rechts oben in den Fotos aufgeführt. Die Embryonen sind wie folgt orientiert: (B1-3, C1-4, D1-3) dorsale Aufsicht, anterior unten; (C5-8a,b) Seitenansicht, dorsal oben; (C5-8,a-d) jeweils identische Embryonen; (C5-7c) Ausschnittsvergrößerungen von transversalen Vibratomschnitten (30 $\mu \mathrm{m})$ auf Höhe des Mittelhirns, (C7d) gesamter Querschnitt von (C7c) durch Mittelhirn und Augen. Abkürzungen: is, injizierte Seite; nis, nicht-injizierte Seite.

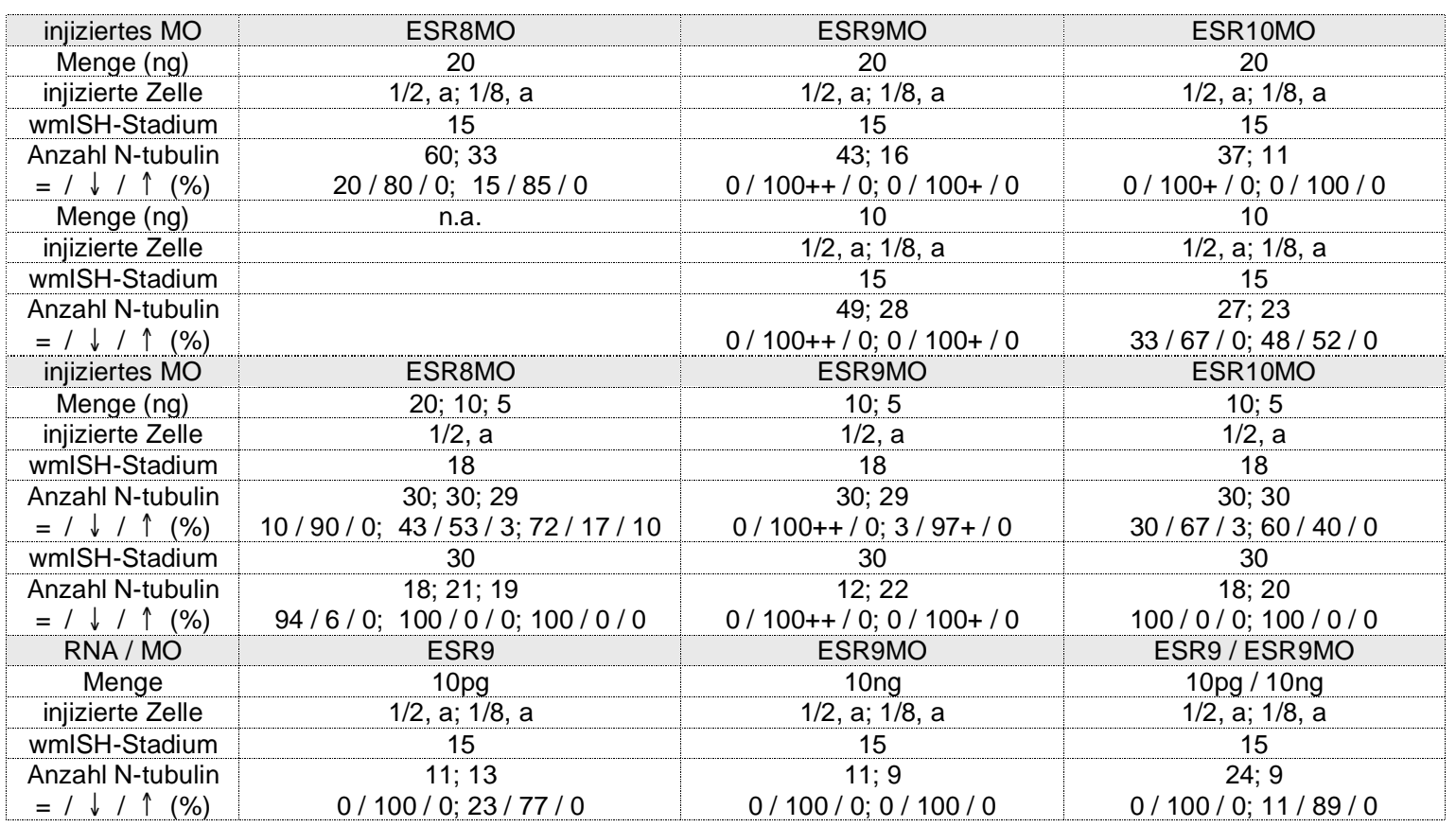

Tab.2-11: Effekte infolge der Injektion von ESR8-MO, ESR9-MO und ESR10-MO auf die Neurogenese. Abkürzungen und Symbole: MO, Morpholino-Oligonukleotid; Anzahl N-tubulin, Anzahl der mittels wmISH (Ntubulin-Expression) analysierten Embryonen; =, Expression unverändert; $\downarrow$, Reduktion der positiven Zellen (im St.18 einhergehend mit einem größeren Abstand der lateralen Expressionsdomänen zur Mittellinie); $\uparrow$, mehr positive Zellen in Expressionsdomäne; a, animal; ++, sehr stark; +, stark. 


\section{Diskussion}

Die Entwicklung des Nervensystems in Vertebraten und Invertebraten unterliegt komplexen Mechanismen, bei denen bHLH-O-Proteine, teilweise als Notch-Effektoren, regulatorische Funktionen übernehmen, indem sie das Schicksal neuraler Zellen mitbestimmen und die Neurogenese und Gliogenese beeinflussen. Trotz mittlerweile zahlreicher Studien über bHLH-O-Gene bzw. bHLH-O-Proteine in verschiedenen Organismen verbleiben eine Vielzahl von Fragen zu ihren Funktionen während der Ausbildung des Nervensystems.

Mit dem Ziel die Funktionen von bHLH-O-Proteinen bei der Entwicklung des Nervensystems, insbesondere bei der Neurogenese, von Xenopus besser zu verstehen, wurden in dieser Arbeit zunächst bHLH-O-Proteine aus Xenopus in silico identifiziert und dann einzelne der nicht näher beschriebenen bHLH-O-Proteine ausführlicher charakterisiert. Die Ergebnisse werden im folgenden, vor allem hinsichtlich ihrer Bedeutung für die Neurogenese in Xenopus, diskutiert und mit Daten anderer Vertebraten, wie Maus, Mensch und Zebrafisch, und Invertebraten, wie Drosophila, verglichen.

\section{1 bHLH-O-Gene und Proteine in Xenopus und anderen Vertebraten}

Durch die Analyse verschiedener Sequenz-Datenbanken wurden in Xenopus laevis 19 bzw. 20 verschiedene, nicht auf allele Varianten zurückzuführende bHLH-O-Proteine identifiziert, von denen zwei der Hairy-Unterfamilie (Hairy1, Hairy2), dreizehn bzw. vierzehn der E(spl)-Unterfamilie (Hes2, HR1, ESR4, ESR5, Hes6, ESR1, ESR2, ESR3/7, ESR6, ESR8, ESR9 (2x?), ESR10, ESR11), eines der Hey-Unterfamilie (HRT1) und drei der Dec-Unterfamilie (Dec1, Dec1r, Dec2p) angehören. In Xenopus tropicalis wurden 18 bHLH-O-Proteine gefunden, von denen zwei der Hairy-Unterfamilie (Hairy1, Hairy2), vierzehn der E(spl)-Unterfamilie (Hes2, HR1, ESR4, ESR5, Hes6, ESR1, ESR2, ESR3/7, ESR6, ESR8, ESR9A, ESR9B, ESR10, ESR11), eines der Hey-Unterfamilie (HRT1) und eines der Dec-Unterfamilie (Dec2p) angehören. Ein Helt-ähnliches Protein konnte weder in Xenopus laevis noch in Xenopus tropicalis identifiziert werden.

Im Zebrafisch-Genom sind mindestens 25 bHLH-O-Gene vorhanden, die zwei HairyProteine (Her6, Her9), siebzehn E(spl)-Proteine (Her10.1/2, Her3, Her5, Her7, Her1, Her11, Her8.1/2, Her13.1/2, Her14, Her12, Her15, Her2, Her4.1/2), drei Hey-Proteine (Hey1, Hey2, HeyL), ein Helt-Protein (Hey-related/Heslike) (Miyoshi et al., 2004; Sieger et al., 2004) und zwei Dec-Proteine (Dec1, Dec2) kodieren (diese Arbeit, s.Abb.A-2). 
Das Genom des Menschen und das der Fliege, die beide bereits weitaus vollständiger als das Genom und die Genprodukte von Zebrafisch, Xenopus laevis und Xenopus tropicalis sequenziert und annotiert sind, besitzen mit jeweils $13 \mathrm{bHLH}-\mathrm{O}-\mathrm{Genen}$ weitaus weniger bHLH-O-Proteine (Davis und Turner, 2001; Ledent et al., 2002; Miyoshi et al., 2004; Moore et al., 2000). Zu den 13 bekannten menschlichen bHLH-O-Proteinen zählen zwei Hairy-Proteine (HES1 und HES4), fünf E(spl)-Proteine (HES2, HES3, HES5, HES6, HES7), drei Hey-Proteine (HEY1, HEY2, HEYL), ein Helt-Protein (Heslike) und zwei Stra13/Dec-Proteine (Stra13/DEC1 und DEC2). Drosophila melanogaster besitzt drei Hairy-Proteine (hairy, deadpan und side), acht $E(s p l)$-Proteine ( $m 8, m 7, m 5, m 3, m \beta, m \gamma$, mo und her) und zwei Hey-Proteine (hesr-1 und sticky/ch1).

Damit ist die Anzahl der bHLH-O-Proteine in Xenopus, ähnlich wie im Zebrafisch, größer als im Menschen und in Drosophila. Die unvollständige DNA-Sequenzierung und das Fehlen von Hey2-, HeyL- und Helt-Homologen/Orthologen lassen weitere bHLH-OProteine in Xenopus vermuten. Es wäre allerdings auch denkbar, dass die Funktionen dieser Proteine in Xenopus von anderen bHLH-O-Proteinen übernommen werden.

Die ungefähre Verdopplung der hairy/E(spl)/hey-Gene in Kugelfisch (21) und Zebrafisch (23) gegenüber der Zahl dieser Gene in Drosophila (13) und im Mensch (11) führte zu der Vermutung, dass während der Evolution eine Duplikation im Fisch oder ein Verlust von Genfamilien-Mitgliedern in höheren Vertebraten, wie dem Menschen, nach der Duplikation in einem allen Vertebraten-gemeinsamen Vorfahren stattgefunden hat (Gajewski und Voolstra, 2002; Sieger et al., 2004). Auch die Anzahl der bisher identifizierten hairy/E(spl)/hey-Genprodukte in Xenopus (17), die sich mit fortschreitender Genomanalyse sicherlich noch erhöht, deutet auf Genduplikationen im diploiden Xenopus-Vorfahren hin.

Die größere Anzahl von bHLH-O-Proteinen in niederen Vertebraten ist ausschließlich auf die größere Anzahl von E(spl)-Proteinen, insbesondere innerhalb der Hes5-Gruppe (Li et al., 2003), zurückzuführen. Während in Maus und Mensch jeweils nur fünf $E(s p l)$-Proteine mit jeweils einem Hes5-Protein vorhanden sind, besitzen Xenopus laevis und tropicalis vierzehn $\mathrm{E}(\mathrm{spl})$-Proteine, von denen neun eindeutig der Hes5-Gruppe zugeordnet werden können (ESR1, ESR2, ESR3/7, ESR6, ESR8, ESR9A, ESR9B, ESR10, ESR11). In Zebrafisch sind sogar siebzehn E(spl)-Proteine bekannt, darunter befinden sich fünf bzw. sechs Mitglieder der Hes5-Gruppe (Her12, Her15, Her2, Her4.1, Her4.2, Her7), aber auch die Hes6- und die Hes7-Gruppe besitzen vier bzw. drei bis vier Mitglieder (Her8.1, Her8.2, Her13.1, Her13.2 bzw. Her1, Her5, Her11, Her7) (Ninkovic et al., 2005; Sieger et al., 2004). Die Beschränkung der Vervielfältigung einzelner bHLH-O-Gene in Xenopus und Zebrafisch auf $E(s p l)$-Gene läßt eher lokale Genduplikationen als eine komplette Genomduplikation in einem gemeinsamen Vertebraten-Vorfahren vermuten, auch lokale 
Genduplikationen in Klassen- bis Arten-spezifischen Vorfahren sind denkbar (Übersichtsartikel: Ledent et al., 2002; Makalowski, 2001). Die Identifizierung von drei $E(s p l)-G e n p a a r e n$ im Zebrafisch-Genom, nicht aber im Maus-Genom, unterstützt diese Hypothese lokaler Genduplikationen in Vertebraten-Linien. Die einzelnen Gene der Genpaare, her7 und her1, her5 und her11 (him), sowie her4 und her12, die jeweils eine hohe Sequenzähnlichkeit und dasselbe Säuger-Ortholog (hes7, hes7, hes5) besitzen, sind jeweils in Kopf-an-Kopf-Orientierung im Genom angeordnet und teilen sich dadurch einige, aber nicht alle der cis-agierenden regulatorischen Sequenzen, was eine überlappende Expression der Gene dieser co-funktionellen Genpaare bewirkt (Henry et al., 2002; Ninkovic et al., 2005; Sieger et al., 2004). Auch bei den einzelnen E(spl)-Genen des $E(s p l)$-Komplexes in Drosophila sind Sequenzähnlichkeiten physikalisch verknüpfter Gene und eine teilweise überlappende Expression durch gemeinsam genutzte Promotorelemente zu beobachten (Knust et al., 1992).

Die Genomanalyse von Xenopus tropicalis und laevis wird zeigen, ob in Xenopus E(spl)Genpaare, wie im Zebrafisch, oder andere Gruppierungen von $E(s p l)$-Genen vorhanden sind, die für lokale Genduplikationen sprechen. In Xenopus wäre speziell die Analyse der Genanordnung und Intronpositionen der neun Säuger-Hes5-ähnlichen Gene interessant, um deren Genduplikationsgeschichte unter Berücksichtigung der Sequenzähnlichkeiten und Expressionsmuster ableiten zu können, wie es für die im Zebrafisch vorhandenen Säuger-Hes7-ähnlichen Gene her1, her5, her7 und her11 vorgeschlagen wurde (Sieger et al., 2004). Erste Hinweise auf lokale Genduplikationen im Xenopus-Genom liefert die Identifizierung eines Xenopus tropicalis Bac-Klons, der die genomische Sequenz von drei untereinander stark konservierten Hes5-ähnlichen Genen, ESR10, ESR9B und ESR9A, in einer Schwanz-an-Kopf-Orientierung enthält (GenBank-Zugangsnummer: AC151464). In Kugelfisch, Zebrafisch und Huhn konnten Cluster von drei Hes5-ähnlichen Genen, immer einhergehend mit der Kopplung an das fang1-Gen, identifiziert werden (Fior und Henrique, 2005). Die Konservierung dieser Genanordnung von Knochenfischen bis zu Vögeln deutet darauf hin, dass diese drei Gene bereits in einem gemeinsamen Vertebraten-Vorfahren vorhanden waren, im Verlauf der Säugerentwicklung jedoch bis auf ein Hes5-ähnliches Gen verloren gingen. Die verschiedenen Genanordnungen von Hes5ähnlichen Genen im Zebrafisch, sowohl in Clustern von drei Genen als auch in Genpaaren, her4 und her12, weisen auf unterschiedliche Genduplikationsmechanismen bei $\mathrm{E}(\mathrm{spl})$-Genen in Vertebraten hin.

Die Vielzahl von bHLH-O-Proteinen, insbesondere in Xenopus und Zebrafisch, wirft u.a. die Fragen auf, welche Funktionen einzelne bzw. Kombinationen dieser Proteine besitzen und inwieweit sich einzelne Aktivitäten überschneiden oder sogar redundant sind. Ein 
solcher Vergleich erfordert eine ausgedehnte Charakterisierung der bHLH-O-Proteine in dem jeweiligen entwicklungsbiologischen Kontext, wie z.B der primären Neurogenese.

\subsection{Das Drosophila Hairy und E(spl) verwandte Protein XHes2 aus Xenopus laevis}

Die aus Xenopus laevis isolierte XHes2-cDNA kodiert ein bHLH-O-Protein mit Merkmalen der Hairy- und $\mathrm{E}(\mathrm{spl})$-Familien und ist eng mit Hes2-Proteinen aus Xenopus tropicalis, Säugern und Zebrafisch verwandt. XHes2 wird während der Embryogenese von Xenopus laevis vorwiegend in sich entwickelnden sensorischen Organen und in bestimmten Zellen im ZNS exprimiert. Die Unterschiede in den Expressionsmustern von XHes2 und anderen bHLH-O-Genen gehen mit einer unterschiedlichen Regulation dieser Gene durch Notch und X-Ngnr-1 einher. Die Überexpressionsstudien deuten darauf hin, dass XHes2 die neuronale Differenzierung hemmen kann, indem es zum einen die Transkription von $X$ Ngnr-1 und NeuroD negativ reguliert und zum anderen die proneurale Aktivität von NeuroD blockiert. Basierend auf den MO-Experimenten und der XHes2-Expression ist anzunehmen, dass XHes2 zwar keine Rolle bei der lateralen Hemmung während der primären Neurogenese übernimmt, aber für die Hemmung der neuronalen Differenzierung in XHes2-positiven Zellen in sich entwickelnden Sinnesorganen und im entstehenden ZNS erforderlich sein könnte.

\subsubsection{XHes2 und der Notch-Signalweg}

Die Expression zahlreicher bHLH-O-Gene wird durch den aktivierten Notch-Signalweg positiv reguliert, was durch die ähnlichen Expressionsmuster von Notch-Liganden, wie $X$ Delta-1, und Notch-Zielgenen, wie ESR1, zum Ausdruck kommt. Unterschiede in den Expressionen sind andererseits auf Modulatoren des Notch-Signalwegs oder andere Regulatoren der Transkription von Notch-Zielgenen zurückzuführen (Kadesch, 2004; Schweisguth, 2004; Takada et al., 2005).

Die wesentlichen Expressionsmerkmale von XHes2 unterscheiden sich in ihrer Kombination deutlich von den Expressionsmustern anderer bHLH-O-Gene und bekannter Notch-Liganden in Xenopus. Im Gegensatz zu Hes5-ähnlichen Xenopus bHLH-O-Genen, die weitläufig in Regionen der primären und sekundären Neurogenese exprimiert werden und die durch die X-Delta-1 vermittelte Notch-Aktivierung (Chitnis et al., 1995) induziert werden (Koyano-Nakagawa et al., 1999; Koyano-Nakagawa et al., 2000; Lamar und Kintner, 2005; Schneider et al., 2001; Wettstein et al., 1997), wird XHes2 nur in einer kleinen Population von Zellen im sich entwickelnden zentralen Nervensystem, sowie in sich entwickelnden Sinnesorganen exprimiert. Während in der Ohrplakode nur XHes2 
exprimiert wird, überlappen die retinalen Expressionsdomänen von XHes2 und Hes5ähnlichen Genen, sowie von $X$-Delta-1 allerdings deutlich. Übereinstimmend mit den Expressionsunterschieden dieser Gene wurde in animalen Kappen und in Embryonen für XHes2 eine im Vergleich zu Hes5-ähnlichen Genen abweichende Regulation durch Notch oder proneurale bHLH-Proteine gefunden. Die XHes2-Expression konnte durch die ektopische Aktivierung des Notch-Signalwegs weder im naiven oder neuralisierten animalen Kappenektoderm, noch in ektodermalen oder der Mehrzahl der neuroektodermalen Zellen von intakten Embryonen induziert werden. Zudem wurde die XHes2-Transkription durch X-Ngnr-1 nur in einer bestimmten Population von ektodermalen Zellen aktiviert, während sie innerhalb der Neuralplatte sogar gehemmt wurde. Die Ergebnisse lassen sich zunächst nicht mit der ldee vereinbaren, dass XHes2 ein primäres Notch-Zielgen ist und durch proneurale Aktivität induziert wird, zumindest nicht während der frühen Phasen der Neurogenese. Andererseits spricht die leichte Aktivierung der XHes2-Transkription an der seitlichen Grenze der Neuralplatte ganzer Embryonen für eine Aktivierung durch Notch im entsprechenden neuralen Entwicklungskontext, wie z.B. während der Retinogenese, wo die Expressionsdomänen von $X$ Hes2, $X$-Delta-1 und $X$-Notch-1 überlappen dürften. XHes2 wäre nicht das einzige Notch-Zielgen, das Unterschiede in der Regulationsweise durch Notch und X-Ngnr-1 aufweist, auch Xhairy2 und XHRT1 zeigen eine spezifische Kontext-abhängige Kontrolle ihrer Genexpression (Lamar und Kintner, 2005; Lopez et al., 2005; Pichon et al., 2002). Eine Promotoranalyse dürfte erforderlich sein, um weitere Einblicke in die Transkriptionsregulation von $X H e s 2$ zu erhalten.

\subsubsection{XHes2 hemmt die neuronale Differenzierung}

Aufgrund seiner Struktur und seines Expressionsmusters dürfte XHes2 als bHLHTranskriptionsfaktor die Neurogenese in spezifischen Regionen des Nervensystems regulieren. Der Einfluß der XHes2-Aktivität auf die Differenzierung von Neuronen wurde in Neuralplattenstadien und späten Neurulastadien mittels Überexpression verschiedener XHes2-Varianten untersucht. Exogenes XHes2 hemmte die Differenzierung primärer Neuronen und auch die späterer Neuronen im Neuralrohr von Xenopus-Embryonen, während antimorphe Formen von XHes2, XHes2- $\Delta$ W-VP16 bzw. XHes2- $\Delta$ C-VP16, in Embryonen und animalen Kappen $N$-tubulin, einen frühen neuronalen Differenzierungsmarker, induzieren konnten. Zudem konnte gezeigt werden, dass XHes2 für die Hemmung der Neurogenese eine intakte DNA-Bindungsdomäne benötigt, das WRPW-Corepressor-Motiv aber in gewissem Maße entbehrlich ist, was auf einen weiteren inhibitorischen Mechanismus neben der Rekrutierung von Groucho als 
Corepressor hinweisen könnte. XHes2 besitzt somit, wie einige andere Hairy- und E(spl)verwandte Proteine in Xenopus, die Fähigkeit, die neuronale Differenzierung zu hemmen (Koyano-Nakagawa et al., 2000; Schneider et al., 2001; Taelman et al., 2004).

\subsubsection{XHes2 reprimiert proneurale bHLH-Gen- und Proteinaktivität}

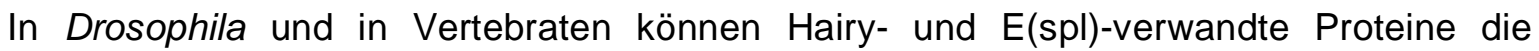
Neurogenese durch unterschiedliche Mechanismen hemmen. Neben der Repression der proneuralen bHLH-Gentranskription können sie auch die proneurale bHLH-Proteinaktivität blockieren (Castella et al., 1999; Castella et al., 2000; Cau et al., 2000; Hirata et al., 2000; Ishibashi et al., 1995; Ohsako et al., 1994; Sasai et al., 1992; Van Doren et al., 1994).

Auch die Neurogenese inhibierende Aktivität von XHes2 scheint auf einer solchen regulatorischen Beziehung mit bHLH-Aktivatoren zu beruhen. Antimorphe Formen von XHes2, XHes2- $\Delta$ W-VP16 bzw. XHes2- $\Delta$ C-VP16, konnten in Embryonen und animalen Kappen die Transkription der bHLH-Aktivatoren X-Ngnr-1 und NeuroD aktivieren, während in Embryonen die Expression von X-Ngnr-1 und NeuroD durch ektopisches XHes2 reprimiert wurde. Die Notwendigkeit der DNA-bindenden Domäne und des WRPW-Motivs für die Repression von X-Ngnr-1 deuten darauf hin, dass X-Ngnr-1 und vermutlich auch NeuroD potentielle XHes2-Zielgene darstellen. Auch die durch XHes2 verursachte Hemmung der NeuroD-induzierenden X-Ngnr-1-Aktivität ließe sich durch eine XHes2 vermittelte Repression der NeuroD-Transkription erklären. Um zu überprüfen, ob $X-N g n r-1$ und NeuroD tatsächlich direkte Zielgene von XHes2 darstellen, müßte in animalen Kappen die Proteinsythese vor der Hormon-Induktion überexprimierter antimorpher Formen von XHes2 blockiert werden.

Da durch die Aktivität von XHes2 nicht nur die NeuroD-Transkription reprimiert wurde, sondern auch die $\mathrm{N}$-tubulin induzierende Aktivität von NeuroD gehemmt werden konnte, stellte sich die Frage, ob XHes2 möglicherweise auch durch die Interaktion mit bHLHAktivatoren deren Aktivität blockieren konnte. In Coimmunopräzipitationsstudien konnten Eric Bellefroid und seine Mitarbeitern zeigen, dass XHes2 sowohl mit NeuroD (Lee et al., 1995) als auch mit Xath3 (Perron et al., 1999; Takebayashi et al., 1997), nicht aber mit XNgnr-1 (Ma et al., 1996) und Xath5 (Kanekar et al., 1997) in vivo interagieren kann (Eric Bellefroid, persönliche Mitteilung), was nahelegt, dass XHes2 der Aktivität von NeuroD und Xath3 durch Protein-Protein-Interaktionen entgegenwirken dürfte.

Zusätzlich zur Bildung von XHes2-Homodimeren interagiert XHes2 auch mit einigen anderen bHLH-O-Proteinen, wie Xhairy1 und XHes6. Eine Bindung von XHes2 und Xhairy2 oder XHes2 und ESR9 konnte in den Bindungsstudien nicht nachgewiesen werden (Eric Bellefroid, persönliche Mitteilung). Frühere Studien lassen vemuten, das 
Hes6 die neuronale Differenzierung fördert, in dem es die Funktion von Hes1 bzw. Xhairy1 und Xhairy2 blockiert (Bae et al., 2000; Gratton et al., 2003; Koyano-Nakagawa et al., 2000). Die Bildung von XHes2-XHes6-Heterodimeren könnte daher bedeuten, dass XHes6 auch der Aktivität von XHes2 entgegenwirken dürfte. Dies ließe sich leicht durch XHes2/XHes6-Coinjektionsexperimente in Xenopus-Embryonen überprüfen. Die selektive Auswahl der Bindungspartner dürfte spezifische Funktionen von bHLH-O-Proteinen ermöglichen.

\subsubsection{XHes2 und die primäre Neurogenese}

Da XHes2 nicht in den drei proneuronalen Domänen auf jeder der beiden Seiten der posterioren Neuralplatte exprimiert wird, wie verschiedene Hes5-ähnliche bHLH-O-Gene in Xenopus, und sich ebenfalls von diesen Genen in der Regulation durch Notch unterscheidet, ist auszuschließen, dass XHes2 als Notch-Effektor bei der lateralen Hemmung während der primären Neurogenese fungiert. Dies wird auch durch die nicht wesentlich veränderte Expression allgemeiner neuraler und neuronaler Marker infolge der XHes2-MO-Injektion in Neuralplattenstadien bestätigt.

XHes2 wird erst ab späteren Neuralplattenstadien, wenn bereits primäre Neuronen differenzieren, in je zwei kleinen, sehr begrenzten Populationen von Zellen auf jeder der beiden Seiten der posterioren Neuralplatte exprimiert. Die zwei folgenden Funktionen von XHes2 wären aufgrund dieser Expression denkbar: Zum einen könnte XHes2 an der Spezifizierung von Subpopulationen primärer Neuronen beteiligt sein, zum anderen könnte XHes2 aber auch in Subpopulationen neuraler Zellen deren Differenzierung verhindern oder/und auch an Zellschicksalsentscheidungen beteiligt sein. Im ersten Fall sollten die XHes2-positiven Zellen innerhalb der proneuronalen Domänen exprimiert werden, im zweiten Fall zwischen den proneuronalen Domänen. Doppel-in situHybridisierungen mit unterschiedlich markierten Sonden, die über verschiedene Farbstoffe detektiert werden, sollten Aufschluß über die genaue Lokalisation der XHes2positiven Zellen innerhalb der Neuralplatte geben. Nach Bestimmung der Subpopulation könnten, falls ausreichend molekulare Marker verfügbar sind, weitere funktionelle Analysen folgen.

\subsubsection{XHes2 und die Retinogenese}

XHes2 wird sowohl im embryonalen als auch im adulten Auge von Xenopus laevis exprimiert. Bereits ab Stadium 21 sind XHes2-Transkripte in der sich entwickelnden, proliferierenden und noch undifferenzierten Retina vorhanden. Später, während der 
Retinoblastendifferenzierung, wird die Expression von XHes2 auf die ciliäre Marginalzone (CMZ), die proliferierende retinale Vorläufer enthält, begrenzt. In der periphersten Region der CMZ, die retinale Stammzellen beherbergt, sind jedoch keine XHes2-positiven Zellen detektierbar. Somit wird XHes2 vorwiegend in retinalen Vorläufern exprimiert und dürfte daher eine Funktion bei der Bestimmung des retinalen Zellschicksals besitzen.

ESR1 und ESR3/7 zeigen ein sehr ähnliches Expressionsmuster während der Retinogenese, auch sie werden beide in retinalen Vorläufern exprimiert (Perron et al., 1998; diese Arbeit). Transkripte vieler anderer bHLH-O-Gene, wie Xhairy1, Xhairy2, XHes6, ESR8, ESR9, ESR10, XHRT1, sind ebenfalls in der sich entwickelnden Retina vorhanden (Davis et al., 2001; Koyano-Nakagawa et al., 2000; Li et al., 2003; Pichon et al., 2002; Sölter, 1999; diese Arbeit). Die Funktion dieser bHLH-O-Gene in der XenopusRetina ist bis auf die von ESR1 jedoch nicht analysiert worden. Die Überexpression von ESR1 in der sich entwickelnden Retina infolge der Mikroinjektion von RNA in eine dorsale Blastomere im 16-Zell-Stadium führte zur einer Reduktion der Anzahl an retinalen Ganglionzellen im Stadium 41 und hemmte die retinale Ganglionzellen induzierende Aktivität von Xath5 (Schneider et al., 2001). Die Expressions- und Überexpressionsstudien deuten darauf hin, dass ESR1 eine Rolle bei der Hemmung der Differenzierung retinaler Ganglionzellen in retinalen Vorläufern spielt und somit an der Bestimmung des Zellschicksals in der Retina beteiligt sein dürfte. Inwieweit ektopisches ESR1 Einfluß auf die Differenzierung von anderen retinalen Neuronen und MüllerGliazellen nimmt, die wie auch die retinalen Ganglionzellen von gemeinsamen, multipotenten Vorläufern abstammen (Turner und Cepko, 1987; Wetts und Fraser, 1988), wurde nicht untersucht.

Die Funktion von XHes2 während der Retinogenese in Xenopus laevis wurde von Muriel Perron und ihren Mitarbeitern durch Überexpression von XHes2-Varianten in der sich entwickelnden Retina näher charakterisiert (Muriel Perron, persönliche Mitteilung). Die XHes2-Varianten wurden zusammen mit GFP als Tracer mittels Lipofektion in den Augenvesikel von St.18-Embryonen in retinalen Zellen überexprimiert. Die Effekte auf die Retinogenese und die Verteilung der verschiedenen retinalen Zelltypen wurden anhand der Zellmorphologie GFP-positiver Zellen und mittels Immunhistochemie in der Zentralretina im Stadium 41 bestimmt.

Die Überexpression von XHes2 in der Retina verursachte einen starken Anstieg der Anzahl an Müller-Gliazellen aufkosten aller neuronaler Zelltypen, die XHes2-DNABindungsmutante XHes2-DBM hatten hingegen keinen Effekt auf die Verteilung der retinalen Zelltypen im Vergleich zu Kontrollen. Die ektopische Expression der XHes2Varianten XHes2 $\Delta \mathrm{W}$ und XHes2 $\mathrm{WW}$-VP16, denen beiden das Corepressor-bindende WRPW-Motiv fehlt, führte hingegen zu einer deutlichen Reduktion der Müller-Gliazellen 
und somit zu einem dominant-negativen Effekt von XHes2 $\Delta \mathrm{W}$ und XHes2 $\Delta \mathrm{W}-\mathrm{VP} 16 \mathrm{im}$ Vergleich zu dem von XHes2 auf die Gliazelldifferenzierung. Die Ergebnisse dieser Funktionsgewinn- und Funktionsverluststudien legen nahe, dass XHes2 in der Retina sowohl die Differenzierung neuronaler Zellen hemmen, als auch die Differenzierung von Müller-Gliazellen fördern kann und dass für diese Aktivität von XHes2 die DNA-bindende Domäne und das WRPW-Motiv notwendig sind. Eine einfache Verzögerung der Differenzierung retinaler Vorläufer infolge der XHes2-Überexpression scheint eher unwahrscheinlich, da von den späten retinalen Zelltypen nur die Müller-Gliazellen, nicht aber die neuronalen bipolaren Zellen vermehrt gebildet wurden. XHes2 könnte daher in der Retina eine wesentliche Rolle bei der Entscheidung des Zellschicksals zwischen Müller-Gliazellen und neuronalen Zelltypen spielen.

Auswirkungen auf die Verteilung neuronaler Zelltypen infolge der Überexpression von XHes2 $\Delta$ W und XHes2 2 W-VP16 in der sich entwickelnden Retina könnten außerdem auf eine Funktion von XHes2 bei der Spezifizierung neuronaler Zelltypen in der Retina hindeuten. Während ektopisches XHes2 $\Delta \mathrm{W}$ die Anzahl der Photorezeptoren erhöhte und die der Ganglionzellen und amakrinen Zellen verminderte, hatte überexprimiertes XHes2 $\Delta$ W-VP16 einen entgegengesetzten Effekt, was vermutlich auf die unterschiedlichen Wirkungsweisen dieser beiden XHes2-Varianten ohne WRPW-Motiv zurückzuführen ist. XHes2 $\Delta \mathrm{W}$ dürfte nur an Promotoren seiner Zielgene binden ohne diese zu reprimieren, der potentielle Transkriptionsaktivator XHes2 $\Delta \mathrm{W}$-VP16 dagegen sollte in der Lage sein, die sonst reprimierten Zielgene zu aktivieren.

Weiterhin konnten Muriel Perron und ihre Mitarbeiter durch Vergleiche der Proliferationsraten von XHes2-überexprimierenden retinalen Zellen und den entsprechenden Kontrollen in verschiedenen Stadien der Retinogenese zeigen, dass die Überexpression von XHes2 im Stadium 30 und 33/34 keinen Einfluß auf die Proliferation neuroepithelialer Zellen in der Retina hat und viele Zellen den Zellzyklus ordnungsgemäß verlassen. Im Stadium 35/36 und 37/38 hingegen ist der Anteil proliferierender Zellen infolge der XHes2-Überexpression deutlich erhöht, was vermuten läßt, dass vom Stadium 34 aufwärts einige der Zellen den Zellzyklus nicht verlassen, sondern weiterhin proliferieren, ähnlich der Vorläufer der erst spät differenzierenden Müller-Gliazellen. Experimente zur Ermittlung des Entstehungszeitpunktes der Hes2-überexprimierenden Müller-Gliazellen ergaben zudem, dass ein weitaus geringerer prozentualer Anteil der im Stadium 41 vorhandenen transfizierten Müller-Gliazellen den Zellzyklus zwischen Stadium 34 und 41 verlassen hatte und differenzieren konnte, was nahelegt, dass einige der XHes2-induzierten Müller-Gliazellen bereits zuvor aus dem Zellzyklus ausgetreten sein dürften. 
Die gliogene Aktivität von XHes2 in der Retina ließe sich demnach mit dem folgenden, auf den zuvor beschriebenen Experimenten basierenden Modell erklären: Zwischen Stadium 30 und 34 verläßt eine definierte Zellpopulation den Zellzyklus und entwickelt sich vorwiegend zu frühen Neuronen. Die Aktivität von XHes2 hat jedoch zur Folge, dass einige dieser Zellen zu Müller-Gliazellen differenzieren. Eine andere Zellpopulation zwischen Stadium 35 und 38 hingegen verläßt den Zellzyklus infolge der XHes2Überexpression nicht ordnungsgemäß, und verhält sich somit eher wie die erst spät aus dem Zellzyklus austretenden Müller-Gliavorläufer, was nahelegt, dass die XHes2-Aktivität den Proliferationszustand einiger retinaler Vorläufer verändern kann, und so die Zellen einem Gliazellschicksal zuführt. Somit dürfte der gliogenen Aktivität von XHes2 mehr als ein Mechanismus zugrundeliegen.

Übereinstimmend mit der Aufrechterhaltung des proliferativen Zustands durch die Hemmung des Zellzyklusaustritts einiger retinaler Vorläufer wird XHes2 in retinalen Vorläufern der undifferenzierten Retina und später der ciliären Marginalzone exprimiert. Dem Modell zufolge könnte XHes2 auch übergangsweise in differenzierenden MüllerGliazellen in der inneren nucleären Schicht der Retina exprimiert werden. Um dies zu klären, ist eine besser auflösende Expressionsanalyse in späteren Stadien der Retinogenese, in denen Müller-Gliazellen differenzieren, erforderlich.

Die bisher ausschließlich mittels Überexpressionsanalysen gewonnenen Daten zur mutmaßlichen Funktion von XHes2 in der Retina erfordern aufgrund möglicher unspezifischer Kreuzfunktionen mit verwandten, ebenfalls in der Xenopus-Retina exprimierten bHLH-O-Genen eine Bestätigung durch eine gezielte endogene Hemmung der XHes2-Aktivität in retinalen Vorläuferzellen mittels Injektion bzw. Lipofektion XHes2spezifischer Morpholinooligonukleotide. Im Falle einer tatsächlichen gliogenen Aktivität von XHes2 dürfte eine verminderte oder komplette Hemmung der endogenen XHes2Translation in retinalen Vorläufern zu einer erhöhten Anzahl von neuralen Zelltypen und einer verminderten Anzahl von Müller-Gliazellen in der Retina im Stadium 41 führen. Weiterhin dürften diese Knockdown-Experimente zeigen, ob XHes2 tatsächlich eine Rolle bei der Spezifizierung der neuralen Zelltypen in der Retina spielt.

In der Xenopus-Retina ist XHes2 bisher das einzige bHLH-O-Gen mit einer gliogenen Aktivität. Die funktionelle Analyse weiterer, ebenfalls in der Retina exprimierten bHLH-OGene wird zeigen, ob auch sie eine Rolle bei der Gliogenese spielen oder andere Funktionen während der Retinogenese übernehmen.

In der Maus werden die bHLH-O-Gene Hey1, Hey2, HeyL, Hes1, Hes5 and Hes6 zunächst alle in der ventrikularen Zone der Retina exprimiert, die gemeinsame, multipotente Vorläufer für Neuronen und Glia enthält (Bae et al., 2000; Hojo et al., 2000; Satow et al., 2001; Tomita et al., 1996). In späteren Stadien der Retinogenese wird die 
Expression mancher dieser Gene in differenzierenden oder differenzierten retinalen Zellen aufrechterhalten. Hey1 wird sowohl in der inneren als auch äußeren Region der inneren Kernschicht exprimiert, die jeweils amakrine bzw. horizontale Zellen enthält (Satow et al., 2001). Die Hey2-Expression ist auf die mittlere Region der inneren Kernschicht begrenzt, die bipolare und Müller-Gliazellen enthält (Satow et al., 2001). Hes5-Transkripte sind in differenzierenden, aber nicht in reifen Müller-Gliazellen vorhanden (Hojo et al., 2000). Hes 6 wird hingegen in Ganglionzellen und in der inneren Kernschicht exprimiert (Bae et al., 2000). Somit dürften Hey1, Hey2, Hes5 und Hes6 bei mehreren Schritten der Retinogenese eine Funktion besitzen. Im Gegensatz dazu ist die Expression von Hes1 und HeyL auf Vorläuferzellen begrenzt (Satow et al., 2001; Tomita et al., 1996).

Während der Retinogenese der Maus sind mehrere, aber nicht alle bHLH-O-Gene an der Auswahl des Glia-Zellschicksals aufkosten des neuralen Zellschicksals beteiligt. Eine gliogene Aktivität konnte bisher für Hes5, Hes1 und Hey2 nachgewiesen werden (Furukawa et al., 2000, Hojo et al., 2000, Satow et al., 2001). Während die ständige Expression von Hes5 in retinalen Zellen dazu führt, dass diese Zellen zu Müller-Gliazellen differenzieren, hat der vollständige Verlust von Hes5 in der Retina eine Reduktion der Anzahl an Müller-Gliazellen zur Folge (Hojo et al., 2000). In Überexpressionsstudien konnte auch Hes1 das Zellschicksal retinaler Vorläufer zugunsten von Müller-Gliazellen beeinflussen, während ein dominant-negatives Hes1-Protein mit einer mutierten DNABindungsdomäne die Differenzierung von Müller-Gliazellen hemmte (Furukawa et al., 2000). Hey2 wird ebenfalls in Müller-Gliazellen exprimiert und besitzt bei konstitutiver Expression in Retina-Explantaten eine Gliogenese fördernde und Neurogenese inhibierende Aktivität (Satow et al., 2001). Zudem geht in Mash1/Math3-Knockout-Mäusen eine erhöhte Anzahl von Müller-Gliazellen aufkosten bipolarer Zellen mit einer deutlich erhöhten Hey2-Expression einher (Satow et al., 2001). Die spezifischen Funktionen von Hes1, Hes5 und Hey2 bei der retinalen Gliogenese wurden bisher nicht untersucht, dürften aber auf die Regulation unterschiedlicher Faktoren auf Transkriptions- und Proteinebene zurückzuführen sein. Es bleibt jedoch anzumerken, dass nicht alle in der Retina exprimierten bHLH-O-Gene eine gliogene Aktivität besitzen, wie z.B. Hes6, dessen Überexpression eine hemmende Wirkung auf die Gliogenese hat (Bae et al., 2000), oder auch Hey1 oder HeyL, die scheinbar keine Rolle bei retinalen Zellschicksalsentscheidungen spielen (Satow et al., 2001).

Die Bedeutung proneuraler bHLH-Aktivität für die Gliazelldifferenzierung veranschaulichen die beiden folgenden Studien. In Mash1/Ngn2-Knockout-Mäusen differenzieren retinale Vorläufer zu Gliazellen und nicht zu Neuronen (Nieto et al., 2001). Im Gegensatz dazu fördert die Überexpression des neuralen bHLH-Proteins Ngn1 nicht nur die neuronale Differenzierung neuraler Vorläufer, sondern hemmt auch ihre 
Differenzierung zu Gliazellen (Sun et al., 2001). Die gliogene Aktivität von XHes2 in der Retina dürfte somit ebenfalls auf die Repression proneuraler bHLH-Gen- und Proteinaktivität zurückzuführen sein. Ob XHes2 auch eine instruktive gliogene Aktivität besitzt, bleibt zu klären.

\subsubsection{XHes2 und die frühe Innenohrentwicklung}

XHes2 wird sowohl im Bereich der Ohrplakoden als auch später in den dorsalen Ohrvesikeln von Xenopus-Embryonen exprimiert, was vermuten läßt, dass XHes2 während der Entwicklung des Innenohres eine wichtige Rolle spielt.

Die Ohrplakode entwickelt sich, wie Seitenlinien- und epibranchiale Plakoden, aus der posterioren Plakodenregion (Schlosser und Ahrens, 2004), in der verschiedene Transkriptionsregulatoren, wie Pax8, Pax2 und Sox9, exprimiert werden (Heller und Brändli, 1997; Heller und Brändli, 1999; Saint-Germain, 2004; Schlosser und Ahrens, 2004). Während die terminale Differenzierung von Neuronen in profundalen und trigeminalen Plakoden bereits in Neuralplattenstadien von Xenopus-Embryonen stattfindet (Chitnis et al., 1995; Ma et al., 1996; Schlosser and Northcutt, 2000), treten erst ab dem Stadium 33/34 morphologische Kennzeichen für die Entstehung eines sensorisches Epithels im ventro-medialen Ohrvesikel auf (Nieuwkoop und Faber, 1994). NeuroDpositive Zellen sind ebenfalls erst ab Stadium 32-34 im Ohrvesikel vorhanden (Schlosser und Ahrens, 2004).

Eine der naheliegensten Funktionen von XHes2 in der Ohrplakode könnte daher die Transkriptionsrepression proneuraler bHLH-Faktoren sein, um eine neuronale Differenzierung in dieser Region zu verhindern. In Überexpressionsexperimenten konnte gezeigt werden, dass XHes2 die neuronale Differenzierung hemmen kann. Im Gegensatz dazu konnte in späten Neurulastadien infolge der XHes2-MO-Injektion eine ektopische Expression von NeuroD in einigen Zellen im Bereich der Ohrplakode detektiert werden. Die schwache Ausprägung dieses Phänotyps ist möglicherweise auf eine redundante Funktion von Xhairy1 zurückzuführen, das ebenfalls in der Ohrplakode exprimiert wird und dessen Expression bei Absinken des XHes2-Niveaus im Bereich der dorsalen Ohrplakode hochreguliert werden könnte. Eine kompensatorische Expression von Hairy- und E(spl)verwandten Genen in Säugern wurde bereits beschrieben (Hatakeyama et al., 2004).

Weiterhin könnte die Expression von XHes2 im dorsalen Bereich der Ohrplakode und die Expression von Xhairy1 im ventralen Bereich der Ohrplakode in späten Neurulastadien auch auf eine Funktion dieser beiden bHLH-O-Gene bei der Spezifizierung verschiedener Zelltypen hindeuten. 
Für eine normale Innenohrentwicklung ist eine kontrollierte Pax2-Expression notwendig. Im Zebrafisch verändert der Funktionsverlust von pax $2 \mathrm{a}$, oder pax $2 \mathrm{~b}$, oder beiden mehrere Aspekte der Haarzellentwicklung, die Ohrplakodenentwicklung ist hingegen nicht betroffen, was aber auf eine redundante Funktion von pax8 zurückzuführen sein könnte (Riley et al., 1999; Whitfield et al., 2002). Maus-Pax2-Mutanten besitzen schwere Innenohrdefekte, innen fehlt die gesamte Cochlea und ein großer Teil des vestibuloakustischen Ganglions, der Vestibularapparat ist hingegen normal (Favor et al., 1996; Torres et al., 1996). Im Menschen gehen Pax2-Mutationen (Nieren-KolobomSyndrom) in hoher Frequenz mit Gehörlosigkeit einher (Übersichtsartikel: Eccles and Schimmenti, 1999). Die folgenden experimentellen Daten lassen vermuten, dass XHes2 einen Einfluß auf die Regulation der Pax2-Expression hat. In späten Neurulastadien wird die Pax2-Expression (Heller und Brändli, 1997) in der Ohrplakode durch XHes2 runterreguliert und durch XHes2- $\Delta$-W-VP16 sogar vollständig unterbunden. Auch die Induktion von XHes2- $\Delta$-W-VP16-GR im Stadium 17 bewirkt eine Hemmung der Pax2Transkription. Außerdem konnte eine starke Reduktion der Pax2-Expression in der Ohrplakode infolge der XHes2-MO-Injektion beobachtet werden. Somit scheint eine feinabgestimmte XHes2-Dosis für eine normale Pax2-Expression in der Ohrplakode notwendig zu sein.

In Medaka konnte gezeigt werden, dass Sox3 ein permissiver Faktor für die Etablierung der plakodalen Kompetenz ist und die Überexpression u.a. eine ektopische Expression von Pax2 und Eya1, sowie die Bildung ektopischer Ohrvesikel im Rumpfektoderm zur Folge hat (Köster et al., 2000). Sox3 verhindert aber auch durch die Hemmung proneuraler Aktivität die neuronale Differenzierung und erhält dadurch undifferenzierte neurale Vorläuferzellen (Bylund et al., 2003). XSox3 (Penzel et al., 1997) konnte in frühen Neurulastadien in der plakodalen Expressionsdomäne durch XHes2, nicht aber durch NLS-XHes2-DBM oder XHes2- $\Delta-\mathrm{W}$, runterreguliert werden. Die antimorphe Form von XHes2, XHes2- $\Delta$-W-VP16, dagegen induzierte XSox3 im Ektoderm. Die Hes2-MOInjektion hatte allerdings nur eine leichte Reduktion der plakodalen XSox3Expressionsdomäne zur Folge. Da XHes2 erst nach XSox3 und darüber hinaus auch begrenzter exprimiert wird, könnte XHes2 vielleicht erst in späteren Stadien für die Repression der XSox3-Transkription im Bereich der dorsalen Ohrplakode verantwortlich sein.

Die hier aufgeführten experimentellen Daten geben erste Hinweise auf die Funktionen von XHes2 während der Innenohrentwicklung und ermöglichen Spekulationen. Weitere funktionelle Analysen, insbesondere spezifische Funktionsverluststudien, sind notwendig, um die Rolle von XHes2 in den verschiedenen Stadien der Innenohrentwicklung zu verstehen. 


\subsubsection{XHes2 und seine orthologen Proteine in Vertebraten}

Aufgrund der hohen Sequenzähnlichkeit mit Säuger-Hes2-Proteinen sind XHes2 aus Xenopus laevis und die in silico identifizierten Hes2-Proteine aus Xenopus tropicalis und Zebrafisch vermutlich Hes2-orthologe Proteine. Im Gegensatz zu den übrigen Hairy und $\mathrm{E}(\mathrm{spl})$ verwandten Proteinen in Vertebraten ist bisher kaum etwas über die biologische Rolle von Hes2-Proteinen bekannt. Nur die Hes2-Proteine aus Maus und Mensch wurden über die Sequenz hinaus näher charakterisiert (Ishibashi et al., 1993; Katoh und Katoh, 2004; Nakayama et al., 1997; Nishimura et al., 1998; White et al., 2005).

Das Maus-Hes2-Gen wird bereits in Embryonen 9,5 Tage nach der Befruchtung $(E 9,5)$ exprimiert und seine Transkripte sind in einer Vielzahl von embryonalen und adulten Organen vorhanden, einschließlich des zentralen Nervensystems (Ishibashi et al., 1993). Die Expressionsanalysen beschränken sich allerdings auf Northern Blots und RNaseProtection-Assays, RNA in situ-Hybridisierungen zur genaueren Bestimmung der Hes2Expressionsdomänen in den sich entwickelnden oder adulten Organen sind mit Ausnahme der Plazenta (Nakayama et al., 1997) nicht publiziert. In der Maus-Plazenta konnten Hes2-Transkripte ab Tag 8,5 nach der Befruchtung in verschiedenen Trophoblasten-Zelltypen, wie z.B. den Trophoblasten-Riesenzellen, mittels in situHybridisierung detektiert werden. Notch-2 und Hes-3 werden ebenfalls in diesen Zellen exprimiert, während Mash-2 deutlich runterreguliert wird. Diese Daten legen nahe, dass Hes2, wie auch Hes3 und Notch-2, für die Entwicklung der Plazenta von Bedeutung sind, z.B. durch die Hemmung der Mash-2-Transkription (Nakayama et al., 1997). Ob Hes2 und/oder Hes3 in Trophoblasten-Riesenzellen durch die Aktivierung von Notch-2 induziert werden und tatsächlich die Expression von Mash-2 negativ regulieren, bleibt experimentell $\mathrm{zu}$ bestätigen. Transiente Transfektionsanalysen zeigten, dass die Promotoraktivitäten von Hes2, wie die von Hes3, in C3H101/2-Zellen, embryonalen MausFibroblasten, durch die konstitutiv-aktive Form von Notch-1 nicht signifikant hochreguliert werden können, ganz im Gegensatz zu Hes1- und Hes5-Promotoraktivitäten (Nishimura et al., 1998). Diese Daten lassen vermuten, dass Hes2 nicht durch die Aktivierung des Notch-1-Signalwegs, sondern durch andere Faktoren induziert wird.

In DNase-I-Footprint-Analysen bindet Hes2 wie andere Hes-Proteine an N-BoxSequenzen (CACNAG) und als einziges der Maus-Hes-Proteine an E-Box-Sequenzen (CANNTG), wobei Hes2 in Gel-Moblilty-Shift-Analysen eine höhere Affinität für die E-Box als für die N-Box aufweist (Ishibashi et al., 1993). Transiente Transfektionsanalysen in $\mathrm{NIH} / 3 \mathrm{~T} 3-$ Zellen und $\mathrm{C} 3 \mathrm{H} 101 / 2-Z e l l e n$, embryonalen Maus-Fibroblasten, zeigten, dass Hes2 die Expression von Reportergenen, deren Promotoren entweder die E-Box oder die N-Box enthalten, vermindern kann. Die durch E47, MASH1 und MyoD vermittelte 
Induktion von Reportergenen, deren Promotoren entweder кE2-Stellen bzw. den MuskelKreatinkinase-Enhancer enthielten, konnte jedoch durch Hes2 nicht beeinflußt werden, während Hes1 eindeutig hemmend wirkte. Diese Daten sprechen dafür, dass Hes2 die Transkription durch eine direkte Bindung an DNA-Zielsequenzen reprimieren kann, aber keine inhibitorische Wirkung auf die Aktivität der bHLH-Aktivatoren E47, MASH1 und MyoD hat (Ishibashi et al., 1993).

Zudem existieren einige wenige Daten für das humane Hes2-Gen. Eine DatenbankAnalyse zeigte u.a., dass die humane Hes2 mRNA in Plazenta, sowie verschiedenen Krebsarten und Tumoren exprimiert wird (Katoh und Katoh, 2004). In einer anderen Studie wurde mittels Real-time RT-PCR-Analyse festgestellt, dass das humane Hes2Gen, das in der genomischen Region 1p36.3 lokalisiert ist, in vielen Organen, einschließlich des Gehirns, und während der frühen Entwicklung differentiell exprimiert wird (White et al., 2005). Da 1 p36.3 in Neuroblastomen mit einer deutlichen Überexpression des MYCN-Protoonkogens auffällig häufig deletiert ist und vermutlich eines oder mehrere Tumorsuppressorgene enthält (White et al., 2005), besteht die Möglichkeit, dass Hes2 bei der Neuroblastom-Tumorentstehung oder -entwicklung als Tumorsuppressor fungiert. Beide Studien legen daher nahe, dass die Deregulation der Hes2-Expression für die Entstehung und Entwicklung verschiedener Tumore von Bedeutung sein könnte.

Weitere Studien, insbesondere zur in vivo-Funktion von Hes2-Proteinen, sind notwendig, um die Rolle von Hes2 während der Vertebraten-Entwicklung zu verstehen und um beurteilen zu können, inwieweit Funktionen der Hes2-Proteine innerhalb der Vertebraten konserviert sind.

\subsection{Die Drosophila E(spl)-verwandten Proteine ESR8, ESR9 und ESR10 aus Xenopus laevis}

Von acht bzw. neun Maus-Hes5-ähnlichen Genen in Xenopus laevis sind ESR8, ESR9 und ESR10 am engsten miteinander verwandt. Die durch Notch-induzierbaren drei Gene werden während der Embryogenese in proneuronalen Domänen, in entstehenden Somiten und im Pankreas exprimiert. Ektopische, Hormon-induzierte ESR8-, ESR9- und ESR10-Wildtypproteine hemmen die Differenzierung primärer Neuronen. Mutationen in der DNA-bindenden Domäne von ESR8 haben hingegen einen dominant-negativen Effekt auf die neuronale Determinierung und Differenzierung und resultieren in zusätzlichen $X$ Ngnr-1- und N-tubulin-positiven Zellen in proneuronalen Domänen. RNA-Coinjektionen von ESR8 und X-Ngnr-1 zeigen, dass ESR8 auch die X-Ngnr-1-Aktivität blockiert. Diese Daten stimmen mit Erwartungen für Proteine überein, die an der lateralen Hemmung 
während der primären Neurogenese beteiligt sind. Die endogene Hemmung der Translation von ESR8-, ESR9- und ESR10 durch MO-Injektionen in Embryonen resultierte jedoch nicht in überzähligen Neuronen, sondern hatte die Reduktion oder das Fehlen primärer Neuronen zur Folge, was für eine weitere, der lateralen Hemmung vorgeschalteten Funktion von ESR8-, ESR9- und ESR10 spricht und deren Notwendigkeit für eine zeitlich und räumlich korrekte neuronale Differenzierung zeigt.

\subsubsection{Hes5-ähnliche Proteine in Xenopus}

Außer ESR8-, ESR9- und ESR10 besitzt Xenopus laevis mindestens fünf weitere Hes5ähnliche Proteine, ESR1, ESR2, ESR3/7, ESR6, und ESR11, die aufgrund von Sequenzähnlichkeiten und vermutlich auch Expressionsmustern verschiedenen Untergruppen zugeordnet werden können. Für ESR2 und ESR11 stehen außer der Sequenzen keine weiteren Daten zur Verfügung, die hier diskutiert werden könnten. Es existieren mindestens drei Untergruppen, die ESR8/ESR9/ESR10-Untergruppe, die ESR1/7-Untergruppe und die ESR6-Untergruppe. ESR8-, ESR9- und ESR10 werden in Neurulastadien in proneuronalen Domänen und in weiten Bereichen des präsomitischen Mesoderms exprimiert (Gawantka et al., 1998; Lahaye et al., 2002; Li et al., 2003; Moreno und Kintner, 2004; Takada et al., 2005; Lamar und Kintner, 2005; diese Arbeit), Transkripte von ESR1 und ESR7 sind vorwiegend in proneuronalen Domänen vorhanden (Koyano-Nakagawa et al., 2000; Lamar und Kintner, 2005; Schneider et al., 2001; Takada et al., 2005; diese Arbeit). ESR6 wird dagegen im nicht-neuralen Ektoderm und der Haftdrüse exprimiert, allerdings auch in einer bilateralen Reihe von Zellen nahe der Mittellinie (Chalmers et al., 2002; Deblandre et al., 1999). Die unterschiedlichen Expressionsmuster der verschiedenen Untergruppen deuten auf Gewebe-spezifische Regulationsmechanismen hin. Die Expressionsdomänen der ESR8/ESR9/ESR10- und der ESR1/7-Untergruppe in der Neuralplatte überlappen räumlich und zeitlich mit denen von X-Delta-1 (Chitnis et al., 1995), was nahelegt, dass sie während der primären Neurogenese eine wesentliche Rolle bei der lateralen Hemmung infolge der Aktivierung des Notch-Signalwegs durch X-Delta-1 spielen. Andererseits ist X-Delta-1 ähnlich ESR6 in Gastrulastadien im nicht-neuralen, ventralen Ektoderm exprimiert und vermittelt durch die Aktivierung des Notch-Signalwegs die Selektion von Zilienzellenvorläufern (Deblandre et al., 1999). Für alle bisher untersuchten Hes5-ähnlichen Gene konnte nachgewiesen werden, dass sie durch Notch induzierbar sind und somit Notch-Effektoren darstellen (Deblandre et al., 1999; Gawantka et al., 1998; Koyano-Nakagawa et al., 2000; Lahaye et al., 2002; Takada et al., 2005; Wettstein et al., 1997). Bis auf ESR6, das nur im Ektoderm durch Notch induzierbar ist (Deblandre et al., 1999), werden alle untersuchten, in 
proneuronalen Domänen exprimierten Hes5-ähnlichen Gene im Ektoderm und Neuroektoderm durch Notch hochreguliert (Koyano-Nakagawa et al., 2000; Lamar und Kintner, 2005; diese Arbeit). Die Unterschiede in der Notch-Antwort lassen vermuten, dass neben Notch noch weitere, jeweils Kontext-abhängige Faktoren für die Induktion der verschiedenen Hes5-ähnlichen Gene notwendig sind. Auch zwischen der ESR8/ESR9/ESR10- und der ESR1/7-Untergruppe gibt es Unterschiede in der Regulation, allerdings nicht nur bezüglich der Expression im präsomitischen Mesoderm, die auf eine Funktion der ESR8/ESR9/ESR10-Untergruppe bei der Somitogenese hindeutet (Li et al., 2003), sondern auch hinsichtlich der scheinbar gleichen Expression in den proneuronalen Domänen. In Transfektionsexperimenten und mittels transgener Frösche konnte gezeigt werden, dass die durch X-Ngnr-1 und Notch induzierten Hes5ähnlichen Gene ESR1 und ESR10 unterschiedlich durch proneurale Aktivitäten reguliert werden (Lamar und Kintner, 2005), wobei die Aktivierung von Notch für die Induktion beider Gene im proneuralen Kontext notwendig, aber allein nicht ausreichend ist und bHLH-Aktivatoren erfordert. Die Ergebnisse sprechen für eine indirekte Regulation von ESR1 durch proneurale Aktivitäten über den X-Delta-1/X-Notch-1-Signalweg, sowie für eine direkte als auch indirekte Regulation von ESR10 durch X-Ngnr-1, und zeigen, dass X-Ngnr-1 und Notch die Transkription von ESR10 synergistisch hochregulieren. Ein solcher Synergismus von proneuralen Proteinen und Notch konnte auch bei der Aktivierung von $E(s p l)-G e n e n$ in Drosophila-Imaginalscheiben beobachtet werden (Bailey and Posakony, 1995; Cooper et al., 2000; Kramatschek and Campos-Ortega, 1994). Da es trotz der scheinbar überlappenden proneuronalen Expressionsdomänen von ESR1 und ESR10 Unterschiede in der Regulation dieser Gene zu geben scheint, liegt es nahe, dass sich auch einzelne Zellen innerhalb dieser Domänen hinsichtlich ihrer ESR1- und ESR10Transkriptmengen unterscheiden, was vermutlich einen Einfluß auf das Zellschicksal haben dürfte. Für den Nachweis einer solchen möglichen differentiellen Verteilung der Transkripte wäre die gemeinsame Detektion von ESR1 und ESR10 bzw. den anderen Migliedern der beiden Untergruppen in einzelnen Zellen zu verschiedenen Zeitpunkten während der primären Neurogenese notwendig, wobei das geringe Expressionsniveau dieser Gene eine äußerst sensitive Nachweismethode erfordert.

Lamar und Kintner (2005) stellten basierend auf ihren Ergebnissen u.a. die Hypothese auf, dass ESR10 und ESR1 infolge ihrer differentiellen Expression unterschiedliche Funktionen bei der lateralen Hemmung haben könnten. Die direkte Regulation von $E(s p l)-$ Genen durch bHLH-Proteine wirkt der Zellschicksalsentscheidung entgegen, wenn die Hemmung der Zellschicksalsannahme, die Runterregulation von Faktoren, die dieses Schicksal regulieren, erfordert (Heitzler et al., 1996). Daher könnte eine Untergruppe von Notch-Effektoren, wie ESR10, erforderlich sein, einen gehemmten Zustand einzuleiten, 
und eine andere Untergruppe, wie ESR1, inn zu erhalten. Dies wäre analog zur scheinbaren Hinlänglichkeit geringer Mengen von bHLH-Aktivatoren, um Delta zunächst breit hochzuregulieren, bevor es auf ausgewählte Zellen begrenzt wird (Kooh et al., 1993; Karp and Greenwald, 2003).

Ein weiterer wichtiger Aspekt zur Funktion der Hes5-ähnlichen Proteine während der primären Neurogenese in Xenopus ist die Frage nach der molekularen Spezifität ihrer repressorischen Aktivität. $\mathrm{Zu}$ den bisher funktionell näher charakterisierten Hes5ähnlichen Genen zählen ESR8, ESR9, ESR10, ESR1, ESR7 und ESR6 (Chalmers et al., 2002; Koyano-Nakagawa et al., 2000; Schneider et al., 2001; Taelman et al., 2004; diese Arbeit). Alle hemmen bei ektopischer Expression in Xenopus-Embryonen die Transkription von N-tubulin und somit die Differenzierung primärer Neuronen. Die DNABindungsdomäne der Hes5-ähnlichen Proteine in Xenopus erwies sich in allen Fällen für die Hemmung der primären Neurogenese als erforderlich. Das gleiche gilt für die DNABindungsdomäne von Her4, einem von mindestens fünf Hes5-ähnlichen Proteinen im Zebrafisch (Takke et al., 1999). Inwieweit sich die molekularen Mechanismen dieser bHLH-Repressoren gleichen bzw. unterscheiden, kann hier nur ansatzweise diskutiert werden, da die vorhandenen Studien jeweils nur einzelne Proteine oder Untergruppen im Kontext mit unterschiedlichen bHLH-Aktivatoren betrachten und bisher nur für ESR9 bHLH-Interaktionspartner identifiziert wurden (Taelman et al., 2004).

In den Funktionsanalysen von ESR1, ESR7 und ESR6 wurden RNAs in XenopusEmbryonen injiziert, die aktive Wildtypproteine kodieren und vermutlich lange vor der primären Neurogenese in frühen Neurulastadien exprimiert werden. Um die Gastrulation und die frühe Entwicklung des Neuroektoderms nicht durch die ektopische Expression von bHLH-O-Proteinen zu beeinträchtigen, wurden für die Überexpressionsstudien von ESR8, ESR9 und ESR10 hormon-induzierbare Fusionsproteine verwendet, die in Xenopus-Embryonen ab dem Midgastrulastadium induziert wurden (Taelman et al., 2004; diese Arbeit). Neben der Hemmung der primären Neurogenese bereits auf der Ebene der $X$-Ngnr-1-Transkription durch induzierte Varianten von ESR8, ESR9 und ESR10 konnte in dieser Arbeit das erste Mal ein dominant-negativer Effekt auf die neuronale Determinierung und Differenzierung in Xenopus-Neurulastadien infolge der Induktion einer DNA-Bindungsmutante eines Hes5-ähnlichen Proteins beobachtet werden. Die Aktivierung der X-Ngnr-1- und N-tubulin-Transkription durch die ESR8-DNABindungsmutante festigt die Hypothese, dass ESR8, und vermutlich auch ESR9 und ESR10, eine wesentliche Rolle bei der lateralen Hemmung spielen. ESR8, ESR9 und ESR10 regulieren allerdings nicht nur die Transkription von $X-N g n r-1$ negativ, sondern sie blockieren auch die $X$-Ngnr-1-Aktivität in Embryonen und animalen Kappen. In vivoBindungsstudien von ESR9 zeigten, dass ESR9 keine Homodimere und Heterodimere mit 
ESR8 und ESR10 und Xhairy1 oder Xhairy2 bildet, sondern nur mit proneuralen bHLHProteinen, wie X-Ngnr-1, Xath3 und NeuroD interagiert (Taelman et al., 2004). Dies legt nahe, dass ESR9 durch die direkte physikalische Interaktion mit X-Ngnr-1 dessen proneurale Aktivität blockiert und die Hemmung der Neurogenese zur Folge hat. Basierend auf den Bindungsexperimenten kann die Transkriptionsrepression von X-Ngnr1 daher nicht durch ESR9-Homodimere oder Heterodimere innerhalb der ESR8/ESR9/ESR10-Untergruppe bewirkt werden. Der dominant-negative Effekt auf die primäre Neurogenese durch die ESR8-DNA-Bindungsmutante deutet aber auf die Inaktivierung einer direkten DNA-Bindung hin. Da die Heterodimerisierungseigenschaften von ESR1 und ESR7 nicht untersucht wurden, besteht die Möglichkeit, dass die ESR8/ESR9/ESR10-Untergruppe und die ESR1/ESR7-Untergruppe Heterodimere in Notch-aktivierten Zellen bilden, die durch direkte DNA-Bindung proneurale Zielgene und $X$-Delta-1, reprimieren. Durch die Überexpression von DNA-Bindungsmutanten könnte durch die Bildung inaktiver Heterodimere, die Transkription proneuraler Gene nicht mehr reprimiert werden und überzählige Neuronen könnten entstehen.

Für ESR1 konnte gezeigt werden, dass es die Xath5-Aktivität blockiert, die in der Förderung der Differenzierung von primären Neuronen und Ganglionzellen in der sich entwickelnden Retina, sowie der direkten Aktivierung von XBrn3d besteht. Die DNAbindende Domäne und das Corepressor-bindende WRPW-Motif sind für diese Aktivitäten von ESR1 erforderlich, was nahelegt, dass sie durch Transkriptionsrepression und nicht durch direkte Interaktion von Xath5 und ESR1 vermittelt werden (Schneider et al., 2001).

Die Identifizierung der Bindungspartner Hes5-ähnlicher Proteine in Xenopus und der Auswirkungen ihrer unterschiedlichen Kombinationen auf DNA-Bindungseigenschaften und in vivo-Funktionen könnte tiefere Einblicke in die molekularen Repressionsmechanismen dieser Proteine ermöglichen und klären, ob sich Funktionsunterschiede Hes5-ähnlicher Gene in Xenopus allein durch ihre differentielle Expression ergeben oder auch auf spezifische Interaktionspartner zurückzuführen sind. Die Sequenzunterschiede in den Orange-Domänen und carboxyterminalen Bereichen der Hes5-ähnlichen bHLH-O-Proteine, speziell zwischen den verschiedenen Untergruppen (siehe Abb.2-21 und Abb.7-6), könnten unterschiedliche Dimerisierungsspezifitäten vermitteln (Taelman et al., 2004).

Studien, in denen die Aktivität von Hes5-ähnlichen Proteinen in Xenopus oder Zebrafisch mittels MO-Injektion verringert bzw. verhindert wurden, sind bisher nicht veröffentlicht worden. Infolge der Injektionen von ESR8, ESR9 und ESR10 antisenseMorpholinooligonukleotiden in Xenopus-Embryonen, die weiteren Aufschluß über die Funktion dieser Proteine liefern sollten, konnten in Neuralplattenstadien und auch später keine überzähligen Neuronen innerhalb der proneuralen Domänen, sondern vielmehr eine 
Reduktion oder ein vollständiges Fehlen differenzierter Neuronen nachgewiesen werden. Diese Ergebnisse, die vermutlich auf eine frühere Funktion dieser Proteine, vielleicht bei der Etablierung der proneuralen Domänen, hinweisen könnten, erfordern eine nähere Charakterisierung der Effekte auf die frühe Entwicklung des Neuroektoderms und die Vormusterung der Neuralplatte. Ein Vergleich der Effekte infolge der Injektionen von MOs für die übrigen Hes5-ähnlichen Xenopus-Gene könnte weitere Aufschlüsse über ihre physiologischen Funktionen während der Entwicklung des Nervensystems geben.

\subsection{Ausblick}

Die Ergebnisse dieser Arbeit bieten verschiedene Ansatzpunkte für weitere Analysen, die zum Verständis der Regulationsmechanismen und der Funktion von bHLH-O-Proteinen bei der Entwicklung des Vertebraten-Nervensystems beitragen könnten.

Für eine detaillierte Charakterisierung von XHes2 und seiner Rolle während der Embryonalentwicklung ist eine genauere Bestimmung der zeitlichen und räumlichen Expression von XHes2 durch den direkten Vergleich mit anderen, ebenfalls in den jeweiligen Regionen exprimierten Genen in Doppel-in situ-Hybridisierungen, u.a. auch in hoher Auflösung, z.B. durch den Einsatz Fluoreszenz-markierter RNA-Sonden und konfokaler Lasermikroskopie, erforderlich.

Da die Regulation von XHes2 nicht sehr ausführlich betrachtet wurde, scheint eine Fortführung dieser Analysen sinnvoll zu sein. Eine vergleichende Expressionsanalyse von XHes2 und Xenopus Notch-Liganden und -Rezeptoren, insbesondere auch von Xenopus Serrate2/Jagged2- und Notch2, die in Xenopus bisher nicht beschrieben wurden, von denen aber partielle EST-cDNA-Sequenzen in der GenBank-Datenbank existieren, könnte zunächst die im jeweiligen entwicklungsbiologischen Kontext vorhandenen NotchLiganden und -Rezeptoren identifizieren. Ihre Rolle hinsichtlich der Regulation von XHes2 sollte dann durch eine zeitlich regulierbare Aktivierung und Blockierung des NotchSignalwegs, z.B. mittels Überexpression geeigneter, Hormon-induzierbarer Proteine wie hGR-X-Su(H)-Ank (Wettstein et al., 1997) und hGR-X-Su(H)-DBM (McLaughlin et al., 2000), weiter geklärt werden. Die Expression von Hes2 und Notch-2 in TrophoblastenRiesenzellen der Maus-Plazenta (Nakayama et al., 1997) macht Notch2 zu einem mutmaßlichen XHes2-Induktor.

Die in der posterioren Plakodenregion ähnliche Expression von Hes2 und der FGF- und Wnt8-induzierten Gene Pax8, Pax2 und Sox9 (Saint-Germain et al., 2004 und darin enthaltene Referenzen) deutet darauf hin, das diese auch für die Induktion von Hes2 notwendig sein könnten, was durch Blockierung der beiden Signalwege überprüfbar wäre, z.B. mittels Überexpression der Glycogensynthasekinase-3 $\beta$ (He et al., 1995), einer 
dominant-negativen Form von LRP6 (Tamai et al., 2000) oder eines dominant-negativen FGF-Rezeptors (Amaya et al., 1991).

Promoteranalysen des XHes2-Gens dürften weitere Einblicke in dessen Regulation liefern und einen Vergleich mit anderen verwandten bHLH-O-Genen, wie Xhairy2, ESR1 und ESR10 (Davis et al., 2001; Lamar und Kintner, 2005), ermöglichen.

Besonders wichtig für die genauere Charakterisierung der XHes2-Funktion bei der Neurogenese ist die Fortführung der MO-Injektionsexperimente zur endogenen Hemmung der XHes2-Aktivität und die anschließende Analyse der Effekte auf die embryonale Morphologie und die Expression relevanter Marker. Die Spezifität der Ergebnisse sollte zudem durch die Verwendung eines zweiten antisense-XHes2-MOs und durch RescueExperimente mit XHes2-Wildtypproteinen bestätigt werden. Neben der Effekte auf neuronale Marker sind vor allem auch die Auswirkungen auf die Expression otischer Marker interessant, da XHes2 vermutlich eine Funktion bei der frühen Innenohrentwicklung besitzt. Durch die Hormon-Induktion von überexprimierten XHes2Varianten zu verschiedenen Zeitpunkten während der Embryogenese läßt sich zudem das Zeitfenster der untersuchten XHes2-Funktionen ermitteln.

Da von den acht verschiedenen Hes5-ähnlichen Genen in Xenopus bisher nicht alle bezüglich ihrer Expression, Regulation und Funktion charakterisiert wurden, liegt es nahe diese, ESR2 und ESR11, zunächst näher zu analysieren, immer im Vergleich mit den bereits beschriebenen Hes5-ähnlichen Genen. Eine detaillierte vergleichende Analyse aller acht Gene ist weiterhin erforderlich, um die Frage nach Gemeinsamkeiten und Unterschieden dieser Gene sicher zu klären. Während in dieser Arbeit bei drei dieser Gene, ESR8, ESR9 und ESR10, im wesentlichen keine Unterschiede in Expression, Regulation und Funktion gefunden wurden, konnten beim Vergleich der Regulation von ESR1 und ESR10 durch Notch und X-Ngnr-1 Unterschiede festgestellt werden (Lamar und Kintner, 2005). Während ESR1 nur indirekt durch X-Ngnr-1 über Notch induziert wird, aktivieren X-Ngnr-1 und Notch die ESR10-Transkription synergistisch. Der Sequenzvergleich aller acht Promotoren und die Identifizierung regulatorischer Elemente, sowie eine vergleichende Expressionsanalyse mit der Auflösung einzelner Zellen sollte daher Gemeinsamkeiten und Unterschiede aufzeigen. Die Charakterisierung von Proteininteraktionspartnern und die Identifizierung von Zielgenen sind weitere Möglichkeiten wie sich diese Proteine funktionell unterscheiden könnten. Aufwendige kombinatorische MO-Experimente sind ebenso denkbar.

Neben diesen weiterführenden Analysen zur Charakterisierung von XHes2 und Hes5ähnlichen Proteinen in Xenopus könnten zudem Untersuchungen zur Expression von Genen der Dec-Familie Aufschluß darüber geben, ob diese bHLH-O-Proteine in Xenopus eine Rolle bei der Entwicklung des Nervensystems spielen. Die Expression von Dec1 und 
Dec2 in verschiedenen Zelltypen neuroektodermaler Herkunft in der Maus und die Förderung der neuronalen anstelle meso- oder endodermaler Differenzierung in embryonalen P19-Carcinomzellen sprechen für eine regulatorische Funktion von DecProteinen während der Neurogenese (Azmi und Taneja, 2002; Boudjelal et al., 1997). 


\section{Material und Methoden}

In dieser Arbeit wurden molekularbiologische Standardtechniken und gängige Methoden zur Analyse der Embryonalentwicklung von Xenopus laevis verwendet. Wenn nicht anders aufgeführt sind diese Methoden entsprechend Sambrook et al. (1989), Sive et al. (2000) und Kay und Peng (1991) durchgeführt worden.

\subsection{Sequenz- und Datenbankanalyse}

Für die Analyse von DNA- und Protein-Sequenzen wurden das DNA Star Software Paket (EditSeq, MegAlign, SeqMan) (Lasergene DNASTAR Inc., Madison, USA) und MacMolly Tetra, Version 3.10 (Analyze) (Soft Gene GmbH, Berlin), sowie Multalin (http://www. toulouse.inra.fr/multalin.html) verwendet. Zudem wurden verschiedene Datenbanken und deren Analyseprogramme für die Identifizierung von bHLH-O-Genen in Xenopus verwendet, die unter den aufgeführten Webadressen $z u$ finden sind: BLASTSequenzabgleich mit GenBank-Sequenzen (http://www.ncbi.nlm.nih.gov/BLAST/), Xenopus laevis EST-Projekt (http://xenopus.nibb.ac.jp/), TIGR Xenopus laevis Gene Index (XGl) (http://www.tigr.org/tdb/tgi/xgi/index.html), Xenopus tropicalis Genomprojekt (http://genome.jgi-psf.org/Xentr4/Xentr4.home.html).

\subsection{Isolierung der XHes2 cDNA}

Basierend auf fünf $X$ Hairy1-verwandten und teilweise überlappenden EST-Sequenzen aus Xenopus laevis (GenBank-Zugangsnummern: AW639943, AW642120, AW643378, AW644752, BI350304) wurden Primer ausgewählt, die den gesamten offenen Leserahmen von XHes2 amplifizieren konnten: 5'-ACC ATG GCT CCC AAT GTA GCG CTC G-3', Sense-Primer; 5'-TCA CCA CGG CCT CCA GAT GGA GCT G-3', AntisensePrimer. PCR-ermittelte XHes2-positive Fraktionen einer Oocyten- $\lambda$ Zap-cDNA-Bank (Claussen und Pieler, 2004) wurden für eine weitere, nicht-radioaktive Durchmusterung ausgewählt, die mit dem "ECL Labelling and detection system" (Amersham), entsprechend des Herstellers durchgeführt wurde. Die XHes2-positiven Klone wurden sequenziert und analysiert. Die längste XHes2-cDNA umfaßt 1075 Nukleotide, einschließlich 5'- und 3'- nicht-translatierten Regionen und poly(A)-Schwanz, und besitzt die GenBank-Zugangsnummer DQ156231. 


\subsection{Expressionskonstrukte}

Für die Überexpressionsstudien zur Funktion von XHes2 wurden verschiedene XHes2Konstrukte erzeugt: $\mathrm{pCS} 2+\mathrm{XHes} 2, \mathrm{pCS} 2+\mathrm{XHes} 2-\Delta \mathrm{W}$ und $\mathrm{pCS} 2+\mathrm{XHes} 2-\Delta \mathrm{C}$ wurden durch die Klonierung der entsprechenden PCR-Produkte via die EcoRI/Xhol-Schnittstellen in den Expressionsvektor pCS2+ (Turner und Weintraub, 1994) erhalten, wobei die isolierte pBKCMV-XHes2-cDNA als Matrize diente und folgende Primer verwendet wurden: 5'CAG AAT TCT ACC ATG GCT CCC AAT GTA GCG-3', gemeinsamer XHes2-SensePrimer; 5'-TGT ACT CGA GTC ACC ACG GCC TCC AGA TGG-3', XHes2-AntisensePrimer; 5'-TGT ACT CGA GGA TGG AGC TGT TGA GCT GCG-3', XHes2- $\Delta$ W-AntisensePrimer und 5'-TGT ACT CGA GCT CAG GGC TCC TCT GCA GGT-3', XHes2- $\triangle$ CAntisense-Primer. pCS2+XHes2- $\Delta \mathrm{W}$-VP16 und pCS2+XHes2- $\Delta \mathrm{C}-\mathrm{VP} 16$ wurden durch die Klonierung der entsprechenden Fragmente in pCS2+VP16 erhalten, einer pCS2+Variante, die die VP16-Transaktivierungsdomäne (Sadowski et al., 1988) kodiert. pCS2+XHes2-DBM wurde durch die Mutagenese von pCS2+XHes2 mit Hilfe des „QuikChange ${ }^{\mathrm{TM}}$ Site-Directed Mutagenesis Kit“s (Stratagene), dem Sense-Primer 5'-TAA AGC CCC TGA TGA AAG AAG AAG AGG AGG CGG AAA TCG ACG AGA GTC TGA AC-3' und seinem entsprechenden Antisense-Primer generiert. Zur Gewährleistung einer Kernlokalisierung wurde das XHes2-DBM-Fragment in pCS2+NLS inseriert und dadurch pCS2+NLS-XHes2-DBM erhalten. Die Hormon-induzierbaren XHes2-Varianten basieren auf der den Leserahmen erhaltenen carboxyterminalen Insertion des hGR-LBDFragments (Kolm und Sive, 1995) bzw. eines VP16-hGR-LBD-Fragments. Während die XHes2- $\Delta \mathrm{W}$ - und XHes2- $\Delta \mathrm{C}$-Fragmente kein Stop-Codon enthalten, und direkt zur Herstellung von pCS2+XHes2- $\Delta \mathrm{W}-\mathrm{GR}$ und pCS2+XHes2- $\Delta \mathrm{C}-\mathrm{GR}$ bzw. pCS2+XHes2- $\Delta \mathrm{W}-$ VP16-GR und pCS2+XHes2- $\Delta \mathrm{C}-\mathrm{GR}$ verwendet werden konnten, mußten für pCS2+XHes2-GR und pCS2+XHes2-DBM-GR zunächst Zwischenprodukte ohne Stopcodon hergestellt werden. Für die Amplifikation dieser beiden Fragmente wurde der XHes2-Antisense-Primer 5'-TGT ACT CGA GCC ACG GCC TCC AGA TGG AGC-3' zusammen mit dem oben beschriebenen XHes2-Sense-Primer eingesetzt.

Für die Funktionsanalysen von ESR8, ESR9 und ESR10 wurden ebenfalls mehrere Konstrukte hergestellt: Die Hormon-induzierbaren ESR8-, ESR9- und ESR10-Konstrukte pCS2+ESR8-GR, pCS2+ESR9-GR und pCS2+ESR10-GR wurden durch die Insertion des entsprechenden Stopcodon-freien PCR-Produkts N-terminal (EcoRI/Xhol-Schnittstellen) und im Leseraster zur Liganden-bindenden Domäne (Xhol/Xbal-Schnittstellen) in den pCS2+GR-Vektor kloniert. Die folgenden Matrizen und Primer wurden dafür eingesetzt: pBKCMV-XTT182 (ESR8) (Diplomarbeit, 1999), pBSKS+8C9 (ESR9) (Gawantka et al., 1998), pBSKS+11A10 (ESR10) (Gawantka et al., 1998), sowie ESR8-Sense-Primer 5'- 
GAT GAA TTC GAG CGC AAT GGC ACC TTG CAC-3', ESR8-Antisense-Primer 5'-GTC TCT CGA GCC ACG GTC TCC ACA AAA CTT-3', ESR9-Sense-Primer 5'-ATC GAA TTC AGA CAG AAT GGC TCC TTA CAC-3', ESR9-Antisense-Primer 5'-ATC ACT CGA GCC AGG GTC TCC AGA GAA CTT-3', ESR10-Sense-Primer 5'-TCA GAA TTC AAA CAG GAT GGC TCC TTA CAG-3' und ESR10-Antisense-Primer 5'-ATG TCT CGA GGT TCC AGG GTC TCC AAA GGA-3'. Die Mutagenese der DNA-bindenden Domäne von ESR8, ESR9 und ESR10, die in allen drei Proteinen sehr stark konserviert ist, wurde wie für XHes2 mit dem "QuikChange ${ }^{\mathrm{TM}}$ Site-Directed Mutagenesis Kit“ (Stratagene), dem SensePrimer 5'-GAA AAC CAG TGG TTC GGG AAA TGG AGG AAG ATG ATA TTG ACA GCA GCA TCG AG-3' und seinem entsprechenden Antisense-Primer durchgeführt und generierte pCS2+ESR8-DBM-GR, pCS2+ESR9-DBM-GR und pCS2+ESR10-DBM-GR. pCS2+ESR9 wurde durch die Klonierung des ESR9-PCR-Fragments in den Expressionsvektor pCS2+ erhalten, wobei pBSKS+8C9 (ESR9) (Gawantka et al., 1998) als Matrize für die PCR mit dem ESR9-Sense-Primer 5'-ATC GAA TTC AGA CAG AAT GGC TCC TTA CAC-3' und dem ESR9-Antisense-Primer 5'-TAC ACT CGA GCT ACC AGG GTC TCC AGA GAA-3' diente.

Die übrigen in dieser Arbeit verwendeten Expressionskonstrukte wurden bereits zuvor beschrieben: NeuroD (Lee et al., 1995), nLacZ (Chitnis et al., 1995), Noggin (Smith und Harland, 1992), Notch ICD (Chitnis et al., 1995), X-Ngnr-1 (Ma et al., 1998), X-Su(H)-Ank (Wettstein et al., 1997).

\subsection{Embryonen, Mikroinjektionen, animale Kappen und Hormon-Induktion}

Xenopus laevis-Wildtyp- und Albino-Embryonen wurden durch hormon-induzierte Eiablage mit HCG (Sigma) und künstliche Befruchtung gewonnen. Die Entwicklungsstadien von Xenopus laevis wurden entsprechend der morphologischen Kriterien von Nieuwkoop und Faber (1994) zugewiesen.

Für RNA-Mikroinjektionen zur Proteinüberexpression in Xenopus-Embryonen wurden Sense-RNAs mittels des "mMessage mMachine ${ }^{T M}$ SP6 kit"s (Ambion) von den jewiligen, meist mit Notl-linearisierten Expressionskonstrukten transkribiert und mit dem "RNeasy Mini kit" (Qiagen) aufgereinigt.

Zur Hemmung der endogenen Translation der zu analysierenden Gene wurden die folgenden Morpholinoolgonukleotide (Gene Tools, LLC) in Xenopus-Embryonen injiziert: XHes2-MO 5‘-ACA GAC TAG GCA GCG GTG CTT CCA G-3‘; ESR8-MO 5‘-GCT CAG TTA CTG TTT CGG TGC TGC T-3; ESR9-MO 5‘-CTG TCT GGT AAT GGG ATG TGA TGG A-3; ESR10-MO 5‘-CTG TTT AGT AAG TGG ATA TGA TGG A-3“; StandardKontroll-MO (KoMO) 5‘-CCT CTT ACC TCA GTT ACA ATT TAT A-3‘. Die Spezifität der 
MOs wurde in vitro unter Verwendung des TNT-gekoppelten Retikulocytenlysat-Systems (Promega) überprüft.

Zur Darstellung RNA- und MO-injizierter Zellen wurde $n L a c Z-R N A$ zusammen mit der zu analysierenden RNA oder dem MO injiziert und eine histochemische Färbung der BGalactosidase Aktivität durchgeführt.

Für die RT-PCR-Analysen in ektodermalen Explantaten wurden animale Kappen im Stadium 9 aus den Embryonen herausgeschnitten und dann solange kultiviert bis Kontrollembryonen die gewünschten Stadien erreicht hatten.

Für die Induktion der überexprimierten hGR-LBD-Fusionsproteine wurde Dexamethason (Sigma) im entsprechenden Entwicklungsstadium zum Kulturmedium hinzugegeben (Kolm und Sive, 1995).

\subsection{In situ-Hybridisierungen}

Die Herstellung Digoxigenin- und Fluorescein-markierter Antisense-RNA-Sonden für in situ-Hybridisierungen in ganzen Embryonen erfolgte wie vom Hersteller (Roche) empfohlen. Zur Aufreinigung der synthetisierten RNAs wurde das "RNeasy Mini kit" (Qiagen) verwendet. XHes2- bzw. ESR8-Antisense-RNA wurde mit T7 RNA-Polymerase von EcoRI-linearisierter Plasmid-DNA, pBK-CMV-XHes2 bzw. pBK-CMV-XTT182 (ESR8), transkribiert. Weitere, hier verwendete RNA-Sonden wurden bereits beschrieben: ESR1 (Schneider et al., 2001), 8C9/ESR9 und 11A10/ESR10 (Gawantka et al., 1998; Li et al., 2003), NeuroD (Lee et al., 1995), N-tubulin (Oschwald et al., 1991), Pax2 (Heller und Brandli, 1997), Xhairy1 und Xhairy2 (Taelman et al., 2004), Xhox11L2 (Patterson and Krieg, 1999), Xlim3 (Taira et al., 1993), X-MyT1 (Bellefroid et al., 1996), X-Ngnr-1 (Ma et al., 1998) und XSox3 (Penzel et al., 1997). Die Durchführung der Whole-mount in situHybridisierungsanalyse erfolgte wie von Hollemann et al. (1999) beschrieben. Von einigen Embryonen wurden Vibratomschnitte mit einer Dicke von $30 \mu \mathrm{m}$ angefertigt.

\subsection{RT-PCR-Analysen}

Zur Isolierung von Gesamt-RNA aus je zwölf bis fünfzehn animalen Kappen oder vier Embryonen wurde das "RNeasy Mini kit" (Qiagen) verwendet. Adulte Gewebe-RNA wurde hingegen mit Trizol (Invitrogen) nach dem Protokoll des Herstellers isoliert. Alle RNAPräparationen wurden mit DNasel (Qiagen oder Roche) verdaut, um genomische DNAKontaminationen zu eliminieren.

Für die semi-quantitativen RT-PCR-Analysen wurde der "Gene Amp RNA PCR core kit" (Perkin-Elmer) verwendet, sowie Gen-spezifische Primerpaare, die entweder unter der 
Webadresse http://www.xenbase.org/WWW/Marker_pages/primers.html oder im folgenden aufgeführt sind:

XHes2 (GenBank: DQ156231) 5'-CTC CGG TCC AGG CAC AAA ATC CC-3' und 5'-TCT GTG GCT GGA GGG TTG GTT CTG-3'; ESR1 (GenBank: AF383157) 5'-CAG TCT CCC AAT CTG GCA AAA CTG-3' und 5'-GGT GTT GCT TGC CAG AGC TGA TTG-3'; ESR7 (GenBank: AF146088) 5'-GAA ATC CCT CAT AAC AAT GAC ATC-3' und 5'-CTA CCA ATG CCA TTT TCA GGT TTG-3'; ESR8 (selbst isoliert und sequenziert; noch keine GenBank-Zugangsnummer) 5'-GCTACTAAAACTGGTGAGATGTC-3' und 5'CTGTTGGTCACAGGGGACTGTAC-3'; ESR9 (GenBank: AJ009282) 5'GCTTCCAAATATGCACAATCATCC-3' und 5'- CCAGTCCCAGGAGTTGTGCATTT -3'; ESR10 (GenBank: AJ009285) 5'-CAACCAAATGTAAACCGTTATCC-3' und 5'TGGTGGTGCGGTGCCTTTGGTAG-3'. Wasser wurde anstelle von RNA als Negativkontrolle und embryonale RNA als Positivkontrolle eingesetzt. Die Ergebnisse wurden entsprechend der relativen Histon H4 mRNA-Expression bewertet (Niehrs et al., 1994). 


\section{Zusammenfassung}

bHLH-Aktivatoren und bHLH-Repressoren sind an zahlreichen Entwicklungsprozessen, einschließlich der Ausbildung des Nervensystems, in Vertebraten und Invertebraten beteiligt. Bei der Bestimmung neuraler Zellschicksale und der Regulation der Neurogenese spielen insbesondere bHLH-O-Proteine eine wesentliche Rolle. Diese mit Drosophila Hairy und E(spl)-verwandten bHLH-Repressoren können die neurale und neuronale Differenzierung durch eine Hemmung proneuraler bHLH-Proteinaktivität verhindern. Um die Regulationsmechanismen während der Neurogenese und die Funktion der zahlreichen bHLH-O-Proteine besser zu verstehen, wurden in Xenopus neue Mitglieder der bHLH-O-Proteinfamilien in silico identifiziert und einige dieser Proteine näher charakterisiert.

In dieser Arbeit konnte ein in Xenopus bisher noch nicht beschriebenes Hairy und E(spl) verwandtes Protein identifiziert werden, das eng mit Hes2 aus Säugern verwandt ist. Die Expression von XHes2 in sich entwickelnden Sinnesorganen und im entstehenden zentralen Nervensystems macht dieses Gen zu einem interessanten Kandidaten für einen Regulator der Neurogenese. Untersuchungen zur Regulation von XHes2 in Embryonen ergaben, dass XHes2 innerhalb der Neuralplatte weder durch das proneurale bHLHProtein X-Ngnr-1 noch durch die Aktivierung des Notch-Signalwegs induziert werden kann. Diese Ergebnisse und die XHes2-Expression in Neuralplattenstadien, die sich auf die Ohrplakode und einige wenige Zellen innerhalb der Neuralplatte beschränkt, zeigen dass XHes2 im Gegensatz zu Hes5-ähnlichen Genen, wie ESR1 und ESR7, keine Rolle bei der Notch-abhängigen lateralen Hemmung während der primären Neurogenese spielt. In Überexpressionsstudien mit verschiedenen, z.T. Hormon-induzierbaren XHes2Varianten in Embryonen und animalen Kappen konnte nachgewiesen werden, dass XHes2, wie viele andere bHLH-O-Proteine, die Neurogenese hemmt, zum einen durch die negative Regulation der Transkription von X-Ngnr-1 und NeuroD und zum anderen durch Hemmung der NeuroD-Aktivität. Die ektopische NeuroD-Expression in späten Neurulastadien infolge der Injektion eines XHes2-antisense Morpholinooligonukleotids unterstützt die Hypothese, dass XHes2 in sich entwickelnden Sinnesorganen und im entstehenden ZNS die neuronale Differenzierung verhindert und dadurch Einfluß auf das weitere Zellschicksal nimmt.

Während die meisten Säuger-bHLH-O-Proteine in Xenopus nur ein ähnliches Protein besitzen, konnten in Xenopus acht verschiedene Maus-Hes5-ähnliche Proteine identifiziert werden. Von diesen wurden die untereinander eng verwandten Proteine ESR8, ESR9 und ESR10 näher untersucht. Während der Embryonalentwicklung unterscheiden sich die Expressionsdomänen der durch Notch-induzierbaren Gene nicht. 
Alle drei Gene werden in proneuronalen Domänen, in entstehenden Somiten und im Pankreas exprimiert. Das Expressionsmuster in Neuralplattenstadien impliziert eine regulatorische Funktion dieser Proteine während der primären Neurogenese, vermutlich bei der Notch-abhängigen lateralen Hemmung. Die Überexpression hormon-induzierbarer ESR8-, ESR9- und ESR10-Varianten in Embryonen ab dem Midgastrulastadium bestätigt diese Vermutung, da die Transkription von X-Ngnr-1 und $N$-tubulin durch induzierte Wildtypproteine negativ und durch DNA-Bindungsmutanten positiv reguliert wird. Zudem hemmt ESR8 nicht nur die X-Ngnr-1-Transkription, sondern auch die X-Ngnr-1-Aktivität. Die Reduktion bzw. das Fehlen primärer Neuronen infolge der Injektion von ESR8 bzw. ESR9/ESR10-spezifischen antisense Morpholinooligonukleotide in Embryonen deutet andererseits auf eine weitere, vor der lateralen Hemmung stattfindenden Funktion dieser Proteine hin und zeigt deren Notwendigkeit für eine zeitlich und räumlich korrekte neuronale Differenzierung. 


\section{Literaturverzeichnis}

Akazawa, C., Sasai, Y., Nakanishi, S., and Kageyama, R. (1992). Molecular characterization of a rat negative regulator with a basic helix-loop-helix structure predominantly expressed in the developing nervous system. J Biol Chem 267, 21879-85.

Amaya, E., Musci, T. J., and Kirschner, M. W. (1991). Expression of a dominant negative mutant of the FGF receptor disrupts mesoderm formation in Xenopus embryos. Cell 66, 257-70.

Aronson, B. D., Fisher, A. L., Blechman, K., Caudy, M., and Gergen, J. P. (1997). Groucho-dependent and -independent repression activities of Runt domain proteins. $\mathrm{Mol}$ Cell Biol 17, 5581-7.

Atchley, W. R., and Fitch, W. M. (1997). A natural classification of the basic helix-loophelix class of transcription factors. Proc Natl Acad Sci U S A 94, 5172-6.

Azmi, S., and Taneja, R. (2002). Embryonic expression of mSharp-1/mDEC2, which encodes a basic helix-loop-helix transcription factor. Mech Dev 114, 181-5.

Bae, S., Bessho, Y., Hojo, M., and Kageyama, R. (2000). The bHLH gene Hes6, an inhibitor of Hes1, promotes neuronal differentiation. Development 127, 2933-43.

Bailey, A. M., and Posakony, J. W. (1995). Suppressor of hairless directly activates transcription of enhancer of split complex genes in response to Notch receptor activity. Genes Dev 9, 2609-22.

Bally-Cuif, L., and Hammerschmidt, M. (2003). Induction and patterning of neuronal development, and its connection to cell cycle control. Curr Opin Neurobiol 13, 16-25.

Barolo, S., and Levine, M. (1997). hairy mediates dominant repression in the Drosophila embryo. Embo J 16, 2883-91.

Bellefroid, E. J., Bourguignon, C., Hollemann, T., Ma, Q., Anderson, D. J., Kintner, C., and Pieler, T. (1996). X-MyT1, a Xenopus C2HC-type zinc finger protein with a regulatory function in neuronal differentiation. Cell 87, 1191-202.

Bellefroid, E., and Souopgui, J. (2003). Basic Helix-Loop-Helix Proneural Genes and Neurogenesis in Xenopus Embryos. In: Grunz, H. (Ed.). The Vertebrate Organizer. Springer Verlag, Berlin. pp. 151- 172.

Bertrand, N., Castro, D. S., and Guillemot, F. (2002). Proneural genes and the specification of neural cell types. Nat Rev Neurosci 3, 517-30.

Bier, E., Vaessin, H., Younger-Shepherd, S., Jan, L. Y., and Jan, Y. N. (1992). deadpan, an essential pan-neural gene in Drosophila, encodes a helix-loop-helix protein similar to the hairy gene product. Genes Dev 6, 2137-51.

Blackwell, T. K., and Weintraub, H. (1990). Differences and similarities in DNA-binding preferences of MyoD and E2A protein complexes revealed by binding site selection. Science 250, 1104-10.

Boudjelal, M., Taneja, R., Matsubara, S., Bouillet, P., Dolle, P., and Chambon, P. (1997). Overexpression of Stra13, a novel retinoic acid-inducible gene of the basic helix-loop-helix 
family, inhibits mesodermal and promotes neuronal differentiation of P19 cells. Genes Dev 11, 2052-65.

Butler, M. P., Honma, S., Fukumoto, T., Kawamoto, T., Fujimoto, K., Noshiro, M., Kato, Y., and Honma, K. (2004). Dec1 and Dec2 expression is disrupted in the suprachiasmatic nuclei of Clock mutant mice. J Biol Rhythms 19, 126-34.

Bylund, M., Andersson, E., Novitch, B. G., and Muhr, J. (2003). Vertebrate neurogenesis is counteracted by Sox1-3 activity. Nat Neurosci 6, 1162-8.

Carroll, T. J., and Vize, P. D. (1999). Synergism between Pax-8 and lim-1 in embryonic kidney development. Dev Biol 214, 46-59.

Casarosa, S., Andreazzoli, M., Simeone, A., and Barsacchi, G. (1997). Xrx1, a novel Xenopus homeobox gene expressed during eye and pineal gland development. Mech Dev 61, 187-98.

Castella, P., Sawai, S., Nakao, K., Wagner, J. A., and Caudy, M. (2000). HES-1 repression of differentiation and proliferation in PC12 cells: role for the helix 3-helix 4 domain in transcription repression. Mol Cell Biol 20, 6170-83.

Castella, P., Wagner, J. A., and Caudy, M. (1999). Regulation of hippocampal neuronal differentiation by the basic helix-loop-helix transcription factors HES-1 and MASH-1. J Neurosci Res 56, 229-40.

Cau, E., Gradwohl, G., Casarosa, S., Kageyama, R., and Guillemot, F. (2000). Hes genes regulate sequential stages of neurogenesis in the olfactory epithelium. Development 127, 2323-32.

Cau, E., Gradwohl, G., Fode, C., and Guillemot, F. (1997). Mash1 activates a cascade of bHLH regulators in olfactory neuron progenitors. Development 124, 1611-21.

Chalmers, A. D., Welchman, D., and Papalopulu, N. (2002). Intrinsic differences between the superficial and deep layers of the Xenopus ectoderm control primary neuronal differentiation. Dev Cell 2, 171-82.

Chen, G., and Courey, A. J. (2000). Groucho/TLE family proteins and transcriptional repression. Gene 249, 1-16.

Chen, G., Fernandez, J., Mische, S., and Courey, A. J. (1999). A functional interaction between the histone deacetylase Rpd3 and the corepressor groucho in Drosophila development. Genes Dev 13, 2218-2230.

Chen, H., Thiagalingam, A., Chopra, H., Borges, M. W., Feder, J. N., Nelkin, B. D., Baylin, S. B., and Ball, D. W. (1997). Conservation of the Drosophila lateral inhibition pathway in human lung cancer: a hairy-related protein (HES-1) directly represses achaete-scute homolog-1 expression. Proc Natl Acad Sci U S A 94, 5355-60.

Chitnis, A., Henrique, D., Lewis, J., Ish-Horowicz, D., and Kintner, C. (1995). Primary neurogenesis in Xenopus embryos regulated by a homologue of the Drosophila neurogenic gene Delta. Nature 375, 761-6.

Claussen, M., and Pieler, T. (2004). Xvelo1 uses a novel 75-nucleotide signal sequence that drives vegetal localization along the late pathway in Xenopus oocytes. Dev Biol 266, 270-84. 
Coffman, C. R., Skoglund, P., Harris, W. A., and Kintner, C. R. (1993). Expression of an extracellular deletion of Xotch diverts cell fate in Xenopus embryos. Cell 73, 659-71.

Cooper, M. T., Tyler, D. M., Furriols, M., Chalkiadaki, A., Delidakis, C., and Bray, S. (2000). Spatially restricted factors cooperate with notch in the regulation of Enhancer of split genes. Dev Biol 221, 390-403.

Cossins, J., Vernon, A. E., Zhang, Y., Philpott, A., and Jones, P. H. (2002). Hes6 regulates myogenic differentiation. Development 129, 2195-207.

Damen, W. G., Weller, M., and Tautz, D. (2000). Expression patterns of hairy, evenskipped, and runt in the spider Cupiennius salei imply that these genes were segmentation genes in a basal arthropod. Proc Natl Acad Sci U S A 97, 4515-9.

Davis, R. L., Cheng, P. F., Lassar, A. B., and Weintraub, H. (1990). The MyoD DNA binding domain contains a recognition code for muscle-specific gene activation.Cell 60, 733-46.

Davis, R. L., and Turner, D. L. (2001). Vertebrate hairy and Enhancer of split related proteins: transcriptional repressors regulating cellular differentiation and embryonic patterning. Oncogene 20, 8342-57.

Davis, R. L., Turner, D. L., Evans, L. M., and Kirschner, M. W. (2001). Molecular targets of vertebrate segmentation: two mechanisms control segmental expression of Xenopus hairy2 during somite formation. Dev Cell 1, 553-65.

Dawson, S. R., Turner, D. L., Weintraub, H., and Parkhurst, S. M. (1995). Specificity for the hairy/enhancer of split basic helix-loop-helix (bHLH) proteins maps outside the bHLH domain and suggests two separable modes of transcriptional repression. Mol Cell Biol 15, 6923-31.

Deblandre, G. A., Wettstein, D. A., Koyano-Nakagawa, N., and Kintner, C. (1999). A twostep mechanism generates the spacing pattern of the ciliated cells in the skin of Xenopus embryos. Development 126, 4715-28.

de la Pompa, J. L., Wakeham, A., Correia, K. M., Samper, E., Brown, S., Aguilera, R. J., Nakano, T., Honjo, T., Mak, T. W., Rossant, J., and Conlon, R. A. (1997). Conservation of the Notch signalling pathway in mammalian neurogenesis. Development 124, 1139-48.

Eccles, M. R., and Schimmenti, L. A. (1999). Renal-coloboma syndrome: a multi-system developmental disorder caused by PAX2 mutations. Clin Genet 56, 1-9.

Favor, J., Sandulache, R., Neuhauser-Klaus, A., Pretsch, W., Chatterjee, B., Senft, E., Wurst, W., Blanquet, V., Grimes, P., Sporle, R., and Schughart, K. (1996). The mouse Pax2(1Neu) mutation is identical to a human PAX2 mutation in a family with renalcoloboma syndrome and results in developmental defects of the brain, ear, eye, and kidney. Proc Natl Acad Sci U S A 93, 13870-5.

Ferre-D'Amare, A. R., Prendergast, G. C., Ziff, E. B., and Burley, S. K. (1993). Recognition by Max of its cognate DNA through a dimeric b/HLH/Z domain. Nature 363, 38-45.

Fior, R., and Henrique, D. (2005). A novel hes $5 /$ hes 6 circuitry of negative regulation controls Notch activity during neurogenesis. Dev Biol 281, 318-33. 
Fisher, A., and Caudy, M. (1998). The function of hairy-related bHLH repressor proteins in cell fate decisions. Bioessays 20, 298-306.

Fisher, A. L., Ohsako, S. and Caudy, M. (1996). The WRPW motif of the hairy-related basic helix-loop-helix repressor proteins acts as a 4-amino-acid transcription repression and protein-protein interaction domain. Mol Cell Biol 16, 2670-7.

Frisen, J., and Lendahl, U. (2001). Oh no, Notch again! Bioessays 23, 3-7.

Gaiano, N., Nye, J. S., and Fishell, G. (2000). Radial glial identity is promoted by Notch1 signaling in the murine forebrain. Neuron 26, 395-404.

Furukawa, T., Mukherjee, S., Bao, Z. Z., Morrow, E. M., and Cepko, C. L. (2000). rax, Hes1, and notch1 promote the formation of Muller glia by postnatal retinal progenitor cells. Neuron 26, 383-94.

Gajewski, M., and Voolstra, C. (2002). Comparative analysis of somitogenesis related genes of the hairy/Enhancer of split class in Fugu and zebrafish. BMC Genomics 3, 21.

Garriga-Canut, M., Roopra, A., and Buckley, N. J. (2001). The basic helix-loop-helix protein, sharp-1, represses transcription by a histone deacetylase-dependent and histone deacetylase-independent mechanism. J Biol Chem 276, 14821-8.

Gawantka, V., Pollet, N., Delius, H., Vingron, M., Pfister, R., Nitsch, R., Blumenstock, C., and Niehrs, C. (1998). Gene expression screening in Xenopus identifies molecular pathways, predicts gene function and provides a global view of embryonic patterning. Mech Dev 77, 95-141.

Graham, V., Khudyakov, J., Ellis, P., and Pevny, L. (2003). SOX2 functions to maintain neural progenitor identity. Neuron 39, 749-65.

Gratton, M. O., Torban, E., Jasmin, S. B., Theriault, F. M., German, M. S., and Stifani, S. (2003). Hes6 promotes cortical neurogenesis and inhibits Hes1 transcription repression activity by multiple mechanisms. Mol Cell Biol 23, 6922-35.

Grbavec, D., Lo, R., Liu, Y., and Stifani, S. (1998). Transducin-like Enhancer of split 2, a mammalian homologue of Drosophila Groucho, acts as a transcriptional repressor, interacts with Hairy/Enhancer of split proteins, and is expressed during neuronal development. Eur J Biochem 258, 339-49.

Grbavec, D., and Stifani, S. (1996). Molecular interaction between TLE1 and the carboxylterminal domain of HES-1 containing the WRPW motif. Biochem Biophys Res Commun 223, 701-5.

Grechez-Cassiau, A., Panda, S., Lacoche, S., Teboul, M., Azmi, S., Laudet, V., Hogenesch, J. B., Taneja, R., and Delaunay, F. (2004). The transcriptional repressor STRA13 regulates a subset of peripheral circadian outputs. J Biol Chem 279, 1141-50.

Guenther, M. G., Lane, W. S., Fischle, W., Verdin, E., Lazar, M. A., and Shiekhattar, R. (2000). A core SMRT corepressor complex containing HDAC3 and TBL1, a WD40-repeat protein linked to deafness. Genes Dev 14, 1048-57.

Handler, M., Yang, X., and Shen, J. (2000). Presenilin-1 regulates neuronal differentiation during neurogenesis. Development 127, 2593-606.

Hardcastle, Z., and Papalopulu, N. (2000). Distinct effects of XBF-1 in regulating the cell cycle inhibitor p27(XIC1) and imparting a neural fate. Development 127, 1303-14. 
Hatakeyama, J., Bessho, Y., Katoh, K., Ookawara, S., Fujioka, M., Guillemot, F., and Kageyama, R. (2004). Hes genes regulate size, shape and histogenesis of the nervous system by control of the timing of neural stem cell differentiation. Development 131, 553950 .

He, X., Saint-Jeannet, J. P., Woodgett, J. R., Varmus, H. E., and Dawid, I. B. (1995). Glycogen synthase kinase-3 and dorsoventral patterning in Xenopus embryos. Nature 374, 617-22.

Heasman, J. (2002). Morpholino oligos: making sense of antisense? Dev Biol 243, 20914.

Heitzler, P., Bourouis, M., Ruel, L., Carteret, C., and Simpson, P. (1996). Genes of the Enhancer of split and achaete-scute complexes are required for a regulatory loop between Notch and Delta during lateral signalling in Drosophila. Development 122, 161-71.

Heller, N., and Brandli, A. W. (1997). Xenopus Pax-2 displays multiple splice forms during embryogenesis and pronephric kidney development. Mech Dev 69, 83-104.

Heller, N., and Brandli, A. W. (1999). Xenopus Pax-2/5/8 orthologues: novel insights into Pax gene evolution and identification of Pax-8 as the earliest marker for otic and pronephric cell lineages. Dev Genet 24, 208-19.

Henry, C. A., Urban, M. K., Dill, K. K., Merlie, J. P., Page, M. F., Kimmel, C. B., and Amacher, S. L. (2002). Two linked hairy/Enhancer of split-related zebrafish genes, her1 and her7, function together to refine alternating somite boundaries. Development 129, 3693-704.

Hirata, H., Ohtsuka, T., Bessho, Y., and Kageyama, R. (2000). Generation of structurally and functionally distinct factors from the basic helix-loop-helix gene Hes3 by alternative first exons. J Biol Chem 275, 19083-9.

Hirsch, N., and Harris, W. A. (1997). Xenopus Pax-6 and retinal development. J Neurobiol $32,45-61$.

Hojo, M., Ohtsuka, T., Hashimoto, N., Gradwohl, G., Guillemot, F., and Kageyama, R. (2000). Glial cell fate specification modulated by the bHLH gene Hes5 in mouse retina. Development 127, 2515-22.

Hollemann, T., Panitz, F. and Pieler, T. (1999). In situ hybridization techniques with Xenopus embryos. In: Richter, J.D. (Ed.). A Comparative Methods: Approach to the Study of Oocytes and Embryos. Oxford Univ. Press Inc., Oxford. pp. 279- 290.

Honma, S., Kawamoto, T., Takagi, Y., Fujimoto, K., Sato, F., Noshiro, M., Kato, Y., and Honma, K. (2002). Dec1 and Dec2 are regulators of the mammalian molecular clock. Nature 419, 841-4.

Hopwood, N. D., Pluck, A., and Gurdon, J. B. (1989). MyoD expression in the forming somites is an early response to mesoderm induction in Xenopus embryos. Embo $\mathrm{J} 8$, 3409-17.

Ishibashi, M., Ang, S. L., Shiota, K., Nakanishi, S., Kageyama, R., and Guillemot, F. (1995). Targeted disruption of mammalian hairy and Enhancer of split homolog-1 (HES-1) leads to up-regulation of neural helix-loop-helix factors, premature neurogenesis, and severe neural tube defects. Genes Dev 9, 3136-48. 
Ishibashi, M., Moriyoshi, K., Sasai, Y., Shiota, K., Nakanishi, S., and Kageyama, R. (1994). Persistent expression of helix-loop-helix factor HES-1 prevents mammalian neural differentiation in the central nervous system. Embo J 13, 1799-805.

Ishibashi, M., Sasai, Y., Nakanishi, S., and Kageyama, R. (1993). Molecular characterization of HES-2, a mammalian helix-loop-helix factor structurally related to Drosophila hairy and Enhancer of split. Eur J Biochem 215, 645-52.

Iso, T., Kedes, L., and Hamamori, Y. (2003). HES and HERP families: multiple effectors of the Notch signaling pathway. J Cell Physiol 194, 237-55.

Iso, T., Sartorelli, V., Poizat, C., lezzi, S., Wu, H. Y., Chung, G., Kedes, L., and Hamamori, Y. (2001). HERP, a novel heterodimer partner of HES/E(spl) in Notch signaling. Mol Cell Biol 21, 6080-9.

Ivanova, A. V., Ivanov, S. V., Danilkovitch-Miagkova, A., and Lerman, M. I. (2001). Regulation of STRA13 by the von Hippel-Lindau tumor suppressor protein, hypoxia, and the UBC9/ubiquitin proteasome degradation pathway. J Biol Chem 276, 15306-15.

Jarriault, S., Brou, C., Logeat, F., Schroeter, E. H., Kopan, R., and Israel, A. (1995). Signalling downstream of activated mammalian Notch. Nature 377, 355-8.

Jen, W. C., Gawantka, V., Pollet, N., Niehrs, C., and Kintner, C. (1999). Periodic repression of Notch pathway genes governs the segmentation of Xenopus embryos. Genes Dev 13, 1486-99.

Jen, W. C., Wettstein, D., Turner, D., Chitnis, A., and Kintner, C. (1997). The Notch ligand, X-Delta-2, mediates segmentation of the paraxial mesoderm in Xenopus embryos. Development 124, 1169-78.

Jennings, B., Preiss, A., Delidakis, C., and Bray, S. (1994). The Notch signalling pathway is required for Enhancer of split bHLH protein expression during neurogenesis in the Drosophila embryo. Development 120, 3537-48.

Jennings, B. H., Tyler, D. M., and Bray, S. J. (1999). Target specificities of Drosophila enhancer of split basic helix-loop-helix proteins. Mol Cell Biol 19, 4600-10.

Jouve, C., Palmeirim, I., Henrique, D., Beckers, J., Gossler, A., Ish-Horowicz, D., and Pourquie, O. (2000). Notch signalling is required for cyclic expression of the hairy-like gene HES1 in the presomitic mesoderm. Development 127, 1421-9.

Kadesch, T. (2004). Notch signaling: the demise of elegant simplicity. Curr Opin Genet Dev 14, 506-12.

Kanekar, S., Perron, M., Dorsky, R., Harris, W. A., Jan, L. Y., Jan, Y. N., and Vetter, M. L. (1997). Xath5 participates in a network of bHLH genes in the developing Xenopus retina. Neuron 19, 981-94.

Karp, X., and Greenwald, I. (2003). Post-transcriptional regulation of the E/Daughterless ortholog $\mathrm{HLH}-2$, negative feedback, and birth order bias during the AC/VU decision in $\mathrm{C}$. elegans. Genes Dev 17, 3100-11.

Katoh, M. (2004). Identification and characterization of human HES2, HES3, and HES5 genes in silico. Int $J$ Oncol 25, 529-34. 
Kay, B. K., and Peng, H. B. (1991). Methods in Cell Biology Vol.36: Xenopus laevis:

Practical Uses in Cell and Molecular Biology. Academic Press, Inc., San Diego.

Kim, H. K., and Siu, G. (1998). The notch pathway intermediate HES-1 silences CD4 gene expression. Mol Cell Biol 18, 7166-75.

Kintner, C. (2002). Neurogenesis in embryos and in adult neural stem cells. $J$ Neurosci 22, 639-43.

Knust, E., Schrons, H., Grawe, F., and Campos-Ortega, J. A. (1992). Seven genes of the Enhancer of split complex of Drosophila melanogaster encode helix-loop-helix proteins. Genetics 132, 505-18.

Kokubo, H., Lun, Y., and Johnson, R. L. (1999). Identification and expression of a novel family of bHLH cDNAs related to Drosophila hairy and enhancer of split. Biochem Biophys Res Commun 260, 459-65.

Kolm, P. J., and Sive, H. L. (1995). Efficient hormone-inducible protein function in Xenopus laevis. Dev Biol 171, 267-72.

Kooh, P. J., Fehon, R. G., and Muskavitch, M. A. (1993). Implications of dynamic patterns of Delta and Notch expression for cellular interactions during Drosophila development. Development 117, 493-507.

Koster, R. W., Kuhnlein, R. P., and Wittbrodt, J. (2000). Ectopic Sox3 activity elicits sensory placode formation. Mech Dev 95, 175-87.

Koyano-Nakagawa, N., Kim, J., Anderson, D., and Kintner, C. (2000). Hes6 acts in a positive feedback loop with the neurogenins to promote neuronal differentiation. Development 127, 4203-16.

Koyano-Nakagawa, N., Wettstein, D., and Kintner, C. (1999). Activation of Xenopus genes required for lateral inhibition and neuronal differentiation during primary neurogenesis. $\mathrm{Mol}$ Cell Neurosci 14, 327-39.

Kozak, M. (1991). An analysis of vertebrate mRNA sequences: intimations of translational control. J Cell Biol 115, 887-903.

Kramatschek, B., and Campos-Ortega, J. A. (1994). Neuroectodermal transcription of the Drosophila neurogenic genes $\mathrm{E}(\mathrm{spl})$ and $\mathrm{HLH}-\mathrm{m} 5$ is regulated by proneural genes. Development 120, 815-26.

Lahaye, K., Kricha, S., and Bellefroid, E. J. (2002). XNAP, a conserved ankyrin repeatcontaining protein with a role in the Notch pathway during Xenopus primary neurogenesis. Mech Dev 110, 113-24.

Lai, E. C. (2004). Notch signaling: control of cell communication and cell fate. Development 131, 965-73.

Lamar, E., and Kintner, C. (2005). The Notch targets Esr1 and Esr10 are differentially regulated in Xenopus neural precursors. Development 132, 3619-30.

Langeland, J. A., and Carroll, S. B. (1993). Conservation of regulatory elements controlling hairy pair-rule stripe formation. Development 117, 585-96. 
Ledent, V., Paquet, O., and Vervoort, M. (2002). Phylogenetic analysis of the human basic helix-loop-helix proteins. Genome Biol 3, RESEARCH0030.

Lee, J. E., Hollenberg, S. M., Snider, L., Turner, D. L., Lipnick, N., and Weintraub, H. (1995). Conversion of Xenopus ectoderm into neurons by NeuroD, a basic helix-loop-helix protein. Science 268, 836-44.

Leimeister, C., Externbrink, A., Klamt, B., and Gessler, M. (1999). Hey genes: a novel subfamily of hairy- and Enhancer of split related genes specifically expressed during mouse embryogenesis. Mech Dev 85, 173-7.

Li, J., Wang, J., Nawaz, Z., Liu, J. M., Qin, J., and Wong, J. (2000). Both corepressor proteins SMRT and $\mathrm{N}-\mathrm{CoR}$ exist in large protein complexes containing HDAC3. EMBO $\mathrm{J}$ 19, 4342-4350.

Li, Y., Fenger, U., Niehrs, C., and Pollet, N. (2003). Cyclic expression of esr9 gene in Xenopus presomitic mesoderm. Differentiation 71, 83-9.

Lopez, S. L., Rosato-Siri, M. V., Franco, P. G., Paganelli, A. R., and Carrasco, A. E. (2005). The Notch-target gene hairy2a impedes the involution of notochordal cells by promoting floor plate fates in Xenopus embryos. Development 132, 1035-46.

Ma, Q., Kintner, C., and Anderson, D. J. (1996). Identification of neurogenin, a vertebrate neuronal determination gene. Cell 87, 43-52.

Maier, M. M., and Gessler, M. (2000). Comparative analysis of the human and mouse Hey1 promoter: Hey genes are new Notch target genes. Biochem Biophys Res Commun $275,652-60$.

Makalowski, W. (2001). Are we polyploids? A brief history of one hypothesis. Genome Res 11, 667-70.

Massari, M. E., and Murre, C. (2000). Helix-loop-helix proteins: regulators of transcription in eucaryotic organisms. Mol Cell Biol 20, 429-40.

Mathers, P. H., Grinberg, A., Mahon, K. A., and Jamrich, M. (1997). The Rx homeobox gene is essential for vertebrate eye development. Nature 387, 603-7.

Mattioni, T., Louvion, J. F., and Picard, D. (1994). Regulation of protein activities by fusion to steroid binding domains. Methods Cell Biol 43 Pt A, 335-52.

McLaughlin, K. A., Rones, M. S., and Mercola, M. (2000). Notch regulates cell fate in the developing pronephros. Dev Biol 227, 567-80.

Miyagi, S., Saito, T., Mizutani, K., Masuyama, N., Gotoh, Y., Iwama, A., Nakauchi, H., Masui, S., Niwa, H., Nishimoto, M., Muramatsu, M., and Okuda, A. (2004). The Sox-2 regulatory regions display their activities in two distinct types of multipotent stem cells. $\mathrm{Mol}$ Cell Biol 24, 4207-20.

Miyoshi, G., Bessho, Y., Yamada, S., and Kageyama, R. (2004). Identification of a novel basic helix-loop-helix gene, Heslike, and its role in GABAergic neurogenesis. $J$ Neurosci 24, 3672-82.

Moore, A. W., Barbel, S., Jan, L. Y., and Jan, Y. N. (2000). A genomewide survey of basic helix-loop-helix factors in Drosophila. Proc Natl Acad Sci U S A 97, 10436-41. 
Moreno, T. A., and Kintner, C. (2004). Regulation of segmental patterning by retinoic acid signaling during Xenopus somitogenesis. Dev Cell 6, 205-18.

Morrison, S. J., Perez, S. E., Qiao, Z., Verdi, J. M., Hicks, C., Weinmaster, G., and Anderson, D. J. (2000). Transient Notch activation initiates an irreversible switch from neurogenesis to gliogenesis by neural crest stem cells. Cell 101, 499-510.

Nakagawa, O., McFadden, D. G., Nakagawa, M., Yanagisawa, H., Hu, T., Srivastava, D., and Olson, E. N. (2000). Members of the HRT family of basic helix-loop-helix proteins act as transcriptional repressors downstream of Notch signaling. Proc Natl Acad Sci U S A 97, 13655-60.

Nakagawa, O., Nakagawa, M., Richardson, J. A., Olson, E. N., and Srivastava, D. (1999). HRT1, HRT2, and HRT3: a new subclass of bHLH transcription factors marking specific cardiac, somitic, and pharyngeal arch segments. Dev Biol 216, 72-84.

Nakatani, T., Mizuhara, E., Minaki, Y., Sakamoto, Y., and Ono, Y. (2004). Helt, a novel bHLH transcriptional repressor expressed in the developing central nervous system. $J$ Biol Chem.

Nakayama, H., Liu, Y., Stifani, S., and Cross, J. C. (1997). Developmental restriction of Mash-2 expression in trophoblast correlates with potential activation of the notch-2 pathway. Dev Genet 21, 21-30.

Nellesen, D. T., Lai, E. C., and Posakony, J. W. (1999). Discrete enhancer elements mediate selective responsiveness of enhancer of split complex genes to common transcriptional activators. Dev Biol 213, 33-53.

Nibu, Y., Zhang, H., and Levine, M. (1998). Interaction of short-range repressors with Drosophila CtBP in the embryo. Science 280, 101-4.

Niehrs, C., Steinbeisser, H., and De Robertis, E. M. (1994). Mesodermal patterning by a gradient of the vertebrate homeobox gene goosecoid. Science 263, 817-20.

Nieto, M., Schuurmans, C., Britz, O., and Guillemot, F. (2001). Neural bHLH genes control the neuronal versus glial fate decision in cortical progenitors. Neuron 29, 401-13.

Nieuwkoop, P. D., and Faber, J. (1994). "Normal table of Xenopus laevis (Daudin): a systematical and chronological survey of development from the fertilized egg till the end of metamorphosis." Garland Publishing, Inc., New York \& London.

Ninkovic, J., Tallafuss, A., Leucht, C., Topczewski, J., Tannhauser, B., Solnica-Krezel, L., and Bally-Cuif, L. (2005). Inhibition of neurogenesis at the zebrafish midbrain-hindbrain boundary by the combined and dose-dependent activity of a new hairy/E(spl) gene pair. Development 132, 75-88.

Nishimura, M., Isaka, F., Ishibashi, M., Tomita, K., Tsuda, H., Nakanishi, S., and Kageyama, R. (1998). Structure, chromosomal locus, and promoter of mouse Hes2 gene, a homologue of Drosophila hairy and Enhancer of split. Genomics 49, 69-75.

Oellers, N., Dehio, M., and Knust, E. (1994). bHLH proteins encoded by the Enhancer of split complex of Drosophila negatively interfere with transcriptional activation mediated by proneural genes. Mol Gen Genet 244, 465-73. 
Ohsako, S., Hyer, J., Panganiban, G., Oliver, I., and Caudy, M. (1994). Hairy function as a DNA-binding helix-loop-helix repressor of Drosophila sensory organ formation. Genes Dev 8, 2743-55.

Ohtsuka, T., Ishibashi, M., Gradwohl, G., Nakanishi, S., Guillemot, F., and Kageyama, R. (1999). Hes 1 and Hes5 as notch effectors in mammalian neuronal differentiation. Embo $J$ 18, 2196-207.

Oschwald, R., Richter, K., and Grunz, H. (1991). Localization of a nervous system-specific class II beta-tubulin gene in Xenopus laevis embryos by whole-mount in situ hybridization. Int J Dev Biol 35, 399-405.

Paroush, Z., Finley, R. L., Jr., Kidd, T., Wainwright, S. M., Ingham, P. W., Brent, R., and Ish-Horowicz, D. (1994). Groucho is required for Drosophila neurogenesis, segmentation, and sex determination and interacts directly with hairy-related bHLH proteins. Cell 79, 805-15.

Patterson, K. D., and Krieg, P. A. (1999). Hox11-family genes XHox11 and XHox11L2 in xenopus: XHox11L2 expression is restricted to a subset of the primary sensory neurons. Dev Dyn 214, 34-43.

Penzel, R., Oschwald, R., Chen, Y., Tacke, L., and Grunz, H. (1997). Characterization and early embryonic expression of a neural specific transcription factor xSOX3 in Xenopus laevis. Int J Dev Biol 41, 667-77.

Perron, M., Kanekar, S., Vetter, M. L., and Harris, W. A. (1998). The genetic sequence of retinal development in the ciliary margin of the Xenopus eye. Dev Biol 199, 185-200.

Perron, M., Opdecamp, K., Butler, K., Harris, W. A., and Bellefroid, E. J. (1999). X-ngnr-1 and Xath3 promote ectopic expression of sensory neuron markers in the neurula ectoderm and have distinct inducing properties in the retina. Proc Natl Acad Sci U S A 96, 14996-5001.

Phippen, T. M., Sweigart, A. L., Moniwa, M., Krumm, A., Davie, J. R., and Parkhurst, S. M. (2000). Drosophila C-terminal binding protein functions as a context-dependent transcriptional co-factor and interferes with both mad and groucho transcriptional repression. J Biol Chem 275, 37628-37.

Pichon, B., Taelman, V., Kricha, S., Christophe, D., and Bellefroid, E. J. (2002). XHRT-1, a hairy and Enhancer of split related gene with expression in floor plate and hypochord during early Xenopus embryogenesis. Dev Genes Evol 212, 491-5.

Pissarra, L., Henrique, D., and Duarte, A. (2000). Expression of hes6, a new member of the Hairy/Enhancer-of-split family, in mouse development. Mech Dev 95, 275-8.

Poortinga, G., Watanabe, M., and Parkhurst, S. M. (1998). Drosophila CtBP: a Hairyinteracting protein required for embryonic segmentation and hairy-mediated transcriptional repression. Embo J 17, 2067-78.

Riley, B. B., Chiang, M., Farmer, L., and Heck, R. (1999). The deltaA gene of zebrafish mediates lateral inhibition of hair cells in the inner ear and is regulated by pax2.1. Development 126, 5669-78.

Rones, M. S., Woda, J., Mercola, M., and McLaughlin, K. A. (2002). Isolation and characterization of Xenopus Hey-1: a downstream mediator of Notch signaling. Dev Dyn 225, 554-60. 
Ross, S. E., Greenberg, M. E., and Stiles, C. D. (2003). Basic helix-loop-helix factors in cortical development. Neuron 39, 13-25.

Rossner, M. J., Dorr, J., Gass, P., Schwab, M. H., and Nave, K. A. (1997). SHARPs: mammalian enhancer-of-split- and hairy-related proteins coupled to neuronal stimulation. Mol Cell Neurosci 10, 460-75.

Sadowski, I., Ma, J., Triezenberg, S., and Ptashne, M. (1988). GAL4-VP16 is an unusually potent transcriptional activator. Nature 335, 563-4.

Saint-Germain, N., Lee, Y. H., Zhang, Y., Sargent, T. D., and Saint-Jeannet, J. P. (2004). Specification of the otic placode depends on Sox9 function in Xenopus. Development 131, 1755-63.

Sambrook, J., Fritsch, E. F., and Maniatis, T. (1989). "Molecular Cloning : A Laboratory Manual (3 Volume Set)." Cold Spring Harbor Laboratory Press, Cold Spring Harbor, New York.

Sasai, Y., Kageyama, R., Tagawa, Y., Shigemoto, R., and Nakanishi, S. (1992). Two mammalian helix-loop-helix factors structurally related to Drosophila hairy and Enhancer of split. Genes Dev 6, 2620-34.

Satow, T., Bae, S. K., Inoue, T., Inoue, C., Miyoshi, G., Tomita, K., Bessho, Y., Hashimoto, N., and Kageyama, R. (2001). The basic helix-loop-helix gene hesr2 promotes gliogenesis in mouse retina. $J$ Neurosci $21,1265-73$.

Schlosser, G., and Ahrens, K. (2004). Molecular anatomy of placode development in Xenopus laevis. Dev Biol 271, 439-66.

Schlosser, G., and Northcutt, R. G. (2000). Development of neurogenic placodes in Xenopus laevis. J Comp Neurol 418, 121-46.

Schmidt, J., Francois, V., Bier, E., and Kimelman, D. (1995). Drosophila short gastrulation induces an ectopic axis in Xenopus: evidence for conserved mechanisms of dorsal-ventral patterning. Development 121, 4319-28.

Schneider, M. L., Turner, D. L., and Vetter, M. L. (2001). Notch signaling can inhibit Xath5 function in the neural plate and developing retina. Mol Cell Neurosci 18, 458-72.

Schweisguth, F. (2004). Notch signaling activity. Curr Biol 14, R129-38.

Shen, M., Kawamoto, T., Yan, W., Nakamasu, K., Tamagami, M., Koyano, Y., Noshiro, M., and Kato, Y. (1997). Molecular characterization of the novel basic helix-loop-helix protein DEC1 expressed in differentiated human embryo chondrocytes. Biochem Biophys Res Commun 236, 294-8.

Shen, M., Kawamoto, T., Teramoto, M., Makihira, S., Fujimoto, K., Yan, W., Noshiro, M., and Kato, Y. (2001). Induction of basic helix-loop-helix protein DEC1 (BHLHB2)/Stra13/Sharp2 in response to the cyclic adenosine monophosphate pathway. Eur J Cell Biol 80, 329-34.

Shinga, J., Itoh, M., Shiokawa, K., Taira, S., and Taira, M. (2001). Early patterning of the prospective midbrain-hindbrain boundary by the HES-related gene XHR1 in Xenopus embryos. Mech Dev 109, 225-39. 
Sieger, D., Tautz, D., and Gajewski, M. (2004). her11 is involved in the somitogenesis clock in zebrafish. Dev Genes Evol 214, 393-406.

Sive, H. L., Grainger, R. M., and Harland, R. M. (2000). "Early Development of Xenopus laevis: A Laboratory Manual." Cold Spring Harbor Laboratory Press, Cold Spring Harbor, New York.

Smith, W. C., and Harland, R. M. (1992). Expression cloning of noggin, a new dorsalizing factor localized to the Spemann organizer in Xenopus embryos. Cell 70, 829-40.

Sölter, M. (1999). Identifizierung von Genen mit morphoregulatorischer Funktion in der frühen Embryogenese von Xenopus laevis aus einer Schwanzspitzen-cDNA-Bank.

Diplomarbeit, Georg-August-Universität Göttingen, unveröffentlicht.

Sun, H., and Taneja, R. (2000). Stra13 expression is associated with growth arrest and represses transcription through histone deacetylase (HDAC)-dependent and HDACindependent mechanisms. Proc Natl Acad Sci U S A 97, 4058-63.

Sun, Y., Nadal-Vicens, M., Misono, S., Lin, M. Z., Zubiaga, A., Hua, X., Fan, G., and Greenberg, M. E. (2001). Neurogenin promotes neurogenesis and inhibits glial differentiation by independent mechanisms. Cell 104, 365-76.

Taelman, V., Van Wayenbergh, R., Solter, M., Pichon, B., Pieler, T., Christophe, D., and Bellefroid, E. J. (2004). Sequences downstream of the bHLH domain of the Xenopus hairy-related transcription factor-1 act as an extended dimerization domain that contributes to the selection of the partners. Dev Biol 276, 47-63.

Taira, M., Hayes, W. P., Otani, H., and Dawid, I. B. (1993). Expression of LIM class homeobox gene Xlim-3 in Xenopus development is limited to neural and neuroendocrine tissues. Dev Biol 159, 245-56.

Takada, H., Hattori, D., Kitayama, A., Ueno, N., and Taira, M. (2005). Identification of target genes for the Xenopus Hes-related protein XHR1, a prepattern factor specifying the midbrain-hindbrain boundary. Dev Biol 283, 253-67.

Takebayashi, K., Sasai, Y., Sakai, Y., Watanabe, T., Nakanishi, S., and Kageyama, R. (1994). Structure, chromosomal locus, and promoter analysis of the gene encoding the mouse helix-loop-helix factor HES-1. Negative autoregulation through the multiple $\mathrm{N}$ box elements. J Biol Chem 269, 5150-6.

Takebayashi, K., Takahashi, S., Yokota, C., Tsuda, H., Nakanishi, S., Asashima, M., and Kageyama, R. (1997). Conversion of ectoderm into a neural fate by ATH-3, a vertebrate basic helix-loop-helix gene homologous to Drosophila proneural gene atonal. Embo $J 16$, 384-95.

Takke, C., and Campos-Ortega, J. A. (1999). her1, a zebrafish pair-rule like gene, acts downstream of notch signalling to control somite development. Development 126, 300514.

Takke, C., Dornseifer, P., v Weizsacker, E., and Campos-Ortega, J. A. (1999). her4, a zebrafish homologue of the Drosophila neurogenic gene $\mathrm{E}(\mathrm{spl})$, is a target of $\mathrm{NOTCH}$ signalling. Development 126, 1811-21.

Talikka, M., Perez, S. E., and Zimmerman, K. (2002). Distinct patterns of downstream target activation are specified by the helix-loop-helix domain of proneural basic helix-loophelix transcription factors. Dev Biol 247, 137-48. 
Tamai, K., Semenov, M., Kato, Y., Spokony, R., Liu, C., Katsuyama, Y., Hess, F., SaintJeannet, J. P., and He, X. (2000). LDL-receptor-related proteins in Wnt signal transduction. Nature 407, 530-5.

Tietze, K., Oellers, N., and Knust, E. (1992). Enhancer of splitD, a dominant mutation of Drosophila, and its use in the study of functional domains of a helix-loop-helix protein. Proc Natl Acad Sci U S A 89, 6152-6.

Tomita, K., Ishibashi, M., Nakahara, K., Ang, S. L., Nakanishi, S., Guillemot, F., and Kageyama, R. (1996). Mammalian hairy and Enhancer of split homolog 1 regulates differentiation of retinal neurons and is essential for eye morphogenesis. Neuron 16, 72334.

Tomita, K., Moriyoshi, K., Nakanishi, S., Guillemot, F., and Kageyama, R. (2000). Mammalian achaete-scute and atonal homologs regulate neuronal versus glial fate determination in the central nervous system. Embo J 19, 5460-72.

Torres, M., Gomez-Pardo, E., and Gruss, P. (1996). Pax2 contributes to inner ear patterning and optic nerve trajectory. Development 122, 3381-91.

Tsuji, S., Cho, K. W., and Hashimoto, C. (2003). Expression pattern of a basic helix-loophelix transcription factor Xhairy2b during Xenopus laevis development. Dev Genes Evol 213, 407-11.

Turner, D. L., and Cepko, C. L. (1987). A common progenitor for neurons and glia persists in rat retina late in development. Nature 328, 131-6.

Turner, D. L., and Weintraub, H. (1994). Expression of achaete-scute homolog 3 in Xenopus embryos converts ectodermal cells to a neural fate. Genes Dev 8, 1434-47.

Umbhauer, M., Boucaut, J. C., and Shi, D. L. (2001). Repression of XMyoD expression and myogenesis by Xhairy-1 in Xenopus early embryo. Mech Dev 109, 61-8.

Van Doren, M., Bailey, A. M., Esnayra, J., Ede, K., and Posakony, J. W. (1994). Negative regulation of proneural gene activity: hairy is a direct transcriptional repressor of achaete. Genes Dev 8, 2729-42.

Vasiliauskas, D., and Stern, C. D. (2000). Expression of mouse HES-6, a new member of the Hairy/Enhancer of split family of bHLH transcription factors. Mech Dev 98, 133-7.

Wang, S., and Barres, B. A. (2000). Up a notch: instructing gliogenesis. Neuron 27, 197200.

Wetts, R., and Fraser, S. E. (1988). Multipotent precursors can give rise to all major cell types of the frog retina. Science 239, 1142-5.

Wettstein, D. A., Turner, D. L., and Kintner, C. (1997). The Xenopus homolog of Drosophila Suppressor of Hairless mediates Notch signaling during primary neurogenesis. Development 124, 693-702.

White, P. S., Thompson, P. M., Gotoh, T., Okawa, E. R., Igarashi, J., Kok, M., Winter, C., Gregory, S. G., Hogarty, M. D., Maris, J. M., and Brodeur, G. M. (2005). Definition and characterization of a region of 1 p36.3 consistently deleted in neuroblastoma. Oncogene 24, 2684-94. 
Whitfield, T. T., Riley, B. B., Chiang, M. Y., and Phillips, B. (2002). Development of the zebrafish inner ear. Dev Dyn 223, 427-58.

Yamada, K., Kawata, H., Shou, Z., Mizutani, T., Noguchi, T., and Miyamoto, K. (2003). Insulin induces the expression of the SHARP-2/Stra13/DEC1 gene via a phosphoinositide 3-kinase pathway. J Biol Chem 278, 30719-24.

Yan, B., Heus, J., Lu, N., Nichols, R. C., Raben, N., and Plotz, P. H. (2001). Transcriptional regulation of the human acid alpha-glucosidase gene. Identification of a repressor element and its transcription factors Hes-1 and YY1. J Biol Chem 276, 1789-93.

Yao, J., Lai, E., and Stifani, S. (2001). The winged-helix protein brain factor 1 interacts with groucho and hes proteins to repress transcription. Mol Cell Biol 21, 1962-72.

Yoon, D. Y., Buchler, P., Saarikoski, S. T., Hines, O. J., Reber, H. A., and Hankinson, O. (2001). Identification of genes differentially induced by hypoxia in pancreatic cancer cells. Biochem Biophys Res Commun 288, 882-6.

Yoon, K., and Gaiano, N. (2005). Notch signaling in the mammalian central nervous system: insights from mouse mutants. Nat Neurosci 8, 709-15.

Zawel, L., Yu, J., Torrance, C. J., Markowitz, S., Kinzler, K. W., Vogelstein, B., and Zhou, S. (2002). DEC1 is a downstream target of TGF-beta with sequence-specific transcriptional repressor activities. Proc Natl Acad Sci U S A 99, 2848-53.

Zhang, H., and Levine, M. (1999). Groucho and dCtBP mediate separate pathways of transcriptional repression in the Drosophila embryo. Proc Natl Acad Sci U S A 96, 535-40.

Zhang, Y., Iratni, R., Erdjument-Bromage, H., Tempst, P., and Reinberg, D. (1997). Histone deacetylases and SAP18, a novel polypeptide, are components of a human Sin3 complex. Cell 89, 357-364.

Zheng, J. L., Shou, J., Guillemot, F., Kageyama, R., and Gao, W. Q. (2000). Hes1 is a negative regulator of inner ear hair cell differentiation. Development 127, 4551-60. 


\section{Anhang}

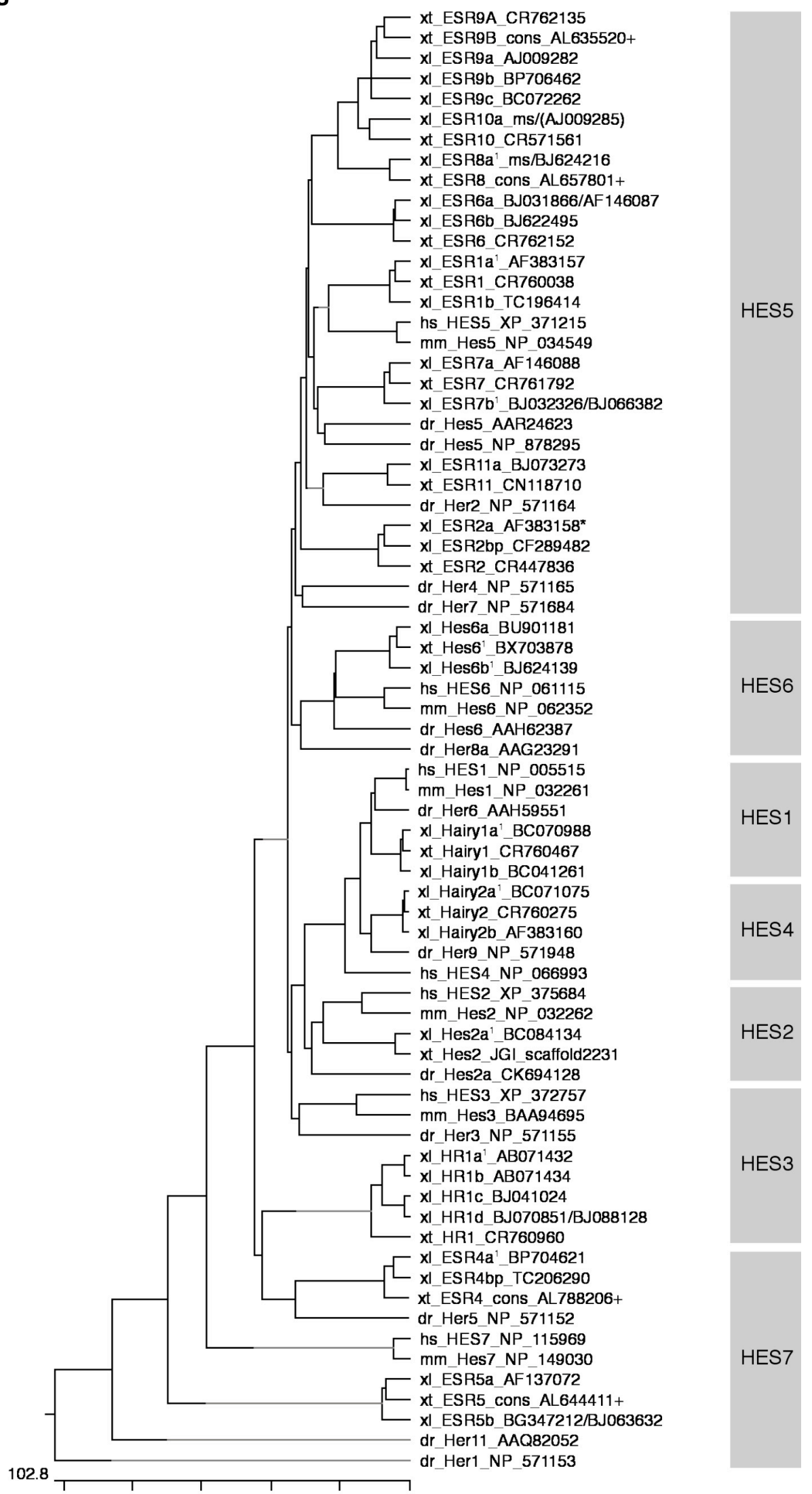

Abb.7-1: Sequenzähnlichkeiten von bHLH-O-Proteinen mit WRPW-Motiv in Vertebraten.

Die bHLH-O-Proteine mit WRPW-Motiv aus Xenopus und Zebrafisch konnten entsprechend ihrer Verwandtschaft mit Säuger-Proteinen 7 Gruppen (HES1-7) zugeordnet werden, die rechts als graue Felder dargestellt sind. Der phylogenetische Stammbaum basiert auf einem Vergleich der Gesamtproteine („Neighbor-joining“-Methode). Die Datenbank-Zugriffsnummern, GenBank oder TIGR (TC), sind hinter den 
Proteinnamen aufgeführt. Abkürzungen: dr, Brachydanio rerio; hs, Homo sapiens; mm, Mus musculus; xl, Xenopus laevis; xt, Xenopus tropicalis; A,B, vermutlich durch Genduplikation entstandene Varianten des diploiden Xenopus tropicalis ; a-d, vermutlich pseudoallele oder/und durch Genduplikation entstandene Varianten des tetraploiden Xenopus laevis; $\mathrm{a}^{1}$, Existenz einer sehr ähnlichen, hier nicht aufgeführten Variante $\mathrm{a}^{2}$ (Tab.A-1,3); cons, Consensus-Sequenz mehrerer cDNA-Klone: nur eine der Datenbank-Zugriffsnummern ist angegeben; +, weitere partielle cDNA-Sequenzen bekannt (Tab.A-2); ms, eigene Sequenzierung; $p$, partielles Protein; *, ab AS20 (Li et al., 2003); ( ), Resequenzierung der cDNA ergab Abweichungen von veröffentlichter Sequenz, das abgeleitete Protein wurde dadurch um acht weitere Aminosäuren, MAPYSASS, am N-Terminus ergänzt. Anmerkungen: Die hier aufgeführten bHLH-O-Proteine dr_Her4, dr_Hes6, dr_Hes2, dr_Her8, dr_Hes5_AAR24623 und dr_Hes5_NP_878295 entsprechen in identischer Reihenfolge den von Sieger et al. (2004) identifizierten bHLH-O-Proteinen dr_Her4.1, dr_13.2, dr_Her10.2 (sehr ähnliches, aber kürzeres Protein vermutlich aufgrund eines nicht identifizierten Exons), dr_Her8.2, dr_Her12 und dr_Her15. Die von Sieger et al. (2004) identifizierten Zebrafisch-bHLH-O-Proteine Her4.2, Her8.2, Her10.1, Her13.1 und Her14 sind im Stammbaum nicht berücksichtigt, ähneln aber außer Her14 entsprechend ihres Namens dem jeweiligen zweiten Protein, so ist z.B. Her4.2 eng mit Her4.1 (entspricht im Stammbaum: dr_her4) verwandt. Her14 scheint keiner der bekannten Vertebraten Hes-Gruppen eindeutig zuzuorden zu sein, gehört aber zur $\mathrm{E}(\mathrm{spl})$-Unterfamilie von bHLH-O-Proteinen (132 AS).
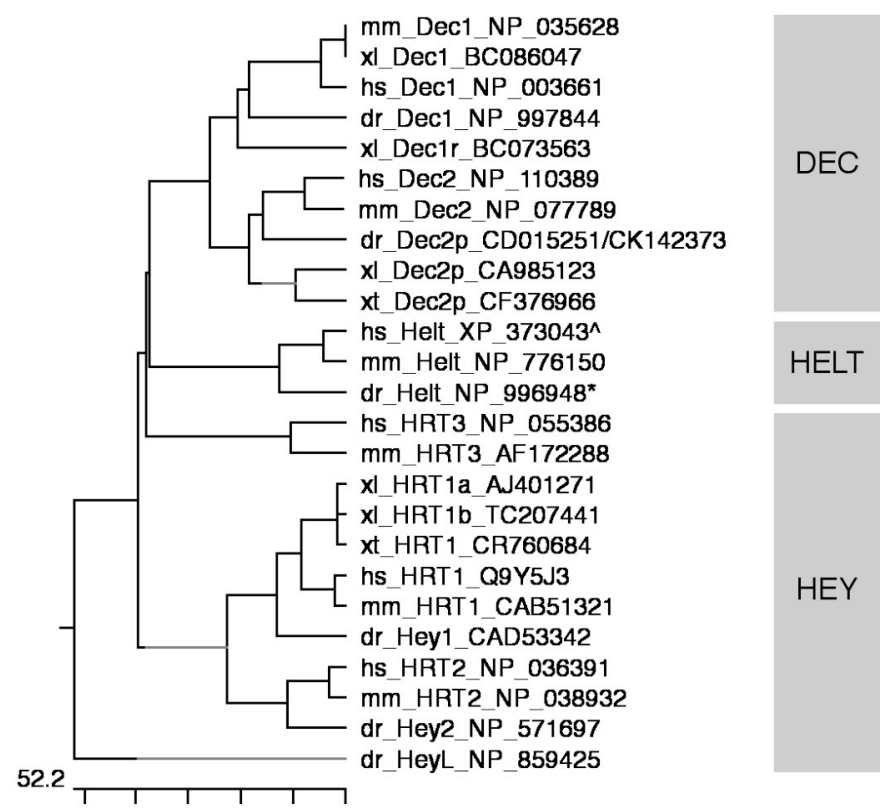

\section{Abb.7-2: Sequenzähnlichkeiten von bHLH-O-Proteinen ohne WRPW-Motiv in Vertebraten.}

Die bHLH-O-Proteine ohne WRPW-Motiv wurden entsprechend ihrer Verwandtschaft den 3 bekannten Familien (DEC, HELT und HEY) zugeordnet, die rechts als graue Felder dargestellt sind. Der phylogenetische Stammbaum basiert auf einem Vergleich der Gesamtproteine. Die Datenbank-Zugriffsnummern, GenBank oder TIGR (TC), sind hinter den Proteinnamen aufgeführt. Abkürzungen: br, Brachydanio rerio; hs, Homo sapiens; mm, Mus musculus; $\mathrm{xI}$, Xenopus laevis; xt, Xenopus tropicalis; a,b, vermutlich pseudoallele Varianten des tetraploiden Xenopus laevis; p, partielles Protein; $r$, „related“, ähnliches Protein, das aufgrund der Sequenzunterschiede vermutlich keine pseudoallele Variante darstellt; ^, ohne Intronsequenzen (Miyoshi et al., 2004); *, ab AS50 (Miyoshi et al., 2004). 


\begin{tabular}{|c|c|c|c|c|c|}
\hline bHLH-O-Protein & $\begin{array}{l}\text { UniGene } \\
\text { X.laevis }\end{array}$ & $\begin{array}{l}\text { Datenbank- } \\
\text { Zugangsnummer }\end{array}$ & bHLH-O-Protein & $\begin{array}{l}\text { UniGene } \\
\text { X.laevis }\end{array}$ & \begin{tabular}{|l} 
Datenbank- \\
Zugangsnummer
\end{tabular} \\
\hline ESR1a $^{1}$ & $\mathrm{XI} .8440$ & AF383157 & Hes2a & - & BC084134 \\
\hline ESR1a $^{2}$ & $\mathrm{XI} .8440$ & BC043639 & HR1a & $\mathrm{XI} .12126$ & AB071432 \\
\hline ESR1b & XI.48575 & BF613622 & HR1a' & XI.12126 & AB071433 \\
\hline ESR2a & XI.12067 & AF383158 & HR1b & $\mathrm{XI} .12126$ & AB071434 \\
\hline ESR2b (p) & XI.34898 & CF289482 & HR1c & XI.34123 & BJ041024 \\
\hline ESR4a & XI.24379 & BP704621 & HR1d & XI.34123 & BJ070851+ \\
\hline ESR4b (p) & XI.15142 & $B G 017175$ & & & BJ088128 \\
\hline ESR5a & XI.14524 & AF137072 & Hes6a & - & BU901181 \\
\hline \multirow[t]{2}{*}{ ESR5b } & XI.9152 & BG347212+ & Hes6b $^{1}$ (MERG) & $\mathrm{XI} .209$ & BJ624139 \\
\hline & & BJ063632 & Hes6b $^{2}$ (MERT) & $\mathrm{XI} .209$ & BJ623807 \\
\hline \multirow[t]{2}{*}{ ESR6a } & XI.585 & AF146087+ & Hairy1a $^{1}$ & XI.21817 & BC070988 \\
\hline & & BJ031866 & Hairy1 $\mathrm{a}^{2}$ & XI.21817 & U36194 \\
\hline ESR6b & XI.20958 & BJ622495 & Hairy1b & XI.972 & BC041261 \\
\hline ESR7a & XI.586 & AF146088 & Hairy2a $^{1}$ & XI.25977 & BC071075 \\
\hline \multirow[t]{2}{*}{ ESR7b } & XI.16321 & BJ032326+ & ${\text { Hairy } 2 a^{2}}^{2}$ & XI.25977 & AF383159 \\
\hline & & BJ066382 & Hairy2a $^{3}$ & XI.25977 & AF139914 \\
\hline ESR8a & XI.33885 & BJ624216 & Hairy2b & XI.1764 & AF383160 \\
\hline ESR9a & XI.29033 & AJ009282 & HRT1a & $\mathrm{XI} .469$ & AJ401271 \\
\hline ESR9b $(p)^{*}$ & XI.47733 & BP706462 & HRT1b & XI.15880 & TC207441 \\
\hline ESR9c & XI.12444 & BC072262 & Dec1 & - & BC086047 \\
\hline ESR10a & XI.9271 & ms / (AJ009285) & Dec1r & XI.19778 & BC073563 \\
\hline ESR11a & - & BJ073273 & $\operatorname{Dec} 2(p)$ & - & CA985123 \\
\hline
\end{tabular}

Tab.7-1: UniGene- und GenBank/TIGR-Zugangsnummern für bHLH-O-Proteine in Xenopus laevis. 


\begin{tabular}{|c|c|c|}
\hline $\begin{array}{l}\text { bHLH-O- } \\
\text { Protein }\end{array}$ & $\begin{array}{l}\text { UniGene } \\
X . \text { tropicalis }\end{array}$ & $\begin{array}{l}\text { GenBank- } \\
\text { Zugangsnummer }\end{array}$ \\
\hline ESR1 & Str.11260 & CR760038 \\
\hline ESR2 & Str.24466 & CR447836 \\
\hline ESR4 & Str.15763 & $\begin{array}{l}\text { Consensus: } \\
\text { AL788206 } \\
\text { AL789144 } \\
\text { AL789214 } \\
\text { AL969892 } \\
\text { BX700371 } \\
\text { BX702537 } \\
\text { CF785485 }\end{array}$ \\
\hline ESR5 & Str.10309 & $\begin{array}{l}\text { Consensus: } \\
\text { AL644411 } \\
\text { AL657114 } \\
\text { AL661494 } \\
\text { AL785592 } \\
\text { AL788217 } \\
\text { AL796693 } \\
\text { BX685632 }\end{array}$ \\
\hline ESR6 & Str.15005 & CR762152 \\
\hline ESR7 & Str.24311 & CR761792 \\
\hline ESR8 & Str.20587 & $\begin{array}{l}\text { Consensus: } \\
\text { AL657801 } \\
\text { AL799418 } \\
\text { CN106068 } \\
\text { CN107483 }\end{array}$ \\
\hline ESR9A & Str.9764 & $\begin{array}{l}\text { CR762135 } \\
\text { AC151464 (bac3) }\end{array}$ \\
\hline ESR9B & Str.4845 & $\begin{array}{l}\text { AC151464 (bac2) } \\
\text { Consensus } \\
\text { (WRPF): } \\
\text { AL635520 } \\
\text { BQ392975 } \\
\text { CN095894 } \\
\text { CR572534 }\end{array}$ \\
\hline ESR10 & - & $\begin{array}{l}\text { CR571561 } \\
\text { AC151464 (bac1) }\end{array}$ \\
\hline ESR11 & Str.15848 & CN118710 \\
\hline Hairy1 & Str.10866 & CR760467 \\
\hline Hairy2 & Str.6018 & CR760275 \\
\hline Hes2 & - & $\overline{J G I}$ Jscaffold 2231 \\
\hline Hes6 & Str.1144 & $\begin{array}{l}\text { BX703878 } \\
\text { BX715190 }\end{array}$ \\
\hline HR1 & Str.1458 & CR760960 \\
\hline HRT1 & Str.11458 & CR760684 \\
\hline Dec1 & - & - \\
\hline $\operatorname{Dec} 2(p)$ & - & CF376966 \\
\hline
\end{tabular}

Tab.7-2: UniGene- und GenBank/JGI-Zugangsnummern für bHLH-O-Proteine in Xenopus tropicalis. 


\begin{tabular}{|c|c|c|c|}
\hline bHLH-O-Protein & $\begin{array}{l}\text { Datenbank- } \\
\text { Zugangsnummer }\end{array}$ & bHLH-O-Protein & $\begin{array}{l}\text { Datenbank- } \\
\text { Zugangsnummer }\end{array}$ \\
\hline \multirow[t]{2}{*}{$\mathrm{ESR}_{1} \mathrm{a}^{1}$} & AF383157 & Hes $2 a^{2}$ & $\mathrm{~ms}$ \\
\hline & C4579 & HR1a & AB071432 \\
\hline \multirow[t]{2}{*}{$\mathrm{ESR}_{1} \mathrm{a}^{2}$} & TC207523 & & BAB78540 \\
\hline & BC043639 & & TC211787 \\
\hline ESR1b & TC196414 & HR1a' & AB071433 \\
\hline \multirow[t]{2}{*}{ ESR2a } & AF383158 & & BAB78541 \\
\hline & TC191897 & HR1b & AB071434 \\
\hline ESR2b (p) & CF289482 & & BAB78542 \\
\hline ESR4a $^{1}(\mathrm{MH})$ & BP704621 & & TC209648 \\
\hline $\mathrm{ESR} \mathrm{a}^{2}$ (MC) & AF137073 & HR1c & BJ041024 \\
\hline $\mathrm{ESR} \mathrm{a}^{2}$ (MC) & AAD42783 & & TC209649 \\
\hline $\mathrm{ESR} 4 \mathrm{a}^{3}$ (ab M2) & TC206291 & HR1d & BJ070851+ \\
\hline \multirow[t]{2}{*}{ ESR4b (p) (ab M2) } & TC206290 & & BJ088128 \\
\hline & C4296 & Hes6a (ab M2) & TC201886 \\
\hline \multirow[t]{2}{*}{ ESR5a } & AAD42782 & Hes6a (ab M1) & BU901181 \\
\hline & TC207650 & Hes6b $^{1}$ (MERG) & $\mathrm{ms}$ \\
\hline \multirow[t]{2}{*}{ ESR5b } & BG347212+ & & TC201920 \\
\hline & BJ063632 & & BJ624139 \\
\hline \multirow[t]{3}{*}{ ESR6a } & AF146087+ & Hes6b $^{2}$ (MERT) & BJ623807 \\
\hline & BJ031866 & Hairy1a $^{1}$ & TC208205 \\
\hline & C1045 & & BC070988 \\
\hline ESR6b & BJ622495 & Hairy $1 a^{2}$ & AAA79185 \\
\hline \multirow[t]{2}{*}{ ESR7a } & AF146088 & & U36194 \\
\hline & TC191199 & Hairy $1 b$ & TC190979 \\
\hline ESR7b $^{1}$ & C1175 & & BC041261 \\
\hline$E^{E S R 7 b^{2}}$ & TC191200 & Hairy2a $^{1}$ & BC071075 \\
\hline \multirow[t]{2}{*}{ ESR8a $^{1}$} & $\mathrm{~ms}$ & & TC188850 \\
\hline & BJ624216 & ${\text { Hairy } 2 a^{2}}^{2}$ & AF383159 \\
\hline ESR8a $^{2}$ & C10656 & ${\text { Hairy } 2 a^{3}}^{3}$ & AF139914 \\
\hline \multirow[t]{3}{*}{ ESR9a } & AJ009282 & Hairy2b & AF383160 \\
\hline & CAE46483 & & AF356000 \\
\hline & TC189498 & & TC197056 \\
\hline ESR9b (p)* & BP706462 & & TC207979 \\
\hline \multirow[t]{3}{*}{ ESR9c } & BC072262 & HRT1a & AJ401271 \\
\hline & TC189499 & & TC207442 \\
\hline & C3872 & & CAB96791 \\
\hline \multirow[t]{3}{*}{ ESR10a } & $\mathrm{ms}$ & HRT1b & TC207441 \\
\hline & (AJ009285) & & C6718 \\
\hline & (CAE46484) & Dec1 & BC086047 \\
\hline \multirow[t]{3}{*}{ ESR11a } & BJ073273 & Dec1r & BC073563 \\
\hline & TC195822 & $\operatorname{Dec} 2(p)$ & CA985123 \\
\hline & C7432 & & \\
\hline \multirow[t]{4}{*}{$\mathrm{Hes}^{2} \mathrm{a}^{1}$} & BC084134 & & \\
\hline & CF521797 & & \\
\hline & CF549226 & & \\
\hline & TC209580 & & \\
\hline
\end{tabular}

Tab.7-3: GenBank/TIGR/NIBB-Zugangsnummern für bHLH-O-Proteine in Xenopus laevis. 
XHes2

XHes2_TC209580

XHes2

XHes2_TC209580

XHes2

XHes2_TC209580

XHes2

XHes2_TC209580

XHes2

XHes2_TC209580

XHes2

XHes2_TC209580

XHes2

XHes2_TC209580

XHes2

XHes2_TC209580

XHes2

XHes2_TC209580

XHes2

XHes2_TC209580

XHes2

XHes2_TC209580

XHes2

XHes2_TC209580

XHes2

XHes2_TC209580

XHes2

XHes2_TC209580
---CTTGCTGGAAGCACCGCTGCCTAGTCTGTACCATGGCTCCCAATGTAGCGCTCGCAGACTCCATGCACAACTACCAG CTGCTTGCTGGAAGCACCGCTGCCTAGTCTGTACCATGGCTCCCAATGTAGCGCTCGCAGACTCCATGCACAACTACCAG

CCCAAGCCTGGCAAGAGGAATCAGGAGGCCAGTGAGCTAAGAAAGACTTTAAAGCCCCTGATGGAAAAAAGAAGGAGGGC CCCAAGCCTGGCAAGAGGAATCAGGAGGCCAGTGAGCTAAGAAAGACTTTAAAGCCCCTGATGGAAAAACGAAGGAGGGC

GAGAATCAACGAGAGTCTGAACCAACTGAAAACCCTCATCCTGCCTCTCATTGGGAAAGATAATTCCCGGTACTCCAAGC AAGAATCAACGAGAGTCTGAACCAACTGAAAACCCTCATCCTGCCTCTCATTGGGAAAGATAATTCCCGGTACTCCAAGC

TGGAAAAAGCTGATATTTTGGAAATGACAGTGAGATTCCTAAGAGACATCCCTCCGGTCCAGGCACAAAATCCCGCAGAT TGGAAAAAGCTGATATTTTGGAAATGACAGTGAGATTCCTAAGAGACATCCCTCCGGTCCAGGCACAAAATCAAGCAGAT

CGCTACAAGGAAGGCTACAGAGCATGTGTAGAGCGTCTGAGCGCAATCCTTGGTAAATCTCATGTGCTGACCGGAGAGGC CGCTACAAGGAAGGCTACAGAGCATGTGTAGAGCGTCTGAGCGCAATCCTTGGTAAATCTCATGTGCTGACCGGAGAGGC

GAGTAACCGCCTTCTAGAATACCTGCAGAGGAGCCCTGAGCTGTGCAGTTCAGATTGTAATCATCCTCCCAAGCCCCAAC GAGTAACCGCCTTCTAGAATACCTGCAGAGGAGCCCTGAGCTGTGCAGTTCAGATTGTAATCATCCTCCCAAGCCCCAAC

GTCCTAGGATTGTGCTCCAAGTGAGTCCCAGAACATCTCAGTTTGGATCTCCTCTCCAGAACCAACCCTCCAGCCACAGA GTCCTAGGATTGTGCTCCAAGTGAGTCCCAGAACATCTCAGTTTGGATCTCCTCTCCAGAACCAACCCTCCAGCCACAGA

CCTGCCCCATGTCCCCCGCAGCTCAACAGCTCCATCTGGAGGCCGTGGTGAATGTCAGCTTGGACTTTGTACTCTCACAA CCTGCCCCATGTCCCCCGCAGCTCAACAGCTCCATCTGGAGGCCGTGGTGAATGTCAGCTTGGACTTTGTACTCTCACAA

AGACTGTGACAATGCTACAGCTCGTGGGCATTATTACCCCCGTTATAAAACACCCCAGTGATATGTGTATTTATTTATTG AGACTGTGACAATGCTACAGCTCGTGGGCATTATTACCCC-GTTATAAAACACCCCAGTGATATGTGTATTTATTTATTG

TAAATATGTCCCCTCACATGAAATCCTGACTTACTAA-GGCAATATATTTTGGACAAATAGTCCTGAATACAAAGGGCAC TAAATATGTCCCCTCACATGAAATCCTGACTTACTAAAGGCAATATATTTTGGACAAATAGTCCTGAATACAAAGGGCAC

GAGAGTGACCCACATTGTGAACCCAAAGGGTTTAATCTAGTATGCGATTTGCATTATTTTACATTAACCCATGGACTGCC GAGAGTGACCCACATTGTGAACCCAAAGGGTTTAATCTAGTATGCGATTTGCATTATTTTACATTAACCCATGGACTGCC

AGAGATGGCCAATGCTACAGTCTCTGCCATGTATTGACTCTTCTGGCAGTCCAGGGGTTTAATGACACAGGGCTATGTGC AGAGATGGCCAATGCTACAGTCTCTGCCATGTATTGACTITTCTGGCAGTCCAGGGGTTTAATGACACAGGGCTATGTGC

AACAATAATGCCTGGACATGAACACTGTTGCCAGCACTTTTTTTTATTGACTTGTTTGTAATGAAAAATGATATTTTTAA AACAATAATGCCTGGACATGAACACTGTTGCCAGCACTTTTTTT-ATTGACTTGTTTGTAATGAAAAATTATATTTTTAA

AATAAAATCCTAAAATGTGAAAAAAAAAAAAAAAAAAAA

1075

AATAAAATCCTAAAATGTG

Abb.7-3: Vergleich von XHes2-cDNA-Sequenzen aus Xenopus laevis.

Nukleotide, die im isolierten XHes2-cDNA-Klon (XHes2) und der TIGR-Contig-Sequenz XHes2_TC209580 identisch sind, sind rot oder im Fall von Start- und Stop-Codon grün dargestellt, unterschiedliche Nukleotide sind schwarz. Der Bereich der TIGR-Contig-Sequenz, der zur Zeit der Isolierung des XHes2-cDNA-Klons zur Verfügung stand (AW639943, AW642120, AW643378, AW644752, BI350304), ist unterstrichen. Die Länge der Sequenzen in Nukleotiden ist jeweils am Ende angegeben. Das Fehlen von Nukleotiden ist durch Bindestriche (-) dargestellt. Die Sequenz des cDNA-Klons BC084134 ist bis auf das Fehlen der ersten zwei Nukleotide mit der TIGR-Contig-Sequenz TC209580 identisch. 
A

$X 1$. Hes $2 a^{2}$

$\mathrm{Xl}$. Hairy $1 a^{1}$

$X 1$. Hai ry2b

Xl. ESR $1 a^{1}$

Xl. ESR5a

XI.HR1a

$\mathrm{Xl}$.Hes6b

Xl. HRT1a

B

$X 1$. Hes $2 a^{2}$

Xl. Hairy $1 a^{1}$

$X \mathrm{Xl}$. Hairy $2 \mathrm{~b}$

Xl.ESR1 $a^{1}$

Xl.ESR5a

$X 1$. HRIa

$\mathrm{X} 1$.Hes6b

Xl. HRT1a basisch

Helix

Loop

Helix

ELRKTLKPLMEKRRRARINESLNOLKTLILPLIGKDNSRYSKLEKADILEMTVRFLRDIPPVO EHRKSSKPIMEKRRRARINESLGQLKTLILDALKKDSSRHSKLEKADILEMTVKHLRNLQRVQ EHRKSSKPIMEKRRRARINESLGQLKTLILDALKKDSSRHSKLEKADILEMTVKHLRNLQRVQ EKNKLRKPIVEKMRRDRINNSIEOLKVLLEKEFHKOEP-NVKLEKADILEMAVNYLOOOKSOS PSRKILKPVVEKQRRDRINRSLGEMRILLFQLTGNQKLQNPKMEKAEILELAV IY IRNVTRMK THRKLLKPLVEKRRRERINNSLEKLRIFLFQTLKSEKLKNPKVEKAEILECTVQFLQSRKLLP GDRQMRKPLVEKRRRARINESLQELRG-ILSDSELQS----KMENAEVLELTVKRVERVLRNR

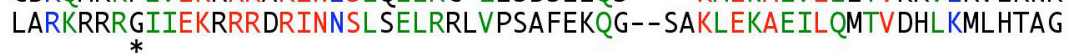

C

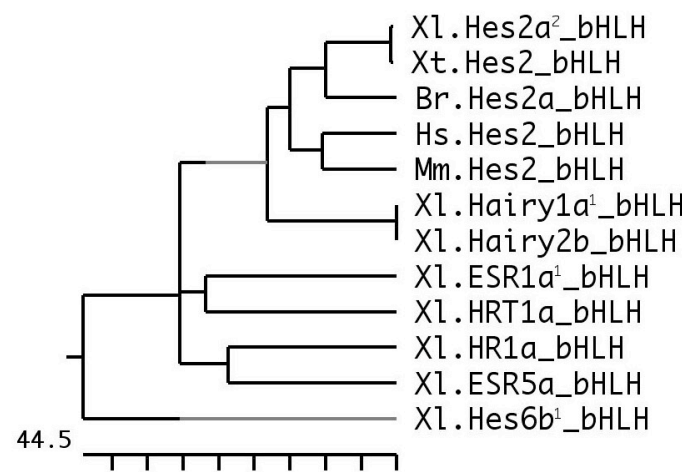

Orange

\begin{tabular}{lll}
\hline YK-EGYRACVERLSAILGKSHVLTGE--ASNRLLEYL & & 34 \\
YR-AGFSECMNEVTRFLSTCEGVNTD--VRTRLLGHL & 34 \\
YR-AGFNECMNEVTRFLSTCEGVNTE--VRTRLLGHL & 34 \\
YK-QGFSSCLREAVQFLCYYPESGET--QMK-LLNHL & 33 \\
YV-SGFRECLDRTEDFISEISPKARAVFLDN-LQTHL & 35 \\
YQ-SGFQHCLETTLHFMNSKPDMNGV--TKE-LLSHQ & 33 \\
FT-AGYIQCMHEVHTFVSSCPGIDAS--LAADLLNHL & 34 \\
YRSLGFRECLAEVARYLSIIEGMETADPLRVRLVHL & 37
\end{tabular}

Abb.7-4: Sequenzvergleich der bHLH- und Orange-Domänen von bHLH-O-Proteinen aus Xenopus.

$(A, B)$ Sequenzvergleich der bHLH- und Orange-Domänen verschiedener bHLH-O-Proteine aus Xenopus laevis. Der Grad der Aminosäurekonservierung ist wie folgt dargestellt: rot, identisch; grün, starke Ähnlichlichkeit; blau, schwache Ähnlichkeit; Bindestriche (-), fehlende Aminosäuren. Die Zahlen am Ende der Sequenzen geben die Anzahl der Aminosäuren an. Die Datenbank-Zugriffsnummern sind identisch mit denen aus Abb.3 und befinden sich im Anhang (Abb.A-1). (C,D) Sequenzähnlichkeiten der bHLH- und OrangeDomänen von XHes2 und anderen Wirbeltier-bHLH-O-Proteinen, jeweils dargestellt in einem phylogenetischen Stammbaum. (A,C) Die bHLH-Domänen der Hes2-Proteine ähneln am ehesten den bHLHDomänen von Hairy-Proteinen. $(B, D)$ Die Orange-Domänen der Hes2-Proteine unterscheiden sich erheblich von den Orange-Domänen der anderen Xenopus-bHLH-O-Proteine. Abkürzungen: *, konserviertes Prolin $(\mathrm{P})$ bzw. Glycin (G) an Position 8 der basischen Domäne; Br., Brachydanio rerio; Hs., Homo sapiens; Mm., Mus musculus; XI., Xenopus laevis; Xt., Xenopus tropicalis. 
A

Prozent Ähnlichkeit

\begin{tabular}{|c|c|c|c|c|c|c|c|c|c|c|c|c|c|}
\hline & 1 & 2 & 3 & 4 & 5 & 6 & 7 & 8 & 9 & 10 & 11 & 12 & \\
\hline 1 & & 92.7 & 42.4 & 43.4 & 46.5 & 34.6 & 34.6 & 22.8 & 19.8 & 24.0 & 23.6 & 18.3 & 1 \\
\hline 2 & 7.3 & & 1.9 & 433.9 & 47.1 & 31.9 & 33.5 & 23.3 & 21.4 & 24.0 & 22.5 & 20.4 & 2 \\
\hline 3 & 55.4 & 54.3 & & 32.9 & 40.1 & 29.3 & 29.8 & 22.8 & 20.9 & 21.4 & 20.9 & 18.8 & 3 \\
\hline 4 & 50.9 & 50.3 & 60.5 & & 68.2 & 36.4 & 37.0 & 24.9 & 22.0 & 22.7 & 24.3 & 24.3 & 4 \\
\hline 5 & 49.0 & 49.0 & 56.6 & 27.6 & & 38.2 & 38.9 & 28.0 & 23.6 & 22.7 & \begin{tabular}{|l}
27.4 \\
\end{tabular} & 28.0 & 5 \\
\hline 6 & 63.4 & 63.4 & 67.0 & 62.5 & 58.6 & & 60.7 & 22.8 & 26.2 & 26.0 & 22.2 & 21.7 & 6 \\
\hline 7 & 62.9 & 61.8 & 65.7 & 59.6 & 57.5 & 29.1 & & 24.4 & 24.6 & 25.3 & 21.7 & 22.7 & 7 \\
\hline 8 & 70.9 & 69.6 & \begin{tabular}{|l}
70.7 \\
\end{tabular} & 69.3 & 66.7 & 74.7 & 72.9 & & 19.4 & 27.9 & 27.2 & 20.6 & 8 \\
\hline 9 & 68.9 & 68.9 & \begin{tabular}{|l}
70.1 \\
\end{tabular} & \begin{tabular}{|l|l}
69.2 \\
\end{tabular} & 65.9 & 74.3 & 73.3 & 66.2 & & 17.5 & 24.6 & 23.0 & 9 \\
\hline 10 & 64.0 & 63.2 & 67.7 & 64.0 & 63.6 & 69.9 & 68.6 & 64.2 & 67.2 & & 24.7 & 26.0 & 10 \\
\hline 11 & 72.5 & 71.2 & 73.0 & \begin{tabular}{|l|l|}
72.1 \\
\end{tabular} & 65.4 & 74.5 & 72.5 & 66.7 & 68.9 & 60.0 & & 22.2 & 11 \\
\hline \multirow[t]{2}{*}{12} & 74.2 & 73.7 & 78.0 & 70.8 & 67.1 & 70.8 & 72.2 & 73.8 & 69.4 & 66.2 & 73.3 & & 12 \\
\hline & 1 & 2 & 3 & 4 & 5 & 6 & 7 & 8 & 9 & 10 & 11 & 12 & \\
\hline
\end{tabular}

xI_Hes2 $a^{2}$

xt_Hes2_JGI_scaffold2231

dr_Hes2a_CK694128

hs_HES2_XP_375684

mm_Hes2_NP_032262

xl_Hairy1a'_BC070988

XI_Hairy2b_AF383160

xI_HR1a_AB071432

XI_Hes6b'_BJ624139

XI_ESR1a $1{ }^{1}$ _AF383157

xl_ESR5a_AF137072

XI_HRT1a_AJ401271

B

Prozent Ähnlichkeit

\begin{tabular}{|c|c|c|c|c|c|c|c|c|c|c|c|c|c|}
\hline \multirow{14}{*}{\begin{tabular}{||c|}
1 \\
2 \\
3 \\
4 \\
5 \\
6 \\
7 \\
8 \\
9 \\
10 \\
11 \\
12 \\
\end{tabular}} & 1 & 2 & 3 & 4 & 5 & 6 & 7 & 8 & 9 & 10 & 11 & 12 & \\
\hline & & 98.4 & 79.4 & 73.0 & 71.4 & 73.0 & 73.0 & 44.4 & 41.4 & 41.9 & 41.3 & 39.3 & 1 \\
\hline & 1.6 & & 81.0 & 73.0 & 71.4 & 71.4 & 71.4 & 46.0 & 41.4 & \begin{tabular}{|l|l}
41.9 \\
\end{tabular} & 41.3 & 39.3 & 2 \\
\hline & 20.6 & 19.0 & & 68.3 & 66.7 & 60.3 & 60.3 & 44.4 & 36.2 & 40.3 & 41.3 & 37.7 & 3 \\
\hline & 27.0 & 27.0 & 31.7 & & 79.4 & 61.9 & 61.9 & 47.6 & 39.7 & 43.5 & 38.1 & 39.3 & 4 \\
\hline & 28.6 & 28.6 & 33.3 & 20.6 & & 60.3 & 60.3 & 49.2 & 39.7 & \begin{tabular}{|l|l}
43.5 \\
\end{tabular} & 39.7 & 42.6 & 5 \\
\hline & 27.0 & 28.6 & 39.7 & 38.1 & 39.7 & & 100.0 & 44.4 & 43.1 & 43.5 & 41.3 & 45.9 & 6 \\
\hline & 27.0 & 28.6 & 39.7 & 38.1 & 39.7 & 0.0 & & 44.4 & 43.1 & \begin{tabular}{|l|l}
43.5 \\
\end{tabular} & 41.3 & 45.9 & 7 \\
\hline & 55.6 & 54.0 & 55.6 & 52.4 & 50.8 & 55.6 & 55.6 & & 41.4 & \begin{tabular}{|l|l}
41.9 \\
\end{tabular} & 52.4 & 39.3 & 8 \\
\hline & 55.2 & 55.2 & 58.6 & 55.2 & 55.2 & 51.7 & 51.7 & 53.4 & & 31.0 & 41.4 & 32.8 & 9 \\
\hline & 53.2 & 53.2 & 54.8 & 51.6 & 53.2 & 51.6 & 51.6 & 54.8 & 64.9 & & 38.7 & 41.0 & 10 \\
\hline & 58.7 & 58.7 & 58.7 & 61.9 & 60.3 & 58.7 & 58.7 & 47.6 & 53.4 & 58.1 & & 34.4 & 11 \\
\hline & 55.7 & 55.7 & 57.4 & 55.7 & 54.1 & 49.2 & 49.2 & 59.0 & 60.7 & 53.3 & 60.7 & & 12 \\
\hline & 1 & 2 & 3 & 4 & 5 & 6 & 7 & 8 & 9 & 10 & 11 & 12 & \\
\hline
\end{tabular}

xI_Hes2a $a^{2}$ bHLH_ms xt_Hes2_bHLH_JGI_scaffold2231 dr_Hes2a_bHLH_CK694128 hs_HES2_bHLH_XP_375684 mm_Hes2_bHLH_NP_032262 xI_Hairy 1a'_bHLH_BC070988 XI_Hairy2b_bHLH_AF383160 xI_HR1a_bHLH_AB071432 xI_Hes6b 1 _bHLH_BJ624139 xI_ESR1a1_bHLH_AF383157 XI_ESR5a_bHLH_AF137072 xI_HRT1a_bHLH_AJ401271

C

Prozent Ähnlichkeit

\begin{tabular}{|c|c|c|c|c|c|c|c|c|c|c|c|c|c|c|}
\hline & 1 & 2 & 3 & 4 & 5 & 6 & 7 & 8 & 9 & 10 & 11 & 12 & & \multirow{14}{*}{$\begin{array}{l}\text { xI_Hes2a } 2{ }^{2} \text { Orange_ms } \\
\text { xt_Hes2_Orange_JGI_scaffold2231 } \\
\text { dr_Hes2a_Orange_CK694128 } \\
\text { hs_HES2_Orange_XP_375684 } \\
\text { mm_Hes2_Orange_NP_032262 } \\
\text { xI_Hairy1a1_Orange_BC070988 } \\
\text { xI_Hairy2b_Orange_AF383160 } \\
\text { xI_HR1a_Orange_AB071432 } \\
\text { xI_Hes6b1_Orange_BJ624139 } \\
\text { xI_ESR1a1_Orange_AF383157 } \\
\text { xI_ESR5a_Orange_AF137072 } \\
\text { xI_HRT1a_Orange_AJ401271 }\end{array}$} \\
\hline 1 & & 91.2 & 24.2 & 52.9 & 52.9 & 23.5 & 26.5 & 18.2 & 17.6 & 21.2 & 17.6 & 14.7 & 1 & \\
\hline 2 & 8.8 & & 24.2 & 52.9 & 52.9 & 26.5 & 29.4 & 21.2 & 23.5 & 27.3 & 20.6 & 14.7 & 2 & \\
\hline 3 & 65.6 & 65.6 & & 21.2 & 27.3 & 12.1 & 12.1 & 12.1 & 21.2 & 18.2 & 21.2 & 15.2 & 3 & \\
\hline 4 & 47.1 & 47.1 & 71.9 & & 88.2 & \begin{tabular}{|l|}
41.2 \\
\end{tabular} & 38.2 & 12.1 & 26.5 & \begin{tabular}{|l|}
21.2 \\
\end{tabular} & 20.6 & 26.5 & 4 & \\
\hline 5 & 47.1 & 47.1 & 68.8 & 11.8 & & 35.3 & 35.3 & 15.2 & 26.5 & 21.2 & 29.4 & 32.4 & 5 & \\
\hline 6 & 76.5 & 73.5 & 81.2 & 58.8 & 64.7 & & 94.1 & 21.2 & 41.2 & 27.3 & 26.5 & 41.2 & 6 & \\
\hline 7 & 73.5 & \begin{tabular}{|l|l}
70.6 \\
\end{tabular} & \begin{tabular}{|l|}
78.1 \\
\end{tabular} & $\begin{array}{ll}61.8 \\
\end{array}$ & \begin{tabular}{|l|l}
64.7 \\
\end{tabular} & 5.9 & & 21.2 & \begin{tabular}{|l|}
41.2 \\
\end{tabular} & \begin{tabular}{|l|}
27.3 \\
\end{tabular} & 26.5 & \begin{tabular}{|l|l}
41.2 \\
\end{tabular} & 7 & \\
\hline 8 & 78.8 & 72.7 & 90.3 & 78.8 & 75.8 & 69.7 & 69.7 & & 18.2 & 30.3 & 24.2 & 15.2 & 8 & \\
\hline 9 & 82.4 & 76.5 & \begin{tabular}{|l|}
75.0 \\
\end{tabular} & 73.5 & 73.5 & 58.8 & 58.8 & \begin{tabular}{|l|l}
75.8 \\
\end{tabular} & & \begin{tabular}{|l|}
21.2 \\
\end{tabular} & $\begin{array}{l}17.6 \\
\end{array}$ & 20.6 & 9 & \\
\hline 10 & 75.8 & 69.7 & \begin{tabular}{|l|}
87.1 \\
\end{tabular} & 72.7 & 72.7 & 63.6 & 66.7 & 69.7 & 69.7 & & 18.2 & 24.2 & 10 & \\
\hline 11 & 78.8 & 75.8 & 84.4 & 78.8 & 69.7 & 69.7 & 69.7 & 68.8 & 75.8 & 71.9 & & 28.6 & 11 & \\
\hline 12 & 76.5 & 73.5 & 78.8 & 58.8 & 55.9 & 44.1 & 44.1 & 69.7 & 70.6 & 69.7 & 62.9 & & 12 & \\
\hline & 1 & 2 & 3 & 4 & 5 & 6 & 7 & 8 & 9 & 10 & 11 & 12 & & \\
\hline
\end{tabular}

Abb.7-5: Sequenzähnlichkeiten von Vertebraten-Hes2-Proteinen und bHLH-O-Proteinen aus Xenopus. $(A, B, C)$ Sequenzähnlichkeiten und -unterschiede der Gesamtproteine (A), sowie der bHLH- (B) und der Orange-Domänen (C) von den aufgeführten Vertebraten-bHLH-O-Proteinen (Clustal V, Megalign, DNASTAR). Abkürzungen: dr, Brachydanio rerio; hs, Homo sapiens; mm, Mus musculus; xl, Xenopus laevis; xt, Xenopus tropicalis. 
A

Prozent Ähnlichkeit

\begin{tabular}{|c|c|c|c|c|c|c|c|c|c|c|c|}
\hline \multirow{12}{*}{8} & 1 & 2 & 3 & 4 & 5 & 6 & 7 & 8 & 9 & 10 & \\
\hline & & 88.6 & 46.8 & 38.0 & 39.6 & 36.0 & 36.1 & 42.4 & 37.1 & 34.6 & 1 \\
\hline & 7.3 & & 47.4 & 38.6 & 42.1 & 36.0 & 35.5 & 42.4 & 37.1 & 33.3 & 2 \\
\hline & 47.1 & 45.4 & 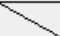 & 37.0 & 40.9 & 39.0 & 41.6 & 45.5 & 37.9 & 31.8 & 3 \\
\hline & 53.5 & 55.2 & 55.2 & 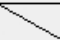 & 36.1 & 35.4 & 36.1 & 34.8 & 55.7 & 63.5 & 4 \\
\hline & 48.7 & 47.0 & 53.0 & 59.3 & & 40.3 & 38.4 & 44.3 & 39.3 & 37.2 & 5 \\
\hline & 56.0 & 56.3 & 57.2 & 58.2 & 52.8 & $d$ & 34.8 & 36.1 & 41.4 & 36.5 & 6 \\
\hline & 58.7 & 57.0 & 54.5 & 57.4 & 57.3 & 59.7 & 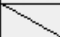 & 33.5 & 39.3 & 34.6 & 7 \\
\hline & 50.0 & 49.0 & 49.0 & 59.7 & 50.3 & 55.6 & 59.7 & $\gamma$ & 36.4 & 32.7 & 8 \\
\hline & 52.7 & 52.3 & 57.6 & 39.6 & 52.7 & 53.2 & 52.4 & 51.6 & 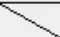 & 54.3 & 9 \\
\hline & 58.0 & 57.6 & 58.3 & 32.3 & 57.2 & 55.3 & 59.4 & 60.6 & 38.4 & $\gamma$ & 10 \\
\hline & 1 & 2 & 3 & 4 & 5 & 6 & 7 & 8 & 9 & 10 & \\
\hline
\end{tabular}

hs_HES5_XP_371215

mm_Hes__NP_034549

XI_ESR1 $1 a^{1}$ _AF383157

XI_ESR10a_ms'(A.J009285)

$X I$ ESR 1 1a_BJ073273

XI_ESR2a_AF383158_M2_AS20

XI_ESR6a_BJ031866/AF146087

$X I$ ESR7a_AF 146088

XI_ESR8a'_msiB.J624216

XI_ESR9a_AJ009282

B

Prozent Ähnlichkeit

\begin{tabular}{|c|c|c|c|c|c|c|c|c|c|c|c|}
\hline & 1 & 2 & 3 & 4 & 5 & 6 & 7 & 8 & 9 & 10 & \\
\hline 1 & & 98.4 & 72.6 & 62.9 & 71.0 & 64.5 & 69.4 & 72.6 & 66.1 & 64.5 & 1 \\
\hline 2 & 1.6 & & 72.6 & 62.9 & 71.0 & 64.5 & 69.4 & 72.6 & 66.1 & 64.5 & 2 \\
\hline 3 & 27.4 & 27.4 & $\gamma$ & 64.5 & 64.5 & 61.3 & 71.0 & 82.3 & 64.5 & 61.3 & 3 \\
\hline 4 & 37.1 & 37.1 & 35.5 & 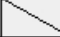 & 61.3 & 59.7 & 66.1 & 62.9 & 87.1 & 83.9 & 4 \\
\hline 5 & 29.0 & 29.0 & 35.5 & 38.7 & $\gamma$ & 64.5 & 64.5 & 67.7 & 69.4 & 66.1 & 5 \\
\hline 6 & 35.5 & 35.5 & 38.7 & 40.3 & 35.5 & 1 & 66.1 & 61.3 & 67.7 & 67.7 & 6 \\
\hline 7 & 30.6 & 30.6 & 29.0 & 33.9 & 35.5 & 33.9 & $\infty$ & 66.1 & 69.4 & 67.7 & 7 \\
\hline 8 & 27.4 & 27.4 & 17.7 & 37.1 & 32.3 & 38.7 & 33.9 & 1 & 61.3 & 58.1 & 8 \\
\hline 9 & 33.9 & 33.9 & 35.5 & 12.9 & 30.6 & 32.3 & 30.6 & 38.7 & $\gamma$ & 90.3 & 9 \\
\hline 10 & 35.5 & 35.5 & 38.7 & \begin{tabular}{|l|l}
16.1 \\
\end{tabular} & 33.9 & 32.3 & 32.3 & 41.9 & 9.7 & 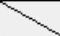 & 10 \\
\hline & 1 & 2 & 3 & 4 & 5 & 6 & 7 & 8 & 9 & 10 & \\
\hline
\end{tabular}

hs_HES5_bHLH_XP_371215 mm_Hes5_bHLH_NP_034549 xI_ESR1a__bHLH_AF383157 xl_ESR10a_bHLH_msi(A.J009285) XI_ESR11a_bHLH_B.J073273 xI_ESR2a_bHLH_AF383158_M2_AS20 XI_ESR6a_bHLH_B.J031866/AF XI_ESR7a_bHLH_AF146088 xl_ESR8a'bHLH_ms/BJ624216 xl_ESR9a_bHLH_A.J009282

C

Prozent Ähnlichkeit

\begin{tabular}{|c|c|c|c|c|c|c|c|c|c|c|c|}
\hline & 1 & 2 & 3 & 4 & 5 & 6 & 7 & 8 & 9 & 10 & \\
\hline 1 & & 100.0 & 50.0 & 34.4 & 37.5 & 37.5 & 31.2 & 39.3 & 28.1 & 50.0 & 1 \\
\hline 2 & 0.0 & $\gamma$ & 50.0 & 34.4 & 37.5 & 37.5 & 31.2 & 39.3 & 28.1 & 50.0 & 2 \\
\hline 3 & 40.6 & 40.6 & & 42.4 & 39.4 & 39.4 & 31.2 & 32.1 & 25.0 & 37.5 & 3 \\
\hline 4 & 56.2 & 56.2 & 57.6 & 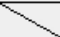 & 48.5 & 51.5 & 34.4 & 39.3 & 28.1 & 37.5 & 4 \\
\hline 5 & 53.1 & 53.1 & 60.6 & 51.5 & 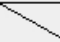 & 42.4 & 28.1 & 39.3 & 31.2 & 37.5 & 5 \\
\hline 6 & 53.1 & 53.1 & 60.6 & 48.5 & 57.6 & $\varnothing$ & 25.0 & 39.3 & 25.0 & 37.5 & 6 \\
\hline 7 & 67.7 & 67.7 & 62.5 & 65.6 & 62.5 & 78.1 & 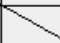 & 25.0 & 15.6 & 31.2 & 7 \\
\hline 8 & 50.0 & 50.0 & 60.7 & 50.0 & 50.0 & 50.0 & \begin{tabular}{|l}
75.0 \\
\end{tabular} & 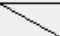 & 39.3 & 53.6 & 8 \\
\hline 9 & 74.2 & 74.2 & 78.1 & 71.9 & 78.1 & 75.0 & 84.4 & 64.3 & 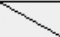 & 43.8 & 9 \\
\hline 10 & 51.6 & 51.6 & 62.5 & 53.1 & 59.4 & 59.4 & \begin{tabular}{|l|l}
68.8 \\
\end{tabular} & 39.3 & 56.2 & $\gamma$ & 10 \\
\hline & 1 & 2 & 3 & 4 & 5 & 6 & 7 & 8 & 9 & 10 & \\
\hline
\end{tabular}

hs_HES5_Orange_XP_371215 mm_Hes5_Orange_NP_034549 Xl_ESR1 a1_Orange_AF383157 XI_ESR11a_Orange_B.J073273 $X I$ ESR22a_Orange_AF383158 $X I$ ESR7 a_Orange_AF146088 XI_ESR6a_Orange_BJ031866/AF $\times I$ ESR8 $a^{1}$ _Orange_ms/BJ.J624216 XI_ESR9a_Orange_A.J009282 XI_ESR10a_Orange_ms/(AJ009285)

D

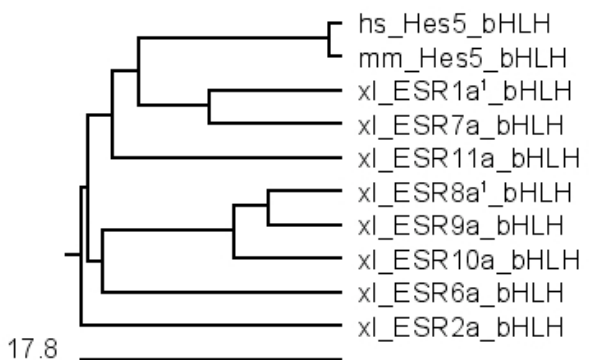

E

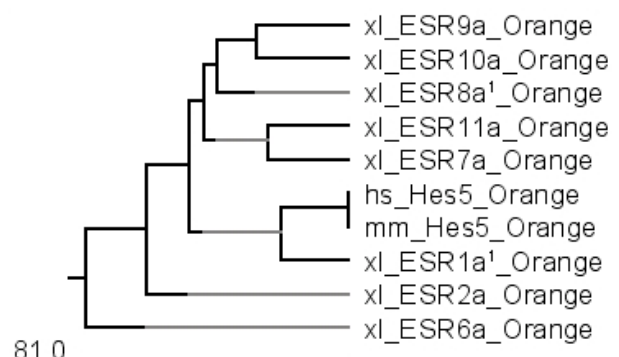

81.0

Abb.7-6: Sequenzähnlichkeiten von Hes5-Proteinen aus Maus, Mensch und Xenopus laevis.

$(A, B, C)$ Sequenzähnlichkeiten und -unterschiede der Gesamtproteine (A), sowie der bHLH- (B) und der Orange-Domänen (C) von den aufgeführten Proteinen der Vertebraten-Hes5-Gruppe (Clustal V, Megalign, DNASTAR). (D,E) Sequenzähnlichkeiten der bHLH- und Orange-Domänen von Hes5-Proteinen aus Säugern und Hes5-ähnlichen Proteinen aus Xenopus laevis, jeweils dargestellt in einem phylogenetischen Stammbaum. Abkürzungen: hs, Homo sapiens; mm, Mus musculus; xl, Xenopus laevis. 
A

Prozent Ähnlichkeit

\begin{tabular}{|c|c|c|c|c|c|c|c|c|c|c|}
\hline & 1 & 2 & 3 & 4 & 5 & 6 & 7 & 8 & 9 & \\
\hline 1 & 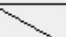 & 77.0 & 81.2 & 77.0 & 78.7 & 63.5 & 63.5 & 54.3 & 50.3 & 1 \\
\hline 2 & 19.1 & 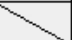 & 70.4 & 68.2 & 72.4 & 61.8 & 61.2 & 54.3 & 50.3 & 2 \\
\hline 3 & 16.9 & 23.3 & 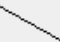 & 69.6 & 69.5 & 69.5 & 70.8 & 55.0 & 51.0 & 3 \\
\hline 4 & 18.9 & 24.1 & 23.3 & $\alpha$ & 79.1 & 60.1 & 64.2 & 50.0 & 47.6 & 4 \\
\hline 5 & 19.4 & 24.5 & 26.1 & 14.3 & $\infty$ & 63.2 & 65.8 & 50.7 & 49.0 & 5 \\
\hline 6 & 32.3 & 31.1 & 28.1 & 32.0 & 31.2 & $\gamma$ & 77.2 & 55.7 & 50.3 & 6 \\
\hline 7 & 32.3 & 31.8 & 25.5 & 27.9 & 27.9 & 22.8 & $\gamma$ & 56.4 & 51.7 & 7 \\
\hline 8 & 39.9 & 38.8 & 37.5 & 40.5 & 38.7 & 39.3 & 40.7 & 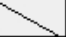 & 84.3 & 8 \\
\hline 9 & 43.4 & 42.4 & 40.4 & 43.4 & 43.0 & 44.1 & 42.8 & 11.4 & $\lambda$ & 9 \\
\hline & 1 & 2 & 3 & 4 & 5 & 6 & 7 & 8 & 9 & \\
\hline
\end{tabular}

XI_ESR9.1_A.J009282

$X I$ ESR9.1r_BP706462

XI_ESR9.2_BC072262

Xt_ESR9_1_CR762135

xt_ESRg_2_cons_AL635520+

$x$ I_ESR10.1_ms'(A.J009285)

xt_ESR10_CR 571561

xl_ESR8.1a_msiB.J624216

Xt_ESR8_cons_AL657801+

B

Prozent Ähnlichkeit

\begin{tabular}{|c|c|c|c|c|c|c|c|c|c|c|}
\hline & 1 & 2 & 3 & 4 & 5 & 6 & 7 & 8 & 9 & \\
\hline 1 & 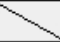 & 93.5 & 98.4 & 93.5 & 93.5 & 83.9 & 91.9 & 90.3 & 88.7 & 1 \\
\hline 2 & 6.5 & $\infty$ & 93.5 & 91.9 & 91.9 & 87.1 & 90.3 & 90.3 & 88.7 & 2 \\
\hline 3 & 1.6 & 6.5 & $\gamma$ & 93.5 & 93.5 & 83.9 & 93.5 & 90.3 & 88.7 & 3 \\
\hline 4 & 6.5 & 8.1 & 6.5 & 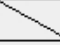 & 96.8 & 87.1 & 96.8 & 91.9 & 90.3 & 4 \\
\hline 5 & 6.5 & 8.1 & 6.5 & 3.2 & $\infty$ & 87.1 & 95.2 & 91.9 & 90.3 & 5 \\
\hline 6 & 16.1 & 12.9 & 16.1 & 12.9 & 12.9 & 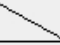 & 85.5 & 87.1 & 82.3 & 6 \\
\hline 7 & 8.1 & 9.7 & 6.5 & 3.2 & 4.8 & 14.5 & 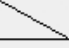 & 90.3 & 88.7 & 7 \\
\hline 8 & 9.7 & 9.7 & 9.7 & 8.1 & 8.1 & 12.9 & 9.7 & 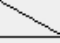 & 95.2 & 8 \\
\hline 9 & 11.3 & 11.3 & 11.3 & 9.7 & 9.7 & 17.7 & 11.3 & 4.8 & 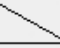 & y \\
\hline & 1 & 2 & 3 & 4 & 5 & 6 & 7 & 8 & 9 & \\
\hline
\end{tabular}

XI_ESR9.1_bHLH_AJ009282

xl_ESR9.1r_bHLH_BP706462

XI_ESRg.2_bHLH_BCO72262

xt_ESR9_1_bHLH_CR762135

xt_ESR9_2_bHLH_cons_AL635520+

xI_ESR10.1_bHLH_ms/(A.J009285)

xt_ESR10_bHLH_CR571561

xI_ESR8.1a_bHLH_msiB.J624216

xt_ESR8_bHLH__cons_AL657801+

C

Prozent Ähnlichkeit

\begin{tabular}{|c|c|c|c|c|c|c|c|c|c|c|}
\hline 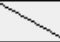 & 1 & 2 & 3 & 4 & 5 & 6 & 7 & 8 & 9 & \\
\hline 1 & 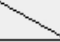 & 53.6 & 43.8 & 38.7 & 65.6 & 38.5 & 50.0 & 75.0 & 41.9 & 1 \\
\hline 2 & 42.9 & 1 & 39.3 & 42.9 & 39.3 & 23.1 & 39.3 & 50.0 & 71.4 & 2 \\
\hline 3 & 56.2 & 60.7 & 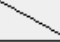 & 64.5 & 62.5 & 53.8 & 65.6 & 43.8 & 29.0 & 3 \\
\hline 4 & 54.8 & 55.6 & 25.8 & $\gamma$ & 58.1 & 46.2 & 51.6 & 45.2 & 35.5 & 4 \\
\hline 5 & 34.4 & 53.6 & 37.5 & 35.5 & 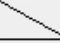 & 42.3 & 56.2 & 68.8 & 35.5 & 5 \\
\hline 6 & 53.8 & 63.6 & 34.6 & 42.3 & 46.2 & 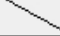 & 50.0 & 38.5 & 19.2 & 6 \\
\hline 7 & 50.0 & 50.0 & 34.4 & 38.7 & 43.8 & 38.5 & 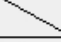 & 46.9 & 35.5 & 7 \\
\hline 8 & 25.0 & 50.0 & 56.2 & 48.4 & 31.2 & 53.8 & 53.1 & $\gamma$ & 38.7 & 8 \\
\hline 9 & 48.4 & 17.9 & 64.5 & 63.3 & 58.1 & 68.0 & 58.1 & 58.1 & 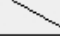 & 9 \\
\hline & 1 & 2 & 3 & 4 & 5 & 6 & 7 & 8 & 9 & \\
\hline
\end{tabular}

XI_ESR10.1_Orange_ms/(AJ009285)

xl_ESR8.1a_Orange_ms/BJ624216

xl_ESR9.1_Orange_AJ009282

XI_ESR9.1r_Orange_BP706462

xl_ESR9.2_Orange_BC072262

xt_ESR9_1_Orange_CR762135

xt_ESR9_2_Orange_cons_AL635520+

xt_ESR10_Orange_CR571561

xt_ESR8_Orange_cons_AL657801 +

Abb.7-7: Sequenzähnlichkeiten von ESR8, ESR9 und ESR10 aus Xenopus laevis und tropicalis.

$(A, B, C)$ Sequenzähnlichkeiten und -unterschiede der Gesamtproteine (A), sowie der bHLH- (B) und der Orange-Domänen (C) von ESR8, ESR9 und ESR10 aus Xenopus (Clustal V, Megalign, DNASTAR). Abkürzungen: hs, Homo sapiens; mm, Mus musculus; xl, Xenopus laevis. 


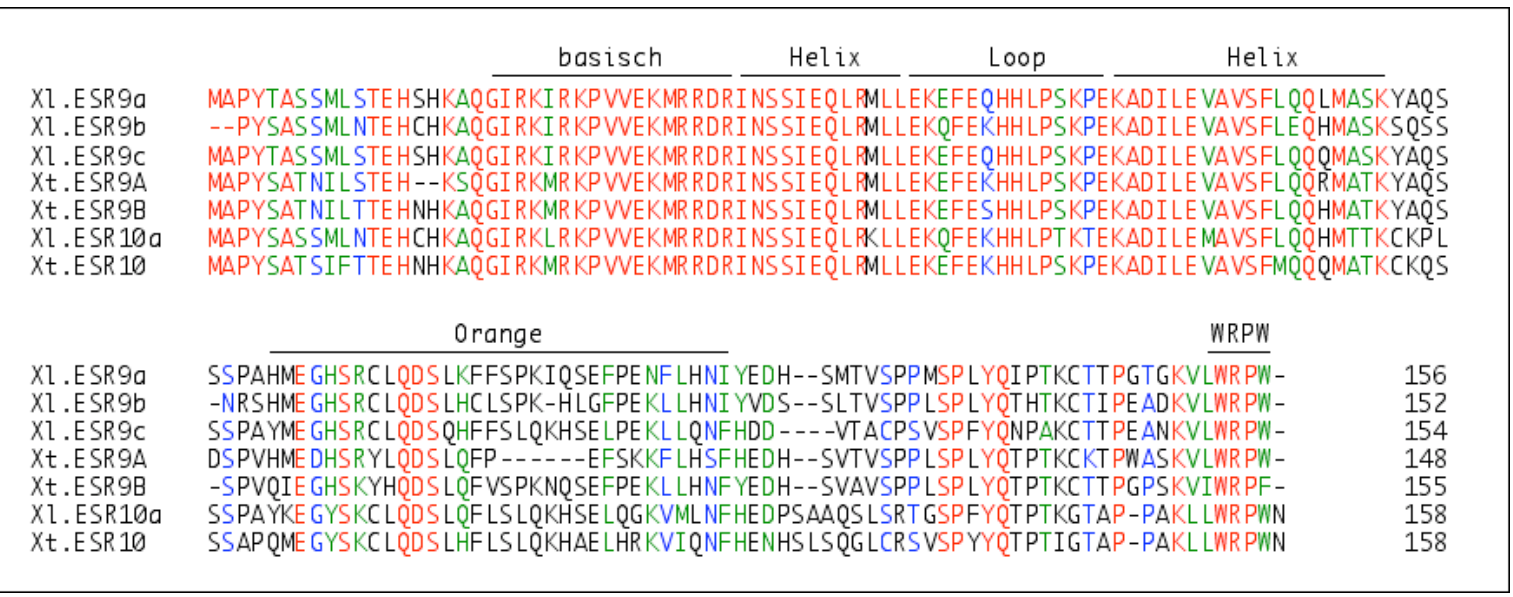

Abb.7-8: Sequenzvergleich von ESR9 und ESR10 aus Xenopus laevis und Xenopus tropicalis.

bHLH- und Orange-Domänen (Davis und Turner, 2001) und das WRPW-Motif sind durch Balken gekennzeichnet. Der Grad der Aminosäurekonservierung ist wie folgt dargestellt: rot, identisch; grün, starke Ähnlichlichkeit; blau, schwache Ähnlichkeit; Bindestriche (-), fehlende Aminosäuren. Die DatenbankZugriffsnummern sind im Anhang in Abb.A-1 zu finden. Abkürzungen: XI., Xenopus laevis; Xt., Xenopus tropicalis. 


\section{Danksagung}

An dieser Stelle möchte ich allen danken, die diese Arbeit ermöglicht haben.

Mein ganz besonderer Dank gilt Herrn Prof. Dr. Tomas Pieler für die Möglichkeit zur Anfertigung einer Dissertationsarbeit in seiner Abteilung einschließlich der Bereitstellung aller dafür erforderlichen Mittel, für die experimentelle Freiheit bei der Bearbeitung des Themas, sowie für seine langjährige Unterstützung während der Arbeit, u.a. durch hilfreiche Vorschläge und Diskussionen.

Herrn Prof. Dr. E. A. Wimmer danke ich für die Übernahme des Korreferats.

Bei Herrn Prof. Dr. Eric Bellefroid möchte ich mich für die Zusendung zahlreicher, in dieser Arbeit verwendeten Plasmide bedanken.

Prof. Dr. Eric Bellefroid und Dr. Muriel Perron danke ich für den stets regen Informationsaustausch und die zahlreichen Diskussionen im Rahmen einer Kooperation zur funktionellen Charakterisierung von XHes2.

Den Mitgliedern der Neurogenese-Arbeitsgruppe, Dr. Kristine Henningfeld, Dr. Jacob Souopgui, Tiemo Klisch, Barbara Rust und Katja Ditter, sowie Dr. Yonglong Chen, Dr. Jörg Wischnewski, Dr. Maike Claußen, Dr. Katja Horvay und Dr. Susanne Loop danke ich für die gute Zusammenarbeit und die wissenschaftlichen Gespräche.

Bei allen Mitarbeitern der Abteilung Entwicklungsbiochemie, auch den ehemaligen, möchte ich mich für ihre zahlreichen gemeinnützigen Arbeiten und ihre stete Hilfsbereitschaft, sowie für die angenehme Arbeitsatmosphäre im Laboralltag bedanken.

Ein Danke auch an alle Tierpfleger, die für das Wohl der Frösche gesorgt haben.

Christine, Daniela, Jan und Katja danke ich für ihre fortwährende Freundschaft.

Ein ganz besonderes und herzliches Dankeschön für ihre vielfältige Unterstützung geht an Jörg, meine Eltern, meine Großeltern und meine Schwester Anja. 


\section{Publikationen}

Sölter, M., Koster, M., Hollemann, T., Brey, A., Pieler, T., Knochel, W. (1999). Characterization of a subfamily of related winged helix genes, XFD-12/12'/12" (XFLIP), during Xenopus embryogenesis. Mech Dev 89, 161-5.

Wischnewski, J., Sölter, M., Chen, Y., Hollemann, T., Pieler, T. (2000). Structure and expression of Xenopus karyopherin-beta3: definition of a novel synexpression group related to ribosome biogenesis. Mech Dev 95, 245-8.

Souopgui, J., Sölter, M., Pieler, T. (2002). XPak3 promotes cell cycle withdrawal during primary neurogenesis in Xenopus laevis. Embo J 21, 6429-39.

Chen, Y., Pan, F. C., Brandes, N., Afelik, S., Sölter, M., Pieler, T. (2004). Retinoic acid signaling is essential for pancreas development and promotes endocrine at the expense of exocrine cell differentiation in Xenopus. Dev Biol 271, 144-60.

Taelman, V., Van Wayenbergh, R., Sölter, M., Pichon, B., Pieler, T., Christophe, D., Bellefroid, E. J. (2004). Sequences downstream of the bHLH domain of the Xenopus hairy-related transcription factor- 1 act as an extended dimerization domain that contributes to the selection of the partners. Dev Biol 276, 47-63.

Sölter, M., Locker, M., Boy, S., Taelman, V., Bellefroid, E. J., Perron, M., Pieler, T. Characterization and function of the bHLH-O protein XHes2: Insight into the mechanisms controlling retinal cell fate decision. Manuskript eingereicht. 


\section{Lebenslauf}

Name:

Marion Sölter

Geburtsdatum:

08.02.1971

Geburtsort:

Northeim

Staatsangehörigkeit: deutsch

1977-1981

$1981-1983$

1983-1990

16.05 .1990

04/1991 - 02/1993

10/1993

18.10.1995

31.10 .1997

11/1997- 01/1999

29.03.1999

seit 04/1999
Pestalozzi-Schule (Grundschule) in Einbeck

Sohnreyschule (Orientierungsstufe) in Einbeck

Goetheschule (Gymnasium) in Einbeck

Abitur

Ausbildung zur MTA-L an der staatlich anerkannten Lehranstalt für medizinisch-technische Laboratoriumsassistenten der GeorgAugust-Universität Göttingen

Beginn des Studiums der Biologie (Diplom) an der Georg-AugustUniversität Göttingen

Diplomvorprüfung in den Fächern Zoologie, Mikrobiologie, Chemie und Physikalische Chemie

Mündliche Diplomprüfung in den Fächern Entwicklungsbiologie (Hauptfach), Immunologie und Chemie

Diplomarbeit am Institut für Biochemie und Molekulare Zellbiologie in der Abt. Entwicklungsbiochemie (Prof. Dr. T. Pieler) der GeorgAugust-Universität Göttingen

Thema: „Identifizierung von Genen mit morphoregulatorischer Funktion in der frühen Embryogenese von Xenopus laevis aus einer Schwanzspitzen-cDNA-Bank“"

Verleihung des Hochschulgrades „Diplom-Biologin“ an der GeorgAugust-Universität Göttingen

Dissertationsarbeit am Institut für Biochemie und Molekulare Zellbiologie in der Abt. Entwicklungsbiochemie (Prof. Dr. T. Pieler) der Georg-August-Universität Göttingen Thema: „Regulation der Neurogenese durch bHLH-O-Proteine in Xenopus laevis “ 